LBL-35982

UC- 1600

\title{
Evaluation of Advanced Technologies for Residential Appliances and Residential and Commercial Lighting
}

\author{
I. Turiel, B. Atkinson, S. Boghosian, P. Chan, J. Jennings, J. Lutz, \\ J. McMahon, and G. Rosenquist \\ Energy Analysis Program \\ Energy and Environment Division \\ Lawrence Berkeley Laboratory \\ University of California \\ Berkeley, California 94720
}

January 1995

This work was supported by the Assistant Secretary for Energy Efficiency and Renewable Energy, Office of Building Technologies, of the U.S. Department of Energy under Contract No. DE-AC03-76SF00098. 


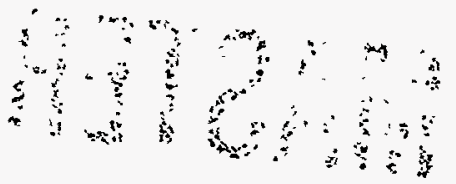

(8) reycles pape 


\section{DISCLAIMER}

This report was prepared as an account of work sponsored by an agency of the United States Government. Neither the United States Government nor any agency thereof, nor any of their employees, make any warranty, express or implied, or assumes any legal liability or responsibility for the accuracy, completeness, or usefulness of any information, apparatus, product, or process disciosed, or represents that its use would not infringe privately owned rights. Reference herein to any specific commercial product, process, or service by trade name, trademark, manufacturer, or otherwise does not necessarily constitute or imply its endorsement, recommendation, or favoring by the United States Government or any agency thereof. The views and opinions of authors expressed herein do not necessarily state or reflect those of the United States Government or any agency thereof. 


\section{DISCLAIMER}

Portions of this document may be illegible in electronic image products. Images are produced from the best available original document. 


\section{Table of Contents}

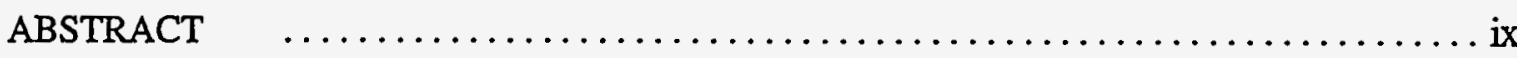

1. INTRODUCTION $\ldots \ldots \ldots \ldots \ldots \ldots \ldots \ldots \ldots \ldots \ldots \ldots \ldots \ldots \ldots \ldots$

2. REFRIGERATORS AND FREEZERS $\ldots \ldots \ldots \ldots \ldots \ldots \ldots \ldots \ldots \ldots \ldots$

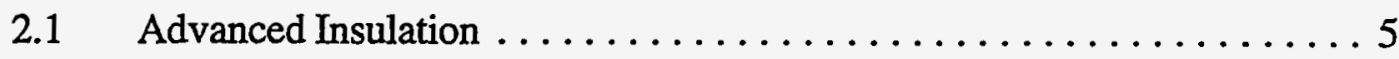

2.2 Low-Capacity High-Efficiency Compressors . . . . . . . . . . . . . 6

2.3 Improved Gaskets $\ldots \ldots \ldots \ldots \ldots \ldots \ldots \ldots \ldots \ldots$

2.4 Improved Fan Motors $\ldots \ldots \ldots \ldots \ldots \ldots \ldots \ldots \ldots \ldots \ldots$

2.5 Variable Speed Compressors $\ldots \ldots \ldots \ldots \ldots \ldots \ldots \ldots \ldots \ldots$

2.6 Hydrocarbon Substitutes for HCFCs and HFCs $\ldots \ldots \ldots \ldots \ldots \ldots 9$

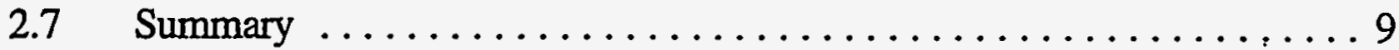

2.8 Discussion of National Energy Savings ... . . . . . . . . 10

3. Clothes WASHERS, Clothes DRYERS, AND DisHWASHERS $\ldots \ldots \ldots \ldots \ldots$

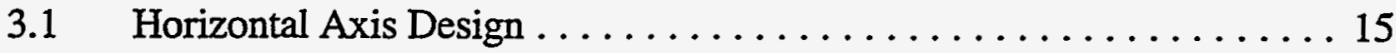

$3.2 \quad$ High-Spin Speed $\ldots \ldots \ldots \ldots \ldots \ldots \ldots \ldots \ldots \ldots \ldots \ldots \ldots$

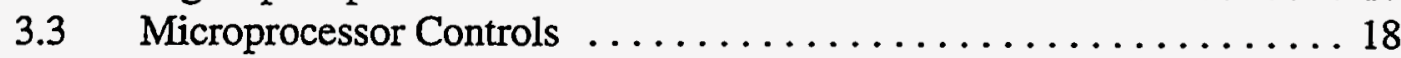

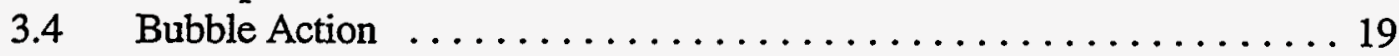

3.5 Discussion of National Energy Savings . . . . . . . . . . . 20

3.6 Microwave Dryers . . . . . . . . . . . . . . . . . 22

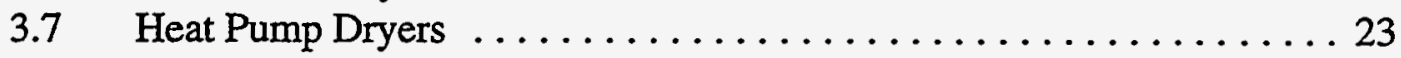

3.8 Discussion of National Energy Savings ... . . . . . . . . . . 24

3.9 Low Water Use Dishwashers . . . . . . . . . . . . . . . 27

3.10 Discussion of National Energy Savings .............. 28

4. WATER Heating AND Hot WATER CONSERVATION $\ldots \ldots \ldots \ldots \ldots \ldots \ldots$

4.1 Pilotless Instantaneous Water Heater $\ldots \ldots \ldots \ldots \ldots \ldots \ldots \ldots \ldots$

4.2 Condensing Storage Water Heater . . . . . . . . . . . . . . . 33

4.3 Triple-Effect Absorption Heat Pump Water Heater . . . . . . . . . . . . 34

4.4 Discussion of National Energy Savings for Gas-Fired Water Heaters . 34

$4.5 \quad$ EPRJ/E-Tech Heat Pump . . . . . . . . . . . . . . . 37

4.6 Solar Water Heating . . . . . . . . . . . . . . . . . . . 39

4.7 Discussion of National Energy Savings for Electric Water Heaters . . . 40

4.8 Other Technologies ...................... 40

5. SPACE HeAting AND Cooling APPliances $\ldots \ldots \ldots \ldots \ldots \ldots \ldots \ldots$

5.1 Baseline Energy Use and Efficiency $\ldots \ldots \ldots \ldots \ldots \ldots \ldots \ldots$

5.2 Methodology $\ldots \ldots \ldots \ldots \ldots \ldots \ldots \ldots \ldots \ldots \ldots \ldots \ldots \ldots \ldots \ldots$ 
5.3 Fuel-Driven Heat Pumps and Integrated Appliances $\ldots \ldots \ldots \ldots .47$

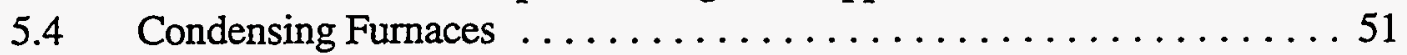

5.5 Integrated Water Heater/Furnace $\ldots \ldots \ldots \ldots \ldots \ldots \ldots \ldots . \ldots \ldots$

5.6 Electric Ground-Source and Air-Source Heat Pumps and Integrated Appliances ............................. 56

5.6.1 Ground-Source Heat Pumps and Integrated Appliances .... 56

5.6.2 Air-Source Heat Pumps and Integrated Appliances ....... 59

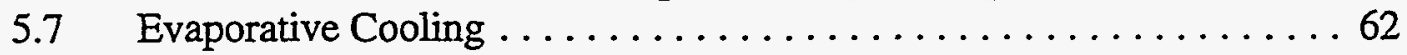

5.7.1 Single-Stage direct Evaporative Coolers . ..........66 63

5.7.2 Two-Stage Indirect/Direct Evaporative Coolers ......... 64

5.8 National Service Improvement Program $\ldots \ldots \ldots \ldots \ldots \ldots \ldots 6$

5.9 Thermal Distribution Systems . . . . . . . . . . . . . . . . 67

5.9.1 Reduced-Leakage Ducting .................. 69

5.10 Discussion of National Energy Savings $\ldots \ldots \ldots \ldots \ldots \ldots \ldots .73$

6. COMMERCIAL AND RESIDENTIAL LIGHTING COMPONENTS AND SYSTEMS $\ldots \ldots 85$

6.1 Scotopically-Rich Lamps $\ldots \ldots \ldots \ldots \ldots \ldots \ldots \ldots \ldots \ldots$

6.2 Efficient Incandescent Lamps-Improvements to Halogen Infrared Reflecting Lamps ........................... 87

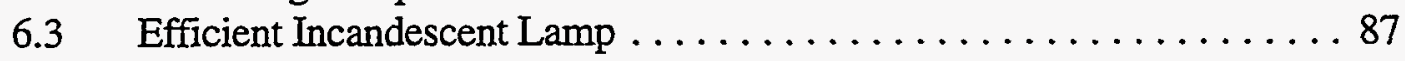

6.4 Compact Electrodeless Fluorescent (Induction) Lamp . . . . . . . . . 88

6.5 CFL Electronic Ballasts . . . . . . . . . . . . . . . . . 89

6.6 CFL Dimmable Ballasts $\ldots \ldots \ldots \ldots \ldots \ldots \ldots \ldots \ldots \ldots \ldots$

6.7 DFL Efficient Luminaires ........................ 91

6.8 Dimmable Electronic Ballasts for Full-Size Fluorescents . . . . . . . 92

6.9 Integrated Workstation Sensors . .................. 93

6.10 Efficient Incandescent Lamps-Improvements to Halogen

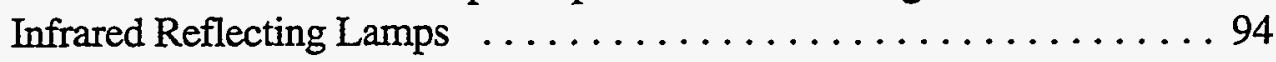

6.11 Efficient Incandescent Lamps ...................... 94

6.12 Compact electrodeless Fluorescent (Induction) Lamp . . . . . . . . . . 95

6.13 CFL Efficient Luminaires ......................... 95

6.14 Improved Compact HID Lamps .................... 109

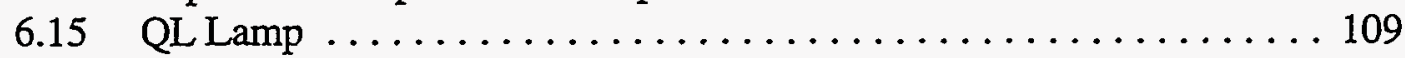

6.16 Advanced Fluorescent Reflector Design $\ldots \ldots \ldots \ldots \ldots \ldots \ldots 110$

6.17 Thermal Bridging for Fluorescent Fixtures $\ldots \ldots \ldots \ldots \ldots \ldots 111$

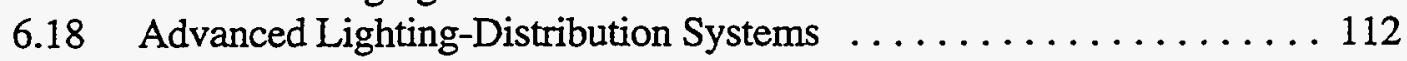

6.19 Optimized Luminaires and Controls $\ldots \ldots \ldots \ldots \ldots \ldots \ldots \ldots \ldots \ldots$

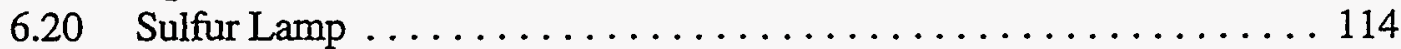

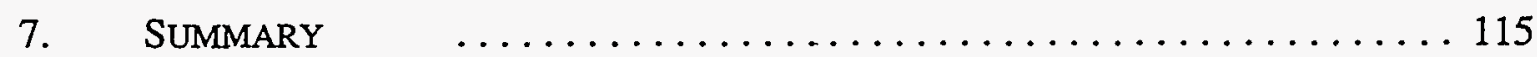




\section{List of Tables}

Table 1

Table 2.1

Table 2.2

Table 3.1

Table 3.2

Table 3.3

Table 3.4

Table 3.5

Table 3.6

Table 4.1

Table 4.2

Table 4.3

Table 4.4

Table 5.1

Table 5.2

Table 5.3

Table 5.4

Table 5.5

Table 5.6

Table 5.7

Table 5.8

Table 5.9

Table 5.10

Table 5.11

Table 5.12

Table 5.13

Table 5.14

Table 5.15

Table 5.16

Table 5.17

Table 5.18

Table 5.19

Table 5.20

Table 5.21

Table 5.22

Table 5.23
End-Use Saturations and Source Energy Consumption $\ldots \ldots \ldots \ldots \ldots \ldots$

Energy Use and Cost Summary for Refrigerators . . . . . . . . . . . . 10

Annual Energy Savings for Refrigerator Technology Options . . . . . . . . 13

Energy Use and Cost Summary for Clothes Washers ............... 16

Annual Energy Savings for Clothes Washer Technology Options ........ 22

Energy Use and Cost Summary for Clothes Dryers ................ 24

Annual Energy Savings for Clothes Dryer Technology Options .......... 26

Energy Use and Cost Summary for Dishwashers . . . . . . . . . . . 28

Annual Energy Savings for Dishwasher Technology Options $\ldots \ldots \ldots \ldots \ldots 30$

Energy Use and Cost Summary for Gas-Fired Water Heaters .......... 35

Annual Energy Savings Gas-Fired Water Heater Technology Options . . . . . 35

Energy Use and Cost Summary for Electric Water Heaters . . . . . . . . . . 39

Annual Energy Savings for Electric Water Heater Technology Options . . . . . 39

Efficiencies and Energy Use for 1990 Stock and Baseline Case . . . . . . . . . 43

$\mathrm{CLH}$ and HLH Values for North and South Regions $\ldots \ldots \ldots \ldots \ldots \ldots 45$

Regional Variations in Baseline UECs . . . . . . . . . . . . . . . 45

Top 16 Advanced Technologies . ......................... 47

Efficiencies, Costs, and Paybacks for Fuel-Driven Heat Pumps ....... . . . 49

Efficiencies, Costs, and Paybacks for Fuel-Driven Heat Pumps,

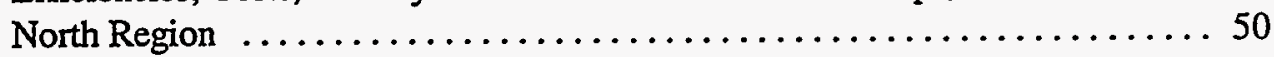

Efficiencies, Costs, and Paybacks for Condensing Furnaces .......... 52

Efficiencies, Costs, and Paybacks for Condensing Furnaces,

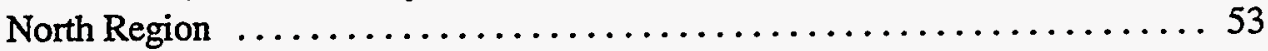

Characteristics, Efficiencies, Costs, and Paybacks for Integrated

Condensing Water Heater/Furnace $\ldots \ldots \ldots \ldots \ldots \ldots \ldots \ldots \ldots \ldots \ldots$

Characteristics, Efficiencies, Costs, and Paybacks for Integrated

Condensing Water Heater/Furnace, North Region $\ldots \ldots \ldots \ldots \ldots \ldots \ldots 5$

Efficiencies, UECs, Costs, and Paybacks for Ground-Source Heat Pumps ... . 58

Efficiencies, UECs, Costs, and Paybacks for Ground-Source Heat Pumps,

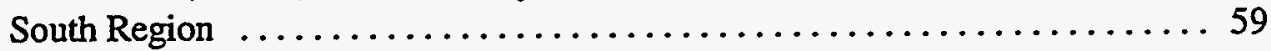

Efficiencies, UECs, Costs, and Paybacks for Air-Source Heat Pumps . . . . . . 61

Efficiencies, UECs, Costs, and Paybacks for Air-Source Heat Pumps,

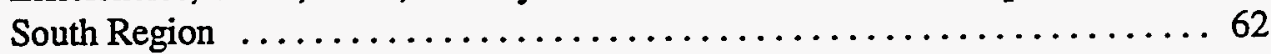

UECs, Costs, and Paybacks for Direct Evaporative Coolers ............ 64

UECs, Costs, and Paybacks for Indirect/Direct Evaporative Coolers . . . . . . . 65

UEC Savings and Homes Affected by HVAC Repair Options . . . . . . . . 67

Summary of Thermal Distribution Improvement Potentials . . . . . . . . . . . 69

Thermal Distribution Types Used in Andres and Modera (1991) . . . . . . . . 70

Available Savings for Two Types of Distribution Systems . .......... 71

Energy Consumption and Savings for Duct Leakage Improvements $\ldots \ldots \ldots 72$

Annual Energy Savings for Gas Heat Pump, Oil Heat Pump,

and Electric Heat Pump Technology Options $\ldots \ldots \ldots \ldots \ldots \ldots \ldots . \ldots 2$

Annual Energy Savings for Oil Furnace Technology Options $\ldots \ldots \ldots \ldots . . .82$ 
Annual Energy Savings for Integrated Gas Heat Pump and Electric

Heat PumpTechnology Options . ..................... 83

Table 5.25 Annual Energy Savings for Evaporative Cooler Technology Options .......83

Table 6.1 Energy Use and Cost Summary for Commercial Interior Lighting $\ldots \ldots \ldots 103$

Table 6.2

Table 6.3

Annual Energy Savings for Commercial Interior Lighting . . . . . . . . . 104

Table 6.4

Energy Use and Cost Summary for Residential Sector Lighting . . . . . . . . 108

Annual Energy Savings for Residential Sector Lighting $\ldots \ldots \ldots \ldots \ldots . \ldots 108$

Table 7.1

Summary of Potrential Energy Savings from Selected Advanced Technologies 116

\section{List of Figures}

Figure 1.1

Figure 2.1

Figure 3.1

Figure 3.2

Figure 3.3

Figure 4.1

Figure 4.2

Figure 5.1

Figure 5.2

Figure 5.3

Figure 5.4

Figure 5.5

Figure 5.6

Figure 5.7

Figure 6.1

Figure 6.2

Figure 6.3

Figure 6.4

Figure 6.5

Figure 6.6
Market Penetration as a Function of Payback Period $\ldots \ldots \ldots \ldots \ldots \ldots$

Annual Energy Use for Technology Options: Refrigerators . . . . . . . . . . 12

Annual Energy Use for Technology Options: Clothes Washers .......... 21

Annual Energy Use for Technology Options: Electric Clothes Dryers . . . . . . 25

Annual Energy Use for Technology Options: Dishwashers ............ 29

Annual Energy Use for Technology Options: Gas-Fired Water Heaters . . . . 36

Annual Energy Use for Technology Options: Electric Water Heaters . . . . . . 38

Annual Energy Use for Technology Options: Gas Heat Pump . . . . . . . . . . . 74

Annual Energy Use for Technology Options: Integrated Gas Heat Pump . . . . 75

Annual Energy Use for Technology Options: Oil Heat Pumps . . . . . . . . . . 76

Annual Energy Use for Technology Options: Oil Furnaces $\ldots \ldots \ldots \ldots \ldots 77$

Annual Energy Use for Technology Options: Electric Heat Pumps . . . . . . 78

Annual Energy Use for Technology Options: Electric Integrated

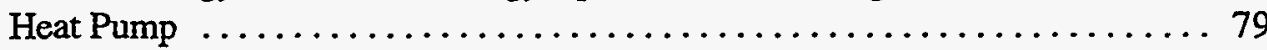

Annual Energy Use for Technology Options: Evaporative Coolers .... . . . 80

Annual Energy Use for Technology Options: Commercial Interior

Lighting, Fluorescent Lamps $\ldots \ldots \ldots \ldots \ldots \ldots \ldots \ldots \ldots \ldots \ldots$

Annual Energy Use for Technology Options: Commercial Interior

Lighting, Incandescent Lamps . . . . . . . . . . . . . . . . . . 99

Annual Energy Use for Technology Options: Commercial Interior

Lighting, Compact Fluorescent Lamps . .................. 100

Annual Energy Use for Technology Options: Commercial Interior

Lighting, Controls ............................... 101

Annual Energy Use for Technology Options: Commercial Interior

Lighting, Combination Policy Case . . . . . . . . . . . . . . . 102

Annual Energy Use for Technology Options: Residential Interior

and Exterior Lighting 


\section{Appendices}

Appendix 1 Simplified Approach to Calculate Technical

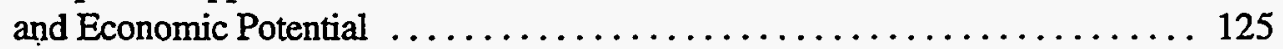

Appendix 2 Technologies Considered for Refrigerators and Freezers . . . . . . . . . . 129

Appendix $3 \quad$ Technologies Considered for Clothes Washers and Dryers . . . . . . . . 131

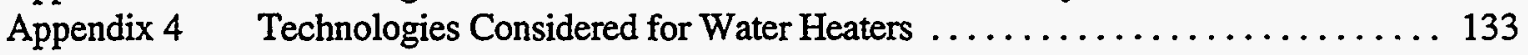

Appendix 5.1 Technologies Considered for Space-Conditioning Appliances . . . . . . . . 135

Appendix 5.2 Methodology for Characterizing and Ranking Technologies $\ldots \ldots \ldots \ldots \ldots 137$

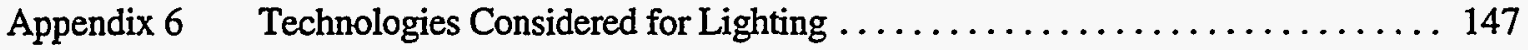

\section{List of Tables for Appendices}

Table 1.A Technical and Economic Potentials Using Simplified Approach $\ldots \ldots \ldots \ldots 127$

Table 5.2.1 Replaceable Systems for Space-Conditioning Technologies . . . . . . . . . . 139

Table 5.2.2 1990 Stock References from LBLREM .................... 140

Table 5.2.3 Sample Calculation for Determining Shipment-Weighted UEC . . . . . . . . 142

Table 5.2.4 Basecase Installed Costs and Efficiencies .................... 143

Table 5.2.5 UECs, Installed Costs, Payback Periods, and Shipments

of Advanced Technologies . .......................... 145

Table 5.2.6 Ranking Indices of Most Promising Technologies $\ldots \ldots \ldots \ldots \ldots \ldots \ldots$ 


\section{Abstract}

Section 127 of the Energy Policy Act requires that the Department of Energy (DOE) prepare a report to Congress on the potential for the development and commercialization of appliances that substantially exceed the present federal or state efficiency standards. Candidate high-efficiency appliances must meet several criteria including:

(1) The potential exists for substantial improvement (beyond the minimum established in law) of the appliance's energy efficiency.

(2) Electric, water, or gas utilities are prepared to support and promote the commercialization of such appliances.

(3) Manufacturers are unlikely to undertake development and commercialization of such appliances on their own, or development and production would be substantially accelerated by support to manufacturers.

This report describes options to improve the efficiency of residential appliances, including water heaters, clothes washers and dryers, refrigerator/freezers, dishwashers, space heating and cooling devices, as well as residential and commercial lighting products. Data from this report (particularly Appendix 1) were used to prepare the report to Congress mentioned previously.

For the residential sector, national energy savings are calculated using the LBL Residential Energy Model. This model projects the number of households and appliance saturations over time. First, end-use consumption is calculated for a base case where models that only meet the standard replace existing models as these reach the end of their lifetime. Second, models with efficiencies equal to the technology under consideration replace existing models that reach the end of their lifetime. The difference in energy use between cases 1 and 2 is the energy that would be saved by replacement of stock with models that have efficiencies equal to that of the technology under consideration rather than by models with efficiencies equal to the applicable efficiency standard. For the commercial sector, the COMMEND model was utilized to project national energy savings from new technologies. In this report, energy savings are shown for the period 1988 to 2015. 


\section{Introduction}

Section 127 of the Energy Policy Act requires that the Department of Energy (DOE) prepare a report to Congress on the potential for the development and commercialization of appliances that substantially exceed the present federal or state efficiency standards. Candidate high-efficiency appliances must meet the following criteria:

(1) The potential exists for substantial improvement (beyond the minimum established in law) of the appliance's energy efficiency.

(2) The potential for significant energy savings at a national or regional level exists.

(3) Such appliances are likely to be cost-effective for consumers.

(4) Electric, water, or gas utilities are prepared to support and promote the commercialization of such appliances.

(5) Manufacturers are unlikely to undertake development and commercialization of such appliances on their own, or development and production would be substantially accelerated by support to manufacturers.

This report describes options to improve the efficiency of residential appliances, including water heaters, clothes washers and dryers, refrigerator/freezers, dishwashers, space heating and cooling devices, as well as residential and commercial lighting products. Data from this report (particularly Appendix 1) were used to prepare the report to Congress mentioned previously. A detailed discussion of policy options for cooperative development and deployment of advanced appliances can be found in another report (Harris, 1994).

Determining which end uses consume the greatest percentage of household energy is key to understanding the potential for lessening consumption. Table 1 presents 1990 data for end-use saturation, unit energy consumption (UEC), and source energy consumption (in quads) for household appliances. The data are based on estimates from the LBL Residential Energy Model (LBLREM) for 1990 (see McMahon, 1987). To avoid double-counting, energy used for heating water for dishwashers and clothes washers is subtracted from water-heating energy use. Therefore, to calculate total electric water heating energy use, the energy used by washers ( 0.195 quads) and dishwashers ( 0.087 quads) must be added to 1.58 quads. The estimates in Table 1 have been compared to those derived from the 1990 Residential Energy Consumption Survey (RECS) administered by the Energy Information Administration (EIA) of DOE. There are large differences in the estimates for some end uses (e.g., space and water heating, cooking, and televisions) indicating that these energy-use estimates should be considered as approximate. 
In the following chapters, baseline UEC is assumed to be the National Appliance Energy Conservation Act (NAECA) standard or the DOE standard, depending on which is applicable. It is important to note that the impact of each technology is considered separately; because of interactions between technologies, their impacts cannot simply be added together. National technical potential and economic potential energy savings are calculated for two scenarios. These assume that all new products bought starting in 1998 are (1) as efficient as required by the existing standard (the base case) and (2) as efficient as the technology under consideration indicates is possible. Technical potential assumes $100 \%$ penetration for the new technology starting in 1998, whereas economic potential is based on a curve of penetration rate as a function of payback period for the technology. The economic potential is determined assuming no policy actions (additional efficiency standards, rebates, and so on) are introduced to transform the marketplace. Paybacks are calculated using projected 1998 retail prices. The relationships between payback period and market penetration for residential retrofits and for new construction are shown in Figure 1.1. These relationships were obtained by Arthur D. Little from field interviews and consumer surveys conducted over the last 10 years. Penetration is seen to increase as payback period decreases. A linear approach to the ultimate penetration rate (achieved ten years after introduction of the new product) was assumed when economic potential was calculated.

National energy savings are calculated using the LBL Residential Energy Model. This model projects the number of households and appliance saturations over time. First, end-use consumption is calculated for a base case where models that only meet the standard replace existing models as these reach the end of their lifetime. New households also receive appliances with efficiencies equal to the standard. Second, models with efficiencies equal to the technology under consideration replace existing models that reach the end of their lifetime. New households receive appliances with efficiencies equal to that of the technology option under consideration. The difference in energy use between cases 1 and 2 is the energy that would be saved by replacement of stock with models that have efficiencies equal to that of the technology under consideration rather than by models with efficiencies equal to the applicable efficiency standard. With this approach, credit is not taken for energy savings that will result from replacement of existing appliances with higher efficiency models required by efficiency standards that are already in place.

Fuel prices have been obtained from the Annual Energy Outlook 1993. For the year 1998, national average electricity and natural gas prices are estimated to be $\$ 0.087 / \mathrm{kWh}$ and $\$ 6.90 / \mathrm{MMBtu}$, in $1993 \$$, respectively.

Appendix 1 describes results from a simplified approach to calculate national energy savings. The simplified approach differs from that of the present study, since it assumes the entire stock of appliances is instantly replaced by either models that meet the existing efficiency standard or with models with efficiencies equal to those of the technologies under consideration. This simplified approach was used in the DOE Report to Congress, "A Market Catalyst for Highly Efficient Building Appliances," which will be published by the Department of Energy. 


\section{Table 1. End-Use Saturations and Source Energy Consumption (Based on LBLREM)}

\begin{tabular}{|c|c|c|c|c|c|c|}
\hline Type & Fuel & $\begin{array}{c}\text { Household } \\
\text { (million) } \\
94.45\end{array}$ & $\begin{array}{c}\text { Stock } \\
\text { Saturation }\end{array}$ & UEC (1) & $\begin{array}{l}1990 \\
\text { Source } \\
\text { Quads }\end{array}$ & $\begin{array}{l}\text { Percent } \\
\text { of Total }\end{array}$ \\
\hline Central Space Heat & gas & 35.9 & $38.0 \%$ & 60.8 & 2.18 & $12.7 \%$ \\
\hline Water Heating & elec (2) & 33.5 & $35.5 \%$ & 4096 & 1.58 & $9.2 \%$ \\
\hline Water Heating & gas (2) & 54.9 & $58.1 \%$ & 25.4 & 1.40 & $8.1 \%$ \\
\hline Refrigerator & elec & 107.4 & $113.7 \%$ & 1109 & 1.37 & $8.0 \%$ \\
\hline Lighting & elec & 94.5 & $100.0 \%$ & 1205 & 1.31 & $7.6 \%$ \\
\hline Central Space Heat & oil & 11.1 & $11.8 \%$ & 82.6 & 0.92 & $5.3 \%$ \\
\hline Central Space Heat & elec & 8.3 & $8.8 \%$ & 8413 & 0.80 & $4.7 \%$ \\
\hline Air Cond. Central & elec & 26.7 & $28.3 \%$ & 2488 & 0.76 & $4.5 \%$ \\
\hline Misc Heat & (3) & - & - & - & 0.65 & $3.8 \%$ \\
\hline Misc & elec & 40.1 & - & 1323 & 0.61 & $3.6 \%$ \\
\hline Room Space Heat & elec & 7.4 & $7.8 \%$ & 7052 & 0.60 & $3.5 \%$ \\
\hline Central Space Heat & gas (4) & 9.0 & $9.5 \%$ & 65.0 & 0.58 & $3.4 \%$ \\
\hline Dryer & elec & 50.7 & $53.7 \%$ & 823 & 0.48 & $2.8 \%$ \\
\hline Clothes Washer & (5) & 76.4 & $80.9 \%$ & (6) & 0.44 & $2.6 \%$ \\
\hline Freezer & elec & 33.6 & $35.6 \%$ & 1009 & 0.39 & $2.3 \%$ \\
\hline Oven & elec & 54.2 & $57.4 \%$ & 561 & 0.35 & $2.0 \%$ \\
\hline Air Cond. Room & elec & 30.5 & $32.3 \%$ & 971 & 0.34 & $2.0 \%$ \\
\hline Cooktop & elec & 55.3 & $58.6 \%$ & 503 & 0.32 & $1.9 \%$ \\
\hline Room Space Heat & gas & 8.1 & $8.6 \%$ & 34.8 & 0.28 & $1.6 \%$ \\
\hline Dishwasher & (7) & 43.9 & $46.5 \%$ & (6) & 0.24 & $1.4 \%$ \\
\hline Cooktop & gas & 38.5 & $40.8 \%$ & 6.2 & 0.24 & $1.4 \%$ \\
\hline Television Color & elec & 157.9 & $167.2 \%$ & 116 & 0.21 & $1.2 \%$ \\
\hline Oven & gas & 38.4 & $40.7 \%$ & 5.2 & 0.20 & $1.2 \%$ \\
\hline Microwave Oven & elec & 66.2 & $70.1 \%$ & 236 & 0.18 & $1.1 \%$ \\
\hline Air Cond. Heat Pump & elec & 5.5 & $5.8 \%$ & 2612 & 0.17 & $1.0 \%$ \\
\hline Central Space Heat & elec (8) & 5.3 & $5.6 \%$ & 2080 & 0.13 & $0.7 \%$ \\
\hline Water Heating & oil (2) & 4.9 & $5.2 \%$ & 24.7 & 0.12 & $0.7 \%$ \\
\hline Misc & gas & 25.9 & - & 3.5 & 0.09 & $0.5 \%$ \\
\hline Room Space Heat & oil & 1.4 & $1.5 \%$ & 59.5 & 0.08 & $0.5 \%$ \\
\hline Dryer & gas & 13.6 & $14.4 \%$ & 3.7 & 0.05 & $0.3 \%$ \\
\hline Pool Heater & gas & 1.5 & $1.6 \%$ & 33.3 & 0.05 & $0.3 \%$ \\
\hline Television B\&W & elec & 24.1 & $25.5 \%$ & 36 & 0.01 & $0.1 \%$ \\
\hline
\end{tabular}

Notes to Table 1:

(1) Electric unit energy consumptions are listed in site kWh; gas UECs in MMBtu.

(2) Water heating energy use for clothes washer and dishwasher not included.

(3) Space heat due to kerosene and wood fuel use.

(4) Gas space heating due to hydronic heating.

(5) Clothes washer end-use breakdown (quads): elec. water heat $=0.195$; gas w.h. $=0.156$; oil w.h. $=0.013$; elec. motor $=0.090$.

(6) UEC not provided due to multiple fuel use.

(7) Dishwasher end-use breakdown (quads): elec. water heat $=0.087$; gas w.h. $=0.069$; oil w.h. $=0.006$; elec. motor $=0.083$.

(8) Electric space heating due to heat pump. 


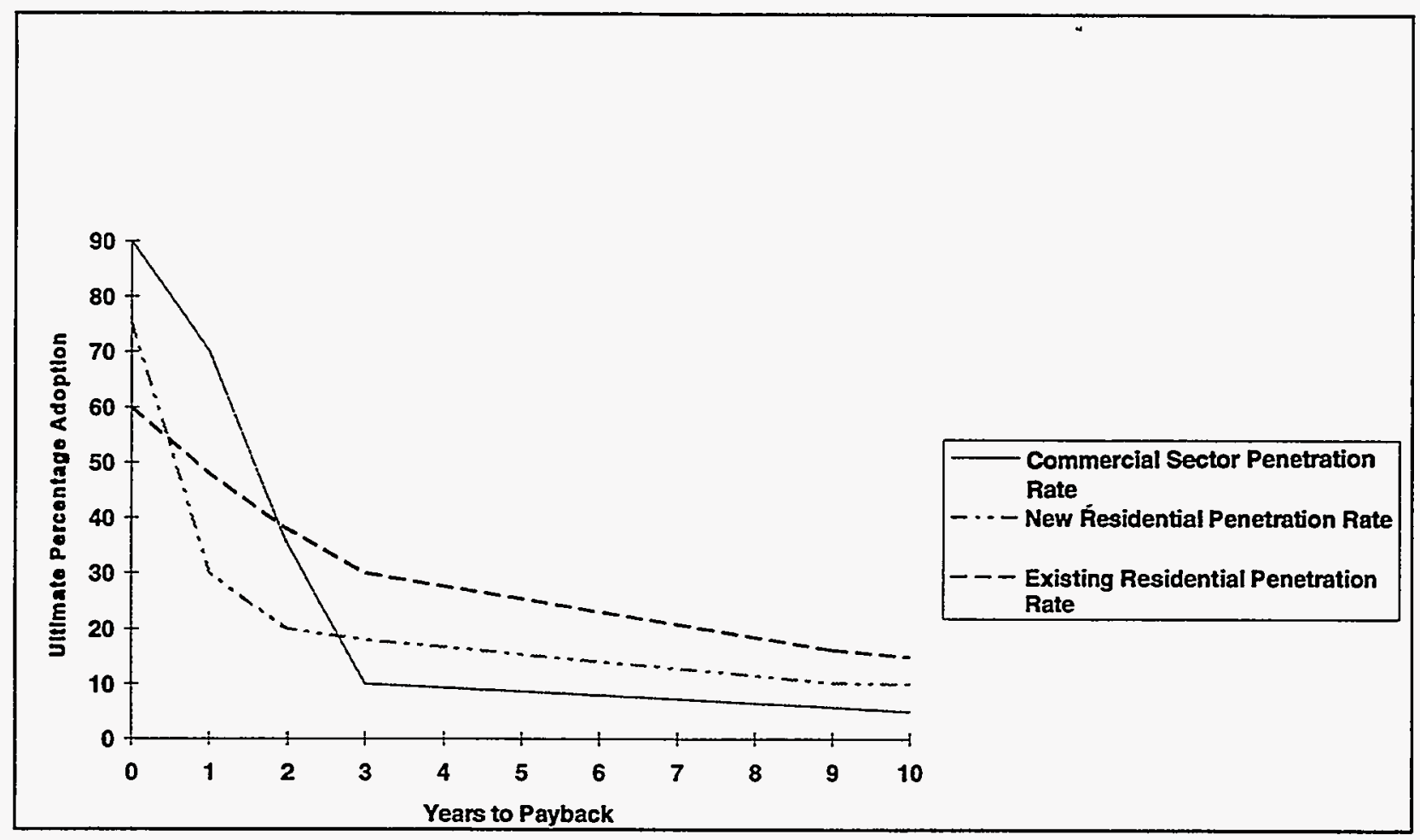

Source: Rusi Patel, Arthur D. Little

Figure 1.1 Market Penetration as a Function of Payback Period. The ultimate percentage adaption occurs ten years after the new product is introduced. 


\section{Refrigerators and Freezers}

We discuss the technologies that may produce refrigerators and freezers with unit energy consumption (UECs) significantly lower than those required by the 1993 DOE standards. For refrigerators and freezers, the following are discussed: (1) the status of each technology, (2) potential energy savings and incremental cost of the technology, and (3) barriers to implementation of the technology.

Refrigerators and freezers use $8.7 \%$ and $2.5 \%$ of total residential primary energy and have 1990 saturation levels at $114 \%$ and $36 \%$, respectively. DOE established minimum efficiency standards for 10 product classes of refrigerators and freezers effective January 1993. A revision of these standards will take effect in 1998.

Many design options for refrigerators and freezers can increase energy efficiency (see Appendix 2). For this report we selected several, noting that each technology is considered separately. Because of interactions among technologies, their impacts cannot be added together to obtain a combined impact on energy use. Except for item two below, all energy use and retail cost estimates are based on a typical $18 \mathrm{ft}^{3}$ top-mount auto-defrost refrigerator-freezer with the following added options:

1. advanced insulation (e.g., vacuum panels and gas-filled panels)

2. low-capacity, high-efficiency compressors

3. improved gaskets

4. improved fan motors

5. variable speed compressors

6. hydrocarbon refrigerants and blowing agents

Low-capacity, high-efficiency compressors are evaluated for manual defrost refrigerators and refrigerator-freezers.

Government and industry groups are undertaking many R\&D efforts to design more efficient refrigerators and freezers. One is the AHAM Appliance Research Consortium, which has been looking for substitutes for CFCs. That consortium includes industry and government participants. The EPA and DOE also sponsor several R\&D efforts in collaboration with university researchers, national laboratories, and industry. Industry also has its own extensive R\&D effort.

\subsection{ADVANCED INSULATION}

Present Status. The use of vacuum panel insulation (VPI) can reduce heat gain to refrigerator/freezer cabinets. Vacuum panel insulation for refrigerators and freezers consists of powder- and fiber-filled panels, compact vacuum insulation (with stainless steel walls), or aerogels. Several manufacturers have tested equipment with and without VPIs. The energy savings depend upon the area covered, 
the resistivity of the panels, edge losses, and so on and can range up to a maximum of $17 \%$ (General Electric, 1992). Several years ago, General Electric produced about 1000 refrigerator-freezers with VPI but decided to withdraw them from the market because of uneven results.

European manufacturers have also been testing VPI. AEG has exhibited two prototype freezers: one with silica powder-filled panels, and the other, with stainless steel walls and a plastic spacer (a more costly approach to producing vacuum panel insulation). The first freezer is available for purchase. The incremental price for the 130-liter VPI freezer is about $\$ 140$ and energy use decreases from 1.0 to $0.85 \mathrm{kWh} /$ day.

Another advanced insulation is a baffle-type panel filled with argon or krypton gas. Such systems have been found to have a resistance of as much as R-15 per inch (through the center panel). A general problem with these advanced insulation techniques is that actual thermal resistance is not as high as the center-of-panel values because of thermal bridging problems and edge effects.

A new approach, substituting plastic for steel, could increase overall thermal resistance (Griffith, 1992). For a significantly more energy-efficient shell without increasing component thickness, a higher performance vacuum, or low-conductivity gas insulation, must substitute for the foam insulation and the steel shell must be replaced with a material with a much lower conductivity. R\&D efforts would need to integrate developers of advanced insulations, refrigerator manufacturers, and those in the plastics industry with expertise in developing manufacturing processes.

Energy Use and Cost. Energy savings from VPI may range from 10 to 20\%, depending upon the technique, insulation levels in the baseline, and percentage coverage of the surface area. Cost estimates varied widely; for this study, the estimate from a recent report is used (Waldron, 1992). For a typical $18 \mathrm{ft}^{3}$ refrigerator-freezer, the incremental consumer price (in mass production) would be about $\$ 110$ for a powder-filled panel approach.

Barriers to Implementation. Manufacturers need additional testing and development of advanced insulation materials before including this technology in mass production. The longevity and efficiency of VPI still need to be proved; a network of suppliers of panels needs to be developed. Developing cabinets of new materials or producing prototype plastic refrigerators would require a coordinated effort by many manufacturers .

\subsection{LOW-CAPACITY HIGH-EFFICIENCY COMPRESSORS}

Present status. Refrigerator and freezer cabinets that transmit less heat need lower-capacity compressors with high efficiencies. The efficiency (EER<3.5) of low-capacity $(\sim 300 \mathrm{Btu} / \mathrm{hr})$ compressors is significantly lower than that of high-capacity compressors ( $>700 \mathrm{Btu} / \mathrm{hr})$. Highcapacity compressors have EERs of up to 5.5 with CFC-12 or HFC-134a as a refrigerant. Smaller manual defrost refrigerators already use low-capacity compressors. Dual-loop systems using two compressors require smaller-capacity compressors with high efficiencies to realize the theoretical efficiency benefits. 
High-efficiency low-capacity compressors can be produced through improved motor efficiency and by implementing measures to reduce mechanical losses, clearance volume, and suction gas heating. A recent study concluded that 5.0 EER compressors would be possible at $200 \mathrm{Btu} / \mathrm{hr}$ for an increased cost to the refrigerator manufacturer of $\$ 10-\$ 20$ over the typical cost of $\$ 20-\$ 25$ (EPA, 1993).

A second approach to producing high-efficiency low-capacity compressors is to promote the development of linear compressors. A small company has developed prototypes of a non-lubricated, linear free-piston compressor. The piston is electronically driven by a linear, permanent magnet motor. Since friction losses are lower than those of standard compressors, the efficiency of a linear compressor should not change significantly with compressor size. It is possible that an EER close to 6.0 could be achieved for low-capacity compressors (Technology Alert, 1993). At present the additional cost is difficult to estimate.

Energy Use and Cost. Depending upon the refrigerator/freezer type, an improvement in compressor efficiency from 3.5 to 5.0 EER would result in a 30 to $43 \%$ reduction in energy use. For this analysis, we have used a $6 \mathrm{ft}^{3}$ manual defrost refrigerator with an energy use of $350 \mathrm{kWh} / \mathrm{yr}$ as the baseline. Assuming a factor of two markup, the incremental price increase would be $\$ 20-\$ 40$.

Barriers to Implementation. Both technical and economic barriers exist to implementing highefficiency low-capacity compressors. Manufacturers would need to research and develop prototype compressors and field-test them. Compressor manufacturers also need to be convinced that markets for more expensive, but more efficient low-capacity compressors exist. Refrigerator manufacturers need to be motivated to incorporate these more expensive components.

\subsection{IMPROVED GASKETS}

Present Status. A significant portion (25-30\%) of the heat gain to refrigerators and freezers occurs around the edges of the doors and through the gaskets on the door edges. Improving the insulating value of the gasket reduces heat leakage through the gasket, thus increasing the efficiency of the refrigerator or freezer. Recent analytic and experimental studies indicate that $25 \%$ and $50 \%$ reductions in gasket loads are possible (EPA, 1992). That study found that significant reductions in heat flow in the gasket region can be realized by substitution of low-conductivity (plastic) materials for the metallic door flange in current designs.

Energy Use and Cost. The EPA Refrigerator Analysis (ERA) simulation program was used to estimate the energy savings from substitution of improved gaskets for standard gaskets in a typical $18 \mathrm{ft}^{3}$ top-mount refrigerator/freezer (EPA, 1992). For 25\% and 50\% reductions in gasket heat flow, the energy-use reductions were $47 \mathrm{kWh}$ and $94 \mathrm{kWh}$, respectively, relative to a baseline energy use of $665 \mathrm{kWh} / \mathrm{yr}$. Incremental manufacturer costs for $25 \%$ and $50 \%$ reductions in gasket heat leak are $\$ 1.10$ and $\$ 2.70$, respectively (Multiple Pathways, 1993).

Barriers to Implementation. The main barrier to implementation of improved gaskets is the lack 
of comprehensive testing of a variety of refrigerators and freezers that include such components. The tests need to be included within a larger set of models with different door gasket designs. Ultimately, demonstrations that the gasket design changes could be mass produced would be necessary.

\subsection{IMPROVED FAN MOTORS}

Present Status. Most large refrigerators use motors to run the evaporator and condenser fan. Typical power demands are 12 Watts for a condenser fan motor and 9.0 Watts for an evaporator fan motor. Shaded pole motors are inexpensive and most commonly used in refrigerators and freezers. Large efficiency gains are possible by switching to electronically commutated motors (ECMs). Also called brushless permanent magnet motors, the power demand for ECM motors would only be about 4-4.5 Watts. ECM motors for refrigerator/freezers have recently become available for purchase in small quantities. At present, insufficient numbers are produced to supply the U.S. market. At least two companies plan to manufacture large quantities of ECMs.

Energy Use and Cost. Energy savings from substitution of ECMs were calculated with the ERA simulation program. Energy is saved both directly from less electric motor energy use and also from reduced heat gain in the cabinets from reduced evaporator motor losses. Results showed that 60 $\mathrm{kWh} / \mathrm{yr}$ could be saved for an incremental consumer price of about $\$ 25$.

Barriers to Implementation. The main barriers to implementation of ECMs are high first cost and insufficient supply. Motor manufacturers do not want to produce large quantities until they feel confident that a market exists. Refrigerator/freezer manufacturers are reluctant to increase the first cost of their products so they will avoid adding a costly purchased part unless they believe a market exists for such products.

\subsection{VARIABLE SPEED COMPRESSORS}

Present Status. Present refrigerator compressor motors operate at one speed. A variable-speed compressor would allow a better match between heat removal loads and compressor power demand. During most of each 24-hour period the compressor would operate at a low speed with a high percentage of on-time. This pattern would reduce cycling - and consequently cycling losses - and also reduce evaporator loading. However, fan energy consumption would increase, thus offsetting some of the gains. ECMs for the evaporator and condenser fans would be necessary to reduce fan energy use. Optimally, variable-speed fans could be incorporated into the final design.

Several manufacturers are testing variable-speed compressors. Additional research could determine the energy savings resulting from the use of such electronic controls for compressors. Variablespeed compressors are used for residential-sized heat pumps and air conditioners.

Energy Use and Cost. One report estimates an incremental OEM cost of $\$ 30-\$ 35$ for a variable- 
speed drive and motor (EPA2, 1993). That same report also performs a theoretical calculation of energy savings when a variable-speed compressor and fans are substituted for a single-speed compressor and fans. The baseline refrigerator is assumed to have fans that employ ECMs. The estimated energy savings are $119 \mathrm{kWh} / \mathrm{yr}$, relative to a baseline of $604 \mathrm{kWh} / \mathrm{yr}$.

Barriers to Implementation. Barriers to implementing variable-speed compressors and fans include the high first cost, uncertainties about reliability, and uncertainties about energy savings. Additional R\&D with extensive field testing might help reduce the latter two uncertainties.

\subsection{HYDROCARBON SUBSTITUTES FOR HCFCS AND HFCS}

Present Status. Some areas of research and development may, or may not, bring about energy savings, but are, nevertheless, important to address: for example, an analysis of hydrocarbon blowing agents and refrigerants with respect to energy consumption, manufacturer usage, service, and disposal. Hydrocarbons are receiving more attention because of the potential of an earlier phaseout of HCFCs (HCFC 141b is presently scheduled for phase-out in 2003). European manufacturers are increasingly turning to hydrocarbons (e.g., butane and pentane) as potential substitutes for CFCs and HCFCs in refrigerants and blowing agents.

Energy Use and Cost. At present, there are few data on the efficiency or cost impacts of substituting hydrocarbons for existing refrigerants and foam blowing agents. Preliminary measurements indicate that cyclopentane foams have about a 10\% higher thermal conductivity than CFC-11 blown foam. That conductivity could be lowered by about $5 \%$ with the addition of perfluoroalcanes (PFAs) (Wenning, 1993). As stated previously, a significant $R \& D$ program is needed to develop costefficiency data.

Barriers to Implementation. The barriers to using hydrocarbons for refrigeration or insulation are based on a lack of information concerning a number of issues; they include safety, efficiency, cost, and rigidity of foam using hydrocarbons. An R\&D program might be able to resolve most of these issues.

\subsection{SUMMARY}

Table 2.1 summarizes the energy use and cost data presented earlier. Also shown are simple payback periods for each technology, based on an electricity price of $\$ 0.087 / \mathrm{kWh}$. For the technology with the lowest payback period, improved gaskets, there are large uncertainties in the incremental price and energy savings. Two scenarios for improved gaskets, a $25 \%$ and a $50 \%$ reduction in gasket heat leak, are shown. The low-capacity, high-efficiency compressor option is applied to a $6 \mathrm{ft}^{3}$ manual defrost refrigerator-freezer.

In addition to analyzing individual design options for an $18-\mathrm{ft}^{3}$ top-mount refrigerator-freezer, three combinations of design options were also evaluated. For improved gaskets and a 5.5 EER 
compressor, the energy use is $560 \mathrm{kWh} / \mathrm{yr}$, for a reduction of $16 \%$ relative to the baseline energy use of $670 \mathrm{kWh} / \mathrm{yr}$. Adding adaptive defrost, ECM fan motors, and a $5.8 \mathrm{EER}$ compressor lowers energy use to about $500 \mathrm{kWh} / \mathrm{yr}$. The addition of vacuum panel insulation lowers energy use to 400 $\mathrm{kWh} / \mathrm{yr}$, for a $40 \%$ energy savings relative to baseline. At $400 \mathrm{kWh} / \mathrm{yr}$, energy use has reached the expected minimum for 1998 with available technology. The incremental retail cost for this combination of design options is approximately $\$ 150$ and the payback period relative to the baseline is about 8 years.

Table 2.1 Energy Use and Cost Summary for Refrigerators

\begin{tabular}{|c|c|c|c|c|c|}
\hline Option & Baseline kWh/yr & $\triangle \mathrm{UEC}$ kWh/yr & $\triangle \mathbf{U E C}$ & $\triangle$ Price & Payback Period yrs \\
\hline VPI & $665^{1}$ & 113 & $17 \%$ & $\$ 100$ & 10.2 \\
\hline $\begin{array}{l}\text { Low-cap } \\
\text { compress. }\end{array}$ & $350^{2}$ & 123 & $35 \%$ & $\$ 30$ & 2.8 \\
\hline Gaskets & 665 & $\begin{array}{l}47 \\
94\end{array}$ & $\begin{array}{l}7 \% \\
14 \%\end{array}$ & $\begin{array}{l}\$ 2.50 \\
\$ 6.20\end{array}$ & $\begin{array}{l}0.6 \\
0.8\end{array}$ \\
\hline Fan motors & 665 & 60 & $9 \%$ & $\$ 25$ & 4.8 \\
\hline $\begin{array}{l}\text { Variable sp } \\
\text { compress. }\end{array}$ & $604^{3}$ & 119 & $20 \%$ & $\$ 80$ & 7.7 \\
\hline Combination $^{4}$ & 665 & 265 & $40 \%$ & $\$ 150$ & 8.0 \\
\hline
\end{tabular}

\subsection{Discussion Of NATIONAL ENERgY SAVINGS}

Figure 2.1 shows annual energy use for refrigerator/freezers over the time period 1995-2015. Topmount and side-by-side refrigerator/freezers only are included in these calculations. Compacts and bottom-mounts, which account for a small percentage of total energy use, are excluded. A base case and five technology options (two are for improved gaskets) are shown for technical and economic potential cases (see Chapter 1 for details concerning these two cases). In the base case, retiring models are replaced with models that have an efficiency equal to that required by the existing DOE standard. For each technology option (the five bottom curves), they are replaced with models that have an efficiency equal to that of the specific technology. The ultimate market penetrations for the economic potential cases are obtained from the market penetration curve (Figure 1.1) shown in Chapter 1. Penetration rates are a function of the simple payback periods. The technical potential $(100 \%)$ is significantly greater than the economic potential for each technology evaluated. The 
economic potential is determined assuming no policy actions (additional efficiency standards, rebates, and so on) are introduced to transform the marketplace.

Table 2.2 shows the base case energy use and the annual energy savings for specific years and the cumulative (1998-2015) energy savings, relative to the base case. The largest energy savings is for variable-speed compressors; the technical potential is 1.7 quads (8.4\%) over the period 1998-2015, compared to 20.2 quads of base case refrigerator/freezer energy use. The economic potentials for each technology are much lower than the technical potential. The economic potentials are based on 1998 prices for each technology; that is, the penetration rates used for estimating economic potentials are based on payback periods calculated with 1998 prices for each technology. 


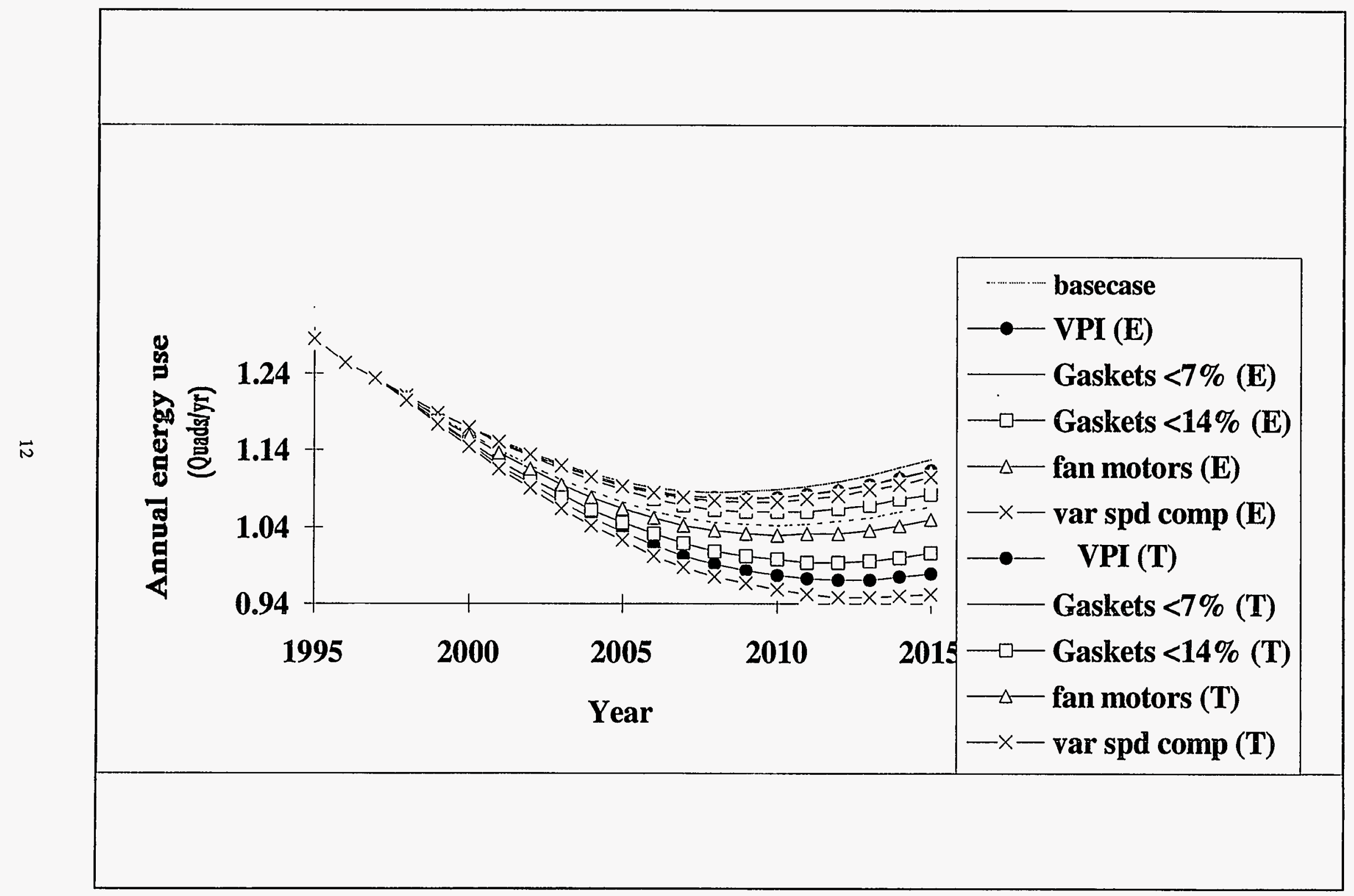

Figure 2.1 Annual Energy Use for Technology Options: Refrigerators 
One technology option, efficient low-capacity compressors, has been omitted from the preceding table. A more approximate method was used to estimate energy savings for this technology; and only cumulative energy savings were calculated. Over the time period 1998-2015, the estimated cumulative energy savings (technical potential) is 0.24 quads for manual defrost refrigerators. That figure is lower than the estimates for any of the other technologies discussed above. However, it is a large fraction (27\%) of the total base case energy use ( $\sim 0.9$ quads) for compact refrigerators.

Table 2.2 Annual Energy Savings for Refrigerator Technology Options

\begin{tabular}{|c|c|c|c|c|c|c|}
\hline & & \multicolumn{4}{|c|}{ Annual energy savings (Quads) } & $\begin{array}{c}\text { Cumulative } \\
\text { En sav (quads) }\end{array}$ \\
\hline Option & Case & 2000 & 2005 & 2010 & 2015 & $1998-2015$ \\
\hline Basecase* & & 1.170 & 1.099 & 1.088 & 1.128 & 20.173 \\
\hline VPI & $\begin{array}{l}\text { TP } \\
\text { EP }\end{array}$ & $\begin{array}{l}0.022 \\
0.000\end{array}$ & $\begin{array}{l}0.066 \\
0.003\end{array}$ & $\begin{array}{l}0.111 \\
0.009\end{array}$ & $\begin{array}{l}0.149 \\
0.015\end{array}$ & $\begin{array}{l}1.424 \\
0.112\end{array}$ \\
\hline Gaskets $<7 \%$ & $\begin{array}{l}\mathrm{TP} \\
\mathrm{EP}\end{array}$ & $\begin{array}{l}0.009 \\
0.000\end{array}$ & $\begin{array}{l}0.027 \\
0.006\end{array}$ & $\begin{array}{l}0.046 \\
0.015\end{array}$ & $\begin{array}{l}0.061 \\
0.024\end{array}$ & $\begin{array}{l}0.586 \\
0.183\end{array}$ \\
\hline Gaskets $<14 \%$ & $\begin{array}{l}\text { TP } \\
\text { EP }\end{array}$ & $\begin{array}{l}0.018 \\
0.001\end{array}$ & $\begin{array}{l}0.054 \\
0.011\end{array}$ & $\begin{array}{l}0.091 \\
0.028\end{array}$ & $\begin{array}{l}0.122 \\
0.045\end{array}$ & $\begin{array}{l}1.172 \\
0.336\end{array}$ \\
\hline Fan motors & $\begin{array}{l}\mathrm{TP} \\
\mathrm{EP}\end{array}$ & $\begin{array}{l}0.011 \\
0.000\end{array}$ & $\begin{array}{l}0.035 \\
0.003\end{array}$ & $\begin{array}{l}0.059 \\
0.009\end{array}$ & $\begin{array}{l}0.078 \\
0.014\end{array}$ & $\begin{array}{l}0.754 \\
0.104\end{array}$ \\
\hline Var speed compressor & $\begin{array}{l}\mathrm{TP} \\
\mathrm{EP}\end{array}$ & $\begin{array}{l}0.026 \\
0.000\end{array}$ & $\begin{array}{l}0.077 \\
0.006\end{array}$ & $\begin{array}{l}0.130 \\
0.015\end{array}$ & $\begin{array}{l}0.175 \\
0.023 \\
\end{array}$ & $\begin{array}{l}1.674 \\
0.173 \\
\end{array}$ \\
\hline
\end{tabular}

* Basecase is annual energy use in Quads, not energy savings.

$\mathrm{EP}=$ Economic potential; $\mathrm{TP}=$ Technical potential.

Basecase energy and energy savings from technology options do not include bottom mount or compact refrigerators. 
. 


\section{Clothes Washers, Clothes Dryers, and Dishwashers}

In this section of the report, we discuss the technologies that may be used to produce washers, dryers, and dishwashers with efficiencies greater than required by the 1994 DOE standards. Only those technologies that reduce unit energy consumption by a significant amount (>15\%) will be discussed in any detail. For each product covered, the following are discussed: (1) the status of each technology, (2) potential energy savings and incremental cost of the technology, and (3) barriers to implementation of the technology. A list of all technologies initially considered appears in Appendix 3.

\section{Clothes WAShers}

Eighty-one percent of households have clothes washers, consuming $2.6 \%$ of total residential primary energy. Most of the energy is required for hot water rather than for electric motor use. For clothes washers, the technology options considered in detail are (1) horizontal axis design, (2) high-spin speed, (3) microprocessor controls, and (4) bubble action.

\subsection{HoRIZONTAL AXIS DESIGN}

Present Status. The vast majority of clothes washers sold in the U.S. are top-loading, vertical axis machines. Horizontal axis washers, where the tub spins around a horizontal axis, are also available, but are not as common. The horizontal axis machines use less water than their vertical axis counterparts and therefore, less hot water is required from water heaters. Less total water use and detergent are required as well. At present, Frigidaire is the only U.S. manufacturer producing a horizontal axis washer $(\sim 50,000 / \mathrm{yr})$. Re-introduced in the U.S. in 1992, Frigidaire's model is frontloading. Another company, Staber Industries of Columbus, Ohio, plans to produce a similar quantity of top-loading horizontal axis washers beginning in 1995 (Appliance, 1993). Whirlpool Corporation recently announced that it will produce horizontal axis washers in 1996 (Consumer Electronics 1994). Europeans have been using horizontal axis washers (both top- and front-loading) for many years. Small quantities of European washers are imported to the U.S.

The Western Utilities Consortium and the Center for Energy Efficiency have announced a program whereby utilities would offer a rebate to consumers purchasing energy-efficient clothes washers. (Pacific Gas and Electric, a California utility, already offers a $\$ 75$ rebate for purchasing horizontal axis washers.) The rebate amount will depend upon the energy and water consumption levels and will be set by each participating utility. The goal is to reduce energy and water use to levels achievable by horizontal axis and higher spin speed designs, although performance goals - rather than specific technologies - will be specified.

Energy Use and Cost. Typical vertical axis clothes washers that meet the 1994 DOE energy efficiency standard and are connected to an electric water heater will use about $674 \mathrm{kWh} / \mathrm{yr}$. That energy use is based on 380 cycles per year for a standard-size $2.6 \mathrm{ft}^{3}$ vertical axis washer. Hot water 
consumption is equal to 7 gallons per cycle (or $1.50 \mathrm{kWh} /$ cycle energy use), motor energy use is $0.27 \mathrm{kWh} /$ cycle, and total water use is 33.3 gallons per cycle. The energy factor of this baseline washer is $1.47 \mathrm{ft}^{3} / \mathrm{kWh}$, based upon 1988/89 Procter and Gamble usage factors (Procter, 1989), rather than existing DOE usage factors.

A horizontal axis washer connected to an electric water heater, will use only 2.5 gallons of hot water and about 23 gallons of total water during one cycle (DOE, 1990). Motor energy use is about 0.15 $\mathrm{kWh} /$ cycle and total energy use is about $262 \mathrm{kWh} / \mathrm{yr}$. The unit energy savings therefore is about $412 \mathrm{kWh} / \mathrm{yr}$. For a clothes washer connected to a gas-fired water heater, the unit energy savings is almost 17 therms. Consumers also save money on detergent and water use. Assuming a water cost to consumers of $\$ 2.12 / 1000$ gallons and a detergent cost of $\$ 0.23 /$ cycle for vertical axis machines (\$0.115/cycle for horizontal axis machines), the total operating cost savings can be calculated. For households with electric water heaters, the operating cost savings are about $\$ 88$ and for households with gas-fired water heaters, the operating cost savings are about $\$ 68$. The present price range of horizontal axis washers manufactured by Frigidaire runs from $\$ 600$ to $\$ 700$. That range is about $\$ 200-\$ 300$ greater than that of a vertical axis washer. At higher production volumes and with greater competition, that price differential will fall, as will the payback period. The fuel prices projected for 1998 , in $1993 \$$, are $\$ 0.087 / \mathrm{kWh}$ and $\$ 0.69 /$ therm for electricity and natural gas, respectively. Payback period has been calculated based on a price differential of $\$ 200$. Accounting for water and detergent use, the payback periods for electric-and gas-fired water heaters are about 2 and 3 years, respectively (see Table 3.1 ).

\section{Table 3.1 Energy Use and Cost Summary for Clothes Washers}

\begin{tabular}{lccccc} 
Option & Baseline $(\mathbf{k W h} / \mathbf{y r})$ & $\Delta \mathbf{U E C}(\mathbf{k W h} / \mathbf{y r})$ & $\Delta$ UEC & $\Delta$ Price & Payback Period (yrs) \\
\hline H-Axis & $674 \mathrm{kWh}$ & $412 \mathrm{kWh}$ & $61 \%$ & $\$ 200$ & 2.3 \\
& 25.9 therm & $16.7 \mathrm{therm}$ & $64 \%$ & & 3.0 \\
Spin & 834 & $296 \mathrm{kWh}$ Vaxis & $35 \%$ & $\$ 95$ & 3.7 \\
Speed" & & $274 \mathrm{kWh}$ Haxis & $33 \%$ & & 4.0 \\
Controls & 674 & $135 \mathrm{kWh}$ & $20 \%$ & $\$ 83$ & 2.4 \\
& & 5.2 therms & & & 2.9 \\
Bubble & 674 & $183 \mathrm{kWh}$ & $27 \%$ & $\$ 100$ & 2.0 \\
Action & & 8.3 therms & & & 2.5 \\
\hline
\end{tabular}

*For this option, table entries, including baseline energy use, are for an electric dryer. Payback periods are much longer for gas dryers.

Barriers to Implementation. At least two barriers impede an increased market share for horizontal axis washers in the U.S. First, the model presently produced in the U.S. by Frigidaire is a frontloading version. Manufacturers have indicated that some consumers are resistant to front-loading machines. Objections include the inconvenience of loading and unloading clothes from the front as 
well as the resistance to a new technology when the existing one performs well. Consumers are concerned about washing performance and mechanical performance of new washers. A survey carried out by Consumer Reports in 1992 indicated that front-loaders are subject to more repair work than are top-loaders (Consumer Reports, 1993). On the other hand, there is evidence that horizontal axis type machines cause less damage to clothes because of the absence of an agitator. The second barrier to an increased market share is the high price of horizontal axis washers. Imports can cost about $\$ 1000$. The Frigidaire front-loaders range from $\$ 600$ to $\$ 700$ in price. For 1998 , we are estimating an incremental price of $\$ 200$ in $1993 \$$. Even with a short payback period, the large, firstcost increase will present a significant barrier to an increased penetration. Additionally, the industry has estimated a cost of more than one billion dollars (AHAM, 1990) to convert U.S. manufacturing plants to produce horizontal axis washers.

\subsection{HIGH-SPIN SPEED}

Present status. A higher drum speed for clothes washers decreases the water content of the load at the end of the cycle. Water extraction by mechanical means in a clothes washer is much more efficient than by thermal energy in a clothes dryer. Average water-removal efficiency of a typical vertical axis electric clothes dryer is approximately $2 \mathrm{lb}$ water $/ \mathrm{kWh}$. The water-removal efficiency is about $134 \mathrm{lb} / \mathrm{kWh}$ for a washer cycle with a typical spin speed of $525 \mathrm{rpm}$. A remaining moisture level of $40 \%$ is a reasonable goal for a spin speed of about $850 \mathrm{rpm}$ on vertical axis machines. Present vertical axis washers $(\sim 525 \mathrm{rpm})$ probably achieve about a $65 \%$ remaining moisture level. For horizontal axis machines, the achievable spin speed (without major costs to improve the suspension system) may be a little lower than $850 \mathrm{rpm}(-750 \mathrm{rpm})$.

High, variable spin speeds ( $>1000 \mathrm{rpm}$ ) are common for European horizontal axis clothes washers. However, these washers have a smaller tub diameter than U.S. models; therefore, centrifugal forces would be less than for U.S. models. Wrinkles may appear with higher spin speeds. For this reason, some European manufacturers have developed an elaborate rinse-and-spin process for their high spin speed washing machines.

Energy Use and Cost. For higher spin speed with a vertical axis design, an increase from 550 to 850 rpm would reduce moisture retention from 65 to 41\% (Lovett, 1981). Although with a 65\% moisture retention (as compared to $70 \%$ in the test procedure), dryer energy use will be somewhat less than the 1994 standard, for these energy-use calculations, we assume that baseline UEC equals that required by the $1994 \mathrm{DOE}$ efficiency standards. This assumption will make all end-use calculations for the various product types consistent. Electric dryer energy use decreases from about 2.32 $\mathrm{kWh} /$ cycle to $1.36 \mathrm{kWh} /$ cycle. For higher spin speed with a horizontal axis design, an increase in spin speed from 550 to $750 \mathrm{rpm}$ reduces moisture retention from 65 to $47 \%$. This assumes that the same moisture-retention curve can be used as was used for vertical axis washers. Electric dryer energy use decreases from about $2.32 \mathrm{kWh} /$ cycle to $1.56 \mathrm{kWh} /$ cycle. Motor energy use increases for higher spin speeds. Taking clothes washer motor energy use and electric dryer energy use into account, the net energy savings from the use of higher spin speed washers can be calculated. Usage values for these 
calculations are 380 and 359 cycles/yr respectively, for washers and dryers.

For vertical axis washers, the estimated net (increased washer motor energy use accounted for) electric dryer energy savings is $296 \mathrm{kWh} / \mathrm{yr}$; baseline 1994 electric dryer energy use is $834 \mathrm{kWh} / \mathrm{yr}$. For gas-fired dryers, baseline energy use is 32.8 therms/yr and the net dryer energy savings is 12 therms/yr. For horizontal axis washers, the estimated net electric dryer energy savings is $274 \mathrm{kWh} / \mathrm{yr}$ and the net gas dryer energy savings is 10.2 therms/yr. The incremental price increase for higher spin speed is estimated at $\$ 95$ (CCIG, 1992).

Barriers to Implementation. There are several barriers to a large-scale commercialization of high spin speed washers. These include: (1) the need for additional R\&D with both vertical axis machines and large horizontal axis machines, (2) consumer unfamiliarity with the technology and how energy may be saved indirectly in clothes dryers, (3) higher first cost for such washers, (4) investment cost required by manufacturers, and (5) lack of credit for dryer energy savings in existing clothes washer test procedures. Proposed changes to the current DOE test procedure that are planned for clothes washers will allow for higher energy factors for washers that yield clothes with a lower moisture content at the end of a spin cycle. EPRI is currently working with a manufacturer to develop a high spin speed horizontal axis clothes washer. Additional development work and extensive field testing would help reduce some of the barriers listed above.

\subsection{MiCROPROCESSOR CONTROLS}

Present status. Automatic controls that can detect the size, type, and dirtiness of a load of clothes are currently available. Water and energy savings are realized over the use of conventional electromechanical controls when the amount of water and detergent, wash temperature, and spin speed are controlled to match precisely the wash requirements of the clothes load.

Japanese (Matsushita, Sanyo, Toshiba) and German (AEG) manufacturers have introduced washers incorporating neuro-fuzzy logic controls (CCIG, 1992, DOE, 1992, \& Appliance Manufacturer, May 1993). Bosch and Samsung exhibited fuzzy logic washers at the 1992 Domotechnica, the International Appliance Exposition in Cologne, Germany. According to Bosch literature, wash times and energy use are reduced. Optical sensors and special control circuitry are used to detect the amount of water absorbed by the laundry and the rate at which it is being used. In addition, the sensors optically measure the transparency of the water and the rate at which it becomes turbid. Coupling these optical functions with its capability to determine the size of the load based on the strain of the motor allows fuzzy logic controls to be able to select the appropriate wash/spin cycle. In the U.S., the Eaton Corporation has developed a prototype clothes washer that also incorporates fuzzy logic controls (CCIG, 1992). Like its Japanese and German counterparts, this washer incorporates fill level, water temperature, and turbidity sensors to eliminate excess water use, limit hot water use, and sense the dirtiness of wash and rinse water to select appropriate wash/rinse cycles.

Energy Use and Cost. Laboratory tests in the U.S. and Europe of automatic fill systems show $20 \%$ 
reductions in motor electricity and hot water use (DOE, 1990 and CCIG, 1992). Savings could be increased significantly by the addition of turbidity sensors and the selection of optimal motor speeds for spin drying. In order to be conservative, energy savings due to automatic controls are based on a $20 \%$ reduction in baseline clothes washer energy consumption ( $674 \mathrm{kWh} / \mathrm{yr})$. This results in a UEC reduction of $135 \mathrm{kWh} / \mathrm{yr}$. Based on manufacturer estimates, the retail cost increase of a clothes washer incorporating fuzzy logic-based automatic controls increases by $\$ 83$ (CCIG; 1992). It must be noted that this cost is subject to substantial uncertainty.

Barriers to Implementation. Questions regarding performance are the primary barriers to implementation. Standardized and independent tests have yet to be conducted on the performance of the control systems. Such issues as the accuracy and long-term reliability of the controls and sensors and the cleaning performance of the machines have yet to be resolved. The retail price increase of a washer incorporating these advanced control systems also presents a barrier since consumers will probably be hesitant to purchase more costly clothes washers.

\subsection{BUBBLE ACTION}

Present status. The Sharp Corporation currently markets a fully automatic bubble action washer using neuro-fuzzy logic controls. The bubble-action design uses a combination of air bubbles and a swirling water action to clean clothes and, according to Sharp, results in clothes $20 \%$ cleaner than those washed in conventional washers (Appliance Manufacturer, May 1993). The bubble-action design replaces the mechanical agitator, which is used in typical clothes washers. From a nozzle located at the bottom of the washer, air bubbles are generated by a computer-controlled pulsator and circulated upward in vertical and horizontal swirling motions. Horizontal bubble swirls aid in cleaning large wash loads, while vertical bubble swirls are used to gently wash small loads and delicate fabrics. In addition, built-in optical sensors are able to detect how well the detergent has been dissolved and to what extent any dirt has been removed from the clothing. The controls then adjust the amount of bubbles generated to match the wash cycle to the user's needs. The bubble-action washer reduces water use by using a single-tub design that washes the same amount of laundry as a typical dual-tub (inner and outer) configuration. Water and detergent use are only $70 \%$ of that used in conventional dual-tub designs (Appliance Manufacturer, May 1993). The bubble-action washer combines the wash tub and spin-extraction tub into a single unit by incorporating a new spin-extraction technology. A conical-shaped wash/spin tub facilitates water extraction in the upward direction through a channel built into the tub.

The bubble-action washer is currently available only in Japan and Southeast Asia, and Sharp has no plans in the near future to market it in the United States.

Energy Use and Cost. If Sharp's assertion that water and detergent savings of 30\% are achievable with its bubble-action design, hot water use should be reduced by the same percentage. For a bubbleaction washer connected to an electric water heater, this translates into only 4.74 gallons of hot water and about 23.3 gallons of total water being used during one cycle. With motor energy use at 
approximately $0.27 \mathrm{kWh} /$ cycle, total energy consumption is about $491 \mathrm{kWh} / \mathrm{yr}$. The unit energy savings is therefore about $183 \mathrm{kWh} / \mathrm{yr}$ compared to a washer meeting the 1994 minimum efficiency standards. For a clothes washer connected to a gas-fired water heater, the unit energy savings is about 8.3 therms. Consumers also save money on detergent and water use. Assuming a water cost to consumers of $\$ 2.12 / 1000$ gallons and a detergent cost of $\$ 0.23 /$ cycle, the total operating cost savings can be calculated. For households with electric water heaters, the operating cost savings is about $\$ 50$ and for households with gas-fired water heaters, the operating cost savings is about $\$ 40$. The additional retail cost of the bubble-action washer over that of a conventional vertical axis washer is estimated at $\$ 100$ (CCIG, 1992).

Barriers to Implementation. Questions regarding performance are the primary barriers to implementation. Standardized and independent tests have yet to be conducted on the performance of the bubble-action system. The bubble-action washer's higher retail price also presents a barrier since consumers will probably be hesitant to purchase a more costly machine.

\subsection{DISCUSSION OF NATIONAL ENERGY SAVINGS}

Figure 3.1 shows annual energy use for clothes washers over the time period 1995-2015. Annual energy use is the sum of direct clothes washer electricity use, the clothes washer's portion of water heater energy use, and total (gas plus electric) dryer energy use. Dryer energy use is added because two of five technology cases impact dryer energy use. A base case and five technology options are shown for the technical and economic potential cases (see Chapter 1 for description of methodology). For the base case, retiring appliances are replaced with models that have an efficiency equal to that required by the existing DOE standard. For each technology option, they are replaced with models that have an efficiency equal to that of the specific technology. The market penetration for the economic potential cases are obtained from the market penetration curve (Figure 1.1) shown in Chapter 1. Penetration rates are a function of simple payback periods (shown in Table 3.1). The technical potential ( $100 \%$ penetration) is shown to be significantly greater than the economic potential for each technology evaluated. The economic potential is determined assuming no policy actions (additional efficiency standards, rebates, and so on) are introduced to transform the marketplace.

Table 3.2 depicts the annual energy savings for specific years and the cumulative (1998-2015) energy savings, relative to the basecase. The largest technical potential is for a horizontal axis washer with high spin speed: 4.5 quads of energy are saved between 1998-2015, compared to a basecase energy use of 24.2 quads (includes washer, dryer, and portion of water heater energy assigned to clothes washer) over the same period. The economic potential is significantly lower than the technical potential for this technology case and for all other technologies studied. The penetration rates used for calculating the economic potentials are based on paybacks calculated with estimated 1998 prices for each technology. 


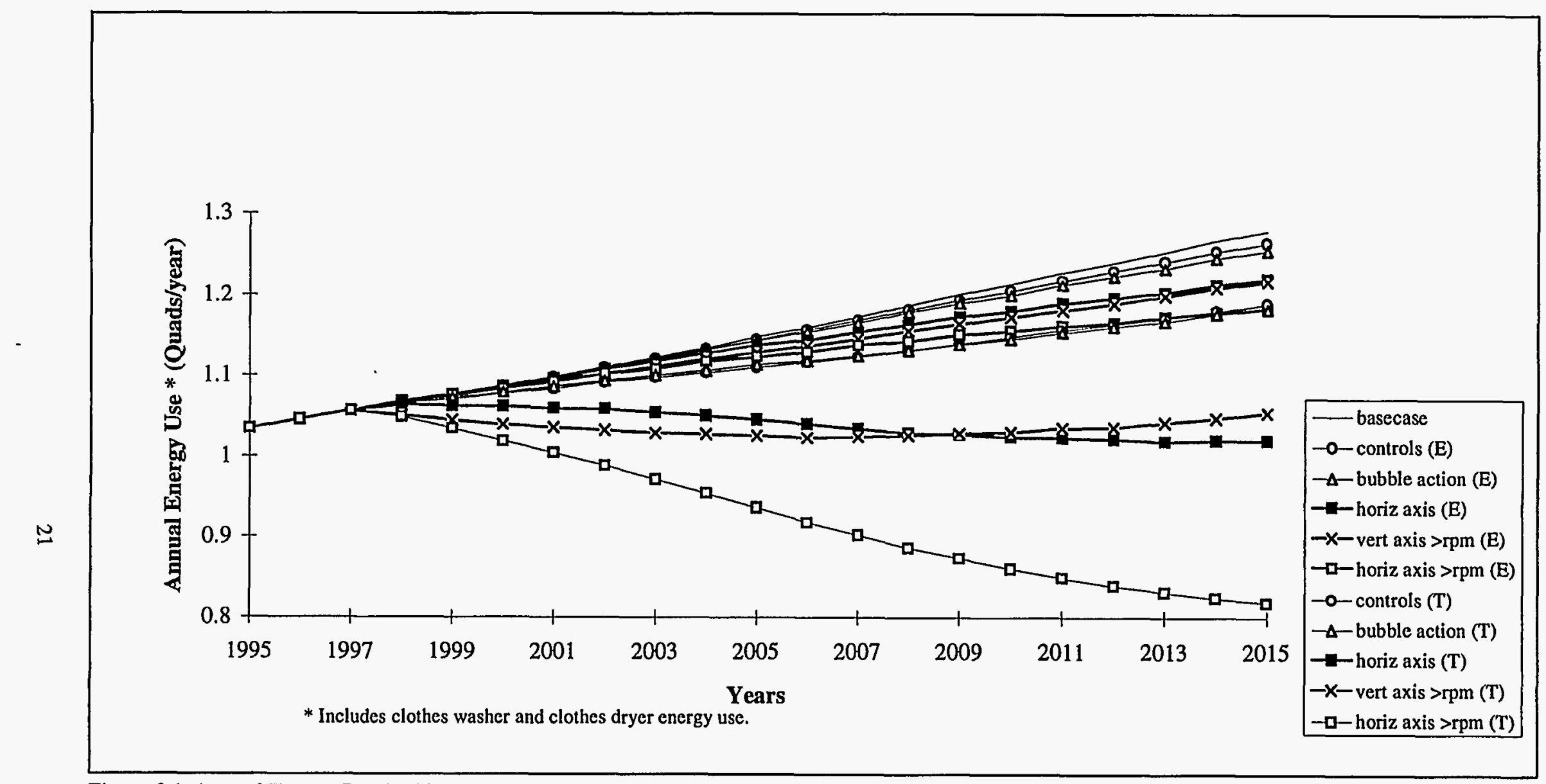

Figure 3.1 Annual Energy Use for Technology Options: Clothes Washers 
Table 3.2 Annual Energy Savings for Clothes Washer Technology Options

\begin{tabular}{|c|c|c|c|c|c|c|}
\hline \multirow[b]{2}{*}{ Option } & \multirow[b]{2}{*}{ Case } & \multicolumn{4}{|c|}{ Annual energy savings (Quads) } & \multirow{2}{*}{$\begin{array}{c}\begin{array}{c}\text { Cumulative } \\
\text { savings } \\
\text { (quads) }\end{array} \\
1998-2015 \\
\end{array}$} \\
\hline & & 2000 & 2005 & 2010 & 2015 & \\
\hline Baseline* & & 1.087 & 1.147 & 1.214 & 1.279 & 24.176 \\
\hline \multirow[t]{2}{*}{ Controls } & TP & 0.010 & 0.037 & 0.067 & 0.090 & 0.826 \\
\hline & $\mathrm{EP}$ & 0.001 & 0.003 & 0.009 & 0.015 & 0.095 \\
\hline \multirow[t]{2}{*}{ Bubble action } & $\mathrm{TP}$ & 0.008 & 0.034 & 0.069 & 0.097 & 0.829 \\
\hline & EP & 0.001 & 0.004 & 0.014 & 0.024 & 0.153 \\
\hline \multirow[t]{2}{*}{ Horiz axis } & TP & 0.026 & 0.102 & 0.190 & 0.259 & 2.329 \\
\hline & EP & 0.001 & 0.010 & 0.034 & 0.059 & 0.389 \\
\hline \multirow[t]{2}{*}{$\mathrm{VA},>\mathrm{rpm}$} & TP & 0.048 & 0.122 & 0.184 & 0.225 & 2.412 \\
\hline & EP & 0.003 & 0.019 & 0.042 & 0.062 & 0.493 \\
\hline \multirow[t]{2}{*}{$\mathrm{HA},>\operatorname{rpm}$} & TP & 0.069 & 0.211 & 0.354 & 0.461 & 4.485 \\
\hline & EP & 0.004 & 0.024 & 0.059 & 0.095 & 0.695 \\
\hline
\end{tabular}

* Baseline energy use is total annual energy used for washers and dryers, not energy saved.

\section{Clothes Dryers}

Clothes dryers use $3.03 \%$ of all U.S. residential energy use (see Table 1.2). The saturations of electric and gas dryers are approximately $54 \%$ and $14 \%$, respectively. The clothes dryer technology options discussed in detail are microwave and heat pump dryers. Appendix 3 lists all design options considered.

\subsection{MICROWAVE DRYERS}

Present Status. In conventional drying, hot air passes over moist clothes vaporizing the surface water. During the later stages of drying, the surface dries out and heat from the hot air must be transferred to the interior, where the remaining moisture resides. In microwave drying, water molecules in the interior of a fabric absorb electromagnetic energy at microwave wavelengths, thereby heating the water and allowing it to vaporize. In addition to being a more efficient method, microwave drying should extend the life of clothes because the fabric temperature will be lower and the action of the tumbler will be eliminated or reduced (if a combination of microwave and conventional drying is used).

Several appliance manufacturers in the U.S. have experimented with microwave technology for drying clothes, and some small companies have demonstrated the technology in prototypical machines. EPRI has been working with Thermo Energy and JG Microwave, of California, to provide industry with generic data that could be used in the development of new products (EPRI1, 1993). One of the 
objectives of the EPRI work is to quantify the hazards (e.g, arcing and heating of metals, possibly leading to dryer fires) and to develop designs that would eliminate or minimize those hazards. Maytag Company and Whirlpool Corporation are members of the Industrial Advisory Committee. Beginning in the spring of 1995 , twelve test units will be placed into homes around the U.S.

Energy Use and Cost. For an electric dryer with clothes entering at a moisture level of $70 \%$, baseline energy use is $834 \mathrm{kWh} / \mathrm{yr}$. Energy savings estimates for a microwave dryer range from $20 \%$ to $26 \%$ (EPRI2 and Pesci, 1989). Incremental cost estimates range from $\$ 30$ (RMI, 1990) to $\$ 225$ (CCIG, 1992) at the retail level. For this analysis, we use $\$ 160$ (DOE, 1990 and EPRI2, 1993), which appears to be a reasonable estimate for the addition of two magnetrons plus electronic controls to a conventional dryer.

Barriers to Implementation. The barriers to large-scale commercialization of microwave dryers include (1) safety concerns, (2) lack of consumer knowledge about the technology, (3) manufacturers' concerns about the lack of a market, and (4) manufacturers' reluctance, considering the other barriers, to introduce this new technology. Extensive field testing would help reduce some of these barriers. Additional research and development would be required to reduce potential safety hazards; this includes working with sensors to shut down magnetrons if a fire were to start and evaluating magnetrons with different frequency outputs (to reduce metal absorption).

\subsection{HeAT PUMP DRYers}

Present Status. A heat pump dryer is essentially a dryer and an air conditioner packaged as one appliance. In a heat pump dryer, exhaust heat energy is recovered by recirculating all the exhaust air back to the dryer while moisture is removed by a refrigeration-dehumidification system. The exhaust air passes the evaporation coil of the dehumidifier, where it cools to below the dew point, and sensible and latent heat are extracted. The heat is transferred to the condenser coil by the refrigerant and reabsorbed by the air, which is moving in a closed cycle. A drain is required to remove the condensate; however, one is usually available since washers and dryers are usually located side by side.

One U.S. company has developed a heat pump dryer and has successfully tested several prototypes and found energy savings of $68 \%$ compared to a conventional electric dryer (Nyle, 1987). The refrigeration system coefficient of performance (COP) is approximately 2.6. Drying times were essentially the same as for the conventional dryer. No vent is required because the air moves in a closed cycle. The depth of the prototype is the same as that of a conventional dryer with a vent; therefore, the heat pump dryer should fit the same space as a conventional dryer. The dryer operates on a conventional $120 \mathrm{~V}$ circuit. The prototype uses a disposable filter to reduce lint in the air system. Installation costs may be similar to those for a conventional dryer because a drain connector is needed (although an exhaust vent is not). Maintenance costs may be higher because the electric heater will be replaced by the equipment found in a small room air conditioner. 
Next year EPRI is planning to test some of the prototype heat pump dryers described here. At the 1992 Domotechnica, the International Appliance Exposition, two European manufacturers exhibited heat pump dryers. AEG and Miele both estimated 50\% energy savings relative to a conventional European dryer. Costs are not yet available. The Miele prototype is essentially the same size as conventional electric dryers. Neither company is presently selling these units.

Table 3.3 Energy Use and Cost Summary for Clothes Dryers

\begin{tabular}{cccccc} 
Option & $\begin{array}{c}\text { Baseline } \\
(\mathbf{k W h} / \mathbf{y r})\end{array}$ & $\begin{array}{c}\Delta \mathbf{U E C} \\
(\mathbf{k W h} / \mathbf{y r})\end{array}$ & $\Delta$ UEC & sPrice & $\begin{array}{c}\text { Payback } \\
\text { Period (yrs) }\end{array}$ \\
\hline Microwave & 834 & 192 & $23 \%$ & $\$ 160$ & 9.6 \\
Heat Pump & 834 & 542 & $65 \%$ & $\$ 300$ & 6.4 \\
\hline
\end{tabular}

Energy Use and Cost. Baseline electric dryer energy use is $834 \mathrm{kWh} / \mathrm{yr}$. A heat pump dryer will use $292 \mathrm{kWh} / \mathrm{yr}$ for an energy savings of $542 \mathrm{kWh} / \mathrm{yr}$ (a $65 \%$ decrease). For an estimated price increase of $\$ 300$ the simple payback period is 6.4 years (DOE, 1990). Changes in installation costs or maintenance costs have not been included in this payback calculation. Connection of a water drain to the condensate pan should have a minimal cost, which could be offset by the elimination of time and materials needed to connect an exhaust vent to the dryer. Data on maintenance costs are not available for conventional or heat pump dryers.

Barriers to Implementation. The barriers to implementation of this technology are similar to those for the other options considered in this chapter: (1) high first cost, (2) newness of the technology to consumers, and (3) large investment needed by manufacturers to convert plants to new technology. For this technology and for microwave dryers, some additional development work and field testing would also be needed before mass production could begin.

\subsection{Discussion OF NATIONAL ENERgY SAVINGS}

Figure 3.2 shows annual energy use for electric dryers over the time period 1995-2015. A basecase and two technology options are shown for the technical and economic potential cases (see Chapter 1 for details). For the basecase, retiring appliances are replaced with models that have an efficiency equal to that required by the existing DOE standard. For each technology option, they are replaced with models that have an efficiency equal to that of the specific technology. The market penetration for the economic potential cases are obtained from the market penetration curve (Figure 1.1) shown in Chapter 1. Penetration rates are a function of simple payback periods. The technical potential (100\% penetration) is shown to be significantly greater than the economic potential for each 


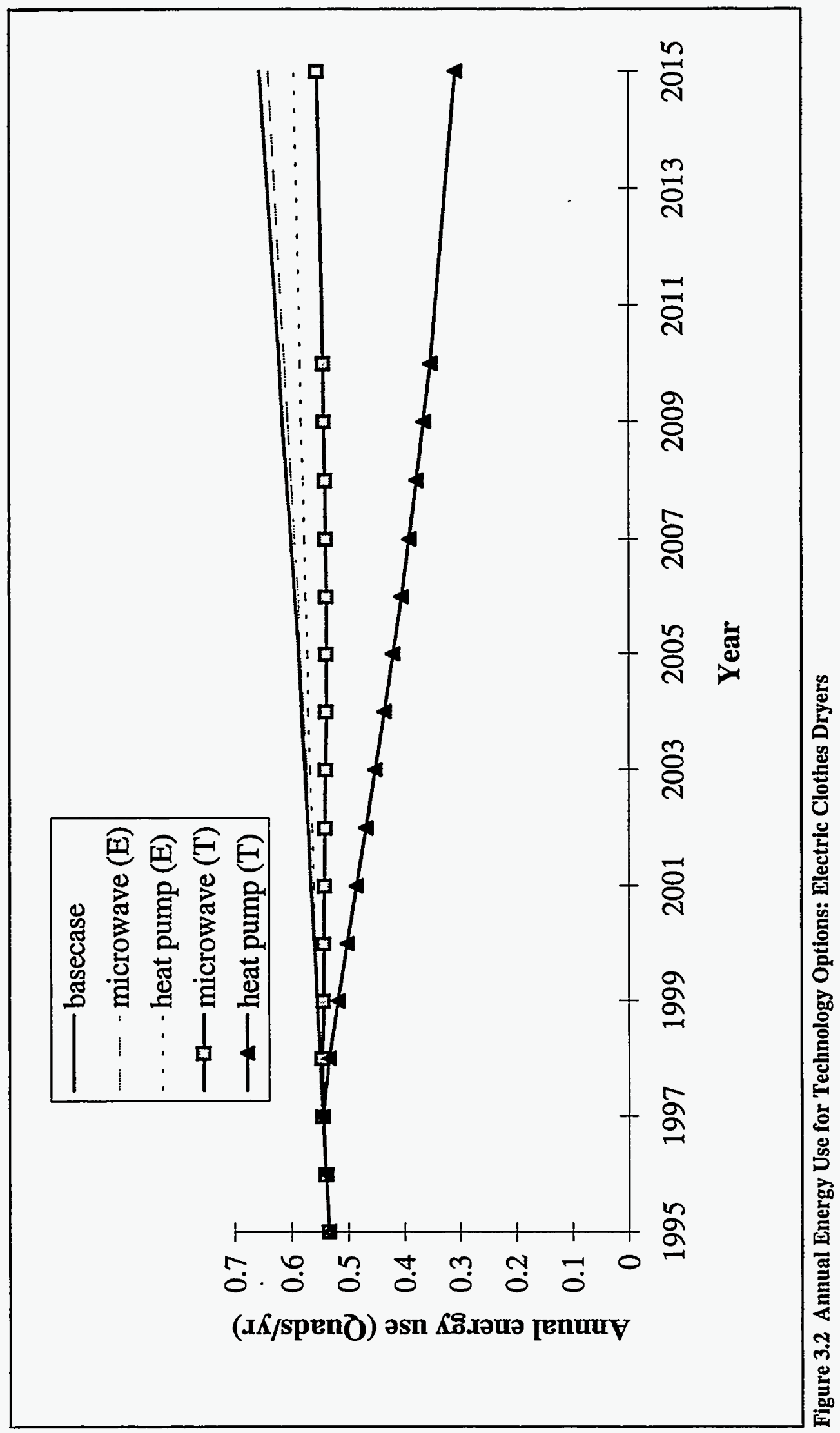


technology evaluated. The economic potential is determined assuming no policy actions (additional efficiency standards, rebates, and so forth) are introduced to transform the marketplace.

Table 3.4 shows the annual energy savings for specific years and the cumulative (1998-2015) energy savings, relative to the basecase. The larger energy savings is for heat pump dryers; the technical potential is 3.5 quads (32\%) over the period 1998-2015, compared to 10.8 quads of basecase electric dryer energy use. Microwave dryer technical potential over the same period is 1 quad of primary energy. The economic potentials for both technologies are much lower than the technical potentials. The penetration rates used for calculating the economic potentials are based on paybacks calculated with estimated 1998 prices for each technology.

\section{Table 3.4 Annual Energy Savings for Electric Clothes Dryer Technology Options}

\begin{tabular}{|c|c|c|c|c|c|c|}
\hline \multirow[b]{2}{*}{ Option } & \multirow[b]{2}{*}{ Case } & \multicolumn{4}{|c|}{ Energy savings (Quads) } & \multirow{2}{*}{$\begin{array}{c}\begin{array}{c}\text { Cumulative } \\
\text { En sav (quads }\end{array} \\
1998-2015 \\
\end{array}$} \\
\hline & & 2000 & 2005 & 2010 & 2015 & \\
\hline Basecase* & & 0.560 & 0.587 & 0.621 & 0.656 & 10.80 \\
\hline \multirow[t]{2}{*}{ Microwave } & TP & 0.017 & 0.048 & 0.077 & 0.101 & 1.000 \\
\hline & $\mathrm{EP}$ & 0.001 & 0.003 & 0.009 & 0.016 & 0.117 \\
\hline \multirow[t]{2}{*}{ Heat Pump } & $\mathrm{TP}$ & 0.058 & 0.167 & 0.268 & 0.348 & 3.465 \\
\hline & $\mathrm{EP}$ & 0.002 & 0.015 & 0.037 & 0.061 & 0.449 \\
\hline
\end{tabular}

\footnotetext{
* Basecase is annual energy use in quads, not energy savings.
}

$\mathrm{EP}=$ Economic potential; $\mathrm{TP}=$ Technical potential. 


\section{Dishwashers}

Dishwashers use $1.4 \%$ of total residential energy with a saturation of $47 \%$ in 1990 . Like clothes washers, they obtain hot water from electric or oil- or gas-fired water heaters. Most of their energy consumption is for water heating rather than for electric motor use or dish drying. Appendix 3 lists all the design options considered for dishwashers. Instead of analyzing particular design options that would save small amounts of energy, a generic low water-use option is considered.

\subsection{LOW WATER USE DISHWASHERS}

Present Status. As of May 1994 newly manufactured dishwashers sold in the U.S need to meet a DOE standard for maximum energy use of about $500 \mathrm{kWh} / \mathrm{yr}$ when connected to an electric water heater. That standard is based on 229 cycles per year usage. Such dishwashers will use about 9 to 9.5 gallons of hot water. The European dishwashers that use the least amount of water use about 5 gallons. The number of place settings capacity is similar for U.S. and European models. There is no one feature that accounts for the lower water use in European models, but much attention is paid to the design of spray arms, the efficiency of the food filters, and the avoidance of redeposition of food particles. Asko Cylinda uses a pressure plate to attain an even water flow over the face of its food filter to improve the efficiency of food removal. Many European dishwashers use two pumps (one controls spray arms and the other pumps water out) while U.S. models use only one. This difference may allow for lower water use because of the need for less water in the sump region.

Energy Use and Cost. Reducing hot water use from 9.5 gallons to at least 7 gallons per load should be possible. One U.S. manufacturer already markets a dishwasher (manufactured in Europe) that uses 7 gallons per load (Consumer Reports, 1993). Consumer Reports found that the one European model (Asko) they tested used 5.5 gallons of hot water per load; however, they reported that it did not clean as well as the model using 7 gallons per load. When water use was increased for the Asko model to 7 gallons per load, it cleaned as well as the U.S. model. Of the $500 \mathrm{kWh} / \mathrm{yr}$ baseline energy use, $387 \mathrm{kWh}$ is for heating water with an electric water heater; the rest is for motor and dryer energy use. Therefore, if motor and dryer energy use remain constant, a 7 gallon per load dishwasher connected to an electric water heater should have a total energy use of $398 \mathrm{kWh} / \mathrm{yr}$, for a $20 \%$ energy savings. For a gas-fired water heater, baseline energy use is 17.6 therms and electric energy use is $113 \mathrm{kWh} / \mathrm{yr}$. A 7 gallon per load dishwasher connected to a gas-fired water heater will use 13 therms $/ \mathrm{yr}$ (a 20\% reduction) and $113 \mathrm{kWh} / \mathrm{yr}$.

The price of European dishwashers are typically $\$ 700-\$ 800$. The U.S model that uses 7 gallons per load is $\$ 530$ (Consumer Reports, 1993). The incremental price estimate for the low water use

dishwasher is $\$ 20$ (CCIG, 1993). Payback periods for households with electric and gas-fired water heaters are 2.3 and 6.3 years, respectively. 
Table 3.5 Energy Use and Cost Summary for Dishwashers

\begin{tabular}{lccccc} 
Option & $\begin{array}{c}\text { Baseline } \\
(\mathbf{k W h} / \mathbf{y r})\end{array}$ & $\begin{array}{c}\Delta \text { UEC } \\
\mathbf{k W h} / \mathbf{y r}\end{array}$ & $\Delta$ UEC & $\Delta$ Price & $\begin{array}{c}\text { Payback Period } \\
\text { ( yrs) }\end{array}$ \\
\hline $\begin{array}{l}\text { Low Water } \\
\text { Electric WH }\end{array}$ & 500 & 102 & $20 \%$ & $\$ 20$ & 2.3 \\
Low Water & $\begin{array}{c}17.6 \text { therm } \\
\text { Gas WH }\end{array}$ & $\begin{array}{c}4.6 \text { therm } \\
113 \mathrm{kWh}\end{array}$ & $\begin{array}{c}20 \% \\
0 \%\end{array}$ & $\begin{array}{c}\$ 20 \\
0 \%\end{array}$ & 6.3 \\
\hline
\end{tabular}

Barriers to Implementation. One of the barriers to production of low energy use dishwashers in the U.S. is the perception of an absence of an established market for such dishwashers. It would also be important to field test a large number of low-water, low-energy dishwashers to provide consumers and manufacturers with evidence that they perform as well as conventional dishwashers.

\subsection{Discussion of National ENERgy SAVINGS}

Figure 3.3 shows annual energy use for dishwashers over the time period 1995-2015. Annual energy use is the sum of direct dishwasher electricity use and the portion of water heater energy use allocated to dishwashers. A basecase and one technology option are shown for the technical and economic potential cases (see Chapter 1 for description of methodology). For the basecase, retiring appliances are replaced with models that have an efficiency equal to that required by the existing DOE standard. For each technology option, they are replaced with models that have an efficiency equal to that of the specific technology. The market penetration for the economic potential cases are obtained from the market penetration curve (Figure 1.1) shown in Chapter 1. Penetration rates are a function of simple payback periods. The penetration rates used for calculating the economic potentials are based on paybacks calculated with estimated 1998 prices for each technology. It can be seen that the technology potential (100\% penetration) is significantly greater than the economic potential for the one technology evaluated. The economic potential is determined assuming no policy actions (additional efficiency standards, rebates, and so forth) are introduced to transform the marketplace.

Table 3.6 shows the annual energy savings for specific years and the cumulative (1998-2015) energy savings relative to the basecase. The technical potential is 0.24 quads $(5.8 \%)$ over the period 19982015 , compared to 4.1 quads of basecase dishwasher energy use. In the year 2015, the annual savings for the technical potential is greater than $10 \%$, relative to the basecase energy use. The economic potential is only 0.03 quads over the $1998-2015$ time period. 


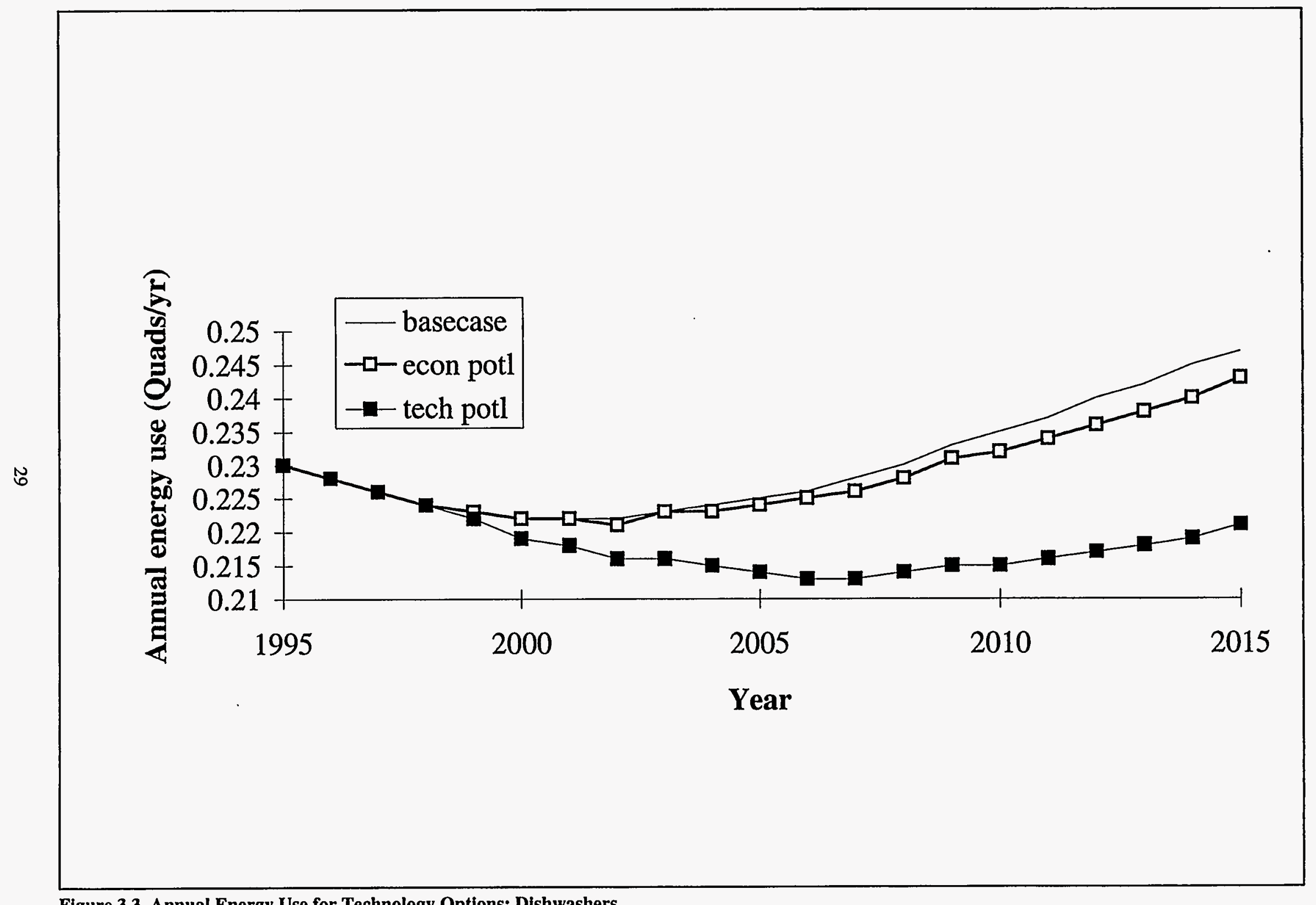

Figure 3.3 Annual Energy Use for Technology Options: Dishwashers 
Table 3.6 Annual Energy Savings for Dishwasher Technology Options

\begin{tabular}{lllllll} 
& & \multicolumn{3}{c}{ Energy savings (Quads) } & & $\begin{array}{c}\text { Cumulative } \\
\text { En sav (quads) }\end{array}$ \\
\cline { 3 - 7 } Option & Case & 2000 & 2005 & 2010 & 2015 & $1998-2015$ \\
\hline Basecase* & & 0.222 & 0.225 & 0.235 & 0.247 & 4.148 \\
& & & & & & \\
Low water & TP & 0.003 & 0.011 & 0.020 & 0.026 & 0.241 \\
Energy use & EP & 0.000 & 0.001 & 0.003 & 0.004 & 0.032 \\
\hline
\end{tabular}

* Basecase is annual energy use in Quads, not energy savings. $\mathrm{EP}=$ Economic potential; $\mathrm{TP}=$ Technical potential . 


\section{Water Heating and Hot Water Conservation}

We discuss the technologies that may be used to produce water heaters with efficiencies greater than required by the 1990 DOE standards. Only those technologies that reduce water heating unit energy consumption by a significant amount $(>15 \%)$ will be discussed in detail. For each product, the following are discussed: (1) the status of each technology, (2) potential energy savings and incremental cost of the technology, and (3) barriers to implementation of the technology. A list of other technologies initially considered appears in Appendix 4.

The potential energy savings are from baseline water heaters that only meet the 1990 NAECA minimum efficiency standards. The energy calculations discussed are based on 64.3 gallons of hot water use per day as specified in the DOE test procedure. The national energy savings reported in Tables 4.2 and 4.4 do include the recovery energy used to heat 12.5 gallons per day of water for use by clothes washers or dishwashers (DOE, 1990). Caution should be used when totaling end-use energy consumption since much of the energy use attributed to clothes washers and dishwashers only provides the required hot water. Clothes washers and dishwashers are discussed in Chapter 3. A list of other technologies initially considered appears in Appendix 4.

\section{Gas-Fired Water Heaters}

Gas-fired water heaters make up nearly $55 \%$ of total domestic water-heating devices, using $8.1 \%$ of total household primary energy. The baseline for gas-fired water heaters is a center-flue, bottom-fired 40-gallon storage water heater with an input rate of $34.4 \mathrm{KBtu} / \mathrm{hr}$. It just meets the minimum NAECA efficiency with an energy factor of approximately 0.55 . The resulting annual gas consumption is 273 therms or about $\$ 188$, based on a gas cost of $\$ 0.69$ per therm. The average energy factor of the existing stock for gas water heaters in 1990 was assumed to be approximately 0.50. The total annual energy consumption for gas-fired residential water heaters in 1990 was estimated to be about 1.86 quads.

For gas-fired water heaters, the technology options considered are (1) a pilotless instantaneous water heater, (2) a condensing storage water heater, and (3) a triple-effect absorption heat pump water heater.

\subsection{Pilotless Instantaneous Water Heater}

Present Status. The vast majority of gas-fired water heaters sold in the U.S. have a storage tank with a central flue. Instantaneous gas-fired water heaters (IWH) do not have the large standby losses associated with maintaining the hot water temperature in a storage tank. Water is only heated when needed. Some thermal loss occurs as the heated water in the heat exchanger cools to ambient temperature, but we could not find any data on these losses. All instantaneous water heaters currently available in the U.S. have standing pilots. The energy consumed by the standing pilots 
is lost. In traditional water heaters with a storage tank, part of the pilot light energy helps maintain tank temperature. There would be no technical difficulty in adding an intermittent ignition system to a gas-fired instantaneous water heater. If the ignition system were powered by 24 volts, a lowwattage wall-hung transformer could be used (CCIG, 1992), which would allow connecting to be as simple as plugging in a small appliance. Currently, instantaneous water heaters are not manufactured within the U.S. One manufacturer does some assembly in the U.S.

IWHs need more maintenance than gas-fired storage water heaters, however this was not included in this analysis. Control mechanisms vary among models, but all require a minimum flow rate be exceeded before the burner starts firing. The burner of some models has only one firing rate, which can sometimes cause unexpected variations in temperature as flow rate is adjusted. Better models have modulated gas flow, so hot water temperatures stay constant over a wider range of water flow rates.

Energy Use and Cost. The energy calculations for an IWH were based on a rated input of 125 $\mathrm{kBtu} / \mathrm{hr}$, an assumed recovery efficiency or steady-state efficiency of $80 \%$, and an assumed standby loss of 5 watts in the low-voltage transformer for the electronic ignition system. The rated input and recovery efficiency are typical values for gas-fired instantaneous water heaters. These are sufficient to raise the temperature of water flowing at 3 gallons per minute by $67.5^{\circ} \mathrm{F}$. To deliver 64.3 gallons of hot water per day at that flow rate, the heater will need to fire for fewer than 25 minutes per day.

The annual unit energy consumption for this water heater is calculated as 186 therms plus $43 \mathrm{kWhs}$. This results in a $30 \%$ per unit savings of source energy, compared to baseline gas-fired water heaters.

The projected annual energy cost for pilotless instantaneous water heaters is $\$ 132$. Current retail price is from $\$ 800-\$ 1000$. A quoted installation cost was $\$ 400$, about $\$ 200$ higher than normal water heater installation costs because plumbers are not familiar with mounting requirements for IWHs. The assumed incremental retail cost for adding a low-voltage ignition system was $\$ 50$. The payback period for this option is 19 years. Volume production in the U.S. might be able to reduce the installed cost and therefore the payback.

Barriers to Implementation. Gas-fired instantaneous water heaters are so uncommon (approximately $0.5 \%$ of water heater shipments are instantaneous) no significant sales or service infrastructure exists. Consumers, retailers, and plumbers are not familiar with these products. IWHs need more maintenance than storage water heaters. Although the maintenance is not difficult or expensive, consumers may be reluctant to accept this for a water heater. Because of the lack of infrastructure, finding people who can install and maintain the heater may be difficult. None of the IWH models being sold in U.S. use electronic ignition. Adding one should not require major redesign work on the part of manufacturers.

First cost issues are very important in the residential water heater market. Most residential water heater replacements are the result of failures. People usually do not have the time to arrange financing in this situation and will usually request the cheapest available model. Currently the first 
cost to consumers for IWH is estimated to be more than $\$ 700$ higher than a baseline gas-fired storage water heater.

\subsection{CONDENSINg Storage WATER Heater}

Present Status. Only one company produces residential gas-fired condensing water heaters (American Water Heater Group, Polaris model). This model has a stainless steel helical condensing heat exchanger inside the storage tank with a submerged combustion chamber. The burner is also stainless steel; a fan pushes the combustion products through the heat exchanger. Because this is a condensing water heater, the flue gases are sufficiently cool to allow venting through PVC pipe. Using these low-cost materials reduces the costs of the venting system. The burner is ignited with a hot surface ignition system. The efficiency of this heater is further increased by 2 inches of foam insulation. Most of the plumbing connections are made at the lower end of the tank.

For residential use, these condensing water heaters are sold as combined water heater/space-heating systems, so they are not directly comparable to the baseline residential water heater. No sales data are publicly available for these models, but shipments are assumed to be very low.

Energy Use and Cost. The energy calculations for the condensing water heater were based on a rated input of $100 \mathrm{kBtu} / \mathrm{hr}$, a recovery efficiency of $94 \%$, and an energy factor of 0.86 . Power demand, when the burner was operating, was assumed to be $120 \mathrm{~W}$. The standby power demand was assumed to equal 10W to account for controls and transformer losses.

The annual unit energy consumption for this water heater is calculated as 169 therms and $106 \mathrm{kWhs}$. This results in a $34 \%$ per unit energy savings from the baseline model. This results in a payback period of 27 years. Note that this payback period is much longer than the typical lifetime of a water heater. Designing residential.condensing water heaters to permit volume production and reducing rated input could reduce this installed cost significantly. No costs were available for such a unit, however if the incremental installed cost were reduced to $\$ 750$, considered a reasonable possibility, the payback period would be reduced to about 12 years (Dieckmann, 1994).

Barriers to Implementation. The installed first cost for the condensing water heater is about $\$ 1600$ higher than a baseline gas-fired storage water heater. An incremental first cost of this magnitude will be hard for consumers to accept. This unit uses expensive components and materials that are difficult to work with. Use of less expensive components or redesign for ease of manufacturing would reduce the manufacturer's cost. Because sales are low, plumbers are not familiar with this unit and it is not available from retailers and suppliers. There may also be concerns about reliability and maintenance for this unit because it differs so much from standard water heaters. 


\subsection{TrIPLE-EFfect AbSorPtion HeAT PUMP WATER HeAter}

Present Status. Oak Ridge National Laboratory (ORNL) has been researching triple-effect gas-fired absorption heat pumps (GAX HP) for residential heating and cooling. ORNL has built several prototypes and the technology has been licensed to a manufacturing company. This technology should be adaptable to residential water heating, but would require designing the system to provide heating only, downscaling the system to match domestic water-heating loads, and incorporating safety features to manage indoor ammonia and the proximity to potable water.

Energy Use and Cost. The $\$ 3600$ retail equipment cost taken from an ORNL estimate for a tripleeffect gas-fired absorption heat pump was multiplied by $80 \%$ to account for both scaling down and limiting capability to heating only. The installation costs are assumed to be the same as for a condensing water heater. This figures totaled an installed cost of $\$ 3129$. At this cost the payback would be 28 years. Further cost reductions are probably achievable, but ORNL has not performed a detailed cost estimate for this type of appliance. An indication of the possible scale of savings is the 1 to 9 ratio of installed costs of a typical 1/2-ton room air conditioner to a typical 3-ton residential heat pump. This analogy gives a lower reasonable limit for incremental cost of a GAX HP of about $\$ 400$. At this hypothetical price the payback is reduced to about 4 years.

Barriers to Implementation. This technology has not yet been developed for domestic water heating. Current research and development efforts have been directed at residential space heating and cooling. Significant design work and testing are needed before a domestic water heater based on this technology would be ready for commercialization. Intensive effort would have to be invested to keep costs down to assure this product would be acceptable in the domestic waterheating market.

\subsection{DISCUSSION OF NATIONAL ENERGY SAVINGS FOR GAS-FIRED WATER HEATERS}

The unit energy consumption (UEC) savings and cost summaries for gas-fired water heaters are presented in Table 4.1. Table 4.2 presents the annual energy savings. Figures 4.1 depicts the estimated national total annual energy use for residential gas-fired water heating over the time period 1995-2015. A basecase and various technology options are shown for technical and economic potential cases. In the basecase, retiring water heaters are replaced with models that have an energy factor equal to the minimum required by the existing DOE standards. For each technology option, heaters are replaced with models that have an energy factor equal to that of the specific technology. Technical potential refers to the estimated total annual energy consumption if all units are replaced with the new technology at the end of their standard lifetime. Economic potential is explained in the Introduction. The economic potential is determined assuming no policy actions (additional efficiency standards, rebates, and so forth) are introduced to transform the marketplace. 
Table 4.1 Energy Use and Cost Summary for Gas-Fired Water Heaters

\begin{tabular}{lccccc}
\multicolumn{1}{c}{ Option } & Baseline & $\Delta$ UEC & $\Delta$ UEC $^{*}$ & $\Delta$ Price & Payback Period (yrs) \\
\hline $\begin{array}{l}\text { Instantaneous w/o } \\
\text { pilot }\end{array}$ & 273 therm & $\begin{array}{l}86 \text { therm } \\
-43 \mathrm{kWh}\end{array}$ & $30 \%$ & $\$ 1051$ & 18.8 \\
Condensing & 273 therm & $\begin{array}{l}169 \text { therm } \\
-106 \mathrm{kWh}\end{array}$ & $34 \%$ & $\$ 1672$ & $12-26.8$ \\
& 273 therm & $\begin{array}{l}110 \mathrm{therm} \\
-107 \mathrm{kWh}\end{array}$ & $55 \%$ & $\$ 2820$ & $4-27.5$ \\
\hline
\end{tabular}

* $\triangle \mathrm{UEC}$ is calculated in source energy using a conversion of 11500 source Btus per $\mathrm{kWh}$

Table 4.2 Annual Energy Savings for Gas-Fired Water Heater Technology Options

\begin{tabular}{|c|c|c|c|c|c|c|}
\hline \multirow[b]{2}{*}{ Option } & \multirow[b]{2}{*}{ Case } & \multicolumn{4}{|c|}{ Annual energy savings (Quads) } & \multirow{2}{*}{$\begin{array}{l}\text { Cumulative } \\
\text { savings } \\
\text { (quads) } \\
1998-2015\end{array}$} \\
\hline & & 2000 & 2005 & 2010 & 2015 & \\
\hline Baseline * & & 1.66 & 1.71 & 1.78 & 1.85 & 25.74 \\
\hline \multirow[t]{2}{*}{ IWH } & TP & 0.09 & 0.23 & 0.33 & 0.40 & 4.39 \\
\hline & EP & $0.00^{+}$ & 0.02 & 0.05 & 0.07 & 0.56 \\
\hline \multirow[t]{2}{*}{ Cond } & TP & 0.10 & 0.25 & 0.37 & 0.44 & 4.83 \\
\hline & $\mathrm{EP}$ & $0.00^{+}$ & 0.03 & 0.06 & 0.08 & 0.68 \\
\hline \multirow[t]{2}{*}{ GAX HP } & TP & 0.16 & 0.42 & 0.61 & 0.73 & 8.04 \\
\hline & EP & 0.01 & 0.06 & 0.13 & 0.19 & 1.57 \\
\hline
\end{tabular}

- Baseline energy use is total energy used for water heaters, not energy saved. Includes energy to heat hot water used by dishwashers and clothes washers.

+ Actual figure is 0.004 . 


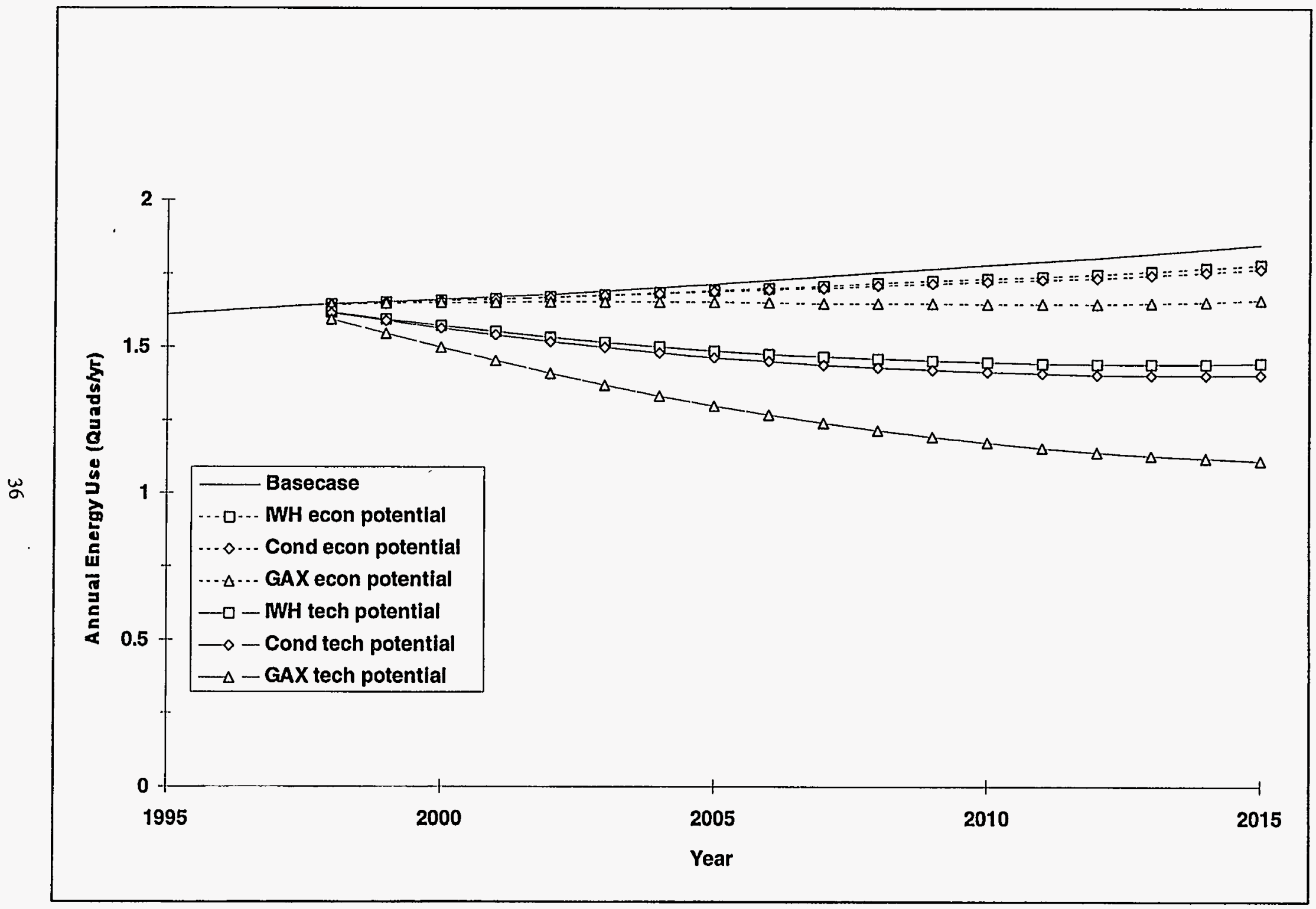

Figure 4.1 Annual Energy Use for Technology Options: Gas-Fired Water Heater 


\section{ELECTRIC WATER HEATERS}

Typical electric storage water heaters that meet the 1990 DOE energy efficiency standard will use about $5055 \mathrm{kWh}$ per year according to the DOE test procedure. The baseline electric water heater is a 52 gallon heater with resistance elements. It has a rated input of $4.5 \mathrm{~kW}$. The energy factor for this model is 0.86 . The annual electricity consumption is approximately $5055 \mathrm{kWh}$, with an annual cost of $\$ 413$ based on an electricity cost of $\$ 0.087$ per $\mathrm{kWh}$. The existing stock of residential electric water heaters in 1990 were assumed to have an average energy factor of about 0.80 . The total annual electricity consumption by electric water heaters was calculated to be about 1.6 quads that year.

For electric water heaters, only the EPRI/E-Tech heat pump and solar water heating technology options were considered in detail.

\subsection{EPRI/E-TECH HEAT PUMP}

Present Status. This heat pump water heater (HPWH) is the result of collaborative research and development between EPRI and Crispaire Corporation. (EPRI, 1993) The HPWH was introduced and publicly displayed at the sixth annual EPRI Water Heating Interest Group meeting in October of 1993. The unit is a remote heat pump; water is circulated out of the storage tank, through the heat pump and back into the storage tank. This heat pump is small enough to sit atop a standard electric water heater, but can be located anywhere near the water heater. The fan blowing air across the evaporator is strong enough to blow air through a duct more than 20 feet. This "ducting" of an air stream allows the pump to be installed where others could not be. With both high and low temperature cutouts, the heat pump water heater can operate at temperatures as low as $35^{\circ} \mathrm{F}$.

This smaller model is more efficient, less costly, and easier to install than the conventional residential HPWHs. Field and lab tests have been completed for several prototypes. Extensive field monitoring is planned by EPRI within the next few years. This model is currently available for sale and is being targeted to utility rebate conservation programs.

Energy Use and Cost. The EPRI/E-Tech heater has been tested at ETL Labs. The energy factor under the DOE test procedure was 2.4. The unit energy consumption is estimated to be $1811 \mathrm{kWh}$ per year At this efficiency, the annual energy savings are about $64 \%$.

Barriers to Implementation. The main barrier to implementation is the lack of awareness about this product. The heat pump water heater is a new product manufactured by a small company that is not well integrated into the normal distribution systems for water heaters. Consumers will need to be convinced that the produce is reliable and long-lived. The first cost of this product, although lower than other HPWHs, is still much higher than standard electric water heaters. 


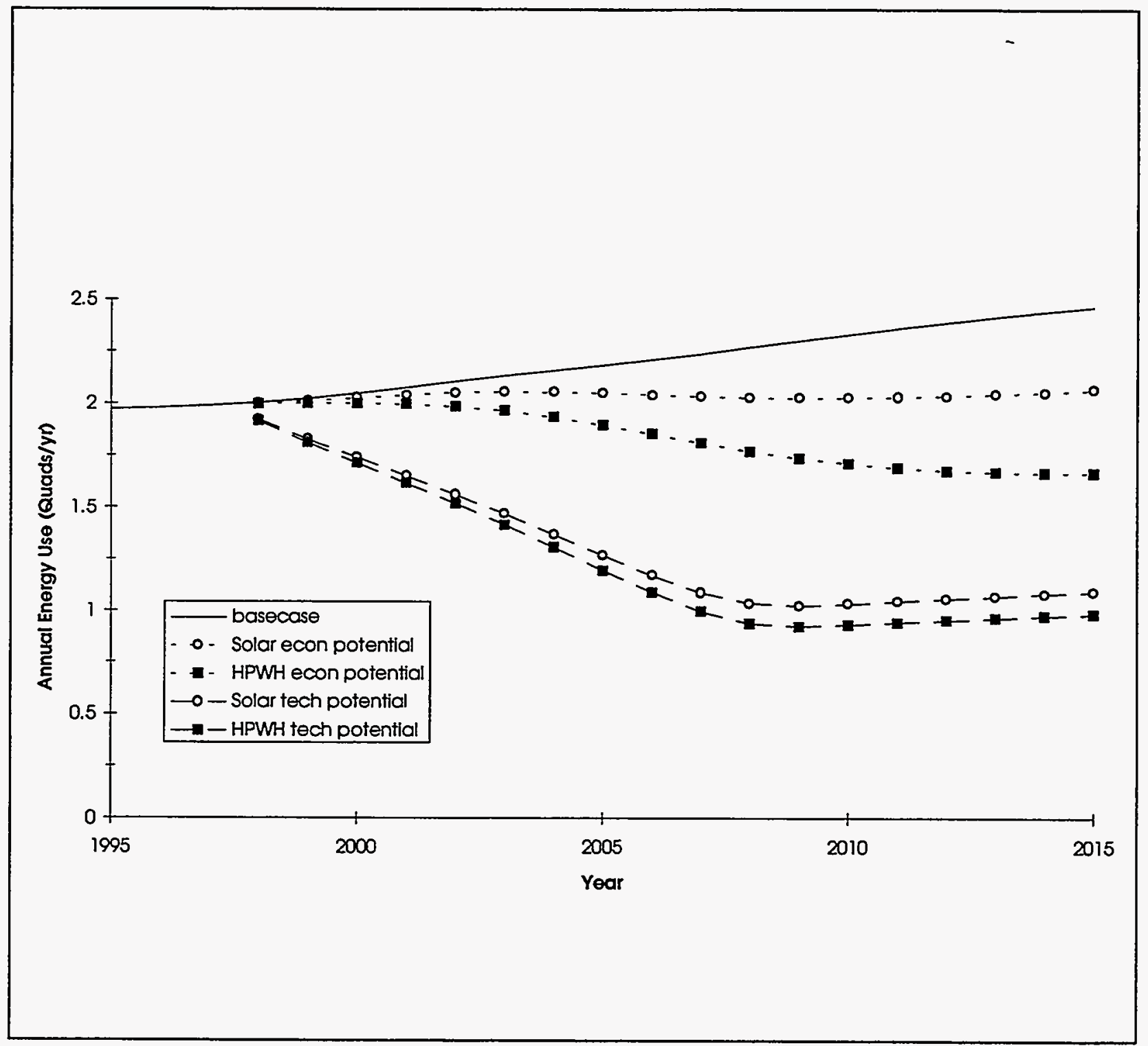

Figure 4.2 Annual Energy Use for Technology Options: Electric Water Heater 
Table 4.3 Energy Use and Cost Summary for Electric Water Heaters

\begin{tabular}{cccccc} 
Option & Baseline & $\Delta$ UEC & $\Delta$ UEC & $\Delta$ Price & Payback Period (yrs) \\
\hline HPWH & $5055 \mathrm{kWh}$ & $3243 \mathrm{kWh}$ & $65 \%$ & $\$ 720$ & 2.6 \\
\hline
\end{tabular}

Table 4.4 Annual Energy Savings for Electric Water Heater Technology Option

\begin{tabular}{|c|c|c|c|c|c|c|}
\hline \multirow[b]{2}{*}{ Option } & \multirow[b]{2}{*}{ Case } & \multicolumn{4}{|c|}{ Annual energy savings (Quads) } & \multirow{2}{*}{$\begin{array}{l}\text { Cumulative } \\
\text { savings } \\
\text { (quads) } \\
1998-2015\end{array}$} \\
\hline & & 2000 & 2005 & 2010 & 2015 & \\
\hline Baseline * & & 2.045 & 2.182 & 2.332 & 2.465 & 38.480 \\
\hline HPWH & TP & 0.334 & 0.987 & 1.401 & 1.483 & 17.962 \\
\hline & $\mathrm{EP}$ & 0.047 & 0.287 & 0.623 & 0.801 & 7.145 \\
\hline Solar & $\begin{array}{l}\text { TP } \\
\text { EP }\end{array}$ & $\begin{array}{c}0.309 \\
0.20\end{array}$ & $\begin{array}{l}0.915 \\
0.134\end{array}$ & $\begin{array}{l}1.299 \\
0.306\end{array}$ & $\begin{array}{l}1.375 \\
0.403\end{array}$ & $\begin{array}{c}16.649 \\
3.489\end{array}$ \\
\hline
\end{tabular}

* Baseline energy use is total energy used for water heaters, not energy saved. Includes energy to heat hot water used by dishwashers and clothes washers.

\subsection{SOLAR WATER HEATING}

Present Status. Technological improvements in the last decade have improved the quality and performance of solar water heaters. There are several types of solar water heaters commercially available today. A typical system will use a closed loop with an antifreeze solution actively pumped through the collector as the heat transfer fluid. Other common solar water heating systems are drainback, thermosiphon, and batch. A relatively recent development is a geyser or phasechange system. It operates like a coffee percolator. The heat transfer fluid boils into a vapor in the collector. As it rises, the vapor pushes some liquid to the heat exchanger, where it transfers heat to the water in the storage tank. Another somewhat unusual collector uses evacuated glass tubes around absorber tubes. The absorber tubes in this model can be heat pipes using a refrigerant as a 
Barriers to Implementation. Actual first costs could be prohibitive for many customers, but the perceived cost-effectiveness or lack of reliability of solar water heaters may be a greater barrier to wide-spread acceptance and implementation.

\subsection{Discussion OF NATIONAL ENERgy SAVINGS FOR Electric WATER HEATERS}

The UEC and cost summary for electric water heaters is shown in Table 4.3. Figure 4.2 shows annual energy use for electric water heating over the time period 1995-2010. Annual energy use is the sum of direct gas use and the source energy for generation electricity used by the water heater. A base case and one technology option are shown for the technical and economic potential cases (see Chapter 1 for description of methodology). For the base case, retiring appliances are replaced with models that have an efficiency equal to that required by the existing DOE standard. For each technology option, they are replaced with models that have an efficiency equal to that of the specific technology. Technical potential assumes $100 \%$ penetration of all replaced models. The market penetration for the economic potential cases are obtained from the market penetration curve (Figure 1.1) shown in Chapter 1. Penetration rates are a function of simple payback periods. The penetration rates used for calculating the economic potentials are based on paybacks calculated with present prices for each technology. It can be seen that the technology potential is significantly greater than the economic potential for each technology evaluated. The economic potential is determined assuming no policy actions (additional efficiency standards, rebates, and so forth) are introduced to transform the marketplace.

Table 4.4 shows the annual energy savings for specific years and the cumulative (1998-2015) energy savings, relative to the base case.

\subsection{OTHER TECHNOLOGIES}

Other technologies were also considered in the initial investigation, i.e., showerheads and faucet aerators, refrigerator/water heaters, solar water heating, and indirect gas-fired water heaters.

The 1994 NAECA minimum efficiency standards for dishwashers and clothes washers and the 1994 EPAct standards for showerheads and faucet aerators imply that hot water usage would drop to 48.1 gallons per day (Koomey, 1994). This drop would give an energy savings of about $15 \%$ to $20 \%$ for water heating as these standards are incorporated into the housing stock. Further improvements beyond the 1994 standards for showerheads and faucet aerators are also possible. Preliminary calculations indicate potential energy savings of about $15 \%$ beyond the 1994 standards and cost data are still being developed. Plumbing fittings were not included in this analysis. They will be addressed in other reports and workshops.

Another interesting technology that has significant potential is combined water heaters and refrigerators. This technology would use the waste heat from the refrigerator to heat water, instead of just dumping it into the kitchen as is normally done. One source estimates that replacing a gas- 
fired storage water heater and a 1993 standards refrigerator with a combined refrigerator/water heater would yield 57\% source energy savings (CCIG, 1992). A Dutch research group is developing an absorption refrigerator/water heater to replace an electric compressor-type refrigerator and supplement domestic water heating by a gas-fired boiler (Nov., 1993). The net savings are estimated at $50 \%$ of source energy.

Indirect gas-fired water heaters eliminate the losses associated with a central flue. The only example of this technology available in the residential market is the Marathon water heater manufactured by Water Heater Innovations. The payback was slightly higher than the payback for instantaneous water heaters, but the savings were only about $21 \%$, compared to the $34 \%$ savings for the instantaneous water heaters. 


\section{Space Heating and Cooling Appliances}

We discuss the technologies that may produce space-heating and cooling equipment with efficiencies greater than those required by the NAECA minimum efficiency standards. Only those technologies that reduce space-conditioning unit energy consumption by a significant amount $(>12 \%)$ will be discussed in any detail. For each product, we discuss (1) the status of each technology, (2) potential energy savings and incremental costs of the technology, and (3) barriers to implementing the technology. A list of all technologies initially considered appears in Appendix 5.1.

\subsection{BASEline ENERgy USE AND EFFiCIENCY}

Baseline energy use is defined here as the unit (Unit Energy Consumption, or UEC) and national consumption based on the present NAECA minimum efficiency standards as applied to housing population (stock) as it existed in 1990. The nationally-averaged baseline information is presented in the last 3 columns of Table 5.1.

Table 5.1 Efficiencies and Energy Use for 1990 Stock and Baseline Case

\begin{tabular}{|c|c|c|c|c|c|c|}
\hline \multirow[b]{2}{*}{ APPLIANCE } & \multicolumn{3}{|c|}{1990 Stock Appliances } & \multicolumn{3}{|c|}{ NAECA Standard Appliances } \\
\hline & $\begin{array}{l}\text { Average } \\
\text { Effic'cies }\end{array}$ & $\begin{array}{c}\text { UEC } \\
\text { Source* } \\
\text { MMBtu/yr }\end{array}$ & $\begin{array}{l}\text { Annual } \\
\text { Energy } \\
\text { Use } \\
\text { (Quads) }\end{array}$ & $\begin{array}{l}\text { Required } \\
\text { Efficiencies }\end{array}$ & $\begin{array}{c}\text { UEC } \\
\text { Source* } \\
\text { MMBtu/yr }\end{array}$ & $\begin{array}{c}\text { Annual } \\
\text { Energy } \\
\text { Use } \\
\text { (Quads) }\end{array}$ \\
\hline Gas Furnace & 67.5 AFUE & 60.81 & 2.18 & $\begin{array}{c}\text { 78 AFUE } \\
\left(25.4 \mathrm{COP}_{e}\right)\end{array}$ & 52.62 & 1.89 \\
\hline Oil Furnace & 75.8 AFUE & 101.18 & 0.42 & $\begin{array}{l}78 \text { AFUE } \\
\left(21 \mathrm{COP}_{c}\right)\end{array}$ & 98.33 & 0.41 \\
\hline Elect. Centrl Furnc & 100 AFUE & 35.10 & 0.29 & na & na & na \\
\hline Centrl A/C & 8.56 SEER & 28.62 & 0.76 & 10.0 SEER & 24.50 & 0.65 \\
\hline Room A/C & 7.687 EER & 11.17 & 0.34 & 8.73 EER & 9.84 & 0.30 \\
\hline Central Heat Pump & $\begin{array}{l}\text { 5.80 HSPF } \\
\text { 8.34 SEER }\end{array}$ & $\begin{array}{l}79.10 \\
30.04\end{array}$ & 0.30 & $\begin{array}{c}\text { 6.8 HSPF } \\
10.0 \text { SEER }\end{array}$ & $\begin{array}{l}67.46 \\
25.05\end{array}$ & 0.25 \\
\hline Elec Water Heaterf & $0.80 \mathrm{EF}$ & 59.84 & 1.86 & $0.86 \mathrm{EF}$ & 55.67 & 1.73 \\
\hline Gas Water Heatert & $0.50 \mathrm{EF}$ & 29.94 & 1.62 & $0.55 \mathrm{EF}$ & 27.22 & 1.47 \\
\hline Oil Water Heater $\dagger$ & $0.50 \mathrm{EF}$ & 27.07 & 0.14 & $0.52 \mathrm{EF}$ & 26.03 & 0.14 \\
\hline Existing Ducts & $77 \%$ & 16.34 & 0.89 & na & na & na \\
\hline
\end{tabular}

NOTES:

* These values (millions of Btus) include fan electric power, $\mathrm{COP}_{e}$, for fuel-fired furnaces. The $\mathrm{COP}_{e}$ values are electric COP values (not defined by NAECA) that we established to calculate site energy consumption by furnace electrical components: $\mathrm{COP}_{c}=$ (Furnace output Btu/hr)/(3413 $\mathrm{x}$ fan kwh).

$\dagger$ Water heater efficiency standards vary according to storage volume. We have used representative volumes. 
We obtained usage data for the "1990 Stock Appliances" columns of Table 5.1 from LBLREM (see Introduction). The energy consumption values for the last two columns were calculated by assuming that the UECs and national energy consumption values are inversely proportional to efficiency.

In order to perform regional economics, we also obtained regional baseline energy usage values for all appliances with significant variations in UEC due to geographical location. For example, we obtained regionally-adjusted UEC values for the "North" region using the following calculation:

$$
U E C_{\text {north }}=U E C_{\text {standard }} \times\left(\frac{H L H_{\text {north }}}{H L H_{\text {standard }}}\right) \times\left(\frac{\eta_{\text {standard }}}{\eta_{\text {north }}}\right)
$$

where HLH is the heating load hours for both furnaces and heat pumps ${ }^{1}$. The $\eta$ values in the above equation can represent either HSPF for heat pumps, AFUE for furnaces, EF for water heaters, or COP for other equipment. For heat pumps, we performed the above calculation twice, once each for both the heating (using HLH and $\eta=H S P F$ ) and cooling (using $\eta=S E E R$ and CLH, or cooling load hours) modes.

For purposes of this report, we chose Atlanta and Chicago as representative Southern and Northern cities, respectively, in order to establish load and efficiency variation with weather. With these chosen locations, we examined the variations in efficiency, as reported by the EPA (EPA, 1993) for all of the appliances listed in Table 5.1, and found significant variations in efficiency for heat pumps and air conditioners. We therefore applied the percentage efficiency variations determined by the EPA to the national average values listed in Table 5.1 for heat pumps and air conditioners ${ }^{2}$. Efficiencies for all other appliances varied less than $2 \%$ from the national average, and we chose to analyze those appliances as though they had no efficiency variation. The EPA source lists no variation in efficiency or UEC for room air conditioners, and we chose not to consider any regional differences for that appliance.

Table 5.2 presents the $\mathrm{HLH}$ and $\mathrm{CLH}$ values used to characterize the Chicago and Atlanta climates (ARI, 1992). Table 5.3 presents the calculated efficiency and energy usage values.

\footnotetext{
' Water heater loads are not considered to vary with climate, so there is no equivalent of the HLH for water heaters.

${ }^{2}$ We chose not to use the efficiency variations for gas-fired heat pumps developed by the EPA. The efficiency variations from our source of data (reported in Section 4.5.2), which reported actual field test data, showed geographical efficiency variations to be insignificant.
} 


\section{Table 5.2 CLH and HLH Values for North and South Regions}

\begin{tabular}{lccc} 
& U.S. Average & North - Chicago & South - Atlanta \\
\hline Heating HLH & 2080 & 2500 & 1700 \\
Cooling CLH & 1000 & 700 & 1300 \\
\hline
\end{tabular}

Table 5.3 Regional Variations in Baseline UECs

\begin{tabular}{|c|c|c|c|c|c|c|}
\hline \multirow[b]{2}{*}{ Appliance } & \multicolumn{2}{|c|}{$\begin{array}{l}\text { NAECA Standard } \\
\text { Conditions }\end{array}$} & \multicolumn{2}{|c|}{ North Region (Chicago) } & \multicolumn{2}{|c|}{ South Region (Atlanta) } \\
\hline & Efficiency & $\begin{array}{c}\text { UEC } \\
\text { (MMBtu/yr) }^{*}\end{array}$ & Efficiency & $\begin{array}{c}\text { UEC } \\
\text { (MMBtu/yr) }\end{array}$ & Efficiency & $\begin{array}{c}\text { UEC } \\
\text { (MMBtu/yr) }\end{array}$ \\
\hline Gas Furnace & 78 AFUE & 52.6 & 78 AFUE & 63.22 & 78 AFUE & 42.99 \\
\hline Oil Furnace & 78 AFUE & 98.3 & 78 AFUE & 118.15 & 78 AFUE & 80.34 \\
\hline Elect Furnace & na & 35.1 & $1.0 \mathrm{COP}$ & 42.19 & $1.0 \mathrm{COP}$ & 28.69 \\
\hline Centrl A/C & 10.0 SEER & 24.5 & 10.2 SEER & 16.81 & 9.8 SEER & 32.50 \\
\hline Heat Heat & $6.8 \mathrm{HSPF}$ & 67.5 & $6.1 \mathrm{HSPF}$ & 90.39 & 7.5 HSPF & 49.99 \\
\hline 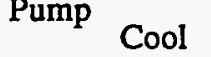 & 10.0 SEER & 25.1 & 10.2 SEER & 17.23 & 9.8 SEER & 33.30 \\
\hline
\end{tabular}

MMBtu/yr = millions of Btu's per year

In addition to requiring regional baseline energy usage data, regionalized fuel and electricity prices were necessary in order to perform a regional economic analysis. In order to generate regional payback values, we first determined average fuel and electricity price variations between the South and North regions, using projections of 1998 prices for each of the ten Federal Regions (EIA, 1993). We defined a "South" region consisting of the South Atlantic (no. 4), Southwest (no. 6), and West (no. 9) Federal regions, and a "North" region as the balance of the regions. We then obtained weighted-average gas, oil, and electric prices for both the North and South regions. Depending on the weighting scheme (either no weighting or detached single family house population weighting), we obtained average gas prices that varied less than $4.5 \%$ and oil prices that varied less than $4.7 \%$ between North and South. We chose to ignore these variations, and used the national average oil and gas prices for both the North and South. Electricity prices, however, averaged a 15\% variation between North and South. We chose to characterize them as 6\% greater in the North and 9\% less in the South than the national average price of $\$ 0.087 / \mathrm{kWh}(\mathrm{EIA}, 1993)$.

The advanced technologies evaluated in this report are analyzed on a regional basis in order to demonstrate their improved cost-effectiveness in areas of the country where they will yield greater energy savings than a nationally representative climate. In evaluating advanced technologies on a regional basis, installed costs were adjusted to reflect a mature market (i.e., higher production volume). Mature market costs coupled with a regional analysis allow the advanced technologies to 
be evaluated under the most favorable economic conditions. Thus, the "regionalized" analysis provides an estimate of a technology's future cost-effectiveness after increased market saturation. One method to increase market saturation is through policy actions such as support for research and development, fostering of rebate programs, and Golden-Carrot initiatives.

\subsection{METHODOLOGY}

To determine which space-conditioning technologies were the most promising for saving energy on a national basis, we formulated a methodology to characterize and rank the technologies. The methodology consisted of (1) determining which space-conditioning systems the advanced technology could replace, (2) determining the actual percentage of new shipments, for each replaceable system, that the advanced technology would replace, (3) calculating a shipmentweighted source unit energy consumption (UEC) for the advanced technology, (4) calculating a payback period for the advanced technology, and (5) ranking the advanced technology based on its cost-effectiveness and magnitude of saved energy.

In Section 127 of the Energy Policy Act of 1992, two of the five criteria for identifying highefficiency appliances specify that (1) the candidate appliance demonstrates the potential for significant energy savings at the national or regional level and (2) such appliances are likely to be cost-effective for consumers. The following equation provides a ranking value or index that places equal emphasis on the appliance's ability to save energy (in 1998) and its payback period.

$$
\text { Ranking Index }=\frac{(\text { UEC savings }) \times(1998 \text { Shipments })}{\text { Payback }}
$$

The above ranking equation provides a simple way to estimate the relative benefit of competing technologies. The complete methodology for characterizing and ranking the technologies is described in detail in Appendix 5.2. A complete list of the technology options that were considered for this report can be found in Appendix 5.1.

Table 5.4 presents the 16 most promising advanced technologies for providing national energy savings in the most cost-effective manner. For each advanced technology listed, the following are provided: (1) the technology's nationally averaged site and source UEC, (2) the UEC of the baseline technology (from which the advanced technology is being compared), (3) the percent reduction change in the baseline UEC, (4) the nationally averaged increase in installed cost, and (5) the nationally averaged payback period. The following sections describe the advanced technologies listed in Table 5.4 in more detail. 


\section{Table 5.4 Top 16 Advanced Technologies for Space Heating and Cooling}

\begin{tabular}{|c|c|c|c|c|c|c|c|}
\hline \multirow[b]{3}{*}{ Technology } & \multicolumn{4}{|r|}{ Baseline } & \multirow[b]{3}{*}{$\%$ DUEC } & \multirow[b]{3}{*}{$\Delta$ price } & \multirow[b]{3}{*}{$\begin{array}{c}\text { Payback } \\
\text { years }\end{array}$} \\
\hline & \multicolumn{3}{|c|}{ Technology's UEC } & UEC & & & \\
\hline & $\begin{array}{c}\text { Sìte } \\
k W h / y r\end{array}$ & $\begin{array}{c}\text { Fuel } \\
\text { MMBtwlyr* }\end{array}$ & $\begin{array}{c}\text { Source } \\
\text { MMBtw/yr* }\end{array}$ & $\begin{array}{c}\text { Source } \\
\text { MMBtu/yr* }\end{array}$ & & & \\
\hline Single-Stage Direct Evap Coolers & 755 & - & 8.7 & 34.7 & $75 \%$ & (1) & 0 \\
\hline Elec Integ 2-Spd Ground-Src Heat Pump & 5626 & - & 64.7 & 119.7 & $46 \%$ & $\$ 3,819$ & 11.5 \\
\hline Gas Adsorption Heat Pump & 782 & 51.1 & 60.1 & 82.2 & $27 \%$ & $\$ 2,026$ & 12.0 \\
\hline Elec 2-Speed Ground-Source Heat Pump & 3862 & - & 44.4 & 80.2 & $45 \%$ & $\$ 3,848$ & 15.8 \\
\hline Leakage-Reducing Ducts & 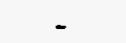 & - & $6.2(2)$ & 72.8 & $9 \%$ & $\$ 250$ & 6.0 \\
\hline Gas Int Engine-Driven Gas Heat Pump & 953 & 70.8 & 81.7 & 112.5 & $27 \%$ & $\$ 4,188$ & 18.1 \\
\hline Gas Integrated Absorption Heat Pump & 1615 & 75.0 & 93.6 & 112.5 & $17 \%$ & $\$ 2,038$ & 14.0 \\
\hline Gas Engine-Driven Heat Pump & 734 & 51.9 & 60.4 & 82.2 & $27 \%$ & $\$ 3,826$ & 23.1 \\
\hline 2-Stage Indirect/Direct Evap Coolers & 539 & - & 6.2 & 24.8 & $75 \%$ & $\$ 761$ & 5.4 \\
\hline Gas Integrated Water Heater/ Furnace & 469 & 59.7 & 65.5 & 83.7 & $22 \%$ & $\$ 1,460$ & 11.6 \\
\hline $\begin{array}{l}\text { Elec Variable-Spd Air-Source Heat } \\
\text { Pump }\end{array}$ & 4675 & - & 53.8 & 80.2 & $33 \%$ & $\$ 4,156$ & 25.1 \\
\hline Elec Int Var-Spd Air-Source Heat Pump & 7148 & - & 82.2 & 119.7 & $31 \%$ & $\$ 6,657$ & 44.3 \\
\hline Oil Absorption Heat Pump & 1727 & 74.7 & 94.3 & 116.0 & $19 \%$ & $\$ 842$ & 6.6 \\
\hline National Service Improvement Program & - & - & $17.2(2)$ & 298.5 & $6 \%$ & $\$ 116$ & 6.0 \\
\hline Oil Condensing Furnace & 612 & 70.34 & 77.38 & 93.4 & $17 \%$ & $\$ 757$ & 6.7 \\
\hline Gas Absorption Heat Pump & 1312 & 57.6 & 72.6 & 82.2 & $12 \%$ & $\$ 1,726$ & 23.0 \\
\hline
\end{tabular}

* MMBtu/yr $=$ millions of Btus per year

(1) Cost of direct evaporative coolers is less than baseline equipment cost.

(2) Source UEC savings are provided.

\subsection{Fuel-Driven HeAT PUMPS AND INTEgRated APPLIANCES}

We identify five gas-fired heat pump technologies that have been or are currently being developed for residential heat pump applications. We investigate in detail the economics of three of the five technologies, omitting chemical adsorption and stirling cycle vapor-compression technologies.

Present Status. The following paragraphs present the status of four different gas-fired heat pump technologies.

(1) Engine-Driven Heat Pumps. The Gas Research Institute (GRD) and York International Corporation have jointly developed a natural gas, engine-driven, variable-speed, vapor-compression heat pump. This unit is similar in many ways to existing vapor-compression heat pumps. However, the compressor is driven by an internal combustion spark-ignition engine, and the unit recovers engine heat in the space-heating mode. The unit has undergone field tests at approximately 10 sites in the U.S. and is scheduled for production in the near future. 
(2) Stirling Cycle Engine/Vapor-Compression Heat Pump. (Fiskum, 1993) The DOE has funded work by MTI Corp. (Layton, NY) to develop this concept, although funding for further development has been terminated. Concept development has evolved to the extent that the following projections have been made:

Production cost: $\$ 5000$ to $\$ 6000$ at a production level of 50,000 units per year Steady-state gas COPs: $\mathrm{COP}_{\text {heat }}=1.6 ; \mathrm{COP}_{\text {cool }}=0.71$

We were unable to obtain performance data for seasonal COPs or electrical energy consumption. This technology was not further pursued because we lacked adequate data for analysis, and we believe that the steady-state COP values listed make the current concept economically less attractive than the other options presented here.

(3) Absorption Heat Pump. (Fiskum, 1993) The DOE has been funding Phillips Engineering in the development of a gas-fired, ammonia-water absorption cycle heat pump. The unit is in full-scale testing, and a major equipment manufacturer has been selected to produce a number of units for field testing.

(4) Solid Sorption (Adsorption) Heat Pump. (Shelton, 1993) Wave Air Corporation (Atlanta, $\mathrm{Ga}$.) is developing a gas-fired solid sorption heat pump concept that was previously researched by the Gas Research Institute. Wave Air Corp. is in the process of obtaining investors and a manufacturer to develop the concept further.

At the present time, development of the above technologies has centered around space heating and cooling applications (without water heating), and around natural gas as the fuel. We believe that oil firing should be additionally considered for at least the absorption and adsorption technologies, and that water heating combined with space conditioning (so called "integrated" appliances) should be considered for all of the technologies. These options are discussed further below.

Energy Use and Cost.. Table 5.5 presents characteristics of the engine-driven, absorption, and adsorption heat pump concepts. For the cases we believe appropriate, we have also generated cost and performance estimates for heat pump configurations that include water-heating as well as space conditioning. It should be emphasized that these water heating costs and $\mathrm{COP}$ values are estimates only. ${ }^{3}$ None of the units are currently configured with the water heating feature.

The shipment-weighted UEC values (based on source energy) and payback periods in Table 5.5 are based on the calculation procedure explained in Appendix 5.2.

\footnotetext{
${ }^{3}$ For all the combined appliances examined here, water heating $\mathrm{COP}_{\text {gas }}$ values were obtained by subtracting 0.3 from the space heating $C O P_{\text {ggs }}$. This is a very conservative approach, based on the rationale that the water must be heated to a higher temperature (about $135^{\circ} \mathrm{F}$ ) than space heating air (about $105^{\circ} \mathrm{F}$ ). Our approach does not take into account that much of the water heating takes place during warmer periods of the year. Thus, the water-heating COP gas values could be significantly higher than those given here.
} 
It should be noted that water-heating ("integrated") configurations in Table 5.5 are suggested only for the engine-driven and absorption units. We believe that these technologies feature the easiest and most economic adaptations to water heating. In particular, the absorption unit appears to be very readily adapted to water heating. The outdoor portion of this unit generates both hot and cold water and then pumps the water to an indoor coil for space conditioning. Adding the water-heating capability to this unit appears to be relatively easy by adding a water tank with heat exchanger, additional piping, and additional controls. The engine-driven unit could be configured to provide water heating also, but with additional complications and costs, since that unit delivers heat to the indoor coil through both refrigerant and hot water piping.

We have additionally provided in Table 5.5 our estimates for cost and performance of an oil-fired absorption beat pump, both for the space-conditioning-only implementation and the combined appliance (space conditioning with water heating) implementation. We chose performance values to be the same as for the gas absorption unit and incremental costs of $\$ 150$ for the oil burner and $\$ 1200$ for incremental present value of maintenance.

The performance values are given in terms of seasonal COP values for both fuel and electric inputs to the units. The $\mathrm{COP}_{\mathrm{gas}}$ value has the customary definition of load Btus divided by input gas Btus. The $\mathrm{COP}_{\text {elec }}$ values are similarly defined as load Btus divided by input electric Btus, or

$$
\mathrm{COP}_{\text {elec }}=\frac{(\text { load Btus })}{(\text { input kw }) \times 3413}
$$

Table 5.5 Efficiencies, Costs and Paybacks for Fuel-Driven Heat Pumps

\begin{tabular}{|c|c|c|c|c|c|c|c|c|c|c|}
\hline \multirow{2}{*}{ TECHNOLOGY } & \multicolumn{2}{|c|}{$\begin{array}{l}\text { Heating } \\
\text { Performance }\end{array}$} & \multicolumn{2}{|c|}{$\begin{array}{l}\text { Cooling } \\
\text { Performance }\end{array}$} & \multicolumn{2}{|c|}{$\begin{array}{l}\text { Water Heating } \\
\text { Performance }\end{array}$} & \multirow{2}{*}{$\begin{array}{l}\text { Installed } \\
\text { Cost }\end{array}$} & \multirow{2}{*}{$\begin{array}{l}\text { Incremental } \\
\text { Cost Assumed } \\
\text { for Water } \\
\text { Heating }\end{array}$} & \multirow{2}{*}{$\begin{array}{l}\text { Shipment- } \\
\text { Weighted } \\
\text { UEC } \\
\text { (MMBtu/yr) }\end{array}$} & \multirow{2}{*}{$\begin{array}{c}\text { Payback } \\
\text { (years) }\end{array}$} \\
\hline & $\mathrm{COP}_{\mathrm{gas}}$ & COPelec & $\mathrm{COP}_{\text {gas }}$ & COPelex & $\mathrm{COP}_{\mathrm{gas}}$ & $\mathrm{COP}_{\text {elec }}$ & & & & \\
\hline Gas Eng-Driven HP & 1.27 & 24.5 & 1.05 & 24.5 & na & na & $\$ 6800$ & na & 60.4 & 23 \\
\hline Gas Absorption HP & 1.35 & 17.6 & 0.77 & 9.8 & na & na & $\$ 4700$ & na & 72.6 & 23 \\
\hline Oil Absorption HP & 1.35 & 17.6 & 0.77 & 9.8 & na & na & $\$ 6050$ & na & 94.8 & 6.6 \\
\hline Adsorption HP & 1.35 & 23.0 & 1.0 & 23.0 & na & na & $\$ 5450$ & na & 60.1 & 12 \\
\hline $\begin{array}{c}\text { Integrated Gas } \\
\text { Engine-driven } \\
\text { HP }\end{array}$ & 1.27 & 24.5 & 1.05 & 24.5 & 0.97 & 24.5 & $\$ 7560$ & $\begin{array}{l}\text { Contrls: } \$ 200 \\
\text { Wtr Htr: } \$ 410 \\
\text { Piping: } \$ 150\end{array}$ & 81.7 & 18 \\
\hline $\begin{array}{l}\text { Integrated Gas } \\
\text { Absorption } \\
\text { HP }\end{array}$ & 1.35 & 17.6 & 0.77 & 9.8 & 1.05 & 17.7 & $\$ 5410$ & $\begin{array}{l}\text { Contrls: } \$ 150 \\
\text { Wtr Htr: } \$ 410 \\
\text { Piping: } \$ 150\end{array}$ & 93.6 & 14 \\
\hline $\begin{array}{c}\text { Integrated Oil } \\
\text { Absorption } \\
\text { HP } \\
\end{array}$ & 1.35 & 17.6 & 0.77 & 9.8 & 1.05 & 17.7 & $\$ 6760$ & $\begin{array}{l}\text { Contrls: } \$ 150 \\
\text { Wtr Htr: } \$ 410 \\
\text { Piping: } \$ 150 \\
\end{array}$ & 114.4 & 0 \\
\hline
\end{tabular}


We additionally investigated the performance of the above systems in a Northern US climate, using the methods previously discussed in Section 5.1. The heat pump units have an advantage in heatingdominated Northern climates because their heating COPs are much better than their cooling COPs. We chose to use the same heating and cooling COPs for the North region as for the National average case. This was based on regional field test data for the engine-driven heat pump (Klausing, 1993) that indicated little regional difference in efficiency between the North and South. However, we chose to analyze a range of water heating COPs for the North region, since we have no actual water heating efficiency data. Our efficiency assumptions and UEC results are presented in Table 5.6. We chose not to vary installation costs from North to South for these units, since no experience with actual costs variations is available at present. But installed costs have been adjusted to reflect a mature market (i.e., higher production volumes). We estimated these mature market costs by using two methods: With the first method, we simply adjusted costs upward based on unit weight. In the second method, the "learning curve" method, we assumed that manufacturing costs would decrease by $10 \%$ for each doubling of production volume (using a mature market volume of 4.05 million units). The payback ranges presented for the integrated (space conditioning plus water heating) units account for the variations in water heating efficiencies that are shown in the table.

\section{Table 5.6 Efficiencies, Costs and Paybacks for Fuel-Driven Heat Pumps, North Region}

\begin{tabular}{|c|c|c|c|c|c|c|c|c|c|c|}
\hline \multirow{2}{*}{ TECHNOLOGY } & \multicolumn{2}{|c|}{$\begin{array}{c}\text { Heating } \\
\text { Performance }\end{array}$} & \multicolumn{2}{|c|}{$\begin{array}{c}\text { Cooling } \\
\text { Performance }\end{array}$} & \multicolumn{2}{|c|}{$\begin{array}{l}\text { Water Heating } \\
\text { Performance }\end{array}$} & \multirow{2}{*}{$\begin{array}{c}\text { Mature } \\
\text { Market } \\
\text { Installed } \\
\text { Cost }\end{array}$} & \multirow{2}{*}{$\begin{array}{l}\text { Incremental } \\
\text { Cost Assumed } \\
\text { for Water } \\
\text { Heatng }\end{array}$} & \multirow{2}{*}{$\begin{array}{l}\text { Shipment- } \\
\text { Weighted } \\
\text { UEC } \\
\text { (MMBtu/yr) }\end{array}$} & \multirow{2}{*}{$\begin{array}{c}\text { Payback } \\
\text { (years) }\end{array}$} \\
\hline & $\mathrm{COP}_{82 s}$ & COP elec & $\mathrm{COP}_{\mathrm{gas}}$ & COP elec & $\mathrm{COP}_{825}$ & $\mathrm{COP}_{\text {elec }}$ & & & & \\
\hline Gas Eng-Driven HP & 1.27 & 24.5 & 1.05 & 24.5 & na & na & $\$ 5600$ & na & 61.0 & 14 \\
\hline Gas Absorption HP & 1.35 & 17.6 & 0.77 & 9.8 & na & nа & $\$ 3600$ & nа & 69.8 & 4.8 \\
\hline Oil Absorption HP & 1.35 & 17.6 & 0.77 & 9.8 & na & na & $\$ 5300$ & na & 97.8 & 0 \\
\hline Adsorption HP & 1.35 & 23.0 & 1.0 & 23.0 & na & na & $\$ 4100$ & na & 60.0 & 3.2 \\
\hline $\begin{array}{c}\text { Integrated Gas } \\
\text { Engine-driven } \\
\text { HP }\end{array}$ & 1.27 & 24.5 & 1.05 & 24.5 & $\begin{array}{c}0.97 \text { to } \\
1.20\end{array}$ & 24.5 & $\$ 6360$ & $\begin{array}{l}\text { Contrls: } \$ 200 \\
\text { Wtr Htr: } \$ 410 \\
\text { Piping: } \$ 150\end{array}$ & $\begin{array}{c}78.4 \text { to } \\
75.5\end{array}$ & $\begin{array}{c}10.8 \text { to } \\
11.7\end{array}$ \\
\hline $\begin{array}{l}\text { Integrated Gas } \\
\text { Absorption } \\
\text { HP }\end{array}$ & 1.35 & 17.6 & 0.77 & 9.8 & $\begin{array}{l}1.05 \text { to } \\
1.25\end{array}$ & 17.7 & $\$ 4310$ & $\begin{array}{l}\text { Contrls: } \$ 150 \\
\text { Wtr Htr: } \$ 410 \\
\text { Piping: } \$ 150\end{array}$ & $\begin{array}{c}86.9 \text { to } \\
84.6\end{array}$ & $\begin{array}{c}4.3 \text { to } \\
4.7\end{array}$ \\
\hline $\begin{array}{c}\text { Integrated Oil } \\
\text { Absorption } \\
\text { HP }\end{array}$ & 1.35 & 17.6 & 0.77 & 9.8 & $\begin{array}{l}1.05 \text { to } \\
1.25\end{array}$ & 17.7 & $\$ 6010$ & $\begin{array}{l}\text { Contrls: } \$ 150 \\
\text { Wtr Htr. } \$ 410 \\
\text { Piping: } \$ 150\end{array}$ & $\begin{array}{l}114.7 \text { to } \\
112.5\end{array}$ & 0 \\
\hline
\end{tabular}

Barriers to Implementation. Cost is the most significant barrier for the gas-fired appliances. These units find desirable paybacks in only a fraction of the total population, i.e., those homes with utility bills sufficiently high so that the investment is returned in a reasonable time. For example, a utility on the West Coast, in trying to identify possible markets for the engine-driven heat pump, had to identify segments of its population based on house size and current utility bills (Layboume, 1993). 
For the cases in which a desirable payback exists, the usual problems of consumer awareness and availability of the extra money to pay for the equipment still remain.

Despite these barriers, development of the gas-fired appliances listed in Table 5.2, except for the combined appliances, appears to be proceeding through private efforts.

For the oil appliances, the barriers are more significant, apparently arising from:

(1) the absence from the residential oil industry of an organization equivalent to the Gas Research Institute (GRI). The GRI has paid for research and development on the GRI/York engine-driven heat pump, condensing and pulse combustion furnace technology, and many other developments that have significantly benefited the gas appliance industry. It also actively advertises and promotes and develops new markets.

(2) the relatively small sales of oil-burning heating equipment in relation to gas equipment. This circumstance is an obvious discouragement to manufacturing organizations that need to realize an acceptable return on their research and development dollars.

\subsection{CONDENSING FURNACES}

Present Status. The following paragraphs present the status of condensing furnace technology for both oil- and gas-fired applications.

(1) Gas-Fired Condensing Furnaces. These units have been marketed since the 1980s. An early technical problem, corrosion of the secondary heat exchanger, has been resolved by the industry, and the units now have wide acceptance, especially in the colder climates of the U.S. where heating bills are high. Present sales for these units are on the order of $20 \%$ of all central furnaces.

(2) Oil-Fired Condensing Furnaces. One company has marketed condensing oil furnaces but has withdrawn, at least temporarily, from the market. Brookhaven National Laboratory also developed a condensing oil-fired pulse combustion boiler in the 1980s (McDonald, 1986). Secondary heat exchanger corrosion and fouling are key technical problems, and it remains unclear at the time of this writing whether these have been resolved.

Energy Use and Cost. Table 5.7 presents results from DOE test-procedure calculations for gas and oil furnaces. While the test procedure does not replicate actual field performance, we believe it gives acceptable determinations of the relationship between actual gas and electric usages and load. We obtain load values (in MMBtu/yr) from LBLREM, as explained in Appendix 5.2; we obtain UEC (based on source energy) from the procedure discussed in Appendix 5.2.

The gas furnace AFUE value (identical to $\mathrm{COP}_{\text {gas }}$ ) reported below is an average efficiency for nonmodulating condensing furnaces, as reported by the Gas Appliance Manufacturers' Association (GAMA, 1993). GAMA also provides electrical consumption values, and we averaged a number 
of the electrical consumption values for $100,000 \mathrm{Btu} / \mathrm{yr}$ input furnaces in order to obtain an average electrical consumption in terms of $\mathrm{kWh} / \mathrm{yr}$. We converted the $\mathrm{kWh} / \mathrm{yr}$ value to the $\mathrm{COP}_{\text {elec }}$ value as described in Section 5.3.

The oil furnace efficiency values in Table 5.7 are LBL estimates. We chose the oil AFUE value to be slightly higher than the condensing gas AFUE because oil efficiencies are typically higher than gas efficiencies for the same equipment. The $\mathrm{COP}_{\text {elec }}$ value is derived from our test procedure calculations for a hypothetical oil condensing furnace.

The cost of the condensing gas furnace is taken from an LBL survey of contractor costs and includes our estimate of venting costs. The oil furnace cost is based on an LBL survey of contractor costs for non-condensing oil furnaces, but it also includes: (1) our assessment of the typical differential costs between condensing and non-condensing gas furnaces, and (2) an additional $\$ 1200$ for the present value of oil burner maintenance over the lifetime of the furnace.

\section{Table 5.7 Efficiencies, Costs and Paybacks for Condensing Furnaces}

\begin{tabular}{ccccccc} 
Fuel & $\begin{array}{c}\text { Typical Input Rate } \\
\text { (Btu/hr) }\end{array}$ & $\begin{array}{c}\text { AFUE or }_{\mathbf{C O P}_{\text {gs }}} \\
\text { Gas }\end{array}$ & COP $_{\text {elec }}$ & $\begin{array}{c}\text { UEC } \\
(\mathbf{M M B t u} / \mathbf{y r})\end{array}$ & $\begin{array}{c}\text { Installed } \\
\text { Cost }\end{array}$ & $\begin{array}{c}\text { Payback } \\
\text { (years) }\end{array}$ \\
\hline Oil & 100,000 & 0.905 & 36.0 & 47.6 & $\$ 2300$ & 12 \\
\hline
\end{tabular}

For the North Region, we used the same efficiencies, but altered the heating load hour (HLH) values according to the method described in Section 5.1. Our efficiency assumptions and UEC results are presented in Table 5.8. We chose not to vary installation costs from North to South for these units, since no experience with actual costs variations is available at present. But installed costs have been adjusted to reflect a mature market (i.e., higher production volumes). For both gas and oil furnaces, we assumed that half of the differential costs between condensing and non-condensing furnaces can be reduced due to production innovations, then used the "learning curve" method to calculated mature market costs. ${ }^{4}$

${ }^{4}$ Since present gas condensing furnace production is about $25 \%$ of the total gas furnace market, two production doublings would be possible in a mature market. We assumed a cost decrement of $10 \%$ for each production doubling. For oil furnaces, we based differential costs on the gas differential costs (between condensing and noncondensing), so used the same number of production doublings to obtain mature market costs. 
Table 5.8 Efficiencies, Costs and Paybacks for Condensing Furnaces, North Region

\begin{tabular}{ccccccc} 
Fuel & $\begin{array}{c}\text { Typical Input Rate } \\
\text { (Btu/hr) }\end{array}$ & $\begin{array}{c}\text { AFUE or } \\
\text { COP }_{\text {sos }}\end{array}$ & COP $_{\text {elec }}$ & $\begin{array}{c}\text { UEC } \\
\text { (MMBtu/yr) }\end{array}$ & $\begin{array}{c}\text { Mature Mkt } \\
\text { Installed } \\
\text { Cost }\end{array}$ & $\begin{array}{c}\text { Payback } \\
\text { (years) }\end{array}$ \\
\hline Gas & 100,000 & 0.905 & 36.0 & 57.2 & $\$ 2250$ & 9.4 \\
Oil & 105,000 & 0.920 & 31.0 & 93.0 & $\$ 4040$ & 3.9 \\
\hline
\end{tabular}

Barriers to Implementation. For gas condensing furnaces, high cost is the primary barrier to implementation in areas of the country where the weather is mild - primarily the South and the West. Despite cost differential however, penetration of the technology has reached about $20 \%$ of yearly sales.

For oil condensing furnaces, the barriers are more numerous and significant and are the same as those listed in Section 5.3:

(1) An absence for the residential oil industry of an organization equivalent to the Gas Research Institute.

(2) The relatively small sales of oil furnaces (on the order of 140,000 per year) places a low priority on the development of new oil-furnace technologies. This circumstance is an obvious discouragement to manufacturing organizations that need to realize an acceptable return on their research and development dollars.

\subsection{INTEGRATED WATER HEATER/FURNACE}

We discuss the bases for our analysis of a particular integrated appliance: a condensing gas water heater connected to a space-heating fan coil. The economics of this system are intended to be representative of the general class of combined or integrated appliances that feature high-efficiency water heating combined with space heating.

There are two variations on this type of system. The most prevalent features a standard water heater coupled by piping and a circulation pump to a fan coil "furnace." The water heater can, in theory, be any standard unit, although one of the manufacturers also markets and requires the use of its own specially fitted water heaters in conjunction with its fan coil units. We focus on high-efficiency water heaters, i.e., those for which the recovery efficiency is above the condensing level.

The second variation features two main components: a non-fired water-heating tank and a gas furnace/boiler, interconnected by piping. The furnace/boiler unit contains a boiler, fan coil, circulation pump, and fluid circulation system. When space heat is called for, the boiler heats the heat-transfer fluid (water or a glycol solution) and the pump circulates the fluid through the fan coil. 
With a call for water heating, the boiler heats the fluid and the pump circulates the fluid through the interconnecting piping to a heat exchanger in the domestic hot water tank.

We have not investigated oil-fired condensing space- and water-heating appliances. There appears to be no reason why oil-fired versions of this equipment should not be either technically or economically viable.

Present Status. At present two primary manufacturers produce residential fan coil units designed for operation with domestic hot water from the home hot water heater. Their markets are in the South and West and probably are dominated by residences heated with gas. The primary market appears to be driven by cost advantage, where, in new construction, contractors can install them at lower cost than the primary competing system, a separate gas water heater and furnace. The primary cost advantage is derived by eliminating the vent and gas connections for one of the two appliances, while the added cost would be the interconnecting piping.

There presently is only one manufacturer of a condensing gas water heater: Mor-Flo/American manufacturers the Polaris series, a gas-fired unit with an Energy Factor (overall efficiency rating) of 0.86 and a recovery efficiency of $94 \%$. The unit is marketed both as a stand-alone water heater and as part of a water-heating plus space-heating system with fan coil. There are no condensing oil water heaters.

Until five years ago, both Amana Refrigeration, Inc., and Glowcore Heating and Cooling Products Company manufactured the second variation of the hot water heater/furnace system. At the present time, only Glowcore remains in this market. A 1992 version of the Glowcore unit offered a system with a space-heating efficiency of 91.5 AFUE. At that time, the company had stated intentions of producing a unit with 95 AFUE. Both Amana and Glowcore have offered only gas-fired versions of the units.

Energy Use and Cost. Table 5.9 presents the efficiency and cost values that we use in evaluating the integrated water heater/furnace system. We base performance calculations for the water heating on the reported Energy Factor of the Polaris unit and space-heating efficiency on the "Effective AFUE" calculation procedure available in the California residential energy standards compliance procedures manual (CEC, 1992). This procedure yielded an "Effective AFUE" that was approximately equal to the water heater recovery efficiency of $94 \%$. A new test method, ASHRAE Standard 124 (ASHRAE, 1991), has been developed to describe the water heating and space heating efficiencies of integrated systems (Kweller, 1992), but we presently have no ratings based on this method.

We estimate the space-heating $\mathrm{COP}_{\text {elec }}$ as approximately equal to the condensing furnace $\mathrm{COP}_{\text {elec }}$. To estimate the $\mathrm{COP}_{\text {elec }}$ for water heating, we assumed the ratio of water-heating-to-space-heating $\mathrm{COP}_{\text {elec }}$ values to be equal to the ratio of water-heating-to-space-heating $\mathrm{COP}_{\mathrm{gas}}$ values.

We obtained an installed cost of $\$ 3450$ for the integrated condensing water heater and fan coil ("combo") system. We based our cost estimate for the condensing water heater on contractor 
quotations for the Polaris unit. According to the recommendation of a manufacturer of fan/coil units (Cummings, 1993) and previous conversations with installers, we estimated the installed cost for an integrated system to be approximately equal to the sum of the costs of an independent condensing water heater plus an independent baseline furnace.

\section{Table 5.9 Characteristics, Efficiencies, Costs and Paybacks for Integrated Condensing Water Heater/Furnace}

\begin{tabular}{|c|c|c|c|c|c|c|c|c|}
\hline \multirow[b]{2}{*}{ Fuel } & \multicolumn{3}{|c|}{ Water Heating } & \multicolumn{2}{|c|}{ Space Heating } & \multirow[b]{2}{*}{$\begin{array}{l}\text { Source UEC } \\
\text { (MMBtu/yr) }\end{array}$} & \multirow[b]{2}{*}{$\begin{array}{l}\text { Installed } \\
\text { Cost }\end{array}$} & \multirow[b]{2}{*}{$\begin{array}{c}\text { Payback } \\
\text { (years) }\end{array}$} \\
\hline & $\begin{array}{c}\text { Input Rate } \\
\text { (Btu/hr) }\end{array}$ & $\begin{array}{l}\text { EF or } \\
\text { COP }_{\text {eas }}\end{array}$ & COP $_{\text {elec }}$ & $\mathrm{COP}_{\text {os }}$ & $\mathrm{COP}_{\text {elec }}$ & & & \\
\hline Gas & 100,000 & 0.86 & 32 & 0.94 & 35 & 65.5 & $\$ 3540$ & 12 \\
\hline
\end{tabular}

For the North Region, we used the same efficiencies, but altered the space heating HLH value according to the method described in Section 5.1. Our efficiency assumptions and UEC results are presented in Table 5.10. We chose not to vary installation costs from North to South for these units, since no experience with actual cost variations is available at present. For a mature market cost, we used the "learning curve" method, assuming a $10 \%$ unit cost reduction for every doubling of production volume. 5

Table 5.10 Characteristics, Efficiencies, Costs and Paybacks for Integrated Condensing Water Heater/Furnace, North Region

\begin{tabular}{|c|c|c|c|c|c|c|c|c|}
\hline \multirow[b]{2}{*}{ Fuel } & \multicolumn{3}{|c|}{ Water Heating } & \multicolumn{2}{|c|}{ Space Heating } & \multicolumn{2}{|r|}{ Mat. Mkt. } & \multirow[b]{2}{*}{$\begin{array}{c}\text { Payback } \\
\text { (years) }\end{array}$} \\
\hline & $\begin{array}{c}\text { Input Rate } \\
\text { (Btu/hr) }\end{array}$ & $\begin{array}{l}\text { EF or } \\
\text { COP }_{p g s}\end{array}$ & $\mathrm{COP}_{\text {elec }}$ & $\mathrm{COP}_{\text {ges }}$ & $\mathrm{COP}_{\text {elec }}$ & $\begin{array}{l}\text { Source UEC } \\
\text { (MMBtu/yr) }\end{array}$ & $\begin{array}{c}\text { Installed } \\
\text { Cost }\end{array}$ & \\
\hline Gas & 100,000 & 0.86 & 32 & 0.94 & 35 & 74.4 & $\$ 2700$ & 5 \\
\hline
\end{tabular}

Barriers to Implementation. For the variation of gas combined appliances discussed, a condensing water heater plus a fan coil unit, the high installed cost is the primary barrier to implementation in all geographic areas of the country. The differential cost of the system is more than $\$ 1500$. This high cost appears to be brought about in part by the low production volume of the condensing water heater, but probably the lack of competition - since only one manufacturer supplies a condensing unit - is equally responsible.

For oil condensing water heaters, the low production volume/high cost barrier to development is

${ }^{5}$ For this analysis, we assumed a present production of 25,000 units, a mature market production of 2.1 million units (which is the same as the present production of gas furnaces), and obtained a mature market cost of approximately $50 \%$ of the present consumer cost. 
severe, since the total shipments of oil water heaters is much smaller than that of gas water heaters. Shipment statistics for oil water heaters are difficult to obtain. However, the housing stock with oil water heaters, the primary driving force for replacement shipments, was approximately $8 \%$ of the housing stock with gas water heaters in 1990 (EIA, 1992).

As for the other oil technologies listed, we again point to the absence for the residential oil industry of an organization equivalent to the GRI. The GRI has paid for research and development on the GRI/York engine-driven heat pump, condensing and pulse combustion furnace technology, and many other developments that have significantly benefited the gas appliance industry. It also actively advertises, and promotes, and develops new markets.

\subsection{Electric Ground-Source AND Atr-SourCe HeAt PuMPS AND INTEGRATED APPLIANCES}

Split-system electric air-source heat pumps currently must meet NAECA minimum efficiency standards of 10.0 SEER for cooling and 6.8 HSPF for heating. For electric heat pumps and integrated appliances, the technology options considered in detail are listed following. The technologies are part of the top 16 advanced technologies that were presented in Table 5.4.

1. Integrated 2-speed ground-source heat pump

2. Two-speed ground-source heat pump

3. Integrated variable-speed air-source heat pump

4. Variable-speed air-source heat pump.

\subsubsection{Ground-Source Heat Pumps and Integrated Appliances}

Present Status. Ground-source heat pumps comprise a small portion, approximately $0.4 \%$, of the entire nationwide heat pump market. Sales estimates for the past eight years have remained stable. Because some of the major manufacturers moved into larger manufacturing facilities, there is speculation that the ground-source heat pump market has actually increased in the past few years. (EPA, 1993)

Ground-source heat pumps operate on the same principle as air-source equipment with the exception that heat is rejected or extracted from the ground instead of the air. Since ground temperatures do not vary over the course of a day (or a year) as much as the ambient air temperature, more stable operating temperatures are achieved. The ground loop for a ground-source heat pump is a closed system that uses a pressurized, sealed piping system filled with a water/antifreeze mixture. Ground loops are either configured horizontally or vertically. A conventional horizontal loop system is placed in a trench 3 to 6 feet deep with 400 to 600 feet of piping required per ton of heat-pump capacity. As much as 5000 square feet of total land space are required for the installation (EPA, 1993). A relatively new type of horizontal loop configuration, the SLINKY loop, significantly reduces the amount of trenching required, by essentially "stuffing" more pipe into less trench space. 
Vertical loop systems consist of four to five loops inserted in vertically drilled holes of approximately 6 inches in diameter. As much as 500 square feet of footprint area are required for the installation. Hole depths range from 60 to 200 feet with approximately 250 to 450 feet of piping needed per ton of heat pump capacity. (EPA, 1993)

The indoor mechanical equipment of a ground-source system consists of a fan coil unit (with indoor coil), a compressor, and a circulation pump for the ground loop. As with air-source heat pump systems, ground-source systems can employ single-speed, two-speed, or variable-speed compressors and fan motors. EPRI is currently sponsoring the research and development of a variable-speed system (Kavanaugh, 1993). Several manufacturers already offer two-speed and single-speed systems.

Integrated systems provide water heating in addition to space conditioning. Water heating is provided by the use of either a desuperheater or a dedicated water-to-refrigerant heat exchanger. Those systems employing a desuperheater can only satisfy a small portion of the water-heating load. Electric resistance coils are used as the primary source of heat. Systems using a dedicated heat exchanger can satisfy a majority of the water-heating requirements. Auxiliary electric resistance heat is used sparingly.

Energy Use and Cost. Ground-source closed-loop heat pumps are currently rated with ARI standard 330-90. Cooling efficiency (EER) and capacity are rated at $77^{\circ} \mathrm{F}$ entering fluid temperature. Heating COP and capacity are rated at $32^{\circ} \mathrm{F}$ entering fluid temperature. It is important to note that the EER and COP efficiencies should not be universally applied as seasonal efficiencies. Cyclic losses and auxiliary heating penalties are not included. In addition, the entering fluid temperatures are only for cold-climate systems (Kavanaugh, 1992).

Rather than rely on the steady-state performance ratings from ARI 330-90, we used one manufacturer's calculated seasonal performance ratings. Seasonal performance ratings were based on installations for a typical 1500 square foot residence in St. Louis, Missouri. Both the size and location of the residence were assumed to be representative of average home sizes and average climatic conditions in the U.S. The manufacturer's energy-use calculations were performed with an "in-house" developed computer simulation model (Meyer, 1993).

Table 5.11 provides the efficiency ratings, site UECs, installed costs, and payback periods for two-speed and single-speed ground-source systems. For a discussion on the formulation of the unit energy consumptions and payback periods, refer to Appendix 5.2. Total installed costs for the systems were provided by the same manufacturer that performed the energy-use calculations (Meyer, 1993). The total installed cost is based on a conventional horizontal ground-loop installation. 


\section{Table 5.11 Efficiencies, UECs, Costs and Paybacks for Ground-Source Heat Pumps}

\begin{tabular}{llccccccc} 
Speeds & Type & DHW Type & $\begin{array}{c}\text { Heat Eff } \\
\text { avg COP }\end{array}$ & $\begin{array}{c}\text { Cool Eff } \\
\text { avg EER }\end{array}$ & $\begin{array}{c}\text { DHW Eff } \\
\text { avg COP }\end{array}$ & $\begin{array}{c}\text { Site UEC } \\
k W h \text { lyr }\end{array}$ & $\begin{array}{c}\text { Installed } \\
\text { Cost }\end{array}$ & $\begin{array}{c}\text { Payback } \\
\text { years }\end{array}$ \\
\hline 2-speed & Space cond. & - & 3.81 & 17.60 & - & 3,862 & $\$ 7,192$ & 16 \\
1-speed & Space cond. & - & 3.40 & 13.80 & - & 4,518 & $\$ 6,552$ & 17 \\
2-speed & Integrated & Dedicated HX & 3.56 & 15.20 & 3.01 & 5,626 & $\$ 7,662$ & 11 \\
1-speed & Integrated & Desuperheater & 3.33 & 13.60 & 1.76 & 6,969 & $\$ 6,872$ & 16 \\
\hline
\end{tabular}

Because a majority of U.S. heat pump installations are in the southern region of the country, it is important to compare UECs for heat pumps installed in the south as opposed to a climate representing national average weather conditions. Table 5.12 provides the variations in the equipment efficiencies, UECs, installed costs, and payback periods for a southern climate (Atlanta). Variations in efficiency were determined from EPA reported values. (EPA, 1993) UEC variations were determined using the calculation procedure outlined in Section 5.1. Because the UEC is contingent on the system it is replacing and since ground-source heat pumps are marketed to replace either standard air-source heat pumps or gas furnace and electric air conditioner systems, two UEC values are reported for each ground-source heat pump technology. The two reported UEC values were calculated based on the assumption that all new shipments of the conventional technology (i.e., standard heat pumps or gas furnace/standard air conditioner systems) would be replaced by the new technology. The new installed costs and payback periods in Table 5.12 have been adjusted to reflect a mature market (i.e., higher production volumes) and to account for the lower cost for installing a system in the South (EPA, 1993). The mature market costs are based on reducing the cost of installation (i.e., cost associated with laying the ground-loop) by one-half (from $\$ 1800$ to $\$ 900$ ). This reduction is based on the assumption that installation contractors in a mature market will be able to streamline their operations and reduce their costs. 
Table 5.12 Efficiencies, UECs, Costs and Paybacks for Ground-Source Heat Pumps, South Region

\begin{tabular}{|c|c|c|c|c|c|c|c|c|}
\hline Speeds & Type & $\begin{array}{l}\text { Heat Eff } \\
\text { avg } C O P\end{array}$ & $\begin{array}{l}\text { Cool Eff } \\
\text { avg EER }\end{array}$ & $\begin{array}{c}\text { DHW Eff } \\
\text { avg } C O P\end{array}$ & $\begin{array}{c}\text { Replaced } \\
\text { System }\end{array}$ & $\begin{array}{c}\text { Site UEC } \\
k W h / y r\end{array}$ & $\begin{array}{l}\text { Mat. Mkt } \\
\text { Inst. } \\
\text { Cost } \\
\end{array}$ & $\begin{array}{c}\text { Payback } \\
\text { years }\end{array}$ \\
\hline 2-speed & Space cond. & 4.21 & 16.72 & - & $\begin{array}{l}\text { Elec Heat Pump } \\
\text { Gas Fur/Elec AC }\end{array}$ & $\begin{array}{l}4,203 \\
3,901\end{array}$ & $\$ 5,936$ & $\begin{array}{l}13 \\
11\end{array}$ \\
\hline 1-speed & Space cond. & 3.76 & 13.11 & - & $\begin{array}{l}\text { Elec Heat Pump } \\
\text { Gas Fur/Elec AC }\end{array}$ & $\begin{array}{l}4,973 \\
4,628\end{array}$ & $\$ 5,318$ & $\begin{array}{l}13 \\
10\end{array}$ \\
\hline 2-speed & Integrated & 3.94 & 14.44 & 3.01 & $\begin{array}{l}\text { Elec HP + Elec WH } \\
\text { Furn/AC + Gas WH }\end{array}$ & $\begin{array}{l}6,031 \\
5,704\end{array}$ & $\$ 6,379$ & $\begin{array}{l}7 \\
9\end{array}$ \\
\hline 1-speed & Integrated & 3.68 & 12.92 & 1.81 & $\begin{array}{l}\text { Elec HP + Elec WH } \\
\text { Furn/AC + Gas WH }\end{array}$ & $\begin{array}{l}7,361 \\
7,009\end{array}$ & $\$ 5,619$ & $\begin{array}{c}7 \\
10\end{array}$ \\
\hline
\end{tabular}

For this report, we selected one system to represent each type of ground-source heat pump system (i.e., one system selected for space-conditioning equipment only and another selected for integrated equipment). Based on their cost effectiveness at providing national energy savings, the two-speed space-conditioning and integrated systems were selected. (Variable-speed ground-source systems were not considered because they are not yet commercially available.)

Barriers to Implementation. The primary barrier to implementation seems to be the system's high installed cost. But because of the potential that exists for shaving high summer peak loads through the use of ground-source heat pumps, many utilities are seriously considering rebate programs and other financial incentives to promote this technology. But a high installed cost is not the only barrier. The infrastructure for servicing the equipment is not yet firmly in place. Because ground-source heat pumps have a low market penetration, consumers are unaware of the system's performance and might not want to purchase a seemingly untested technology. The large land area needed to install the equipment might prevent consumers from considering ground-source heat pumps as a space-conditioning option.

\subsubsection{Air-Source Heat Pumps and Integrated Appliances}

Present Status. The most efficient air-source heat pumps are the variable-speed and two-speed models. Variable-speed heat pumps employ electronically commutated motors (ECM) (also referred to as brushless permanent magnet motors). These motors are more efficient than the induction motors used in single-speed systems. In addition, the speed of the ECMs can be varied to match 
system capacity more precisely to a building load, and thus, to improve system efficiency by significantly reducing cycling losses. Because ECMs retain their efficiency at low speeds (unlike induction motors), energy use is also significantly reduced at low-load conditions.

Two-speed heat pumps, like variable-speed models, are also capable of reducing cycling losses. By employing two-speed induction motors to drive the compressor and fans, the system can operate at two distinct capacities. Cycling losses are reduced because the heat pump can operate at a low speed to meet low building loads. In some models, two-speed compressors are coupled with variable-speed indoor blowers to improve system efficiency further.

Two heat pump manufacturers, Carrier and Trane, currently offer variable-speed heat pump models. Carrier offers models with cooling capacities of 2 and 3 tons. Models with cooling capacities of 2.5, 3,4 , and 5 tons are offered by Trane. Two-speed heat pump models are offered by both Carrier and Lennox (another heat pump manufacturer) in 3-, 4-, and 5-ton cooling capacities.

EPRI and Carrier have co-sponsored the development of a variable-speed integrated heat pump that provides water heating in addition to space conditioning. The integrated heat pump model was marketed by Carrier under the trade name HydroTech 2000 . The heat pump provided almost all water heating needs through the use of a tube-in-tube heat exchanger (EPRI, 1991). Due to low sales volumes, Carrier removed the HydroTech 2000 from the market in January 1993. The HydroTech 2000 was offered in 2- and 3-ton cooling capacities.

EPRI also co-sponsored the development of a single-speed integrated heat pump with Nordyne Corp. Nordyne currently markets two different models of single-speed integrated heat pumps under the Powermiser trade name. Both models are offered in 2-, 3-, and 4-ton cooling capacities.

Energy Use and Cost. Efficiency ratings for air-source heat pumps are SEER for cooling and HSPF for heating. These are seasonal efficiency ratings and are meant to represent more accurately the seasonal performance of the heat pump. Currently the DOE does not have an official test procedure for rating integrated air-source heat pumps. Work has been on-going at the National Institute of Standards and Technology (NIST) to develop one. Without a specific test procedure for integrated systems, the individual functions of the system are tested with the appropriate test procedure. The space-conditioning performance is rated in accordance with the DOE test procedure for heat pumps, while the water-heating performance is tested in accordance with the DOE test procedure for water heaters.

Table 5.13 provides the efficiency ratings, site unit energy consumptions, installed costs and payback periods of various variable-speed, two-speed, and integrated heat pumps. For a discussion on the formulation of the unit energy consumptions and payback periods, refer to Appendix 5.2. For each manufacturer listed in the table, the ratings of both the high-efficiency model and the average of the entire model line are reported. The fourth to last column in the table reports the efficiency ratings that were chosen to represent the particular technology for this analysis. With regard to variable-speed heat pumps, the most efficient model on the market was chosen as being representative for the technology. Based on discussions with manufacturers, indications are that 
current variable-speed systems can be optimized to yield even higher efficiencies. Thus, the most efficient model was chosen as being the most representative of the technology.

Installed costs for the variable-speed, two-speed, and variable-speed integrated systems were provided by a manufacturer (Swan, 1993). The installed cost of the single-speed integrated system was based on estimates from contractors.

Table 5.13 Efficiencies, UECs, Costs and Paybacks of Air-Source Heat Pumps

\begin{tabular}{|c|c|c|c|c|c|c|c|c|c|c|c|c|}
\hline \multirow[b]{2}{*}{ System } & \multirow[b]{2}{*}{ Rate } & \multicolumn{2}{|c|}{ Carrier } & \multicolumn{2}{|c|}{ Trane } & \multicolumn{2}{|c|}{ Lennox } & \multirow{2}{*}{$\frac{\text { Nordyne }}{\text { Avg }}$} & \multirow[b]{2}{*}{ Select } & \multirow{2}{*}{$\begin{array}{c}\text { Site UEC } \\
k W h y r\end{array}$} & \multirow{2}{*}{$\begin{array}{c}\text { Install } \\
\text { Cost }\end{array}$} & \multirow{2}{*}{$\begin{array}{c}\text { Payback } \\
\text { years }\end{array}$} \\
\hline & & $\mathbf{H i}$ & Avg & $\overline{\mathrm{Hi}}$ & Avg & $\mathrm{Hi}$ & Avg & & & & & \\
\hline Var.- & $\overline{\text { SEER }}$ & 16.0 & 15.4 & 16.4 & 15.0 & - & - & - & 16.4 & 4,675 & $\$ 7,500$ & 25 \\
\hline Speed & HSPF & 10.2 & 9.5 & 8.7 & 8.9 & - & - & - & 10.2 & & & \\
\hline Two- & SEER & 16.0 & 14.0 & - & - & 14.9 & 13.5 & - & 15.0 & 5,245 & $\$ 5,500$ & 20 \\
\hline Speed & HSPF & 9.0 & 8.0 & - & - & 8.6 & 8.4 & - & 9.0 & & & \\
\hline Var.- & SEER & 14.1 & - & - & - & - & - & - & 14.1 & 7,148 & $\$ 10,500$ & 44 \\
\hline Speed & HSPF & 9.05 & - & - & - & - & - & - & 9.05 & & & \\
\hline Int. & COP & 2.40 & - & - & - & - & - & - & 2.40 & & & \\
\hline Single- & SEER & - & - & 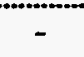 & - & - & - & 12.0 & 12.0 & 7,955 & $\$ 6,450$ & 81 \\
\hline Speed & HSPF & - & - & - & - & - & - & 8.0 & 8.0 & & & \\
\hline Int. & $\mathrm{COP}$ & - & - & - & - & - & - & 2.35 & 2.35 & & & \\
\hline
\end{tabular}

Because a majority of U.S. heat pump installations are in the South, we chose to compare heat pump UECs, as shown in Table 5.14, based on a southern climate rather than the national average. Variations in efficiency were determined from EPA reported values. (EPA, 1993) The same assumptions that were used to develop efficiency and UEC regional variations for ground-source heat pumps were also applied to air-source heat pumps. The new installed costs and payback periods in Table 5.14 have been adjusted to reflect a mature market (i.e.. higher production volumes) and to account for the lower cost for installing a system in the South (EPA, 1993). The mature market installed cost reductions are based on the percentage reductions in the total installed costs for ground-source systems. The variable-speed airsource, 2-speed air-source, integrated variable-speed air-source and integrated single-speed air-source systems have the same percentage reductions as the 2-speed ground-source, single-speed ground-source, integrated 2-speed ground-source and integrated single-speed ground-source systems, respectively. 


\section{Table 5.14 Efficiencies, UECs, Costs and Paybacks for Air-Source Heat Pumps, South}

Region

\begin{tabular}{|c|c|c|c|c|c|c|c|c|}
\hline Speeds & Type & $\begin{array}{c}\text { Heat Eff } \\
H S P F \\
\end{array}$ & $\begin{array}{c}\text { Cool Eff } \\
\text { SEER } \\
\end{array}$ & $\begin{array}{c}\text { DHW Eff } \\
C O P \\
\end{array}$ & $\begin{array}{c}\text { Replaced } \\
\text { System }\end{array}$ & $\begin{array}{c}\text { Site UEC } \\
k W h / y r\end{array}$ & $\begin{array}{l}\text { Mat. Mkt } \\
\text { Inst. Cost }\end{array}$ & $\begin{array}{c}\text { Payback } \\
\text { years }\end{array}$ \\
\hline Var-spd & Space cond. & 10.74 & 15.73 & - & $\begin{array}{l}\text { Elec Heat Pump } \\
\text { Gas Fur/Elec AC }\end{array}$ & $\begin{array}{l}5,162 \\
4,770\end{array}$ & $\$ 4,979$ & $\begin{array}{c}13 \\
9\end{array}$ \\
\hline 2-speed & Space cond. & 9.48 & 14.39 & - & $\begin{array}{l}\text { Elec Heat Pump } \\
\text { Gas Fur/Elec AC }\end{array}$ & $\begin{array}{l}5,778 \\
5,336\end{array}$ & $\$ 3,823$ & $\begin{array}{l}9 \\
3\end{array}$ \\
\hline Var-spd & Integrated & 10.22 & 13.31 & 2.64 & $\begin{array}{l}\text { Elec HP + Elec WH } \\
\text { Furn/AC + Gas WH }\end{array}$ & $\begin{array}{l}7,327 \\
6,910\end{array}$ & $\$ 7,209$ & $\begin{array}{l}10 \\
18\end{array}$ \\
\hline 1-speed & Integrated & 9.03 & 11.33 & 2.58 & $\begin{array}{l}\text { Elec HP + Elec WH } \\
\text { Furn/AC + Gas WH }\end{array}$ & $\begin{array}{l}8,201 \\
7,727 \\
\end{array}$ & $\$ 4,563$ & $\begin{array}{l}5 \\
6 \\
\end{array}$ \\
\hline
\end{tabular}

For this report one system was selected to represent each type of air-source heat pump system (i.e., one system selected for space-conditioning only equipment and another system selected for integrated equipment). Based on their cost effectiveness at providing national energy savings, the variable-speed systems were selected.

Barriers to Implementation. The primary obstacle for the implementation of variable-speed and two-speed systems is their high installed cost. Proper servicing of the equipment also seems to be a barrier. These systems are generally "loaded" with electronics and service technicians are usually not knowledgeable about properly servicing them. Problems with the systems tend to be blamed initially on the electronics. Maintenance costs are significantly increased when replacement of electronics does not solve the problem.

\subsection{Evaporative CoOlng}

Evaporative coolers are an energy-saving alternative to air conditioning suited to arid to moderately humid climates. Since they only require power to drive fans and pumps, evaporative coolers consume much less electricity than conventional air conditioners. For evaporative coolers, the technology options considered in detail are listed following. The technologies are part of the top 16 advanced technologies presented in Table 5.4.

1. Single-Stage Direct Evaporative Coolers

2. Two-Stage Indirect/Direct Evaporative Coolers 
2. Two-Stage Indirect/Direct Evaporative Coolers

\subsubsection{Single-Stage Direct Evaporative Coolers}

Present Status. By drawing fresh outside air through wet and porous pads, single-stage direct evaporative systems cool air by directly evaporating water into it. Heat in the air is transferred to the water and evaporates some portion of it. Here, adiabatic heat transfer occurs as the sensible heat in the air is converted into latent heat in the form of water vapor entering the air. In other words, the temperature of the air is reduced but its relative humidity is increased. The temperature of the air is lowered to approximately $90 \%$ of the original wet-bulb depression. (The wet-bulb depression is the difference between outdoor dry-bulb and wet-bulb temperatures.) The resulting "washed air" is then blown through rooms or spaces at three to eight times the air flow rate of conventional air conditioning. Because the "washed air" has a high relative humidity, it cannot be recirculated through a return air system and must be discharged through partially opened windows or special exhaust systems.

Inexpensive drip-type direct evaporative coolers are common throughout low-humidity areas of the U.S. (primarily the West and the Southwest). Direct coolers are available in models for roof mounting or window installation. Roof-mounted units are larger in capacity than window-installed models and are designed to provide cooling to an entire house. Roof units use a duct system to convey conditioned air, while window units, like room air conditioners, blow air directly into the space. Direct coolers with modern rigid-media pads have recently entered the market and should save more energy than the original drip-type units.

Energy Use and Cost. Direct evaporative coolers are restricted to low-humidity areas of the U.S. In damper areas, high wet-bulb temperatures create "washed air" that is too warm to provide comfort at reasonable room air velocities. For this analysis, we assumed that areas with design wet-bulb temperatures of $68^{\circ} \mathrm{F}$ or less were suitable for direct coolers. The entire West census region of the U.S. (as defined by the Energy Information Administration) was assumed to meet this criteria.

Discussions with researchers and manufacturers indicated that direct evaporative coolers consume 75\% less energy than standard efficiency vapor-compression air-conditioning equipment (Morse, 1993). This estimate is applicable to both roof-mounted and window-installed direct coolers.

Installed costs for roof-mounted systems were obtained through a direct evaporative cooler manufacturer (Montini, 1993). Installed costs used for this analysis were an average between those costs applicable to new and existing homes. Because direct coolers use higher air-flow rates than conventional air-conditioning systems, traditional duct systems must be re-designed. The installed costs assumed for existing homes include the additional costs to re-design existing duct systems. New homes are assumed to incur only slightly higher costs for re-design since duct systems are assumed to be designed specifically with evaporative coolers in mind.

Installed costs for window-type direct coolers were obtained from the Sears and Roebuck Company 
(Sears, 1993). Installed costs, UECs and payback periods for direct evaporative coolers are provided in Table 5.15. Because the installed cost of evaporative cooling systems are lower than vapor-compression air-conditioning systems, the length of the payback period is zero. For a discussion on the formulation of the UECs and payback periods, refer to Appendix 5.2.

\section{Table 5.15 UECs, Costs and Paybacks for Direct Evaporative Coolers}

\begin{tabular}{lccc} 
System & $\begin{array}{c}\text { Site UEC } \\
(k W h / y r)\end{array}$ & $\begin{array}{c}\text { Installed } \\
\text { Cost }\end{array}$ & $\begin{array}{c}\text { Payback } \\
\text { (years) }\end{array}$ \\
\hline Window Direct Evap Coolers & 539 & $\$ 1663$ & 0 \\
Roof Mounted Direct Evap Cooler & 216 & $\$ 225$ & 0 \\
\hline
\end{tabular}

Barriers to Implementation. The primary barrier to implementation is geographic. Only areas with arid climates are suitable for direct evaporative coolers. In addition, consumer perception about the effectiveness of evaporative coolers to provide adequate space conditioning (compared to traditional vapor-compressor air conditioning) might also be a barrier.

\subsubsection{Two-Stage Indirect/Direct Evaporative Coolers}

Present Status. As its name implies, two-stage indirect/direct evaporative systems condition air by cooling it first indirectly and then directly. In indirect cooling, fresh outside air in streams termed "primary air" is cooled by thermal conduction from wet "secondary" airstreams in evaporatively cooled heat exchangers. This process separates the dry "primary" air from the evaporating water and resulting vapor, removing only sensible heat. Unlike direct evaporative cooling, the temperature of the "primary" air is reduced without adding humidity (latent heat). But since the indirect cooling stage can deliver conditioned air that seldom exceeds $80 \%$ of the wet-bulb depression, a direct cooling stage is incorporated. Direct evaporative cooling lowers the temperature of the "primary" air further, but humidity (latent heat) is added. Thus, indirect/direct cooling resembles simple direct cooling in that it delivers comparable high air-flow rates of "washed air."

Most modern indirect coolers use tubular or plate-type heat exchangers. In the former, "primary" air is usually drawn inside banks of dripping-wet tubes, while "secondary" air is drawn crosswise between and around them. In the second type, "primary" air is usually drawn through narrow parallel spaces inside multiple thin plates that are externally wet and subjected to "secondary" airflow. In either case, no water or secondary air contacts the "primary" air and non-adiabatic heat is transferred by conduction through tube or plate walls. Tube or plate walls are generally made of non-corroding polystyrene or polyvinyl chloride plastic rather than metal. 
Indirect/direct coolers are typically available in roof-mounted models and are designed to provide cooling to the entire house. Conditioned air is conveyed through a duct system.

Energy Use and Cost. Indirect/direct evaporative coolers can serve a more expansive area than direct coolers. Because of the indirect cooling stage, these systems can be used in moderately humid areas. For purposes of this analysis, we assumed that areas with design wet-bulb temperatures of $71^{\circ} \mathrm{F}$ or less were suitable for indirect/direct coolers. The entire Western census region, the entire Northeast region, and 75\% of the Midwest region of the U.S. (as defined by the Energy Information Administration) were assumed to meet this criteria.

Discussions with researchers and manufacturers indicated that indirect/direct evaporative coolers consume $75 \%$ less energy than minimum efficiency vapor-compression air-conditioning equipment. (Morse, 1993)

Installed costs were obtained through an indirect/direct evaporative cooler manufacturer (Montini, 1993). Installed costs used for this analysis were an average between those costs applicable to new and existing homes. As with direct cooling systems, because indirect/direct coolers use higher airflow rates than conventional air-conditioning systems, traditional duct systems must be re-designed. The installed costs assumed for existing homes include the additional costs to re-design existing duct systems. New homes are assumed to incur slightly higher costs for re-design since duct systems are assumed to be designed specifically with evaporative coolers in mind.

Installed costs, payback periods and site UECs for indirect/direct evaporative coolers are provided in Table 5.16. For a discussion on the formulation of the unit energy consumptions and payback periods, refer to Appendix 5.2.

Table 5.16 UECs, Costs and Paybacks for Indirect/Direct Evaporative Coolers

\begin{tabular}{lccc} 
System & $\begin{array}{c}\text { Site UEC } \\
(k W h / y r)\end{array}$ & Installed Cost & $\begin{array}{c}\text { Payback } \\
(k W h / y r)\end{array}$ \\
\hline Indirect/Direct Evap Coolers & 539 & $\$ 2901$ & 5 \\
\hline
\end{tabular}

Barriers to Implementation. The primary barrier to implementation is geographic. Only areas with relatively humid climates are suitable for direct evaporative coolers. In addition, consumer perception of the effectiveness of evaporative coolers to provide adequate space conditioning as compared to traditional vapor-compressor air conditioning might also be a barrier.

\subsection{National Service Improvement Program}

Residential HVAC service technicians are generally instructed to repair equipment without concerning themselves with whether the system is operating efficiently. Energy savings could be 
realized if systems were not only repaired to operate, but also to operate efficiently. A national service improvement program that properly trained HVAC service technicians could result in energy savings to the country. Such a program would have to include (1) a training program that provided initial and on-going training of service technicians to instruct them on the proper repair of HVAC systems and (2) a quality control program to monitor the on-job performance of service technicians to ensure that they are servicing equipment properly.

Training programs that emphasize the importance of energy savings do exist. The North Carolina Alternative Energy Corporation currently offers a one-week training program to technicians (Neal, 1993). This program emphasizes the need to repair systems correctly so that their clients will realize savings on their energy bills.

Quality control programs have been proposed to electric and gas utilities to ensure that technicians on the job will not forget how to implement what they have learned. One such program relies on a computer-based checking system that is administered by the utility (Proctor, 1993). Technicians are made to answer a survey on the status of the equipment before and after they service it. The technicians' survey data would be entered into a data entry computer program at the contractor's office. After the data are entered, they could be downloaded (over phone lines) to a utility's mainframe computer. Reports analyzing the performance of the service technician could be generated from the data. If the technician is performing poorly, an expert could re-instruct the technician on proper servicing techniques. The expert would most likely be dispatched from some type of energy service company that has a contract with the utility.

Energy Use and Cost. Energy savings estimates are based on the population of homes that could realize savings from proper servicing. Only those homes that use HVAC equipment frequently and also have high energy bills are considered. These homes are estimated to comprise $25 \%$ of the housing population. Of those homes, $50 \%$ have air-conditioning, heat-pump, or furnace systems that waste energy because of low air-flow problems, and $36 \%$ have air-conditioning or heat-pump systems that waste energy due to refrigerant overcharging (Proctor, 1992). It was estimated that 0.72 million homes annually have HVAC systems that can realize energy savings if repaired properly $^{6}$. Correcting the problems of low air flow results in $2 \%$ energy savings for air conditioners and heat pumps, while $1.9 \%$ savings are realized for furnaces. Correcting overcharging problems results in $10 \%$ energy savings for air conditioners and heat pumps (operating in the cooling mode only) (Proctor, 1993). Table 5.17 summarizes the energy savings that are achievable.

\footnotetext{
${ }^{6}$ Both existing equipment in the housing stock and new equipment shipments comprise the HVAC systems than can realize energy savings if repaired properly.

Stock equipment affected $=[($ A/C Stock + HP Stock $) * 25 \% *(50 \%+36 \%)] /$ Equipment Life $=0.51$ million A/C Stock $=36.2$ million; HP Stock $=6.4$ million; Equipment Life $=18$ years

Shipments affected $=[(1998 \mathrm{~A} / \mathrm{C}$ Ship $+1998 \mathrm{HP}$ Ship $) * 25 \% *(50 \%+36 \%)] *$ Percent Ship Affected $=0.21$ million A/C Shipments $=2.80$ million; HP Shipments $=0.54$ million; Percent Shipments Affected $=30 \%$
} 


\section{Table 5.17 UEC Savings and Homes Affected by HVAC Repair Options}

\begin{tabular}{llccccc} 
& Repair & \% Savings & \multicolumn{2}{c}{$\begin{array}{c}\text { Site UEC Savings } \\
\text { from Repair }\end{array}$} & $\begin{array}{c}\text { Homes Affected } \\
\text { Annually }\end{array}$ \\
\cline { 6 - 7 } System & Problem & from Repair & & $\boldsymbol{k}$ Wh/yr & MMBtu/yr & millions \\
\hline A/C + Furnace & Low Air Flow & $2.0 \%+1.9 \%$ & 43.1 & 1.18 & 0.36 \\
Air Conditioner & Overcharge & $10.0 \%$ & 215.7 & - & 0.26 \\
Heat Pump & Low Air Flow & $4.0 \%$ & 325.0 & - & 0.05 \\
Heat Pump & Overcharge & $10.0 \%$ & 812.5 & - & 0.06 \\
\hline
\end{tabular}

The cost to the consumer of a National Service Improvement Program is based on the additional time a service technician would need to spend to repair an HVAC system so that energy savings would be realized. It was estimated that a service technician would need to spend two additional hours in order to accomplish this. (Proctor, 1993) Based on typical servicing costs of $\$ 58$ per hour ${ }^{7}$, a consumer would spend an additional $\$ 116$ for a service call. This results in a payback period to the consumer of 6 years for having a national service improvement program instituted in the United States.

Barriers to Implementation. Currently, most technicians are burdened with providing eight to twelve service calls a day. Estimates put the duration of a call at two hours to service a system properly (i.e., so that it operates efficiently). Thus, with the current demands that technicians must handle, even properly trained technicians would find it impossible to provide quality energy-saving service. To have a successful national service improvement program, the financial incentive mechanisms must be structured so that technicians will be able to spend the time necessary to repair a system properly.

\subsection{Thermal Distribution Systems}

We discuss thermal distribution systems in general, then focus on the largest segment, ducted distribution systems to obtain values for technical potential energy savings and economic evaluation of new technologies.

The overall efficiencies of space conditioning systems must be characterized by not only the heating and cooling equipment efficiencies, but also by the efficiencies of their associated thermal distribution systems. Thermal distribution (TD) systems are the ducting and piping systems that distribute heating and cooling energy throughout a building. As an example of overall efficiency, a warm air furnace can be characterized as having an $80 \%$ efficiency (or AFUE), and its associated

\footnotetext{
${ }^{7}$ We calculated this as $\$ 43 / \mathrm{hr}$ plus a national average "showup" charge of $\$ 15$ based on an industry survey (ACHR News, 1991).
} 
ducting system is likely to have an efficiency of approximately 70\% (ASHRAE, 1992). The overall efficiency of the system, then, is $56 \%$.

TD systems can incur energy losses because of (1) conduction losses through duct walls (in ducted air systems) and pipes (in hot water and steam systems), and (2) leakage of air through the small holes and seams that exist in ducted air systems. Another loss mechanism (3), which probably characterizes more than $95 \%$ of residential systems, arises in single-zone TD systems. Single-zone systems, having only one thermostat, incur inefficiencies due to their inability to selectively heat or cool only the rooms needing heating or cooling. Thus, they always overheat or overcool some portion of a house. Finally (4), TD systems can degrade the efficiencies normally attributed to multi-capacity space conditioning equipment. With a multi or variable capacity unit, a thermally inefficient ducting system causes the unit to spend a longer time in its (high speed) low efficiency operation mode. Thus, the savings potential of going from single-capacity equipment to variablecapacity equipment is overstated if duct loss effects are ignored. While field measurements have not been made to date, simulations show that the efficiency improvements typically attributed to variable capacity equipment (that is, without accounting for duct inefficiencies) are potentially overstated by as much as $50 \%$ (Modera, 1994).

Andrews and Modera (1991) have studied current ducting and hydronic system efficiencies. Interpretations of their results are shown in Table 5.18. The first row of the table indicates that, out of about 5 quads used in 1990 to condition dwellings with TD systems, about 33\%, a total of 1.6 quads, was lost due to all TD system inefficiencies. This includes the inefficiencies due to single zone (non-perfect zoning) operation. The second row presents the potential savings using technologies that are presently available or being developed. The difference between the first two table rows $(1.6-1.1=0.5$ quads) reflects the fact that perfectly controlled multizone systems can not be approximated with technology presently being developed. The last row of the table ${ }^{8}$ presents technical potential savings assuming that ducts and piping in existing houses will not be moved to indoor spaces due to economic and practical limitations. Thus, duct and piping relocation is considered here as a near term (new housing) rather than a presently available technology. In new buildings, better approaches to initial design and construction have the potential to virtually eliminate heating and cooling distribution system losses. Technologies are available to design and build housing as an integrated system that takes into account requirements for space conditioning and includes proper placement of heating and cooling systems within the conditioned space. This "systems" approach allows smaller heating and cooling energy sources and distribution systems to be used, resulting in both energy and initial cost benefits.

8 Note that the measure "packages" presented in the different rows of Table 5.1 are not additive, but are alternatives to each other. For example, placing the distribution system within the conditioned space, listed in the second row, is an altemative to the measures for leakage and conduction reduction listed in the last row. 


\section{Table 5.18 Summary of Thermal Distribution Improvement Potentials}

\begin{tabular}{lcc}
\multicolumn{1}{c}{ Measures for Reducing Thermal Distribution Losses } & $\begin{array}{l}\text { Technical } \\
\text { Potential } \\
\text { (Quads) }\end{array}$ & $\begin{array}{c}\text { \% Savings of Space } \\
\text { Heating and Cooling } \\
\text { Energy Use }\end{array}$ \\
\hline $\begin{array}{l}\text { Elimination of all TD losses. (Requires perfect zoning.) } \\
\begin{array}{l}\text { Near term technologies for reducing TD losses. Includes total } \\
\text { relocation of ducts and piping to the internal spaces, and limited } \\
\text { amounts of zoning plus better control devices for steam and hot } \\
\text { water systems. }\end{array}\end{array}$ & 1.6 & 23 \\
$\begin{array}{l}\text { Presently available technologies for reducing TD losses. Includes } \\
\text { duct leakage sealing, duct and pipe insulation, limited amounts of } \\
\text { zoning, elimination of air flow restrictions due to closed internal } \\
\text { doors, lower temperature hot water distribution, and better control } \\
\text { devices for steam and hot water systems. }\end{array}$ & 0.65 \\
\hline
\end{tabular}

\subsubsection{Reduced-Leakage Ducting}

This section focuses on new leakage reduction technologies for ducting systems that are located outside the conditioned space. We focus on ducting (instead of piping) because more importance has been placed in recent years on duct efficiency assessment and efficiency improvement technologies. Total U.S. residential duct energy losses, at over 0.7 quads per year, are approximately seven times higher than the sum of steam and hot water system losses (Andrews and Modera, 1991, Table 44).

Estimated current duct losses, excluding those inefficiencies due to single-zone operation, are approximately one-quarter (23\%) of space conditioning energy used in ducted residential systems. Approximately half of these losses are due to thermal conduction through inadequate or non-existent thermal insulation. The other half, the leakage component, allows the leakage of unconditioned air into or out of the ducting and the consequent induction of outdoor unconditioned air into the residence, which creates additional thermal load for the space conditioning system.

We have chosen to analyze only new technologies for reducing the leakage component of losses, specifically reduced-leakage duct connection fittings (as applied to new duct installations) and ductsealing technology (applied as a retrofit measure to existing duct systems). While new technologies are being developed for reducing duct insulation costs (Modera, 1993), our initial assessment has been that new duct-sealing technologies represent a more significant departure from current technology and are therefore more appropriate to the scope of this study. At the time of this study, we also found the costs of the newer conduction-improvement technologies to be considerably less certain than duct-sealing technologies. Lawrence Berkeley Laboratory has recently received a multiyear grant to develop aerosol sealing technology and improved fittings. 
Present Status. We used the work of Andrews and Modera (1991) to determine present thermal losses due solely to existing ducts in residential buildings. In their analysis, all residences with TD systems are segmented into 9 system types or "cells", shown in Table 5.19. Each type or cell is assessed for potential savings. Table 5.20 presents an example of their results for two of the cells or system types.

\section{Table 5.19 Thermal Distribution Types Used in Andrews and Modera (1991).}

\begin{tabular}{cl} 
Cell & \multicolumn{1}{c}{ Description } \\
\hline A & Existing single-family, ducts in unconditioned space, sunbelt \\
B & New single-family, ducts in unconditioned space, sunbelt \\
C & Existing plus new single-family, ducts in part-conditioned space, sunbelt \\
D & Existing plus new multi-family, all ducted locations, sunbelt \\
E & Existing plus new single-family, hydronic system in all locations, frostbelt \\
F & Existing plus new single-family, ducts in part-conditioned space, frostbelt \\
G & Existing plus new single-family, ducts in unconditioned space, frostbelt \\
H & Existing plus new multi-family, all ducted locations, frostbelt \\
I & Existing multi-family, hydronic system in all locations, frostbelt \\
\hline
\end{tabular}


Table 5.20 Available Savings for Two Types of Distribution Systems

\begin{tabular}{|c|c|c|c|c|}
\hline \multirow[b]{2}{*}{ System Type or "Cell" } & \multicolumn{2}{|c|}{$\begin{array}{l}\text { Upgrade to R-8 insulation, } \\
50 \% \text { Sealed Leaks }\end{array}$} & \multicolumn{2}{|c|}{$\begin{array}{l}\text { Upgrade to Perfect Insulation, } \\
100 \% \text { Sealed Leaks }\end{array}$} \\
\hline & $\begin{array}{c}\text { Savings } \\
\text { Technical } \\
\text { Potential } \\
\text { (Quads) } \\
\end{array}$ & $\begin{array}{c}\% \text { Savings of } \\
\text { Space Htg and } \\
\text { Clng Energy Use } \\
\end{array}$ & $\begin{array}{l}\text { Savings } \\
\text { Technical } \\
\text { Potential } \\
\text { (Quads) } \\
\end{array}$ & $\begin{array}{c}\text { \% Savings of } \\
\text { Space Htg and } \\
\text { Clng Energy Use } \\
\end{array}$ \\
\hline $\begin{array}{l}\text { isting Single-Family, Forced } \\
\text { ir Ducts in Unconditioned } \\
\text { ace, Sunbelt }\end{array}$ & 0.23 & $17 \%$ & 0.49 & $35 \%$ \\
\hline $\begin{array}{l}\text { isting Single-Family, Forced } \\
\text { ir Ducts in Uncon-ditioned } \\
\text { ace, Frostbelt }\end{array}$ & 0.11 & $17 \%$ & 0.27 & $35 \%$ \\
\hline$A L$ & 0.34 & & 0.76 & \\
\hline
\end{tabular}

The far right column of Table 5.20 expresses total duct loss as a percentage of total space conditioning energy consumption. We used these percentage values for the seven ducted system cells for further calculations. First, we calculated the population-weighted average duct loss as 23\% of space-conditioning energy for ducted systems. We then used the general guidelines (per Modera, 1993) that (1) duct losses are about equally split between conduction and leakage; and (2) Duct sealing either by aerosol sealants (retrofit) or new fittings can be expected to achieve about $80 \%$ sealing of existing and new home leakages. Application of these guidelines yielded the conclusion that $37 \%$ of the duct thermal losses for both current practice construction and existing ductwork can be eliminated by using leakage-improved fittings for new construction and by using aerosol sealant technology for existing ducts. Again, we emphasize that these measures do not include any savings due to insulation improvements.

Energy Use and Cost. Table 5.21 presents our energy consumption and cost values for evaluating the economics of improved duct-leakage technology. We segmented all ducted systems by the equipment types specified in the table, assuming that the cell types listed above are equally distributed among the equipment types..

The house populations in Table 5.21 are taken from the Residential Energy Consumption Survey of the EIA (Housing Characteristics, 1990, 1992), while the heating and cooling UEC values are derived from the LBLREM residential forecast model. The national energy-savings values, based on conversion of all existing (1990) housing, were obtained by multiplying 1990 populations times the $37 \%$ savings of the $23 \%$ losses. The $37 \%$ and $23 \%$ values were derived as described above, and apply to existing (and new) construction. 
Tentative conclusions from work at LBL are that the $37 \%$ savings described can be achieved at a cost of about $\$ 200$ to $\$ 300$ per house, whether aerosol sealing is used (existing construction) or new fittings are used in new construction (Modera, 1993). In the calculations in Table 5.21, we use an average of $\$ 250$ per house as the cost of all leakage-improvement work.

\section{Table 5.21 Energy Consumption and Savings for Duct Leakage Improvements}

\begin{tabular}{|c|c|c|c|c|c|c|c|}
\hline Type of House & $\begin{array}{c}1990 \\
\text { Population } \\
\text { (Millions) }\end{array}$ & $\begin{array}{c}\text { Heating } \\
\text { Source } \\
U E C \\
(M M B t u / y r)\end{array}$ & $\begin{array}{c}\text { Cooling } \\
\text { Source } \\
\text { UEC } \\
\text { (MMBtu/yr) }\end{array}$ & $\begin{array}{l}\text { Yearly Duct Loss } \\
\text { Savings Per } \\
\text { House with 37\% } \\
\text { Savings of } 23 \% \\
\text { Losses } \\
\text { (\$) }\end{array}$ & $\begin{array}{l}\text { National } \\
\text { Source } \\
\text { Energy } \\
\text { Savings } \\
\left(10^{12} \text { Btulyr }\right)\end{array}$ & $\begin{array}{c}\text { Total } \\
\text { US } \\
\text { Savings } \\
\text { (Milln \$) }\end{array}$ & $\begin{array}{c}\text { Payback } \\
\text { at } \$ 250 \\
\text { Cost per } \\
\text { House }\end{array}$ \\
\hline $\begin{array}{l}\text { Gas Central } \\
\text { Furn./AC }\end{array}$ & 22 & 58.2 & 27.7 & 52 & 161 & 1145 & 4.8 \\
\hline $\begin{array}{l}\text { Elec Central } \\
\text { Furn./AC }\end{array}$ & 5 & 35.1 & 27.7 & 40 & 27 & 202 & 6.2 \\
\hline $\begin{array}{l}\text { Oil Central } \\
\text { Furn./AC }\end{array}$ & 2.4 & 89.2 & 27.7 & 79 & 24 & 189 & 3.2 \\
\hline $\begin{array}{l}\text { Gas Central } \\
\text { Furn. }\end{array}$ & 12.9 & 58.2 & 0 & 34 & 64 & 441 & 7.3 \\
\hline $\begin{array}{l}\text { Elec Central } \\
\text { Furn. }\end{array}$ & 2.4 & 35.1 & 0 & 23 & 7 & 54 & 11.1 \\
\hline $\begin{array}{l}\text { Oil Central Furn. } \\
\text { Heat Pump }\end{array}$ & $\begin{array}{l}2 \\
6.4 \\
\end{array}$ & $\begin{array}{l}89.2 \\
28.3 \\
\end{array}$ & $\begin{array}{c}0 \\
29.1 \\
\end{array}$ & $\begin{array}{l}61 \\
37 \\
\end{array}$ & $\begin{array}{l}15 \\
31 \\
\end{array}$ & $\begin{array}{r}121 \\
236 \\
\end{array}$ & $\begin{array}{l}4.1 \\
6.8 \\
\end{array}$ \\
\hline Total/ Summary & 53.1 & & & & 329 & 2388 & 6.0 \\
\hline
\end{tabular}

The values in the last row of Table 5.21 are summations and summary values. The payback value in the last column was derived as a shipment-weighted average of the paybacks for all the house types.

To calculate the technology-ranking index for ducts to be compatible with the ranking index used in Appendix 5.2, we needed to calculate source energy savings based on 1998 shipments as opposed to the 1990 population, as calculated in the previous table. To do this, we assumed, as the technical potential, that new leakage-reducing fittings would be used for all new duct systems installed in the year 1998, and that aerosol sealing would be used to upgrade existing duct systems for all equipment replacements in the same year. Under this assumption, the technical potential for the number of duct systems upgraded in 1998 simply becomes the total number of shipments of ducted spaceconditioning equipment for that year. From LBLREM we obtained the total shipments of heat pumps, $\mathrm{AC}$ units, and gas, oil, and electric furnaces as 6.84 million units. Using this value, we assumed that the total potential savings based on 1998 shipments would be proportional to the savings based on 1990 system populations. Therefore, we calculated $329 \times(6.84 / 53.1)=42.7$ (in units of $10^{12} \mathrm{Btus} / \mathrm{yr}$ ) as the 1998 shipment-based potential national energy savings. 
Given this new energy savings value, we calculated the technology-ranking index for leakagereducing ducts as

$$
\text { Ranking Index }=\frac{(\text { UEC savings }) \times(1998 \text { Shipments })}{\text { Payback }}=\frac{42.7}{6.0}=7.1
$$

Barriers to Implementation. Technical as well as deployment barriers must be overcome if reducedleakage ducting as a technology is to realize its potential for energy savings. First, the projected costs per house must be achieved in actuality by new fittings and application techniques for aerosol sealants. Second, since both aerosol and new fitting technologies will require training of installation technicians, a private or nationally funded training program will have to be undertaken. Third, consumer education, DSM programs, and other stimulus techniques will be required to overcome the information and first-cost barriers existent in other technologies. Fourth, building codes issues will have to be addressed, and code official training might be required. Fifth, the absence at present of suitable efficiency standards for thermal distribution components and systems makes it difficult to justify the development of new technologies and products that are more efficient. The present development of an ASHRAE standard for TD efficiency will help to stimulate these improvements.

\subsection{Discussion OF NATIONAL ENERgy SAVINGS}

Figures 5.1 through 5.7 depict the annual energy use for space-conditioning appliances over the time period 1995-2015. Each figure depicts the annual energy use for a particular set of spaceconditioning technologies: Figure 5.1 depicts gas heat pump technology options; Figure 5.2, gasintegrated heat pump technology options; Figure 5.3, oil heat pump technology options; Figure 5.4, oil furnace technology options; Figure 5.5, electric heat pump technology options; Figure 5.6, electric integrated heat pump technology options; and Figure 5.7 depicts evaporative cooler technology options. For each figure, a base case and various technology options are shown for technical and economic potential cases (see Chapter 1 for details concerning these two cases). In the base case, retiring space-conditioning appliances are replaced with models that have an efficiency equal to that required by the existing DOE standards. For each technology option, each option is replaced with models that have an efficiency equal to that of the specific technology. The market penetrations for the economic potential cases are obtained from the market penetration curve shown in Chapter 1 (Figure 1.1). Penetration rates are a function of simple payback periods. With the exception of absorption oil heat pumps (Figure 5.3), the technical potential (100\%) is significantly greater than the economic potential for each technology evaluated. The economic potential is determined assuming no policy actions (additional efficiency standards, rebates, etc.) are introduced to transform the marketplace. 


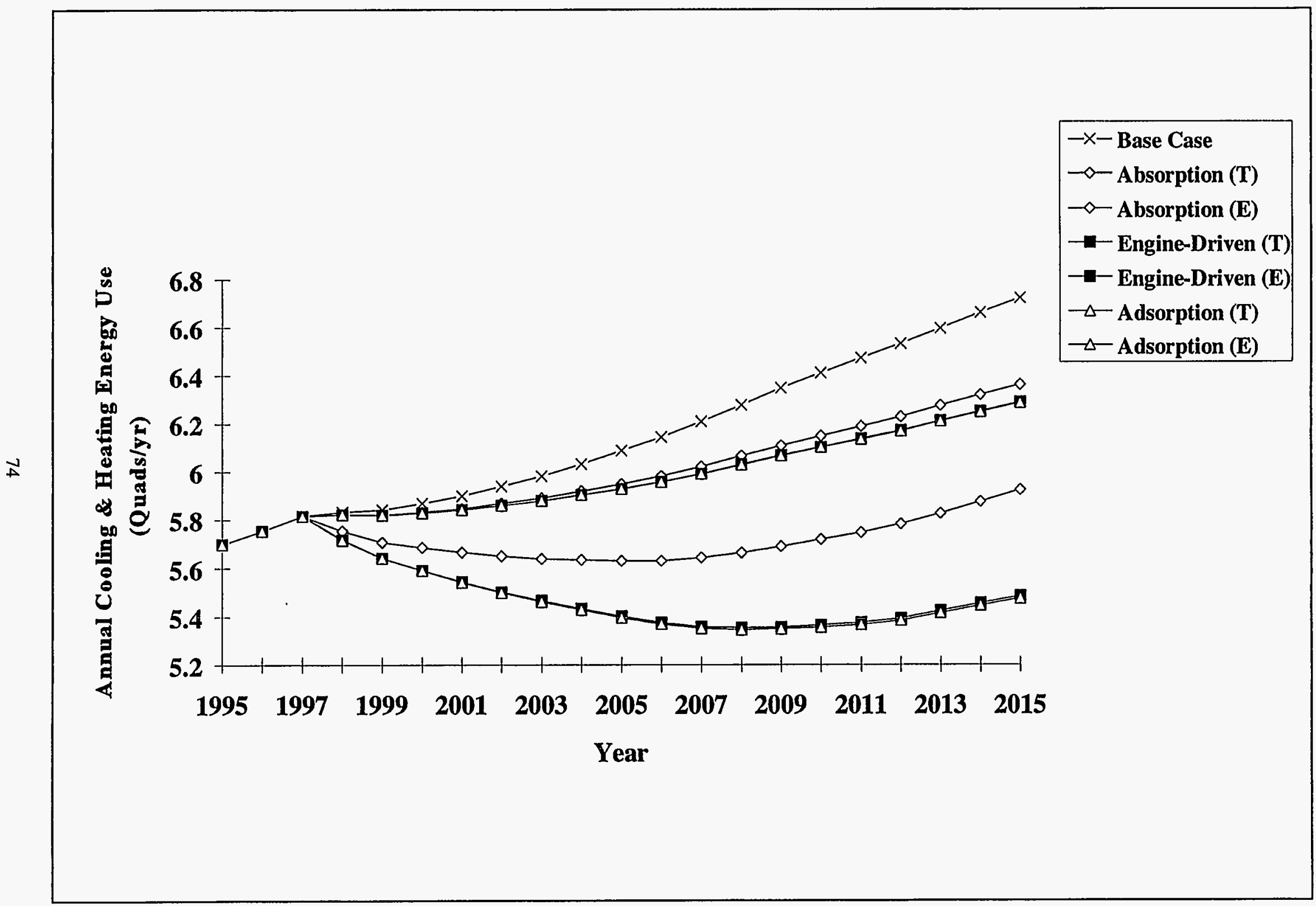

Figure 5.1 Annual Energy Use for Technology Options: Gas Heat Pump 


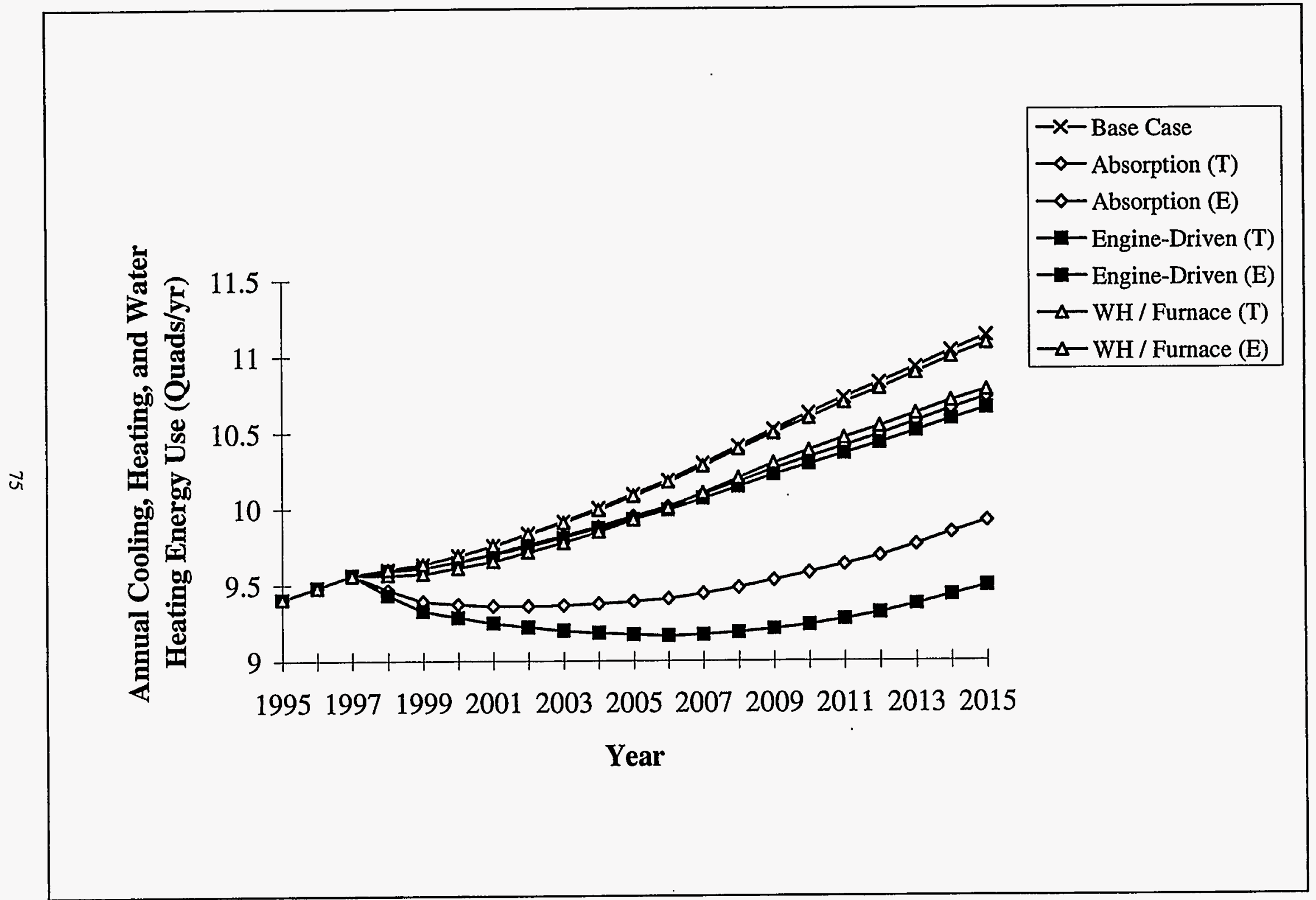

Figure 5.2 Annual Energy Use of Technology Options: Integrated Gas Heat Pumps 


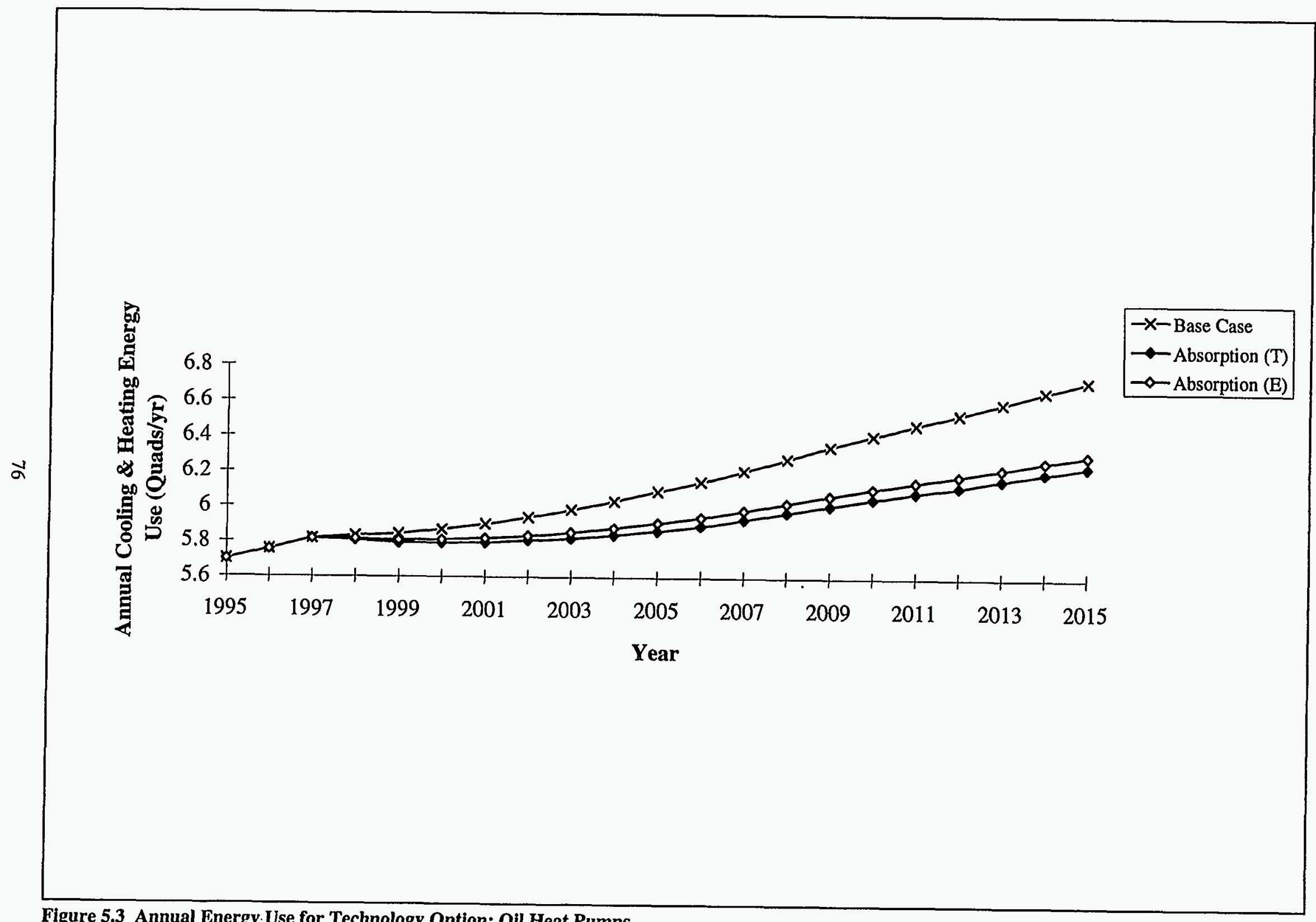

Figure 5.3 Annual Energy. Use for Technology Option: Oil Heat Pumps 


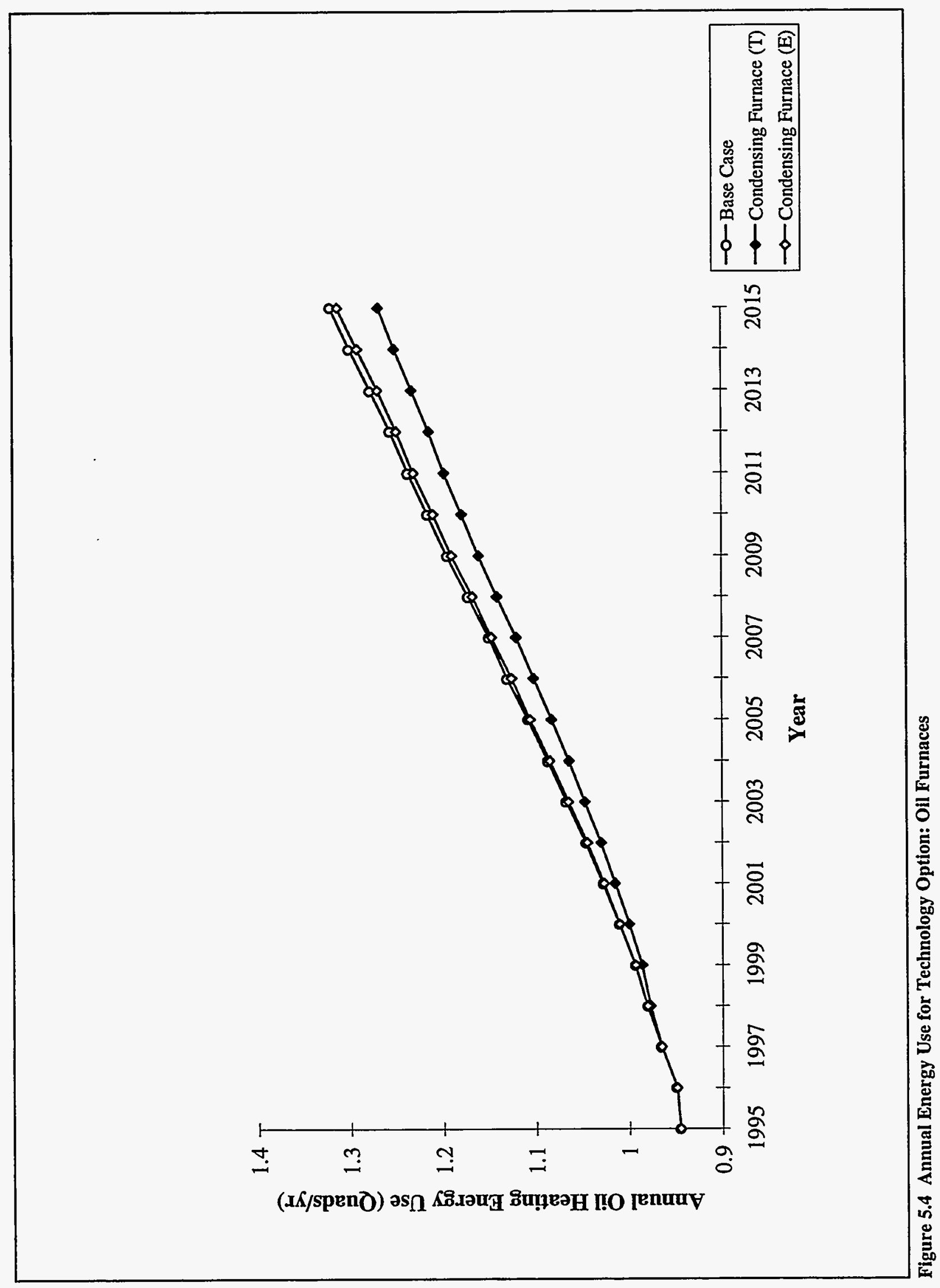




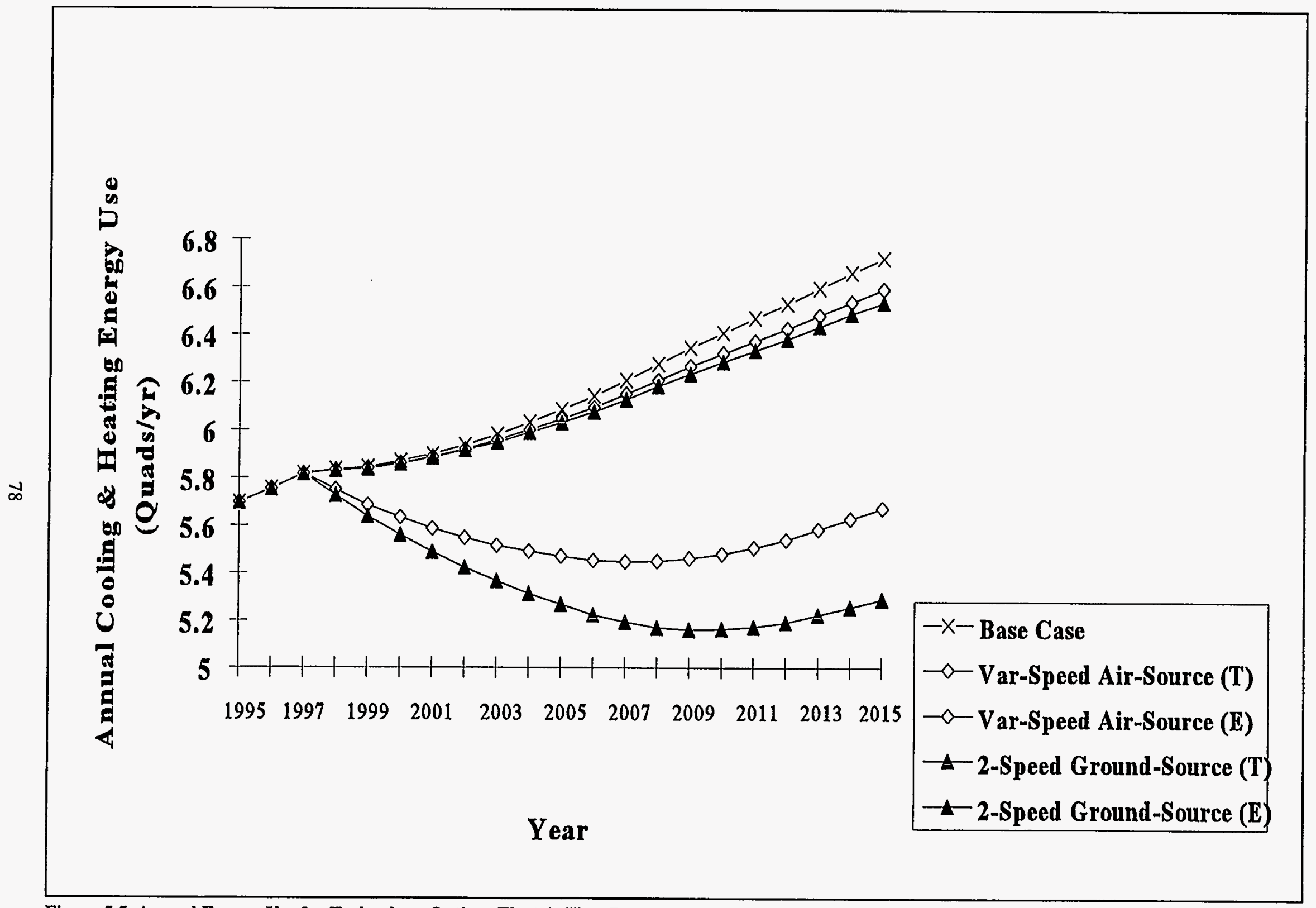

Figure 5.5 Annual Energy Use for Technology Option: Electric Heat Pumps 


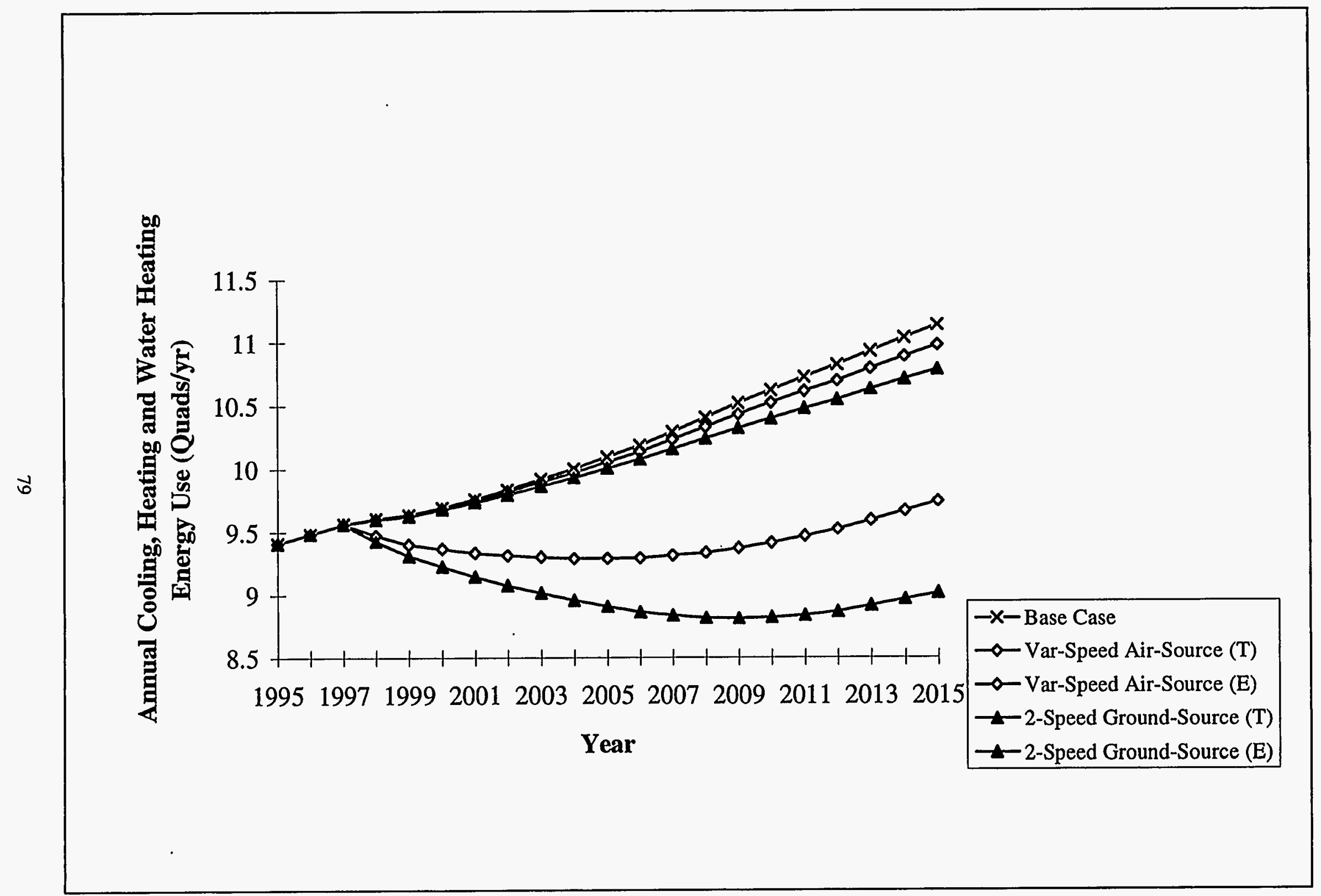

Figure 5.6 Annual Energy Use for Technology Option: Electric Integrated Heat Pump 


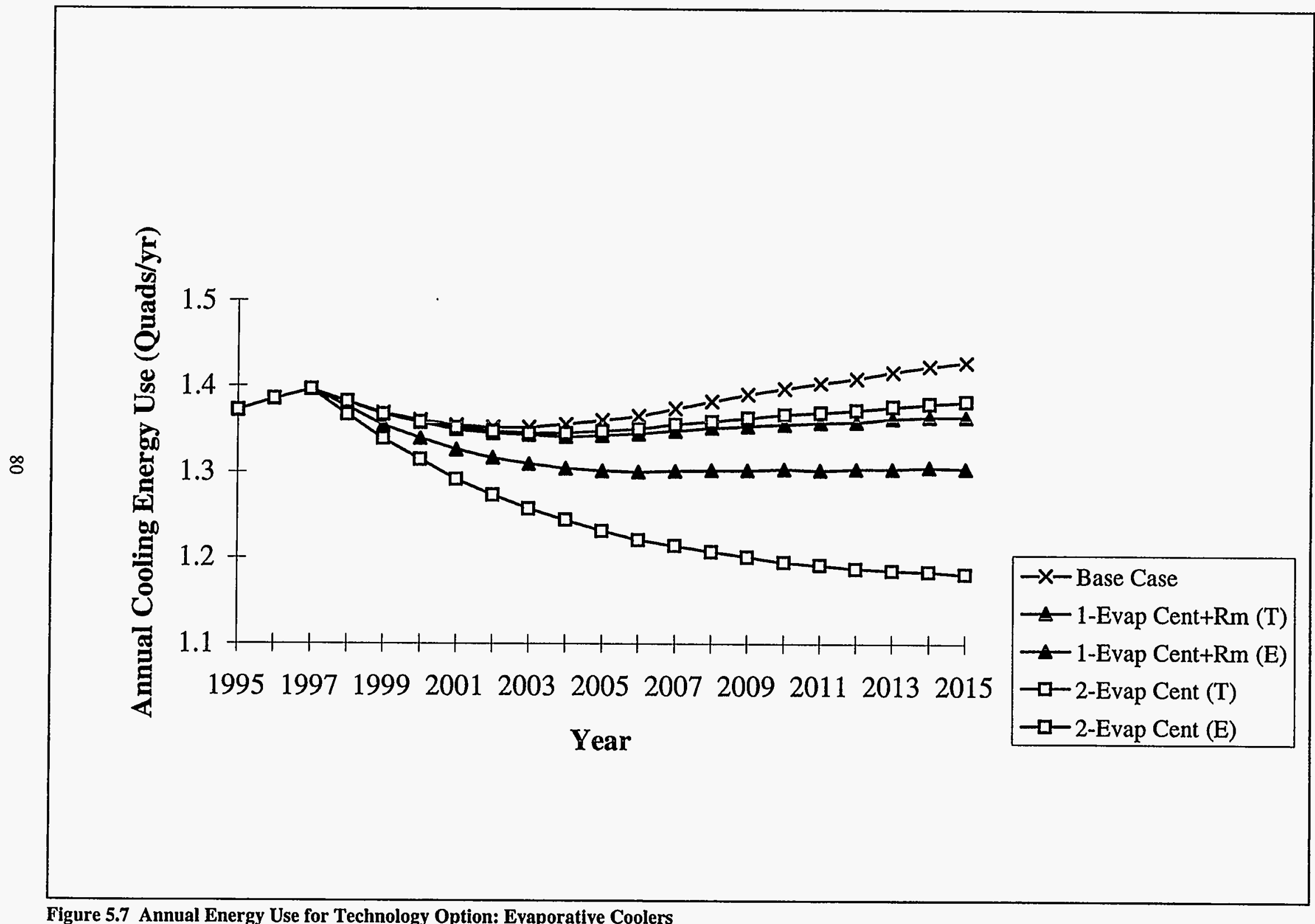


Tables 5.22 through 5.25 show the base case energy use and the annual energy savings for specific years and the cumulative (1998-2015) energy savings, relative to the base case. Table 5.19 depicts the energy savings for all gas, electric, and oil heat pump technology options. Table 5.20 provides the energy savings for oil furnace technology options. Table 5.21 depicts the energy savings for all gas and electric integrated heat pump technology options. Finally, Table 5.22 shows the energy savings for evaporative cooler technology options. In general, gas and electric integrated heat pumps provide the most significant energy savings. The electric 2 -speed ground-source integrated system has the greatest technical potential of all the technology options considered, since it provides 23.4 quads of energy savings over the period 1998-2015. With the exception of the oil heat pump technology option, the economic potentials for each technology are much lower than the technical potential. The economic potentials are based on current prices for each technology. That is, the penetration rates used for estimating economic potentials are based on payback periods calculated with current prices for each technology.

Two technology options, the National Service Improvement Program and Reduced-Leakage Ducting, have been omitted from the tables and figures. A more approximate method was used to estimate energy savings for these technologies; only cumulative energy savings were calculated for the technical potential case. For these two technology options, cumulative energy savings were determined by taking the savings that result in the base year (1998) and multiplying it by the number of years in the time span (18 years). Savings for the year 2015 were approximated as being to equal 1998 savings. Over the time period 1998-2015, the estimated cumulative energy savings (technical potential) is 0.03 quads for the National Service Improvement Program and 6.0 quads for ReducedLeakage Ducting. 
Table 5.22 Annual Energy Savings for Gas Heat Pump, Oil Heat Pump, and Electric Heat Pump Technology Options

\begin{tabular}{|c|c|c|c|c|c|c|}
\hline \multirow[b]{2}{*}{ Option } & \multirow[b]{2}{*}{ Case } & \multicolumn{4}{|c|}{$\begin{array}{l}\text { Annual Space-Cooling and Heating Energy Savings } \\
\text { (quads) }\end{array}$} & \multirow{2}{*}{$\begin{array}{c}\text { Cumulative } \\
\text { Energy saved } \\
\text { (quads) }\end{array}$} \\
\hline & & 2000 & 2005 & 2010 & 2015 & \\
\hline Basecase* & & 5.87 & 6.09 & 6.41 & 6.72 & 111.86 \\
\hline \multirow[t]{2}{*}{ Gas Absorption } & TP & 0.18 & 0.46 & 0.69 & 0.80 & 9.00 \\
\hline & EP & 0.04 & 0.14 & 0.26 & 0.36 & 3.20 \\
\hline \multirow[t]{2}{*}{ Gas Engine-Driven } & TP & 0.28 & 0.69 & 1.05 & 1.24 & 13.63 \\
\hline & EP & 0.04 & 0.16 & 0.31 & 0.44 & 3.77 \\
\hline \multirow[t]{2}{*}{ Gas Adsorption } & TP & 0.28 & 0.69 & 1.06 & 1.25 & 13.74 \\
\hline & EP & 0.04 & 0.16 & 0.31 & 0.44 & 3.78 \\
\hline \multirow[t]{2}{*}{ Oil Absorption } & TP & 0.08 & 0.22 & 0.36 & 0.49 & 4.68 \\
\hline & $\mathrm{EP}$ & 0.06 & 0.18 & 0.30 & 0.42 & 3.89 \\
\hline \multirow[t]{2}{*}{ Elec Var-Speed Air-Source } & TP & 0.23 & 0.62 & 0.93 & 1.05 & 11.95 \\
\hline & EP & 0.01 & 0.04 & 0.09 & 0.13 & 1.04 \\
\hline \multirow[t]{2}{*}{ Elec 2-Spd Ground-Source } & TP & 0.31 & 0.82 & 1.25 & 1.43 & 16.03 \\
\hline & EP & 0.01 & 0.05 & 0.12 & 0.18 & 1.46 \\
\hline
\end{tabular}

* Base case is annual energy use in quads, not energy savings.

Base case space-cooling energy use is comprised of the following end uses: central air conditioner, room air conditioner, and central heat pump.

Base case space-heating energy use is comprised of the following end uses: central gas furnace, central oil furnace, central electric furnace, central heat pump, and hydronic heating.

* EP = Economic potential; TP = Technical potential.

Table 5.23 Annual Energy Savings for Oil Furnace Technology Options

\begin{tabular}{|c|c|c|c|c|c|c|}
\hline \multirow[b]{2}{*}{ Option } & \multirow[b]{2}{*}{ Case } & \multicolumn{4}{|c|}{ Annual Space Oil Heating energy savings (Quads) } & \multirow{2}{*}{$\begin{array}{c}\begin{array}{c}\text { Cumulative } \\
\text { En sav (quads) }\end{array} \\
1998-2015 \\
\end{array}$} \\
\hline & & 2000 & 2005 & 2010 & 2015 & \\
\hline Basecase* $^{*}$ & & 1.01 & 1.11 & 1.22 & 1.32 & 20.57 \\
\hline Condensing Furnace & $\begin{array}{l}\text { TP } \\
\text { EP }\end{array}$ & $\begin{array}{l}0.01 \\
0.00\end{array}$ & $\begin{array}{l}0.03 \\
0.00 \\
\end{array}$ & $\begin{array}{l}0.04 \\
0.01\end{array}$ & $\begin{array}{l}0.05 \\
0.01 \\
\end{array}$ & $\begin{array}{l}0.50 \\
0.07\end{array}$ \\
\hline
\end{tabular}

* Base case is annual energy use in quads, not energy savings.

Base case oil space-heating energy use is comprised of the following end use: oil furnace.

$* * \mathrm{EP}=$ Economic potential; TP = Technical potential. 
Table 5.24 Annual Energy Savings for Integrated Gas Heat Pump and Electric Heat Pump Technology Options

\begin{tabular}{|c|c|c|c|c|c|c|}
\hline \multirow[b]{2}{*}{ Option } & \multirow[b]{2}{*}{ Case"• } & \multicolumn{4}{|c|}{$\begin{array}{l}\text { Annual Space Cooling, Heating and Water Heating } \\
\text { Energy Savings (guads) }\end{array}$} & \multirow{2}{*}{$\begin{array}{c}\begin{array}{c}\text { Cumulative } \\
\text { Energy Savings } \\
\text { (quads) }\end{array} \\
1998-2015 \\
\end{array}$} \\
\hline & & 2000 & 2005 & 2010 & 2015 & \\
\hline Base case* & & 9.69 & 10.09 & 10.62 & 11.13 & 185.19 \\
\hline \multirow[t]{2}{*}{ Gas Absorption } & TP & 0.32 & 0.70 & 1.05 & 1.22 & 13.81 \\
\hline & $\mathrm{EP}$ & 0.04 & 0.15 & 0.29 & 0.40 & 3.49 \\
\hline \multirow[t]{2}{*}{ Gas Engine-Driven } & $\mathrm{TP}$ & 0.41 & 0.92 & 1.39 & 1.64 & 18.29 \\
\hline & EP & 0.04 & 0.16 & 0.33 & 0.47 & 4.03 \\
\hline \multirow[t]{2}{*}{ Gas Water Heater/Furnace } & TP & 0.08 & 0.17 & 0.24 & 0.36 & 3.43 \\
\hline & $\mathrm{EP}$ & 0.00 & 0.01 & 0.03 & 0.05 & 0.33 \\
\hline \multirow{2}{*}{ Elec Var-Speed Air-Source } & TP & 0.33 & 0.81 & 1.21 & 1.39 & 15.75 \\
\hline & EP & 0.01 & 0.04 & 0.10 & 0.16 & 1.19 \\
\hline \multirow[t]{2}{*}{ Elec 2-Spd Ground-Source } & TP & 0.47 & 1.19 & 1.81 & 2.12 & 23.39 \\
\hline & $\mathrm{EP}$ & 0.01 & 0.09 & 0.23 & 0.35 & 2.64 \\
\hline
\end{tabular}

* Base case is annual energy use in quads, not energy savings.

Base case space-cooling energy use is comprised of the following end uses: central air conditioner, room air conditioner and central heat pump.

Base case space-heating energy use is comprised of the following end-uses: central gas furnace, central oil furnace, central electric furnace, central heat pump, and hydronic heating.

Base case water-heating energy use is comprised of the following end-uses: electric water heater, gas water heater, and oil water heater.

* EP = Economic potential; $\mathrm{TP}=$ Technical potential.

Table 5.25 Annual Energy Savings for Evaporative Cooler Technology Options

\begin{tabular}{|c|c|c|c|c|c|c|}
\hline \multirow[b]{2}{*}{ Option } & \multirow[b]{2}{*}{ Case"* } & \multicolumn{4}{|c|}{ Annual Space Cooling Energy Savings (Quads) } & \multirow{2}{*}{$\begin{array}{c}\begin{array}{c}\text { Cumulative } \\
\text { En sav (quads) }\end{array} \\
1998-2015 \\
\end{array}$} \\
\hline & & 2000 & 2005 & 2010 & 2015 & \\
\hline Base case* & & 1.36 & 1.36 & 1.40 & 1.43 & 24.87 \\
\hline \multirow[t]{2}{*}{ 1-Stage Evaporative Coolers } & $\mathrm{TP}$ & 0.02 & 0.06 & 0.09 & 0.12 & 1.22 \\
\hline & EP & 0.00 & 0.02 & 0.04 & 0.06 & 0.48 \\
\hline \multirow[t]{2}{*}{ 2-Stage Evaporative Coolers } & TP & 0.05 & 0.13 & 0.20 & 0.25 & 2.59 \\
\hline & EP & 0.00 & 0.01 & 0.03 & 0.05 & 0.36 \\
\hline
\end{tabular}

* Basecase is annual energy use in Quads, not energy savings.

Basecase space cooling energy use is comprised of the following end-uses: central air conditioner, room air conditioner and central heat pump.

.. $\mathrm{EP}=$ Economic potential; $\mathrm{TP}=$ Technical potential. 



\section{Commercial and Residential Lighting Components and Systems}

We discuss advanced lighting technologies with significant energy-efficiency potential beyond that required by the Energy Policy Act of 1992. These technologies include lamps (fluorescent, highintensity discharge, and incandescent), ballasts, controls, luminaires, and systems. For each technology, we discuss (1) the present status of the technology, (2) potential energy savings and incremental cost, (3) applications, and (4) barriers to implementation.

The advanced technology options fall into three categories: (1) Technologies Modeled technologies for which sufficient data were obtained to make estimates of projected energy savings under stated assumptions. For the commercial sector, the COMMEND 3.2 forecasting model was used to estimate energy savings. For the residential sector, the LBL-REM model was used. The technologies are grouped by type for comparison. (2) Technologies with Insufficient Information to Model - technologies considered to have significant energy savings potential but for which sufficient data could not be obtained for this report. (3) Other Technologies Considered technologies that show promise for energy savings but for diverse reasons were not included in the analysis. These technologies appear in Appendix 6.

\section{TeChNologies Modeled - COMMERCiAl SeCtor}

\section{FULL-SIZED FLUORESCENT LAMP TECHNOLOGIES}

\subsection{SCOTOPICALLY-RICH LAMPS}

Present Status. By displaying a select spectral output, scotopically-rich lamps produce greater visual acuity and depth of field at lower light levels. Light level (illuminance) is typically measured with photometers whose spectral response matches that of the cones of the light-adapted eye, called the photopic response. However, at low light levels, the rods in the human eye respond by adjusting the size of the pupil in the eye (called the scotopic response). Lamps with scotopically-enhanced phosphors are rich in blue, which causes the pupils to contract. Thus, scotopically-rich light can allow greater visual acuity and depth of field at lower light levels. This consequently can reduce lighting energy requirements. Scotopically-rich phosphors can be used with common fluorescent lamp types (T12, T8). Photopic efficacies and lamp lifetimes are the same as those of the base lamp.

This technology is in research and development. Work sponsored by Lawrence Berkeley Laboratory is occurring in three phases: laboratory studies (largely completed), studies in a simulated office space (to be completed in 1995/96), and full-scale field tests in a large office complex. Some of Duro-Test's existing fluorescent lamps are scotopically-rich. General Electric (GE) has built prototype fluorescent lamps and is considering development, and Philips has considered the technology. 
Energy Use and Cost. The savings from this technology arise from the reduced number of lamps required. Based on the delivery of equivalent "pupil-lumens" (a mix of scotopic and photopic lumens), S. Berman (1992) estimates a 24\% savings over halophosphor cool-white lamps from using tri-phosphor 5000 degree $\mathrm{K}$ lamps and a $31 \%$ savings using a hypothetical narrow band lamp. On the same basis, the Vital Care 75 lamp made by Duro-Test appears to give a $28 \%$ savings. Berman notes that reducing the number of lamps per fixture from 4 to 2 achieves as much as an additional $15 \%$ energy savings through thermal effects.

This analysis assumed the use of the hypothetical narrow band lamp with 25\% savings from reducing the number of lamps; no additional savings were assumed for thermal effects. Scotoptically-rich phosphors were assumed to apply to 4-foot T12, 4-foot T8, 8-foot T12, and 8-foot high-output T12 lamps with the same percentage savings for all lamp/ballast combinations. These lamps were assumed technically feasible in $90 \%$ of baseline fluorescent applications. The incremental lamp cost was estimated at $\$ 0.50$ (Rubinstein, 1993).

These savings could represent those from any efficient fluorescent technology with similar percentage savings.

Applications. Scotopically-rich lamps may be used wherever fluorescent lamps are now used, except in areas requiring both low color temperature and high CRI. The greatest savings would accrue in new construction, since retrofitting to reduce the number of lamps would require changing fixture configurations or delamping and reballasting. R. Clear (1993) estimates scotopically-rich lamps can be used in most present commercial fluorescent applications. They are less appropriate for residential use because of the low color temperature requirements of this sector.

No application adjustments are necessary to use scotopically-rich lamps in place of normal fluorescents, and only minor manufacturing process changes need to be made to adjust the phosphor mix.

Barriers to Implementation. Most lighting design is based on illuminance requirements using photopic lumens. Major changes in design practice would be required to incorporate both scotopic and photopic response into the definition of the lumen. The Illuminating Engineering Society would have to modify its recommended design practices. New photometers for both illuminance and luminance would have to be developed and accepted. (LBL is presently designing a photometer with both a photopic and a scotopic filter.) It is possible that lamp test procedures would have to be modified.

Further research is also needed on the implications of scotopic research on $\mathrm{HID}$ lighting. High pressure sodium lamps, very efficacious using photopic lumens, have poorer efficacy using scotopic lumens. This effect may be especially important at low light levels, such as those of exterior lighting. 


\section{INCANDESCENT LAMPS AND REPLACEMENTS}

\subsection{EFFICIENT INCANDESCENT LAMP - IMPROVEMENTS TO HALOGEN INFRARED REFLECTING LAMPS}

Note: This technology is modeled as Efficient Incandescent 1.

Present Status. Tungsten halogen infrared reflecting (HIR) lamps are coated with a multiple layer of metal oxides that are transparent to visible light but reflect infrared radiation back onto the filament. The filament temperature is increased, and the lamp efficacy is improved by as much as $25 \%$. A key to the lamp's operation is its concentric geometry.

HIR PAR (reflector) lamps are already produced by GE. Further efficacy improvements may be possible.

HIR general service lamps are in near-term development. LBL has produced a prototype HIR general service lamp. Efficacies of $25 \mathrm{LPW}$ or higher have been predicted; this analysis assumed $25 \mathrm{LPW}$.

Energy Savings and Costs. Achievable efficacy is assumed to be 25 LPW. Costs are estimated at $\$ 5.35$ for general service and $\$ 6.65$ for reflector lamps. Lifetimes are 2000 hours and 2500 hours respectively.

Applications. This lamp has the potential to be applied anywhere incandescents are presently used. It may serve as an efficient replacement for general service lamps for applications where compact fluorescents are inappropriate because of size, aesthetics, or low operating hours that make retrofit uneconomical.

Barriers to Implementation. Compared with other technologies, there is less manufacturer interest in HIIR improvements at the present time due to the lack of a perceived market. The new national reflector lamp standards (November 1995) in the Energy Policy Act, which require an efficacy at least as high as that of the halogen lamps, will probably help increase the market for HIR technology.

\subsection{EFFICIENT INCANDESCENT LAMP}

Note: This technology is modeled as Efficient Incandescent 2.

Present Status. This technology represents the higher range of potential efficacy improvements to incandescent lamps. Such efficacies may be achieved by several technologies, such as those described in Appendix 6 (Coated Filament, Hafnium Carbide, and Ceria Lamps). These are all in the research and development stage. 
Energy Use and Cost. This analysis used the following assumptions:

Research estimates place the achievable incandescent efficacy at $50 \mathrm{LPW}$, with a lifetime of 3500 to 4000 hours (Lighting Systems). The estimated commercial sector quantity lamp price is $\$ 7.50$ for an 1190-lumen incandescent general service lamp replacement and $\$ 10.00$ for a 150-W PAR replacement. Standard incandescent prices are \$0.34 and \$2.66 respectively (Lighting Systems).

Applications. This lamp has the potential to replace any general service or reflector incandescent lamp.

Barriers to Implementation. Lack of R\&D funds is the present barrier. R\&D success is an obvious prerequisite to commercialization of this product. The next step would be manufacturer acceptance and commitment to manufacture.

\subsection{COMPACT ELECTRODELESS FLUORESCENT (INDUCTION) LAMP}

Present Status. The compact electrodeless fluorescent, or induction lamp, uses a high-frequency magnetic field to excite the mercury in the lamp directly without the electrodes required in conventional fluorescent lamps. Its advantage over compact fluorescent technologies is that it lasts twice as long, fits in more locations, and may become available in higher wattage.

This technology is in near-term development. Initially, reflector lamps will be produced. Two companies plan to introduce compact electrodeless induction lamps in the US.

GE's Genura model (now on sale in Europe) is a 23-watt reflector lamp that will replace a 75-watt incandescent reflector lamp. GE will introduce other Genura wattage in 1995 in the U.S.

Intersource Technologies has continued research on their "E-lamp," aiming toward a 1500 lumen, 20-some watt replacement for the 100-watt PAR reflector lamp. The company is looking for a prospective industry partner to produce prototype products in the near future. While the lamp is FCC-approved for use in the residential sector, Intersource plans to package the lamp inside a luminaire through original equipment manufacturers (OEMs) for the commercial/industrial market.

Since there is no filament to burn out or electrodes to fail, the lamp can be turned on and off without affecting lamp life. The product life is limited only by the lamp phosphor depreciation. GE states that the lamp will still have $70 \%$ of its rated lumen output at 10,000 hours, and $50 \%$ at 20,000 hours. Intersource rates its lamp lifetime as 20,000 hours with $70 \%$ of rated lumen output.

Energy Use and Cost. The Genura lamp has slightly less than 50 lumens per watt (LPW), much better than the 12.5 LPW of the incandescent reflector, but less efficacious than the CFL's 65 LPW. The E-lamp's efficacy is estimated at 60 lumens per watt (measured with center beam lumens). This analysis assumed an efficacy of $50 \mathrm{LPW}$ for reflector incandescents. The commercial sector quantity price of the lamp is estimated at $\$ 13.50$, similar to a CFL lamp with electronic ballast 
Atkinson, 1993). A lifetime of 10,000 hours is assumed.

Applications. The lamp could be used for applications now served by $75-\mathrm{W}$ incandescent reflectors and (when available) higher wattage reflector incandescents. For this analysis the technology is not assumed to apply to general service incandescents; it may eventually be developed for these lamps.

Barriers to Implementation. The cost of the induction lamp is predicted to be high, similar to that of compact fluorescents.

The Genura lamp operates at 2.6 megahertz (MHz), because Europe has standardized at this frequency for induction lighting. The lamp needs shielding for conducted and radiated electromagnetic interference (EMD) emissions. The reflector portion of the lamp provides enough shielding to meet FCC EMI requirements for $2.6 \mathrm{MHz}$. However, the residential FCC requirements are stricter and the Genura does not meet them. The company is attempting to convince the FCC to permit use of the lamp for residences.

Intersource's E-lamp operates at $13.56 \mathrm{MHz}$. This figure is within the Industrial/Scientific/Medical (ISM) band in which the FCC allows unlimited radio-frequency emissions. However, to meet the FCC's residential requirements, the lamp must still be shielded to keep emissions in the $40-68 \mathrm{MHz}$ range (the 3rd through 5th harmonics of the operating frequency.)

Both the E-lamp and the Genura have problems starting at low temperatures and are not recommended for outdoor use. Neither can be used on dimming circuits. Both GE and Intersource plan to introduce dimmable induction lamps in the future.

\section{COMPACT FLUORESCENT TECHNOLOGIES}

\subsection{CFL ELECTRONIC BALLAST}

To compare the following compact fluorescent lamp (CFL) measures with a scenario where CFLs with electronic ballasts have already substituted for incandescents where appropriate, the CFL Electronic Ballast option was modeled. Products with the efficacy of $60 \mathrm{LPW}$ assumed for this technology are already on the market.

In this scenario, CFLs with electronic ballasts substitute for one-third of baseline incandescents. The baseline already has $20 \%$ of Edison-base sockets as CFLs with magnetic ballasts. For this option these CFLs are replaced with CFLs with electronic ballasts, resulting in a total of 47 percent of Edison-base sockets with the technology.

\subsection{CFL DIMMABLE BALLASTS}

Present Status. Several manufacturers have developed dimmable high-frequency ballasts for use 
with four-pin CFLs. No dimmable screw-in (two-pin) CFLs are currently available. For example, Lutron manufactures a hard-wired compact fluorescent dimming ballast that is designed to dim 4pin 18- or 26-watt CFLs as low as 5\%. This ballast is being supplied to downlight fixture manufacturers. Prescolite has a dimming ballast for a quad 26-W lamp. Etta Industries is manufacturing a dimmable CFL ballast. Advance expects to have a dimming ballast available soon. Manufacturers state that CFL dimming can be accomplished with only small losses in lamp efficacy and power factor.

Stepped dimming can be achieved without dimmable ballasts through the use of multi-lamp fixtures with independent ballasts; however, additional switching is needed. Ballasts that provide discrete levels of stepped dimming are also on the market.

Energy Use and Cost. If automatic daylight sensing, occupancy sensing, and manual dimming are included in the system, the savings from dimmable electronic ballasts can be greater than 65\%(Quasi, 1993) compared with non-dimming magnetic ballasts. The total energy savings achievable depend on user behavior as well as daylighting availability.

For this analysis, energy savings from dimming CFL electronic ballasts versus non-dimming electronic ballasts are estimated at $10 \%$. This figure includes manual, daylighting, and occupancysensing dimming. Additional savings are assumed from replacement of an additional 25 percent (beyond those in the CFL Electronic Ballast option above) of commercial sector incandescents with CFLs; these are assumed to be applications that require dimmability. This results in dimmable CFLs in a total of 60 percent of Edison-based sockets.

Hard-wired CFL dimming systems currently cost more than twice as much as hard-wired CFL magnetic ballasts, and 40-50\% more than non-dimming hard-wired electronic ballasts. One manufacturer's non-dimmable CFL electronic ballasts cost about $\$ 20$. The cost of the same manufacturer's dimmable electronic ballasts is expected to drop to approximately $\$ 28$ for a mature market. For higher-end dimmable CFL ballasts, another manufacturer's price is similar to that of dimmable T8 ballasts (Yorgey 1993). For this analysis, an incremental ballast cost of $\$ 8$ was assumed.

Applications. The most appropriate applications for dimming CFL ballasts are display areas, lecture halls, conference rooms, restaurants, offices, residences, and daylighting applications.

Barriers to Implementation. As with all compact fluorescent technologies, equipment first cost is a primary barrier to implementation. Product availability is another barrier. 


\subsection{CFL EFFICIENT LUMMNAIRES}

Present Status. Recessed downlights offer a significant opportunity for energy savings in U.S. commercial buildings. The recessed downlight is the largest selling luminaire in the U.S., representing more than one-fifth of the nation's new incandescent lighting sockets. The majority of recessed downlights (85\% in the 1980s) are incandescent, and the rest are CFL or specialty HID. Typical burn times for these luminaires are between 6 and 24 hours per day.

Lawrence Berkeley Laboratory is researching improvement of the luminaire efficiency of compact fluorescent (and full-size fluorescent) luminaires by better thermal management and optical design. The potential efficiency increase is $20-25 \%$ due to reduction in thermal (10-15\%) and optical (15$20 \%$ ) losses, allowing the use of fewer luminaires compared with ordinary CFL downlights. LBL is working with manufacturers both on luminaire-venting techniques to increase thermal efficiency and on means to decrease the minimum lamp wall temperature through thermal bridging. For integral screw-in compact fluorescents, the thermal bridge will probably be included within the ballast compartment (see Section 6.17, "Thermal Bridging for Fluorescent Lamps").

One-third of incandescent luminaires can be directly replaced with hard-wired CFL luminaires. Another one-third could probably be replaced, but may have problems with lumen matching or aesthetics. The remaining one-third cannot be replaced because of aesthetics or unfavorable economics due to low usage.

This analysis assumed that 33 percent additional incandescents (beyond those in the CFL Dimmable Ballast option above) are retrofit with efficient CFL luminaires. Existing CFL luminaires are also retrofit with efficient versions. This results in a total of 73 percent of Edison-based sockets with efficient CFL luminaires.

Energy Use and Cost. For this analysis $15 \%$ energy savings from the efficient luminaire are assumed. The system efficacy is 70 lumens per watt.

Compact fluorescent luminaires including two 13-W quad lamps are priced between $\$ 45$ and $\$ 95$ for commercial grade equipment. An 150-W PAR incandescent downlight luminaire costs between $\$ 40$ and $\$ 65$ (Nadel 1993). For this analysis the CFL luminaire cost was assumed as the average of the costs mentioned above $(\$ 70)$ with a $25 \%$ additional cost for optical improvements ( $\$ 87.50)$. The incandescent luminaire cost was assumed as $\$ 53$ (Means 1992).

The added cost of thermal venting in a compact fluorescent luminaire is negligible, though in the manufacturing process there will be some cost for retooling. One manufacturer stated no additional cost would be incurred for the venting improvements (Siminovitch 1993). Thermal-bridging techniques are also of very low cost, but for practical reasons they will be applied primarily to screw-in integral CFLs within the ballast compartment. For that situation, the added manufacturing cost is about 5 to 6 cents $(\$ 0.05-\$ 0.06)$ per lamp.

For optical improvements, added costs may be as much as $25 \%$ using current manufacturing 
techniques. However, with the use of methods such as plastic injection molding, non-symmetrical shapes may become inexpensive to produce. Surface treatments and increased manufacturing precision also contribute to the higher cost of optically-improved luminaires.

Barriers to Implementation. Manufacturers have begun to include thermal efficiency improvements in their CFL luminaires. However, the market penetration of CFL luminaires of any kind remains small compared to incandescents. First cost is perhaps the most significant market barrier, but consumer awareness is also very important to the acceptance and widespread use of this technology. On the manufacturing side, incentives to increase production are lacking, and product availability is another important factor in the high price of CFL downlights.

\section{CONTROLS}

\subsection{DIMMABLE EleCTRONIC BALLASTS FOR FULL-SIZE FluORESCENTS}

Present Status. Dimmable electronic high-frequency ballasts are now available for full-sized fluorescent lamps (Ostaffe 1993). Advance Transformer has been making a dimmable electronic ballast for five years. Lutron's dimmable electronic ballast, initially designed for high-end applications, has been in the world market since 1974. Currently less than $4 \%$ of annual electronic ballast sales are dimmable ballasts. Even at the current growth rate of $30-50 \%$ per year, the market penetration of this technology may remain small without policy incentives.

In Europe, much effort has gone into dimmable high-frequency ballasts over the last three years. There has been less penetration than in the U.S. because of higher prices. High energy costs in Japan have created a greater emphasis on energy conservation and increased the demand for dimmable ballasts.

Energy Use and Cost. LBL's Lighting Systems Research Group made savings estimates for daylight/dimming and lumen maintenance made possible by dimmable ballasts (Rubinstein 1991). The dimmable ballasts are assumed to apply to fluorescent luminaires in one-half of building perimeter space. Perimeter space is estimated from EIA's Commercial Buildings Energy Consumption Survey (DOE/EIA 1988) by building type. Savings vary by building type from 0 to $25 \%$; the weighted average savings (by floor space) is $13 \%$.

The price of dimmable electronic ballasts is between $\$ 50$ and $\$ 95$ for T8 systems. Manufacturers offer a range of dimmability. By contrast, magnetic ballasts cost $\$ 10-\$ 12$, hybrids or cathode cutout ballasts, $\$ 15$, and non-dimmable electronic ballasts, more than $\$ 25$. 
For this study, economic analysis was performed type to determine the cost-effectiveness of the technology by building type to determine applicability . However, no economic potential scenario was modeled due to the complexity of calculating payback periods by building type.

Applications. Dimmable fluorescent ballasts allow savings from daylighting in offices and other building types. Display areas, lecture halls, conference rooms, and restaurants also have potential dimming applications. For this analysis, savings are assumed to arise from dimming lights when daylighting can be used.

Barriers to Implementation. Cost and consumer knowledge are fundamental barriers to market growth of dimmable electronic ballasts. Appropriate design methods are lacking, and success is dependent on proper calibration, commissioning, maintenance, and operation of the control system.

\subsection{INTEGRATED WORKSTATION SENSORS}

Present Status. The sensor allows the user to control lighting, electric heating and cooling equipment, and other electric equipment for individual workstations or spaces. For lighting, controls include a daylight sensor and dimming capability for lumen maintenance and daylighting. Area, task, and table lighting can be controlled as well. Users can program the system when they are in the space, and the electrical equipment automatically turns off after they leave. System memory allows the equipment to come back on at the same level. The system is installed locally and operates on radio or infrared frequency.

Other integrated communication systems that enable diverse systems to share information and work together, linking lighting, HVAC, security, and safety systems into an automated userprogrammable control network, are being developed (Lighting Controls 1993; Echelon Cor. 1993). Honeywell, Leviton, Philips Lighting, and Toshiba are among the manufacturers making use of the LonWorks technology for integrated building control including lighting. This technology is also being demonstrated in a residential setting by Honeywell.

Energy Use and Cost. Savings and costs for integrated workstation sensors were estimated by building type. Savings range from $3 \%$ to $36 \%$ by building type, with a floorspace-weighted average of $20 \%$. Cost is $\$ 50$ to $\$ 100$ per sensor serving one work space.

For this study, economic analysis was performed type to determine the cost-effectiveness of the technology by building type to determine applicability . However, no economic potential scenario was modeled due to the complexity of calculating payback periods by building type.

Applications. Integrated workstation sensors are applicable to the commercial sector in both new buildings or retrofits. Their applicability varies by building type.

Barriers to Implementation. The sensors must be used with dimming fluorescent ballasts. Designers need education on appropriate use of these systems. As with any control system, building managers 
need simple assessment tools to analyze cost-effectiveness.

\section{TECHNOLOGIES MODELED - RESIDENTIAL SECTOR}

\section{INCANDESCENT LAMPS AND REPLACEMENTS}

\subsection{EFFICIENT INCANDESCENT LAMP-IMPROVEMENTS TO HALOGEN INFRARED REFLECTING LAMPS}

Note: This technology is modeled as Efficient Incandescent 1.

Present Status. See the description in Section 6.2.

Energy Savings and Costs. Achievable efficacy is assumed to be $25 \mathrm{LPW}$. Costs in this sector are estimated at $\$ 9$ for general service and $\$ 10$ for reflector lamps. Lifetimes are 2000 hours and 2500 hours respectively.

Applications. This lamp has the potential to be applied anywhere incandescents are presently used.

Barriers. First cost is important in the residential sector.

\subsection{EFFICIENT INCANDESCENT LAMP}

Note: This technology is modeled as Efficient Incandescent 2.

Present Status. See the description in Section 6.3.

Energy Use and Costs. Research estimates place the efficacy of the coated filament lamp at 50 LPW, with a lifetime of 3500 hours (LBL). The estimated residential sector lamp price of $\$ 11.63$ for an 1190-lumen incandescent general service lamp replacement and \$12.02 for a 75-W PAR replacement. Standard incandescent prices are $\$ 0.48$ and $\$ 5.19$ respectively (LBL).

Applications. This lamp has the potential to replace any general service reflector incandescent lamp.

Barriers. First cost is important in the residential sector, in addition to the technological barriers described Section 6.3. 


\subsection{COMPACT ELECTRODELESS FLUORESCENT (INDUCTION) LAMP}

Present Status. See the description in Section 6.7.

Energy Use and Cost. This analysis assumed an efficacy of 50 lumens per Watt for reflector incandescents. The price of the lamp in this sector is estimated as $\$ 25$ (Nadel 1993). Its lifetime is assumed as 10,000 hours. The technology is assumed to apply only to reflector incandescent lamps.

Applications. The lamp can replace incandescent reflector lamps, especially high usage lamps.

Barriers to Implementation. Lack of a screw-in product, and a general service lamp version will hamper use in the residential sector. First cost is a significant barrier in this sector. Interference with communications equipment may be a problem.

\subsection{CFL EFFICIENT LUMINAIRES}

Present Status. The size and weight of screw-in CFLs often prohibit their use in standard incandescent residential floor and table lamps as well as wall and ceiling fixtures. Large residential fixture manufacturers have resisted making CFL-dedicated luminaires for a number of reasons, including the high purchase price of the lamps. Some smaller manufacturers are manufacturing dedicated luminaires with a variety of attractive options. Single-wattage systems, three-way lamps, ballasts built into the luminaire, and aesthetically pleasing traditional designs are available both for residential (and commercial) customers.

Energy Use and Cost. CFLs with electronic ballasts are assumed. Savings arise from replacement of 50 percent of incandescent luminaires with CFLs, as described below.

The incremental cost of dedicated CFL table lamps made by Mitor, Inc., is approximately $\$ 40$ higher than standard incandescent luminaires. Fred Davis Corporation also produces residential table and floor lamps at mid-range prices of about $\$ 120$. The incremental cost of these systems ranges from $\$ 25$ for 13-W lamps to $\$ 40$ for $26-W$ lamps (Nadel 1993). For this analysis, an incremental cost of $\$ 35$ per system or luminaire was used. Further savings would be possible through the use of screw-in CFLs, an option not modeled in this analysis.

Applications. CFL luminaires are applicable to most residential end uses. Included are table and floor lamps, wall and ceiling luminaires, and outdoor luminaires in mild climates.

According to the PG\&E Residential Lighting Saturation Survey (Kelsey 1992), 19\% of residential fixtures are free-standing lamps and another $6 \%$ are task lamps (desk or reading). This analysis assumed that $25 \%$ of high-usage (five hours per day) interior lamps were replaced with dedicated CFL table or floor lamps. An additional $25 \%$ of high-usage ceiling and wall fixtures were assumed 
to be replaced with dedicated CFL luminaires, for a total of 50\% of interior luminaires. Fifty percent of outdoor luminaires were also replaced with CFL luminaires, assuming some outdoor luminaires cannot be retrofit with CFLs because they do not start reliably at low temperatures.

Barriers to Implementation. The greatest barriers to increased market penetration of CFL dedicated luminaires are price and availability. Few manufacturers have made significant efforts to produce compact fluorescent luminaires for the residential market. Some residential consumers dislike fluorescent color rendering and lamp color. Others base their opinions on experience with older fullsize fluorescents with unpleasant colors and magnetic ballasts that flicker. Some CFLs interfere with electronic household equipment such as television or stereo controls.

\section{DISCUSSION OF NATIONAL ENERGY SAVINGS - COMMERCIAL SECTOR}

Figures 6-1 through 6-5 show annual energy consumption for commercial-sector interior lighting technologies for the time period 1995-2015. Exterior lighting was not modeled because of the lack of data and forecasting model tool for this sector. Figure 6-1, "Fluorescent Lamps," shows the baseline, one technical potential option, and one economic potential option. Figure 6-2, "Incandescent Lamps," shows the baseline, three technical potential options, and three economic potential options. Figure 6-3, "Compact Fluorescent Lamps," shows the baseline, three technical potential options, and three economic potential options. Figure 6-4, "Controls," shows the baseline and two technical potential options.

Figure 6-5, "Combination," shows one technical potential option. This case assumes a combination of scotopically-rich fluorescent lamps, CFLs with efficient luminaires in 73 percent of Edison-based sockets, compact electrodeless fluorescents replacing all reflector lamps, improved HIR lamps replacing the remaining incandescents, and integrated workstation sensors. The fluorescent, CFL, and incandescent technologies are assumed to be installed before the workstation sensors to avoid double-counting of savings.

In the baseline, retiring equipment is replaced with new equipment according to a distribution of market shares used in Atkinson, et al. (1992). Equipment ranges from that just meeting the efficacy requirements of the Energy Policy Act of 1992 (fluorescent reduced-wattage lamp and incandescent halogen reflector lamp) to more efficacious, commercially available equipment that already has some market shares. In the technical potential cases, the advanced technology replaces the baseline technologies in all applications where it is technically feasible. In the economic potential cases, the advanced technology replaces the baseline technologies at a penetration rate determined by ADL's Market Forecast Penetration Curve for the Commercial/Industrial sector, as shown in Figure 1.1. Penetration rates are a function of the payback periods. Market shares for equipment not replaced by the advanced technology have the same distribution as the baseline.

Table 6-1 shows the baseline energy-use intensities (EUIs in $\mathrm{kWh} / \mathrm{ft}^{2} / \mathrm{yr}$ ) and the change in energy-use intensities for each of the modeled technologies. Table 6.1 also shows the incremental equipment and 
labor costs (change in price) and payback periods for some of the technologies.

Table 6-2 shows the baseline energy use and the annual energy savings for specific years and the cumulative (1998-2015) energy savings relative to the baseline. The greatest energy savings for a single technology is for the scotopically-rich fluorescent lamp. While the individual technology percentage savings is higher for CFL options than for the fluorescent option, the predominance of fluorescent lighting in the commercial sector accounts for the higher national energy savings from this technology. (Note that these national savings could represent those from any efficient fluorescent technology with similar percentage savings.) The technical potential energy use for this technology is 47.7 primary quads over the period 1998-2015, compared to a baseline lighting energy use of 54.0 quads, or a savings of $12 \%$ of total commercial interior lighting electricity. Integrated workstation sensors (which assume dimmable fluorescent ballasts) save slightly more, with cumulative energy consumption of 47.4 primary quads and also a 12 percent savings. The combination policy has a cumulative consumption of 37.5 quads, with a technical potential savings for the commercial interior lighting end use of 31 percent. 


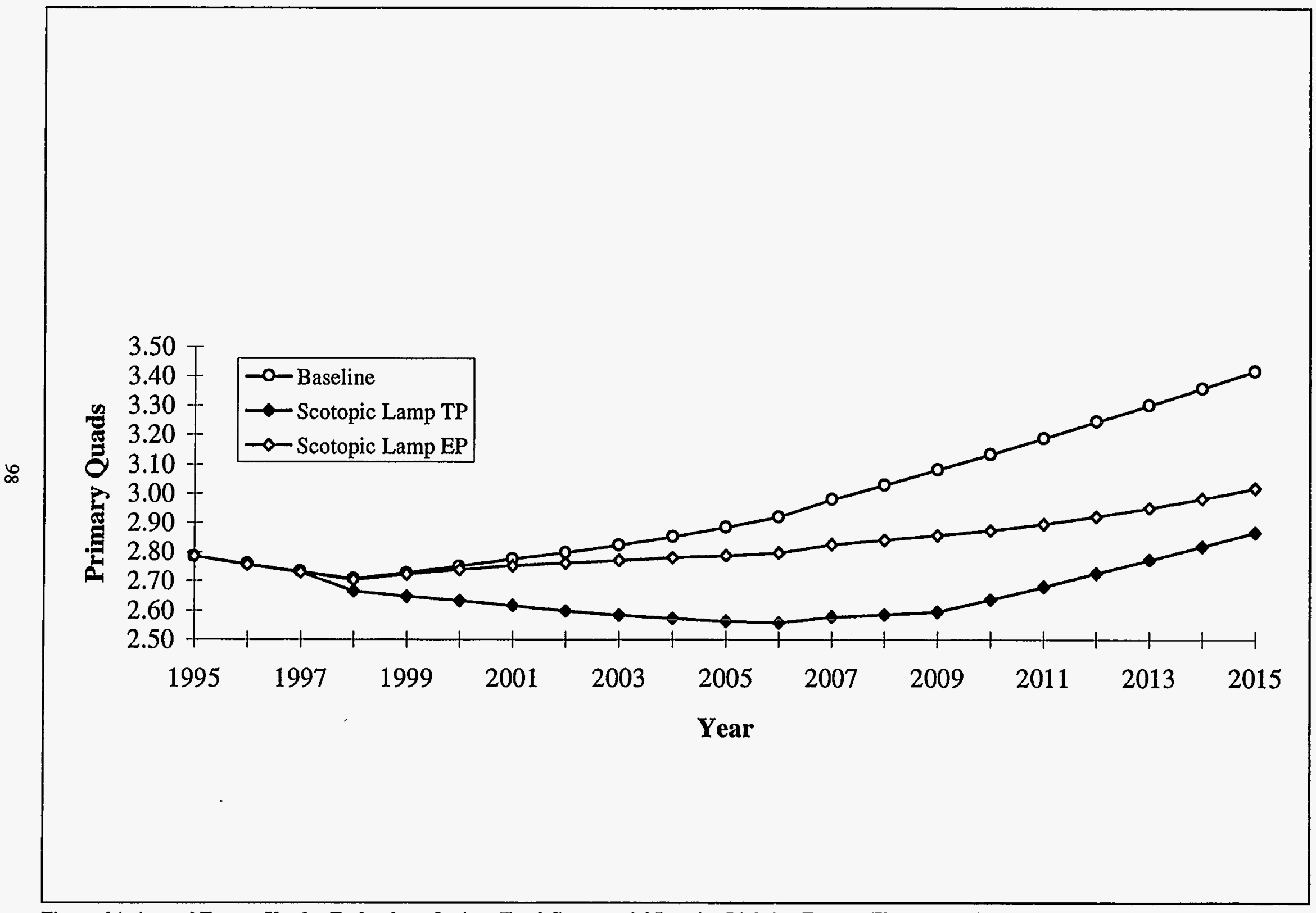

Figure 6.1 Annual Energy Use for Technology Option: Total Commercial Interior Lighting Energy, Fluorescent Lamps 


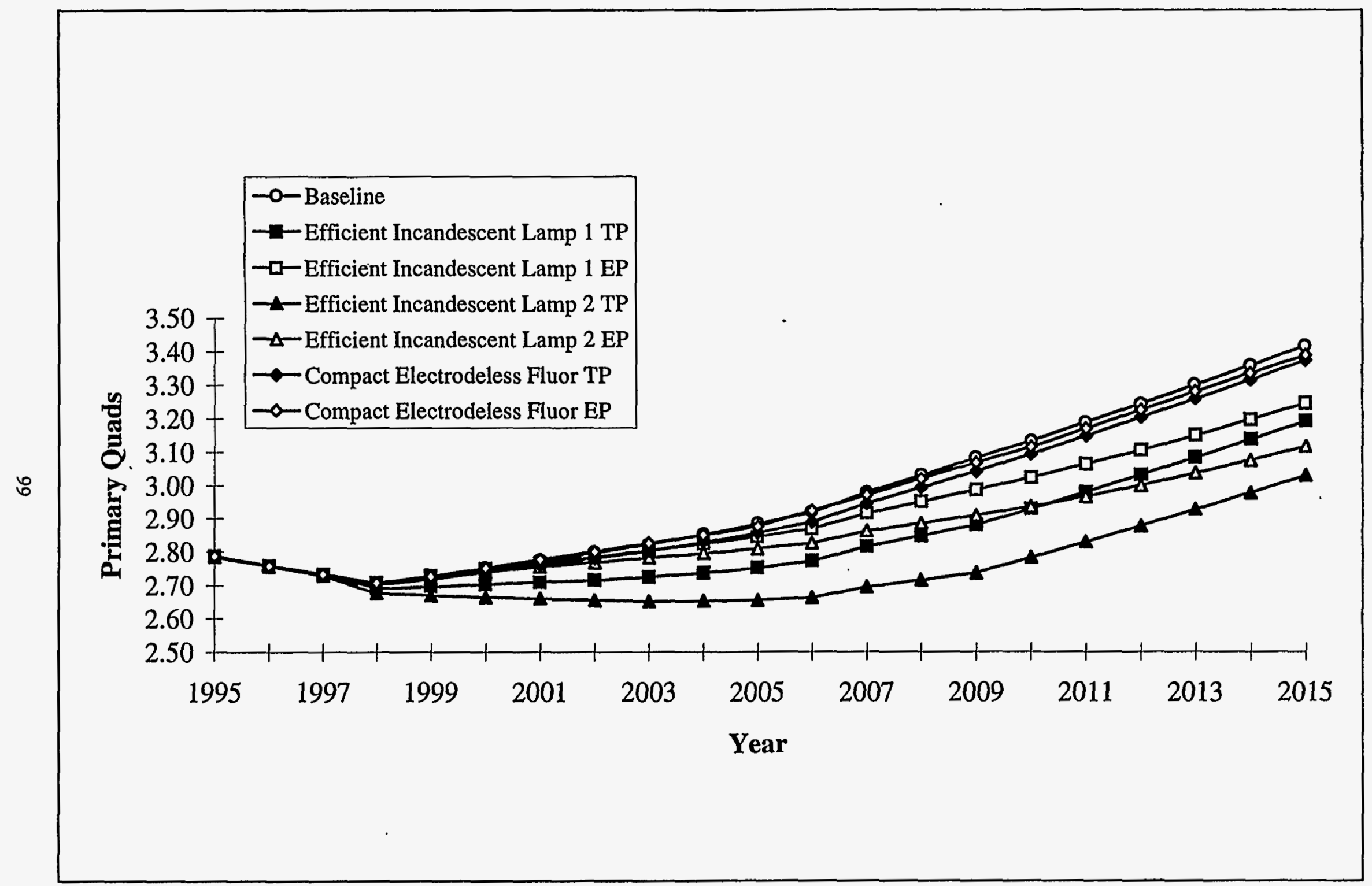

Figure 6.2 Annual Energy Use for Technology Option: Total Commercial Interior Lighting Energy, Incandescent Lamps and Replacements 


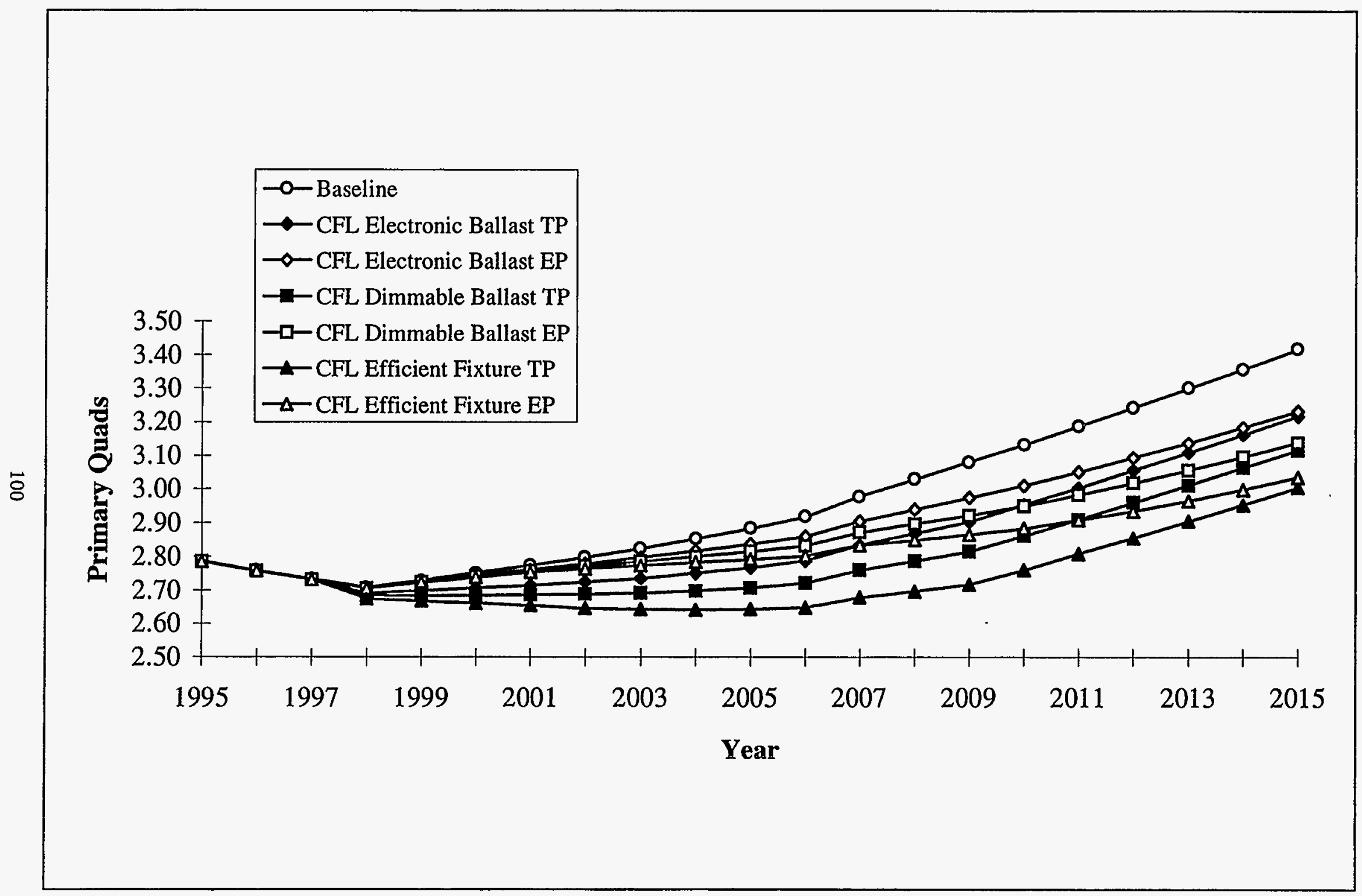

Figure 6.3 Annual Energy Use for Technology Option: Commercial Interior Lighting Energy, Compact Fluorescent Lamps 


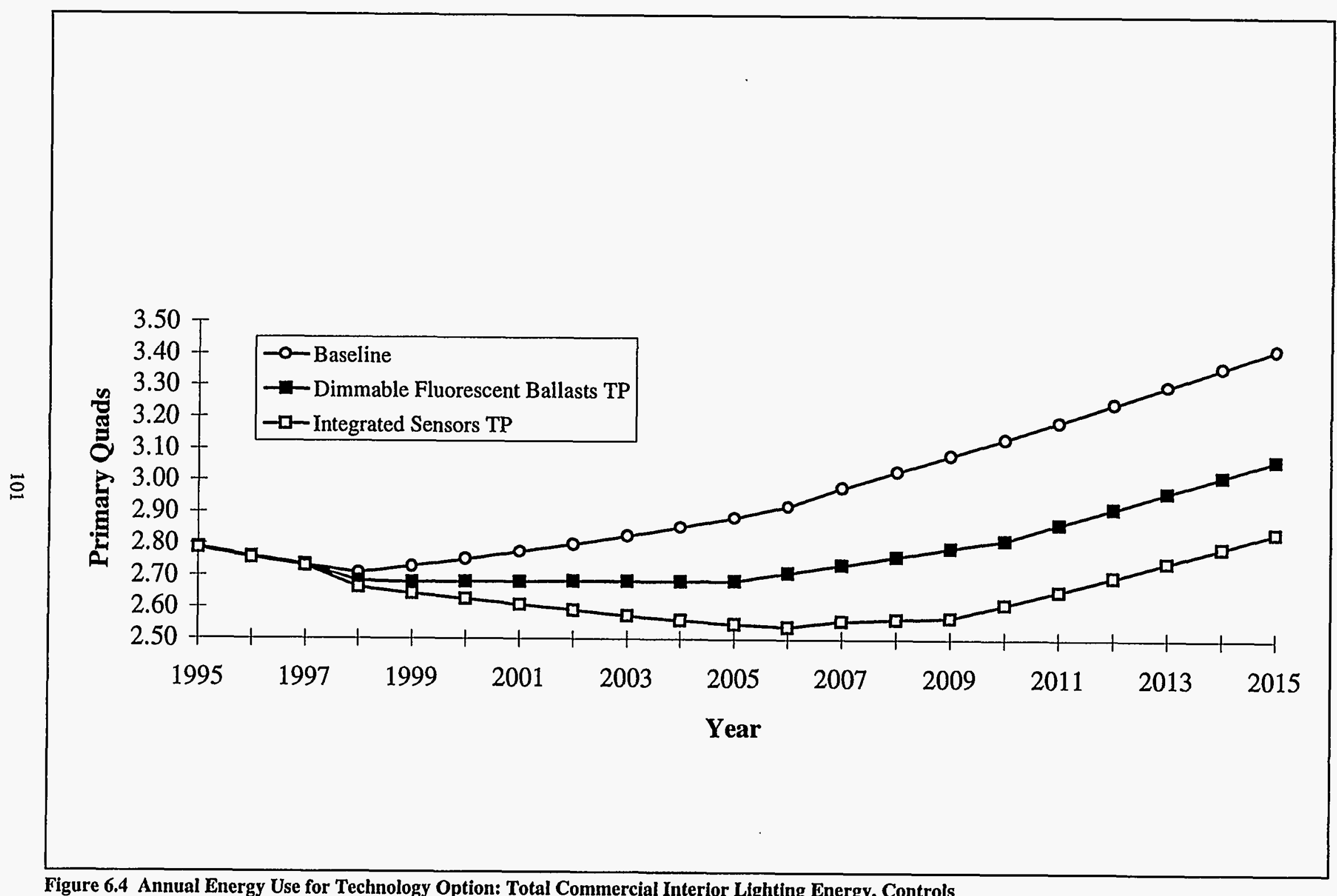




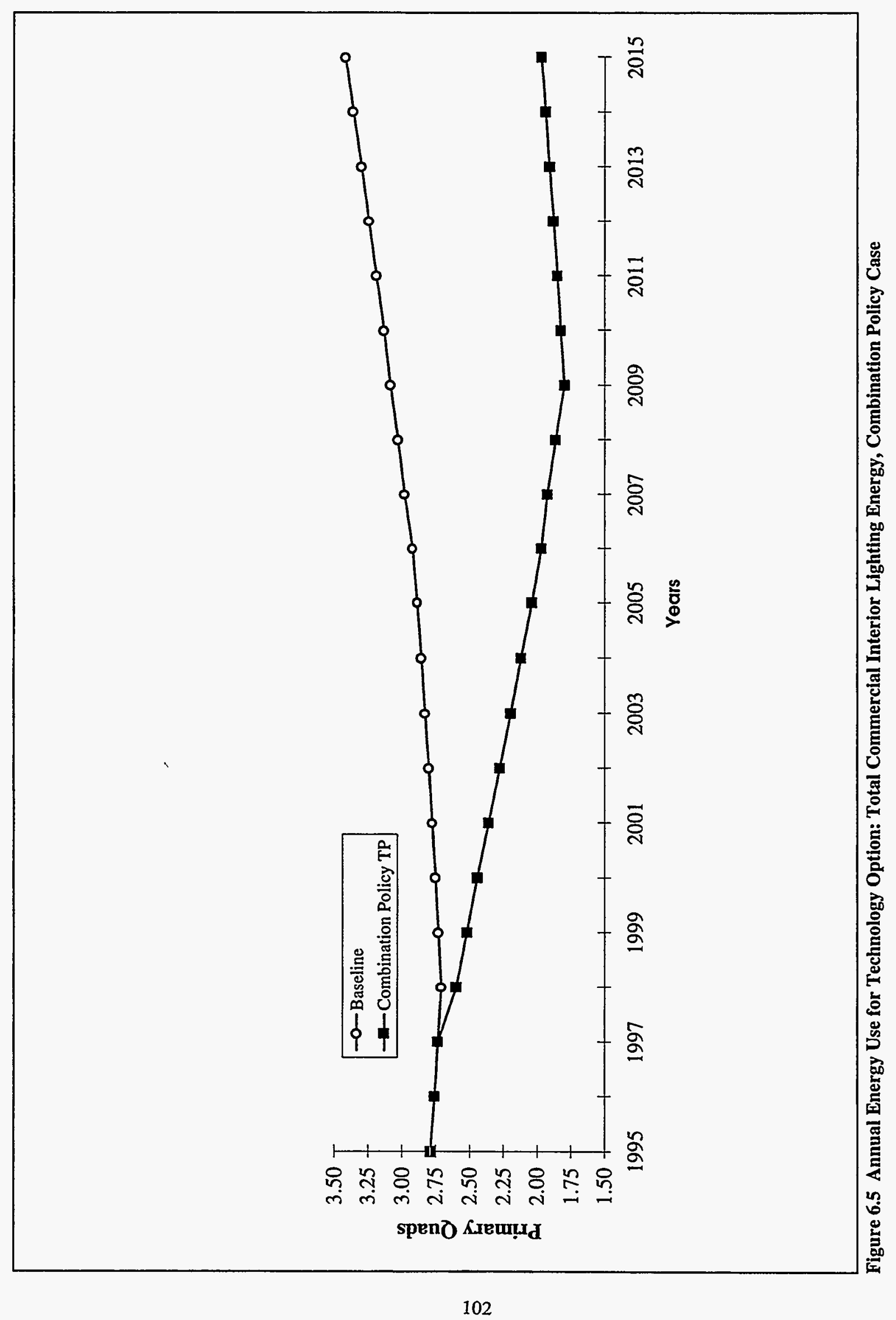


Table 6.1 Energy Use and Cost Summary for Commercial Interior Lighting

\begin{tabular}{|c|c|c|c|c|c|}
\hline OPTION & $\begin{array}{c}\text { EUI } \\
\text { (KWH/FT'/XR) } \\
\text { 1998 NEW } \\
\text { BUILDINGS } \\
\end{array}$ & $\begin{array}{c}\text { CHANGE IN } \\
\text { EUI FROM } \\
\text { BASELENE } \\
\left(\mathrm{KWE} / \mathrm{FT}^{2} / \mathrm{YR}\right)\end{array}$ & $\begin{array}{l}\text { CHANGE IN } \\
\text { EUI (\%) }\end{array}$ & $\begin{array}{l}\text { Change in } \\
\text { Price (\$)* }\end{array}$ & $\begin{array}{c}\text { Payback } \\
\text { Period (YRS) }\end{array}$ \\
\hline Baseline & 2.96 & & & & \\
\hline \multicolumn{6}{|l|}{ Fluorescent } \\
\hline Scotopic Lamp & 2.46 & 0.50 & 17 & 0.50 & 0.67 \\
\hline \multicolumn{6}{|l|}{$\begin{array}{l}\text { Incandescent \& } \\
\text { Replacements }\end{array}$} \\
\hline $\begin{array}{l}\text { Efficient Incandescent } \\
\text { Lamp } 1 \text { (Improved HIR) }\end{array}$ & 2.76 & 0.20 & 7 & $5.00,4.00$ & $0.5,0.2$ \\
\hline $\begin{array}{l}\text { Efficient Incandescent } \\
\text { Lamp } 2\end{array}$ & 2.62 & 0.34 & 11 & $7.16,7.34$ & $0.4,0.3$ \\
\hline $\begin{array}{l}\text { Compact Electrodeless } \\
\text { Fluorescent }\end{array}$ & 2.93 & 0.03 & 1 & 13.50 & 0.6 \\
\hline CFL Electronic Ballast & 2.79 & 0.17 & 6 & $-8.22 * *$ & -5.3 \\
\hline CFL Dimmable Ballast & 2.70 & 0.26 & 9 & $-7.95 * *$ & -5.2 \\
\hline CFL Efficient Luminaire & 2.60 & 0.36 & 12 & $1.11^{* *}$ & -0.5 \\
\hline \multicolumn{6}{|l|}{ Controls } \\
\hline $\begin{array}{l}\text { Dimmable Fluorescent } \\
\text { Ballast }\end{array}$ & 2.64 & 0.32 & 11 & NA & NA \\
\hline Integrated Sensors & 2.45 & 0.51 & 17 & NA & NA \\
\hline Combination & 1.67 & 1.29 & 44 & NA & $\mathrm{NA}$ \\
\hline
\end{tabular}

* Where two values are given, the first is for incandescent general service and the second for reflector lamps.

** For CFL options, Change in Price is the change in annualized equipment plus labor cost at $4 \%$ real over 12 years. This value can be negative since both equipment and labor costs are saved with longer-lived CFLs.

Payback is the market share weighted-average of these two categories.

Payback is calculated using the present value of the cost of equipment and labor over the lifetime of the component with the longest life (e.g., CFL ballast). For incandescent/CFL comparison, this results in a negative payback.

For Scotopic Lamps, payback is weight-averaged by market share of each lamp type.

For Dimmable CFL, payback is calculated in comparison to CFL with non-dimmable electronic ballast.

For Efficient CFL Luminaire, payback is calculated in comparison with an incandescent luminaire.

Controls costs vary per building type; payback is not calculated. 


\title{
Table 6.2 Annual Energy Savings for Commercial Interior Lighting Technology Options
}

\author{
annual Energy Savings (Primary Quads)
}

\begin{tabular}{|c|c|c|c|c|c|}
\hline \multirow[b]{2}{*}{ OPTION } & & & & & \multirow[b]{2}{*}{$\begin{array}{c}\text { CUMULATIVE ENERGY } \\
\text { SAVINGS (QUADS) } \\
1998-2015 \\
\end{array}$} \\
\hline & 2000 & 2005 & 2010 & 2015 & \\
\hline Baseline* & 2.75 & 2.88 & 3.13 & 3.42 & 53.96 \\
\hline \multicolumn{6}{|l|}{ Fluorescent Lamps } \\
\hline Scotopic Lamp TP & 0.12 & 0.32 & 0.50 & 0.55 & 6.28 \\
\hline Scotopic Lamp EP & 0.01 & 0.10 & 0.26 & 0.40 & 2.99 \\
\hline \multicolumn{6}{|l|}{ Incandescents \& Replacements } \\
\hline Efficient Incandescent Lamp 1 TP & 0.04 & 0.11 & 0.18 & 0.20 & 2.2 \\
\hline Efficient Incandescent Lamp $1 \mathrm{EP}$ & 0.00 & 0.03 & 0.10 & 0.15 & 1.09 \\
\hline Efficient Incandescent Lamp 2 TP & 0.08 & 0.23 & 0.35 & 0.39 & 4.44 \\
\hline Efficient Incandescent Lamp 2 EP & 0.01 & 0.07 & 0.20 & 0.30 & 2.27 \\
\hline $\begin{array}{l}\text { Compact Electrodeless Fluorescent } \\
\text { TP }\end{array}$ & 0.01 & 0.03 & 0.04 & 0.04 & 0.51 \\
\hline $\begin{array}{l}\text { Compact Electrodeless Fluorescent } \\
\text { EP }\end{array}$ & 0.00 & 0.01 & 0.02 & 0.03 & 0.18 \\
\hline CFL Electronic Ballast TP & 0.04 & 0.12 & 0.18 & 0.20 & 2.28 \\
\hline CFL Electronic Ballast EP & 0.01 & 0.05 & 0.12 & 0.18 & 1.41 \\
\hline CFL Dimmable Ballast TP & 0.07 & 0.18 & 0.27 & 0.30 & 3.43 \\
\hline CFL Dimmable Ballast EP & 0.01 & 0.07 & 0.18 & 0.28 & 2.10 \\
\hline CFL Efficient Luminaire TP & 0.09 & 0.24 & 0.37 & 0.41 & 4.71 \\
\hline CFL Efficient Luminaire EP & 0.01 & 0.09 & 0.25 & 0.38 & 2.85 \\
\hline \multicolumn{6}{|l|}{ Controls } \\
\hline Dimmable Fluorescent Ballast TP & 0.07 & 0.20 & 0.32 & 0.35 & 3.97 \\
\hline Integrated Sensors TP & 0.12 & 0.34 & 0.52 & 0.58 & 6.59 \\
\hline Combination & 0.311 & 0.84 & 1.31 & 1.45 & 16.49 \\
\hline
\end{tabular}

*Baseline mumbers are annual energy consumption in primary Quads (not energy savings). TP = Technical Potential; EP = Economic Potential (for some options, Economic Potential is not modeled due to insufficient data). Lighting hours assumptions are 4103 hrs for fluorescents and 4270 hrs for incandescents.

Notes: $\quad$ CFL measures are assumed to be implemented in order. They enable succeeding measures.

All savings are from the Baseline. The Baseline assumes $20 \%$ CFLs and $80 \%$ incandescents in Edison sockets.

CFL Electronic Ballast substitutes CFLs with electronic ballasts for $33 \%$ more than baseline incandescent sockets. CFL Dimmable Ballast allows $25 \%$ more CFL substitution and saves $10 \%$ through dimming. CFL Efficient Fixture retrofits $33 \%$ of remaining incandescent sockets and saves 15 percent in all CFL luminaires. Dimmable Fluorescent Ballasts are assumed to be installed with daylight controls. This option enables the Integrated Sensors. 
In Table 6-1, payback is not presented as simple payback, but rather as the present value of equipment and labor costs of the option over a 12-year period (the estimated service life of a fluorescent or CFL ballast). This is done because each of the options may have a different lifetime; some CFL technologies have different lifetimes for separate lamp and ballast components.

The economic potential for each technology is lower than the technical potential in all cases. The payback period is negative for CFL technology options where the higher initial equipment costs are offset by labor and life-cycle equipment savings due to the longer life of the equipment relative to incandescent lamps. For these options, in later years the economic potential is almost the same as the technical potential. The penetration rates used for estimating economic potentials are based on payback periods calculated with present prices for each technology. Economic potentials are calculated under the assumption that no policy options (e.g., additional appliance standards and rebates) are employed to transform the marketplace.

In Table 6-2 all technologies are compared to the baseline for consistency. However, some advanced technology measures depend on the existence of previous technology options, and so measurement of their savings from the baseline is somewhat misleading. For example, the dimmable compact fluorescent ballast savings arise from the additional CFL market shares made possible by the dimming capability as well as the dimming itself. But the baseline has only $20 \%$ CFLs, which is below the technical potential for non-dimmable CFLs. Therefore, to allow calculation of the savings due only to dimmability, an option for non-dimmable CFLs with electronic ballasts (CFL Electronic Ballast) is presented in the tables. Dimmable CFLs may be compared with this case. Similarly, savings from efficient CFL luminaires may be compared with the Dimmable CFL cases. These savings arise from additional CFLs made possible by fixture retrofits as well as the savings from the increased luminaire efficiency.

Savings from the controls measures are both estimated from the baseline. However, the savings from the Integrated Sensors must be considered cumulative, since this option presumes the existence of dimmable fluorescent ballasts. Economic potential for these options has not been estimated because of the difficulty of estimating payback periods by building type. 


\section{DISCUSSION OF NATIONAL ENERGY SAVINGS - RESIDENTIAL SECTOR}

Figure 6-6 shows annual energy use for residential-sector interior and exterior lighting technologies for the time period 1995-2015. Figure 6-6 shows the baseline, four technical potential options, and four economic potential options.

In the baseline, equipment just meets the efficacy requirements of the Energy Policy Act of 1992 (incandescent halogen reflector lamp and fluorescent reduced-wattage lamp). Retiring equipment is replaced with new equipment representing the technology option. In the technical potential cases, the advanced technology replaces the baseline technologies in all applications where it is technically feasible. In the economic potential cases, the advanced technology replaces the baseline technology at a penetration rate determined by ADL's Market Forecast Penetration Curve for the Commercial/Industrial sector, shown in Figure 1.1. Penetration rates are a function of the payback periods. Equipment not replaced by the new technology remains at the baseline efficiency level.

Table 6-3 shows the baseline unit energy consumption (UEC in $\mathrm{kWh} / \mathrm{household/year)} \mathrm{and} \mathrm{the} \mathrm{change}$ in UECs for each of the modeled technologies. Table 6-3 also shows the incremental equipment costs (change in price) and simple payback periods for the technologies.

Table 6-4 shows the baseline energy use and the annual energy savings for specific years and the cumulative (1998-2015) energy savings relative to the baseline. The greatest energy savings is for the Efficient Incandescent 2. Note that these savings could represent any efficient incandescent technology with similar percentage savings. The technical potential energy use for this technology is 11 primary quads over the period 1998-2015, compared to a baseline lighting energy use of 28.5 quads, or a savings of $38 \%$ of total residential indoor and outdoor lighting electricity.

A combination case representing the total lighting technical potential for the residential sector was not modeled for this report. Technical potential savings from advanced fluorescent and incandescent technologies would be higher than those from the single incandescent technology.

In Table 6-3, payback is presented as simple payback. This method was chosen for consistency with the residential appliance analysis, as well as to represent residential consumer behavior. However, it is a simplistic assumption since the options have varying lifetimes (see the explanation in "Discussion of National Energy Savings - Commercial Sector"). The penetration rates used for estimating economic potentials are based on payback periods calculated with present prices for each technology. 


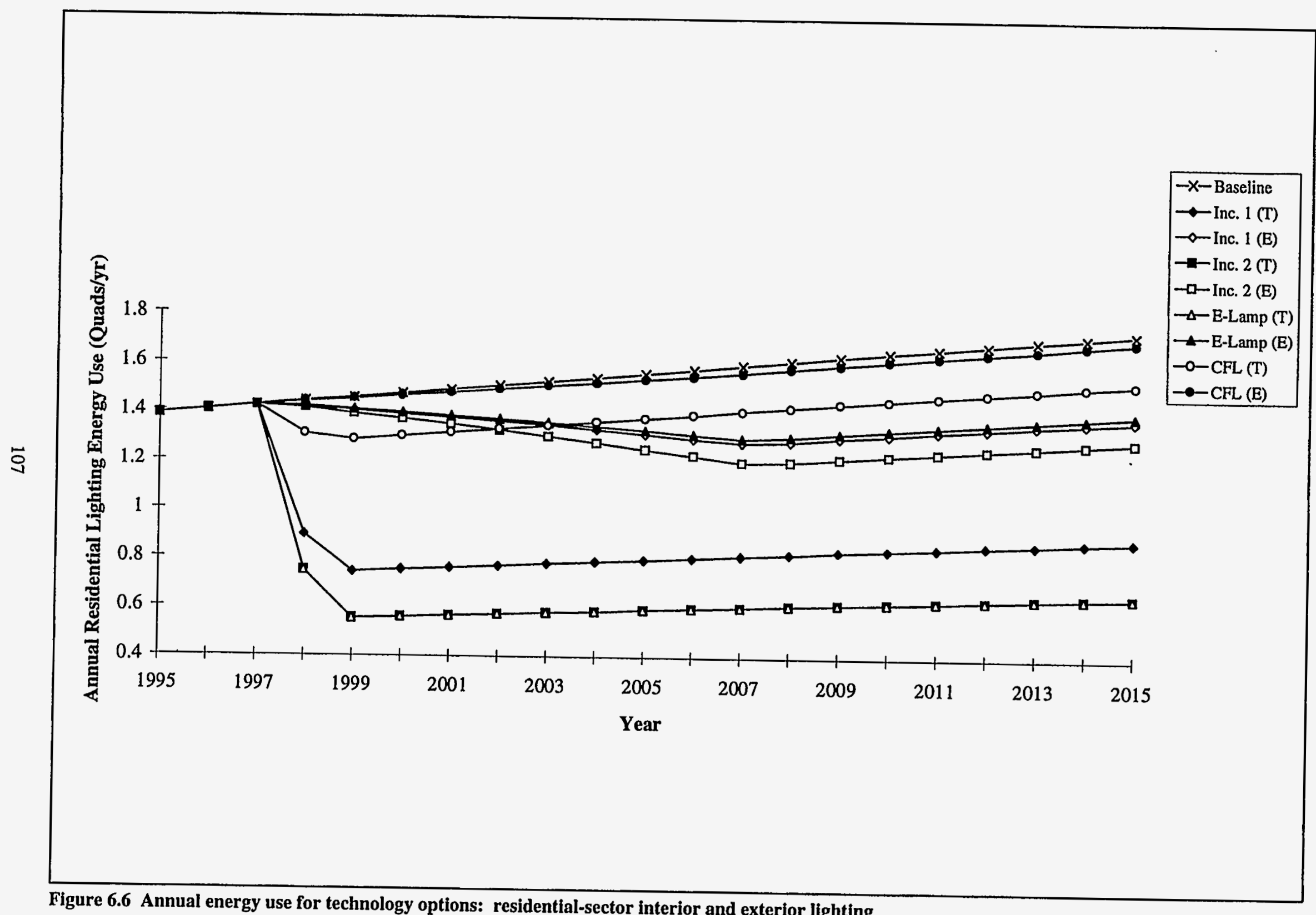

Figure 6.6 Annual energy use for technology options: residential-sector interior and exterior lighting 
Table 6.3. Energy Use and Cost Summary for Residential Sector Lighting

$\begin{array}{cccccc}\text { Option } & \begin{array}{l}\mathrm{UEC} \\ \text { (site } k W h / y r)\end{array} & \begin{array}{c}\Delta \mathrm{UEC} \\ \text { (site } k W h / y r)\end{array} & \Delta \mathrm{UEC}(\%) & \begin{array}{c}\Delta \text { Price } \\ (\$)\end{array} & \begin{array}{c}\text { Payback Period } \\ \text { (years) }\end{array}\end{array}$

\begin{tabular}{lccccc}
\hline Baseline & 1249 & - & - & - & - \\
$\begin{array}{l}\text { Eff. Incandescent 1 } \\
\text { (Improved HIR) }\end{array}$ & 722 & 527 & 43 & $\$ 8.52$, & 1.9, \\
Eff. Incandescent 2 & & & $\$ 4.81$ & 0.7 \\
& 464 & 785 & 63 & $\$ 11.15$, & 1.8, \\
Compact Electrodeless & & & $\$ 6.83$ & 0.7 \\
Fluorescent & 1174 & 75 & 6 & $\$ 19.81$ & 1.9 \\
CFL Efficient Luminaire & 987 & 262 & 21 & $\$ 35.00$ & 8.6 \\
\hline
\end{tabular}

Where two values are given for Change in Price and for Payback, the first is for incandescent general service and the second for reflector lamps.

Payback is simple payback, and is a weighted average for lamps with varying hours of use. Assumptions are that incandescent and CFL general service lamps are used $1593 \mathrm{hrs} / \mathrm{yr}$ and that incandescent and CFL reflector lamps are used $2228 \mathrm{hrs} / \mathrm{yr}$. The weighted-average usage is $1657 \mathrm{hrs} / \mathrm{yr}$.

The CFL Efficient Luminaire option assumes CFL dedicated table and floor lamp fixtures replace 50 percent of baseline high-usage interior and exterior incandescents; the remaining incandescents stay at baseline efficiencies.

Table 6.4 Annual Energy Savings for Residential Sector Lighting Technology Options

\begin{tabular}{|c|c|c|c|c|c|c|}
\hline \multirow[b]{2}{*}{ Option } & \multirow[b]{2}{*}{ Case"* } & \multicolumn{4}{|c|}{$\begin{array}{l}\text { Annual Lighting Energy Savings } \\
\text { (Primary Quads) }\end{array}$} & \multirow{2}{*}{$\begin{array}{c}\text { Cumulative } \\
\text { Energy Savings } \\
\text { (Quads) } \\
\text { 1998-2015 }\end{array}$} \\
\hline & & 2000 & 2005 & 2010 & 2015 & \\
\hline Baseline* & & 1.472 & 1.558 & 1.647 & 1.728 & 28.517 \\
\hline \multirow[t]{2}{*}{ Eff. Incandescent 1} & TP & 0.61 & 0.65 & 0.69 & 0.72 & 11.73 \\
\hline & EP & 0.07 & 0.21 & 0.28 & 0.30 & 3.71 \\
\hline \multirow[t]{2}{*}{ Eff. Incandescent 2} & $\mathrm{TP}$ & 0.91 & 0.97 & 1.02 & 1.08 & 17.50 \\
\hline & EP & 0.10 & 0.31 & 0.42 & 0.44 & 5.46 \\
\hline \multirow{2}{*}{$\begin{array}{l}\text { Compact Electrodeless } \\
\text { Fluorescent }\end{array}$} & TP & 0.09 & 0.09 & 0.10 & 0.10 & 1.67 \\
\hline & EP & 0.01 & 0.02 & 0.03 & 0.03 & 0.39 \\
\hline \multirow[t]{2}{*}{ CFL Efficient Luminaire } & TP & 0.30 & 0.32 & 0.34 & 0.36 & 5.81 \\
\hline & EP & 0.02 & 0.04 & 0.06 & 0.06 & 0.75 \\
\hline
\end{tabular}

- Baseline numbers are annual energy consumption in primary quads, not energy savings.

*. TP $=$ Technical Potential; EP = Economic Potential. 


\section{TECHNOLOGIES WITH INSUFFICIENT INFORMATION TO MODEL}

\subsection{IMPROVED COMPACT HID LAMPS}

Present Status. Compact HID lamps have the potential to penetrate incandescent markets where higher wattage HIDs have been too large. Color rendition and start-up/restrike times need to be improved in order to compete with incandescents, but there are no major design hurdles (Bleasby 1993).

\subsection{QL LAMP}

Present Status. The QL Lamp, or "QL Induction Lighting System," by Philips is in the preliminary stages of marketing in the U.S. Philips hopes this lamp will replace 70-W metal halide and 100-W mercury vapor lamps. The 85 -W lamp produces 6000 lumens (efficacy $=70.6 \mathrm{LPW}$ ), slightly more than a 70-W metal halide lamp at 5000 initial lumens (efficacy $=71.4$ ); and the $55-\mathrm{W}$ version produces 3500 lumens (efficacy $=63.6$ ). Both last 60,000 hours, making them attractive for inaccessible locations. Lumen depreciation at 60,000 hours is less than $30 \%$, due to the lamp's rare earth phosphors. The long lifetime of the QL lamp is brought about by the elimination of the electrode, the element most likely to cause fluorescent lamp failure (Nadel 1993). With no filament, there is no sputtering and deposition on the lamp wall, which contributes to lumen depreciation. In contrast, the lifetime of a metal halide lamp is 10,000 to 15,000 hours.

The QL lamp has FCC Class A status, so it has no restrictions for use in the commercial/industrial market. Philips is applying for Class B status, which would allow residential use, possibly for lighting in multifamily buildings.

The color-rendering index of the QL lamp is the same as that of other lamps with rare earth phosphors, i.e., between 70 and 82. The ignition time and the hot restrike time of the QL lamp are less than 0.1 second. Within 1 second the lamp reaches full light output. The lamp can be coldstarted at temperatures as low as $-20^{\circ} \mathrm{C}$ and can operate over a wide range of temperatures (Ryan 1993).

Energy Use and Cost. The QL lamp system will cost $\$ 175-200$ to original equipment manufacturers (OEMs), who will then package it into a luminaire. Replacement of a 100-W mercury vapor lamp by the 85-W QL lamp will yield a 15\% savings, with an increase in lumen output from 4300 to 6000 . For the same lumen output, fewer QL lamps can be used in a lighting system for greater savings. However, note that the efficacy is lower than that of metal halide or high-pressure sodium lamps.

Applications. The market for the QL lamp is the same as that for high-color-rendering HID lamps. It has the potential to save energy when replacing lamps of lower efficacy that are very difficult to replace; the longer-lived QL lamp would be chosen over a more efficacious but shorter-lived HID. 
Barriers to Implementation. The QL lamp requires a special luminaire that includes a radio frequency generator with shielding. The temperature of the generator, which sits in the ballast compartment, must be kept below $65^{\circ} \mathrm{C}$. At present the QL lamp is manufactured in higher wattage only. Because of its high cost, consumers will require education about the lamps energy-efficient benefits and its long life. The retrofit potential is small because of the high labor costs associated with retrofitting existing fixtures.

\subsection{ADVANCED FLUORESCENT REFLECTOR DESIGN}

Present Status. Currently produced fluorescent luminaires range in efficiency from 60-70\%. Low efficiencies are particularly common in luminaires designed for low glare. However, improvements in the design of luminaires, and in particular reflectors, can increase luminaire efficiencies with little or no compromise in glare control.

Many U.S. manufacturers are researching advanced reflector design. The Centre d' Energetique in Paris is studying the use of non-imaging optics in luminaire design under contract with the Electric Power Research Institute (EPRI). The modification of reflector materials and geometry can improve light distribution, minimize trapping of radiation within the luminaire, increase luminaire efficiency, and potentially lengthen lamp life due to cooler operation. The project will produce prototype luminaires as well as guidelines for improved reflector design by manufacturers by 1994 (Nadel 1993).

Energy Use and Cost. The theoretical range of energy savings from advanced luminaire/reflector design is $15-25 \%$. Preliminary estimates show an incremental cost of $\$ 20$ over standard reflector cost (Nadel 1993; Rubinstein 1993).

Applications. Improved luminaire design is applicable to all end uses where fluorescent lamps are currently used.

Barriers to Implementation. Manufacturers' and end users' acceptances are the major barriers. Architects and engineers must be made aware of the product and its advantages to ensure appropriate specification. These systems will be applied primarily to new fixtures and installations. The retrofit potential is small because of the high labor costs associated with retrofitting existing fixtures. 


\subsection{TherMaL BRDgING FOR FLUORESCENT FIXTURES}

Present Status. Fluorescent lamp efficacy is greatly affected by the temperature of the lamp wall. The ideal minimum lamp wall temperature (MLWT) is approximately $104^{\circ} \mathrm{F}$. Lamp performance is reduced above or below this temperature. In an enclosed fixture, temperatures can reach 130$140^{\circ}$, thereby reducing lumen output by $15-20 \%$.

Measures to reduce the MLWT are being developed at LBL. One is a liquid-filled pouch, attached between the top of the lamp and the shell of the fixture. Heat is convected via the pouch to the shell and subsequently to the ambient air. Another measure consists of a piece of metal (a T-bridge) snapped to the top of the lamp. The T-bridge conducts heat from the lamp to a cooling fin above the fixture and then to the ambient air. Each requires about a square inch of contact area with the lamp wall, and both maintain MLWT near the desired level over a wide range of ambient temperatures (Nadel 1993). LBL has preliminary agreements with three large luminaire manufacturers to produce prototypes of both systems.

LBL has also developed a system for lowering the MLWT of compact fluorescents. The short end of a wire in the shape of the number "7" is attached to a shoulder of the lamp; the long end is attached to a heat sink outside the fixture.

Energy Use and Cost. For 4-foot and compact fluorescent lamps, these cooling technologies can increase lumen output by 15-20\% (Nadel 1993). Assuming fewer lamps would be necessary with the cooling systems, a maximum energy savings of 15 to $20 \%$ can be achieved. Manufacturers estimate the additional cost of the thermal bridging technology will not exceed $\$ 5$.

Barriers to Implementation. Manufacturers' and end users' acceptances are the major barriers. Architects and engineers must be made aware of the product and its advantages to ensure appropriate specification. These systems will be applied primarily to new fixtures and installations. The retrofit potential is small because of the high labor costs associated with retrofitting existing fixtures.

\subsection{ADVANCED LIGHTING DISTRIBUTION SYSTEMS}

Present Status. Advanced systems that use concentrated high-intensity light sources and sophisticated light-distribution systems are being developed to provide light to remote locations. Such systems can replace multiple low-light output sources with one distributed high-output source for a variety of applications. If the source used is significantly more efficient than a conventional source, the system has the potential to reduce energy use and also to raise productivity through improved optical design and glare control.

Fiber optics, light pipes, prismatic light guides, lens guides, and reflective mirror guides can be used to distribute light within interior spaces. Fiber optics, light pipes, and prismatic light guides rely on internal reflections to transmit light. Lens guides and reflective mirror guides use a series of lenses, prisms, and mirrors to transport light. These designs are flexible, but lenses and reflective surfaces 
must be well maintained. The most efficient systems can transmit light as far as 75 feet (Nadel 1993). Light-distribution systems can be designed to provide general lighting as well as diverse specific task lighting.

For daylighting, holographic glazings can be used as part of a lighting-distribution system. They redirect incident light toward the ceiling, from which it is diffused. The extremely thin, transparent, holographic pattern fabricated on the glass is based on a design range of input and output angles. The technology is being developed by Advanced Environmental Research Group.

GE has developed a small lighting-distribution system called the Light Engine for display lighting and automotive applications. It uses a fiber optic light-transmission system with a 60-watt xenon-metal halide light source. The metal halide lamp has an electronic ballast and is capable of instant restrike. The system uses $72 \mathrm{~W}$ to produce 2500 lumens for a system efficacy of 35 lumens/watt with a colorrendering index of about 65-75. The light is delivered to multiple bundles of "large-core plastic optical fibers" as large as three-quarter inch in diameter. These new light guides are capable of conducting more than twice as much light as a bundle of small fibers of the same diameter (General Electric 1992). This technology will advance as more efficacious, higher lumen output sources are used in the future.

When advanced lighting-distribution systems are used, the light source can be located away from the conditioned space, allowing more efficient removal of the heat produced by the lamp and its power supply. Fewer sources and longer lamp life will reduce required maintenance. If the source lamp contains no mercury, its disposal is simpler and less costly than ordinary fluorescent lamps.

Energy Use and Cost. In some of the ongoing research into advanced lighting-distribution systems, very high efficacies are being predicted. Details of energy use and cost are not available.

Costs for light-pipe systems are approximately $\$ 1 / \mathrm{ft}^{2}$ of lit area, varying with building design. Holographic glazing fabrication costs are estimated by LBL to be approximately $\$ 5 / \mathrm{ft}^{2}$ when commercialized. Energy savings vary greatly, but can range from $20-30 \%$ of lighting load. The GE Light Engine can have energy savings when used in applications where color is critical and where an efficient central light source is distributed through a filtered transmission system as a substitute for incandescent lighting. However, there are no energy savings in the majority of system applications, since light engine system efficacy is below that of individual fixtures using the same light source.

Applications. Advanced lighting-distribution systems are applicable to general illumination in offices, schools, and stores, as well as in factories and on manufacturing lines in the industrial sector.

Architectural daylight systems are likely to be used only in new construction and major renovation projects. The Light Engine is applicable to theatrical applications, store designs, transportation, medical, and a variety of signage applications (Nadel 1993).

Barriers to Implementation. Product availability is the first barrier to the use of advanced lightingdistribution systems. Once there are demonstrated products on the market, cost and consumer awareness are significant hurdles. Architectural daylight systems are likely to be used only in new 
construction and major renovation projects. Light pipes and holographic glazings can be costeffective in appropriate applications.

\subsection{OPTIMIZED LUMMNAIRES AND. CONTROLS}

Present Status. EPRI and Genlyte are developing an advanced lighting system that integrates highreflectivity anodized aluminum and vacuum-deposited silver reflectors, T-8 and T-5 fluorescent lamps, high-frequency electronic ballasts, passive infrared occupancy sensors, photo sensors, and electronic controls. All components are currently available. The system is modular and uses luminaires of different kinds including suspended, recessed, 1-lamp, 2-lamp, and 3-lamp, as well as controls and software to analyze the lighting quality for the user. The system is being studied for the office sector and will meet the criteria established in the IES Recommended Practice RP-24 for VDT areas. In addition to energy savings, the system affords higher lighting quality, which reduces glare on computer screens.

Additional wiring is required for the controls. Some of the manufacturing changes require major investments in metal fabrication tooling and in electronic integrated circuits. The system is anticipated to be available by third quarter 1994. The indirect/direct luminaire has already been produced. Current government programs include utility support of R\&D. Demonstration and evaluation are in progress.

Lighting quality is becoming increasingly prominent in the discussions on energy-efficient lighting not only among lighting designers but also between utilities and policymakers. Systems integration holds considerable promise for future lighting design.

Energy Savings and Cost. Using about one-third the energy of current practice, the Advanced Lighting System will meet the RP-24 standards. Efficacy will be 85 lumens per watt (Blitzer 1993). Compared to the standard-practice parabolic luminaire with three lamps and an average luminaire efficiency of 66\%, the system's ESVS (Energy Smart/Vision Smart) luminaire uses two lamps and has a luminaire efficiency of $70 \%$.

The cost premium for the fixture is $\$ 30$ ( $\$ 100$ vs. $\$ 70$, both fixtures with magnetic ballast and without lamps.) Additional incremental costs accrue for the electronic ballast and T8 lamps. The costs of controls are comparable to those estimated by Atkinson et al. (1992). The payback on lumen maintenance is too small to pay for the dimming ballast and occupancy sensors without daylighting (Blitzer 1993).

Applications. The Advanced Lighting System is designed for use in commercial and institutional offices, laboratories, libraries, and other areas where computer terminals (VDTs) are used. The 
market penetration of the technology is predicted to be $5 \%$ of existing buildings and $50 \%$ of new buildings.

Barriers to Implementation. The most important barrier to implementation is the lack of understanding of the benefits of lighting quality. Utilities have typically been less concerned with lighting quality than with energy savings, and much work to date has considered only footcandles instead of overall lighting quality.

There are also objections based on initial cost and risk. Initial system cost will decrease as market share increases. Users need assurance that projected savings will be achieved and that employees will accept the new lighting system.

\subsection{SULFUR LAMP}

Present Status. The sulfur lamp is a high-efficacy, high-lumen package light source. The system consists of a power source that feeds radio-frequency or microwave radiation to a small rotating quartz sphere that contains sulfur and a mixture of noble gases, creating molecular emissions in the sulfur gas. Broadband visible light can be produced by adjusting the gas mixture with very little infrared or ultraviolet emissions.

The advantages of the lamp are high efficacy, long life resulting from the high lumen maintenance from lack of electrodes and phosphors, no use of mercury, high color rendition with a smooth output spectrum, quick start and restrike, precise optical control from the small point source, and dimmability.

Fusion Lighting has led the development and commercialization of the sulfur lamp, and LBL has developed prototypes. Several test installations have been set up in the US and Sweden. Fusion expects to introduce a second-generation product on the market in 1995.

Energy Savings and Cost. Fusion Lighting expects its high power microwave frequency ( $2.45 \mathrm{Ghz})$ version to draw 5000 input watts and produce 480,000 lumens for an efficacy of $96 \mathrm{LPW}$. LBL has built a lower wattage radio frequency ( $33 \mathrm{MHz}$ ) prototype that is expected to achieve $130 \mathrm{LPW}$, far higher than any other white light source available today.

Applications. The first applications for the sulfur lamp will be to light large spaces such as stadia. It may replace HWD sources for tasks requiring high lumen output. It can also be used to power fiberoptic and other light distribution systems; one lamp could potentially replace many fluorescent fixtures in a building.

Barriers to Implementation. The sulfur lamp must be rotated constantly to provide uniform light output and color since the microwave field is not uniform. This requires a motor and mechanical parts that require maintenance. Shielding must be provided from radio frequency or microwave radiation to protect people nearby during maintenance or in the case of fixture damage. FCC requirements must be met to prevent interference with communications and entertainment equipment. 
shielding as well as to ensure proper photometrics from the small high-intensity light source. Microwave magnetron efficiency must be increased. The lamp must compete economically with HID sources. Costs of complex light distribution systems can be high:

\subsection{SUMMARY}

Significant potential energy savings beyond those achieved through existing efficiency standards are possible. These savings can be realized by accelerating the introduction to the marketplace of new technologies discussed in the previous chapters. Possible approaches include increased support of research and development, additional rebate programs, Golden Carrot-type manufacturer incentives, education programs, and early retirement programs. It is important to recognize that additional national energy efficiency standards are likely to impact all of the end uses discussed in this report.

A large number of new technologies have been analyzed. In Table 7.1 we list some example technologies (or combinations of technologies) for all of the end uses studied, except for dishwashing (where specific technologies were not identified). The technologies included in Table 7.1 are representative of what is reasonably possible; they are by no means the best, or only, technologies by any criteria considered in this report. In this report, there is no specific recommendation of any technology.

Table 7.1 shows the estimated annual primary energy use in 2010 of selected end uses under two scenarios. First, end-use consumption is calculated for a base case where models that only meet the present standard replace existing models as these reach the end of their lifetime. New households also receive appliances with efficiencies equal to that of the standard. Second, models with efficiencies equal to the technology under consideration replace existing models that reach the end of their lifetime. New households receive appliances with efficiencies equal to that of the technology option under consideration. Both of these quantities are shown in Table 7.1. The difference in energy use between cases 1 and 2 is the energy that would be saved by replacement of stock with models that have efficiencies equal to the technology under consideration rather than by models with efficiencies equal to the applicable efficiency standard. With this approach, credit is not taken for energy savings that will result from replacement of existing appliances with higher efficiency models required by efficiency standards that are already in place.

The individual technical potential energy savings cannot be added together to obtain the total technical potential for the residential sector. First, not all end uses have been considered and second, there are interactions between some end uses (e.g., clothes washers and water heaters). However, it is possible to add together end-use energy consumption for refrigerator-freezers, gas and electric water heaters (includes most of dishwasher and clothes washer energy use), electric clothes dryers. space heating and cooling and residential lighting. Total base case energy use for these end uses in 2010 is 13.88 primary Quads. This can be decreased to 9.70 primary Quads, a 30\% reduction in 2010. The percentage reduction will increase somewhat in later years as additional stock appliances are retired from use. The technologies utilized in this calculation are the combined refrigerator-freezer options (see Table 7.1), condensing gas water heaters, electric heat pump water heaters, microwave dryers, gas engine driven heat pumps, and coated filament incandescent lamps. Horizontal axis washers were not utilized in this particular scenario. 


\section{Table 7.1 Summary of Potential Energy Savings from Selected Advanced Technologies}

\begin{tabular}{|c|c|c|c|}
\hline \multirow[b]{2}{*}{ Product } & \multicolumn{2}{|c|}{$\begin{array}{c}\text { Energy Use in } 2010 \\
\text { (Quads/Year) }\end{array}$} & \multirow[b]{2}{*}{ Selected Technology } \\
\hline & Base Case & $\begin{array}{c}\text { New } \\
\text { Technology }\end{array}$ & \\
\hline Refrigerator-freezer & 1.09 & 0.83 & $\begin{array}{l}\text { ECM fans, } 5.8 \text { EER compressor, VPI, } \\
\text { adaptive defrost, improved gaskets }\end{array}$ \\
\hline Clothes washer + clothes dryers & 1.21 . & 1.02 & Horizontal axis \\
\hline Clothes washers + clothes dryers & 1.21 & 0.86 & $\begin{array}{l}\text { Horizontal Axis plus higher spin } \\
\text { speed }\end{array}$ \\
\hline Clothes dryers & 0.62 & 0.54 & Microwave dryer \\
\hline Gas Water Heaters ${ }^{2}$ & 1.78 & 1.41 & Condensing water heater \\
\hline Electric Water Heaters ${ }^{2}$ & 2.33 & 0.93 & Heat pump water heater \\
\hline \multirow[t]{2}{*}{ Space heating and cooling } & $6.41^{3}$ & 5.48 & $\begin{array}{l}\text { Electric variable-speed air-source heat } \\
\text { pump }\end{array}$ \\
\hline & $6.41^{3}$ & 5.36 & Gas engine driven heat pump \\
\hline Lighting, Commercial & 3.13 & 1.82 & $\begin{array}{l}\text { Scotopically-rich fluorescent lamps, } \\
\text { CFLs with efficient luminaires, } \\
\text { compact electrodeless fluorescents, } \\
\text { HIR lamps, integrated workstation } \\
\text { sensors, CFLs }\end{array}$ \\
\hline Lighting, residential & 1.65 & 0.63 & Coated filament incandescent lamp \\
\hline
\end{tabular}

${ }^{1}$ Technical potential is expressed in primary quads.

${ }^{2}$ Includes energy to heat water used by dishwashers and clothes washers

${ }^{3}$ Includes all electric, gas, and oil energy for space conditioning.

\section{ACKNOWLEDGEMENTS}

This work was supported by the Assistant Secretary for Conservation and Renewable Energy, Office of Building Technologies of the U.S. Department of Energy, under Contract No. DE-AC0377SF00098. The authors wish to thank two reviewers of this report, Hashem Akbari and Jonathan Koomey of LBL, for their many helpful comments. 


\section{REFERENCES}

\section{INTRODUCTION}

1. McMahon, J.E. 1987. "The LBL Residential Energy Model: An Improved Policy Analysis Tool." Energy Systems and Policy, Vol. 10, No. 1, pp. 41-71.

2. Harris, J. 1994. Federal Policy Options for Cooperative Development and Deployment of Advanced Appliances and Equipment. Lawrence Berkeley Laboratory Report LBL-36567, 1994.

\section{REFRIGERATORS AND FREEZERS}

1. EPA, 1992. "Finite element analysis of heat transfer through the gasket region of refrigerator/freezers", EPA/430/R-92/009, EPA, Washington D.C., October, 1992.

2. EPA2, 1993. "State of the art survey of motor technology applicable to hermetic compressors for domestic refrigerator/freezers", EPA/430/R-93/009, Washington D.C., June, 1993.

3. General Electric, 1992. G. Mellinger and K. Downs, "Development and application of vacuum insulation technology to refrigerators", presented at the 1992 International CFC and Halon Alternatives Conference, Washington D.C., September, 1992.

4. Griffith, 1992. B. Griffith and D. Arasteh, "Advanced Insulations for Refrigerator/Freezers: The Potential for New Shell Designs Incorporating Polymer Barrier Construction", LBL Report 33376, Lawrence Berkeley Laboratory, November, 1992.

5. Multiple Pathways, 1993, "Multiple pathways to super-efficient refrigerators", EPA-430-R-93008, June 1993.

6. Technology Alert, 1993. "Energy-efficient compressors for use in refrigerators and home air conditioners", EPA 430-F-93-008, June 1993.

7. Waldron, 1992. "Vacuum panel and thick wall foam insulation for refrigerators: cost estimates for manufacturing and installation"/ J. Waldron, EPA/430/R-92/110, EPA, Washington D.C. October, 1992.

8. U. Wenning, "Hydrocarbons as PU Blowing Agents in Domestic Appliances," Proceedings of 1993 International CFC and Halon Alternatives Conference," Washington, D.C., 1993. pp. 316325.

\section{Clothes Washers, Clothes Dryers, and Dishwashers}

1. AHAM, 1990, "Comments of AHAM to DOE on energy conservation standards for clothes washers: horizontal axis technology", December 12, 1990. 
2. Appliance Magazine, 1993, "A cleaner future", Dana Chase Publication, Oak Brook, IL 60522, July 1993.

3. Appliance Manufacturer, 1993, "Neuro-Fuzzy Logic Linked to Bubble Action", Business News Publishing, Troy, MI, 48084, May, 1993.

4. CCIG, 1992, S. Nadel et al., "Emerging technologies to improve efficiency in the residential and commercial sectors, prepared for California Conservation Inventory Group", February, 1993.

5. Consumer Electronics, September 5, 1994, pp. 35,36.

6. Consumer Reports, 1993, "Dishwashers", October, 1993.

7. Consumer Reports, 1993, "Washing machines- front loader or top-loader" November, 1993.

8. DOE, 1990, "Technical Support Document: Energy conservation standards for consumer products: dishwashers, clothes washers, and clothes dryers", DOE/CE -0299P, December, 1990.

9. EPRI1, 1993, "Development of a Microwave Clothes Dryer", EPRI TR-102114, July 1993.

10. EPRI2, 1993, Telephone conversation with John Kesselring, EPRI, October, 1993.

11. Lovett, 1981, D. Lovett, "An evaluation of assigning credit/debit to the energy factor of clothes washers based on water extraction performance", NBSIR 81-2309, 1981.

12. Nyle, 1987, D. Lewis, "The Nyle dehumidification residential clothes dryer", Nyle Corporation, Bangor Maine, November, 1987.

13. Pesci, 1989, "Comments on Notice of Proposed Rulemaking, from GMS Products", R. Pesci, Lake Oswego, OR, October 10, 1989.

14. Procter, 1989, "Comments by Procter and Gamble on Notice of Proposed Rulemaking", October, $5,1989$.

15. RMI, 1990, M. Shepard et al., "The state of the art: appliances", RMI, Snowmass, CO, 1990.

\section{WATER HEATING AND HOT WATER CONSERVATION}

1. DOE, 1990, "Technical Support Document: Energy Conservation Standards for Consumer Products: Dishwashers, Clothes Washers, and Clothes Dryers," DOE/CE -0299P, December 1990. 
2. CCIG, 1992, S. Nadel et al., "Emerging Technologies to Improve Efficiency in the Residential and Commercial Sectors, Prepared for California Conservation Inventory Group," February 1993.

3. J. Kieckmann, Memorandum to P. Teagon, et al., "Review of Technology Options, Report for Cooperative Advanced Appliance Project," Arthur D. Little, January 13, 1994.

4. ORNL, 1993, Telephone conversations with Robert DeVault, September 1993, and Ron Fiskum, October 1993.

5. EPRI, 1993, "EPRI/E-Tech Heat Pump Water Heater Sets New Standards for Efficiency, Cost, and Performance", Electric Water Heating News, Vol. 6, No. 3, pg. 1, Electric Power Research Institute, Palo Alto, Fall 1993

6. NREL, 1993, Telephone conversation with Craig Christensen, October, 1993.

7. Sheffer, 1994, Sheffer, M.B. and Lau, A.S., "Solar Water Heating in Pennsylvania," Solar Today, Vol. 8, No.1, pg.12-15, American Solar Energy Society, Boulder, CO, Jan/Feb 1994.

8. Koomey, J.G., C. Dunham, and J.P. Lutz, "The Effect of Efficiency Stnadards on Water Use and Water Heating Energy Use in the U.S.: A Detailed End-Use Treatment," May 1994, Lawrence Berkeley Laboratory Report No. LBL-35475, UC-000.

9. Novem, Trines, R., and Heijnen, I., "Improving Efficiency in Domestic Refrigeration Units in the Netherlands," Centre for the Analysis and Dissemination of Demonstrated Energy Technologies (CADDET) Newsletter, Sittard, The Netherlands, No. 3, September 1993, pg. 17.

\section{HeATING AND SPACE CONDITIONING}

1. ACHR News, 1991. Air Conditioning, Heating and Refrigeration News, "Glowcore ceases operation; will sell technologies", The Air Conditioning Heating and Refrigeration News, Business News Publishing Co., Troy, Michigan, May 25, 1992, p. 2.

2. ARI, 1992. Air-Conditioning and Refrigeration Institute, "Directory of Certified Unitary Products", Air-Conditioning and Refrigerating Institute, Feb., 1992, pp. 16-17.

3. American Society of Heating, Refrigerating and Air-Conditioning Engineers (ASHRAE), "Methods of Testing for Rating Combination Space-Heating/Water-Heating Appliances, ASHRAE Standard 124-1991", ASHRAE Transactions, Vol. 98, Part 1, Atlanta, 1992.

4. Andrews and Modera, 1991. J.W. Andrews and M.P. Modera, "Energy Savings Potential for Advanced Thermal Distribution Technology in Residential and Small Commercial Buildings", Lawrence Berkeley Laboratory, Draft Report LBL-31042, July, 1991.

5. CEC, 1992. "Residential Manual for Compliance with the Energy Efficiency Standards", California Energy Commission, Publication P400-92-001 (Form DHW-5), December, 1992. 
6. Cummings, 1993. R. Cummings, Personal Communication, The First Co., Dallas, Texas, October, 1993.

7. EIA, 1992. Energy Information Administration (EIA), "Housing Characteristics 1990, Residential Energy Consumption Survey", U.S. Department of Energy, Publication DOE/EIA-0314(90), May, 1992, Table 39.

8. EIA, 1993. Energy Information Administration (EIA), "Supplement to the Annual Energy Outlook 1993", U.S. Department of Energy, Publication DOE/ELA-0554(93), February, 1993.

9. EPA, 1993. "Space Conditioning: The Next Frontier", EPA 430-R-93-004, U.S. Environmental Protection Agency, Washington D.C., April, 1993.

10. EPRI, 1991. F.J. Keller, "The HydroTech 2000 Heat Pump", Proceedings from Meeting Customer Needs with Heat Pumps 1991, Electric Power Research Institute, Palo Alto, California, October, 1991.

11. R. Fiskum, 1993. Personal communication, U.S. Department of Energy, October, 1993.

12. Kavanaugh, 1993. S.P. Kavanaugh, R.S. Falls, J.K. Parker, "A Variable-Speed Ground-Source Heat Pump", Draft Report, The University of Alabama, Mechanical Engineering Department, Tuscaloosa, Alabama, November, 1993.

13. Kavanaugh, 1992. S.P. Kavanaugh, "Using Existing Standards to Compare Energy Consumption of Ground-Source Heat Pumps with Conventional Equipment", ASHRAE Transactions 1992, Vol. 98, Part 2.

14. GAMA, 1993. "October 1992 Consumers' Directory of Certified Efficiency Ratings for Residential Heating and Water Heating Equipment", Gas Appliance Manufacturers Association, Arlington, Virginia, October, 1992.

15. Klausing, 1993. Klausing, T.A., et. al., "GRI/York Engine-Driven Residential Gas Heat Pump", Proceedings of the 1992 International Gas Research Conference (Orlando, Florida, November, 1992), Government Institutes, Inc., April, 1993.

16. Kweller, Esher, "Derivation of the Combined Annual Efficiency of Space/Water Heaters in ASHRAE Standard 124-1991", Paper AN-92-2-2, ASHRAE Transactions 1992, Vol. 98, Part 2, American Society of Heating, Refrigerating and Air-Conditioning Engineers (ASHRAE), Atlanta, 1992.

17. D. Laybourne, 1993. Personal communication, Pacific Gas and Electric Co., San Francisco, California, July, 1993. 
18. McDonald, 1986. R. McDonald, et. al., "Report on pulse combustion oil boiler", Brookhaven National Laboratory, Upton, Long Island, New York, 1986.

19. D. Meyer, 1993. Personal communication, WaterFurnace International Inc., Fort Wayne, Indiana, October, 1993.

20. M. P. Modera, 1993. Personal communication, Lawrence Berkeley Laboratory, Berkeley, California, October, 1993.

21. S. Montini, 1993. Personal communication, AdobeAir, Inc., Phoenix, Arizona, October, 1993.

22. D. Morse, 1993. Personal communication, AdobeAir, Inc., Phoenix, Arizona, October, 1993.

23. C. L. Neal, 1993. Personal communication, North Carolina Alternative Energy Corporation, Research Triangle Park, North Carolina, October, 1993.

24. J.P. Proctor, 1993. Personal communication, Proctor Engineering Group, Corte Madera, California, October, 1993.

25. Proctor, 1992. J.P. Proctor and R.K. Pernick, "Getting It Right the Second Time: Measured Savings and Peak Reduction from Duct and Appliance Repairs", Proceedings from the ACEEE 1992 Summer Study on Energy Efficiency in Buildings, Washington, D.C., August, 1992.

26. Sears, 1993. Sears, Roebuck and Company, Spring/Summer Catalog 1993.

27. S. Shelton, 1993. Personal communication, Wave Air Corp. and Georgia Institute of Technology, October, 1993.

28. S. Swan, 1993. Personal communication, Carrier Corporation, Indianapolis, Indiana, October, 1993.

29. Berman, S.M., "Energy Efficiency Consequences of Scotopic Sensitivity," Journal of the Illuminating Engineering Society, Vol .21, No 1, Winter 1992, pp 3-14.

\section{LIGHTING}

1. Berman, S.M., "Energy Efficiency Consequences of Scotopic Sensitivity," Journal of the Illuminating Engineering Society, Vol .21, No 1, Winter 1992, pp 3-14.

2. Rubinstein, F., Lighting Systems Research Group, Lawrence Berkeley Laboratory (LBL), personal communication, Nov. 1993.

3. Clear, R., LBL Lighting Systems Research Group, personal communication, Nov. 1993. 
4. Lighting Systems Research Group, LBL.

5. Ibid.

6. Atkinson, B.A. et al., Analysis of Federal Policy Options for Improving U.S. Lighting Energy Efficiency: Commercial and Residential Buildings. LBL Report No. 31469, December 1992.

7. Quasi, F., Etta Industries, personal communication, Nov. 1993.

8. Yorgey, J., Lutron, personal communication, 22 Nov. 1993.

9. Nadel, S., Bourne, D., Shepard, M., Rainer, L., Smith, L. 1993. "Emerging Technologies to Improve Energy Efficiency in the Residential and Commercial Sectors." American Council for an Energy-Efficient Economy, Davis Energy Group, and E-Source, prepared for California Conservation Inventory Group, Feb. 1993.

10. Means Building Construction Cost Data (1993), 51st Annual Edition, R.S. Means Company, Inc. 1992.

11. Siminovitch, M., Energy Efficient Fixtures Program LBL, personal communication, Nov. 1993.

12. Ostaffe, M., Advance Transformer, personal communication, 1 Nov. 1993.

13. Rubinstein F., Automatic Lighting Controls Demonstration: Long-Term Results. July 1991, PG\&E report.

14. DOE/EIA. 1988. Non-Residential Buildings Energy Consumption Survey 1986. Energy Information Adminstration, Washington, D.C. DOE/EIA-0318(86).

15. Lighting Controls Scoping Study, 1993. Lighting Research Center for California Institute for Energy Efficiency.

16. Echelon Corporation product literature, Nov. 1993. Table 5.18, Summary of Thermal Distribution Improvements Potentials.

17. Lighting Systems Research Group, LBL.

18. Ibid.

19. Nadel et al., op. cit.

20. Ibid. 
21. Kelsey, J. 1992. "1991 Residential Appliance Saturation Survey -A Profile of the Residential Lighting Load in Northern California." Proceedings of the ACEEE 1992 Summer Study. Washington, D.C., p. 4.117.

22. Atkinson, et al., op. cit.

23. Bleasby, P., personal communicaiton, Nov. 1993.

24. Nadel et al., op. cit.

25. Ryan, B., Philips Corporation, personal communication, Nov. 1993.

26. Nadel et al., op. cit.

27. Nadel et al., op. cit.; Rubinstein, F., op. cit.

28. Nadel et al., op. cit.

29. Ibid.

30. Nadel et al., op. cit.

31. General Electric Company, GE Light Engine product literature, 1992.

32. Nadel et al., op cit.

33. Blitzer, W., Genlyte/Lightolier, personal communication, Nov 1993.

34. Atkinson, et al., op. cit.

35. Blitzer, W., Genlyte/Lightolier, personal communication, Nov 1993.

36. Nadel et al., op. Cit.

37. McGowan, T., General Electric Co., personal communication, Oct. And Nov. 1993.

38. Atkinson, et al., op. cit.

39. Nadel et al., op. cit.

41. Peralta, S.B. and Ruda, H.E., "Advanced Solid State Semiconductor Lighting Sources." Pub. \#07803-1462-x/93S03.00, IEEE 1993. 
42. Rubin, M., LBL Lighting Systems Research Group, personal communication, Nov. 1993.

43. Pakbaz, H., U.C. Santa Barbara, personal coummication, Nov. 1993.

44. Packer, M., LBL Lighting Systems Research Group, personal communication, Nov. 1993.

45. Peralta, S.B. and Ruda, H.E., op.cit.

46. National Lighting Product Information Program, Multilayer Polarizer Panels, Lighting Answers, Lighting Research Center, Rensselaer Polytecnic Institute, Vol. 1, No. 2, August 1993. pp. 1-5.

47. Nadel et al., op. cit.

48. Morse, O., LBL Lighting Systems Research Group, personal communication Nov. 1993.

49. Blake, N., Osram Sylvania, presentation at EPRI Lighting Workshop, Scottsdale, AZ, Dec. 1993.

50. Kelsey, J., op. cit.

51. Hawk, D., Etta Industries, personal communication, Dec. 1993. 


\section{Appendix 1. Simplified Approach to Calculate Technical and Economic Potential}

The EPAct Section 127 Report to Congress presents estimated energy savings for candidate advanced appliances based on a simplified approach. In the simplified approach, the technical and economic potential energy savings are calculated assuming that the entire stock of appliances is instantaneously replaced by the candidate advanced appliances. The calculation relies on determining the percent energy savings of an advanced appliance relative to the stock or baseline equipment. The percent energy savings is determined by calculating the percentage difference between the efficiencies of the advanced and baseline equipment. This calculation is performed as follows:

$$
\text { Percent Energy Savings }=\left[\left(\text { Efficiency }_{\text {oew }}-\text { Efficiency }_{\text {bsec }}\right) \div \text { Efficiency }_{\text {new }}\right] * 100
$$

The technical potential energy savings is determined by multiplying the baseline energy use of the stock equipment by the percent energy savings. The technical potential is calculated as follows:

\section{Technical Potential $=$ Stock Baseline Energy Use $\mathrm{x}$ Percent Energy Savings}

The economic potential is simply determined by multiplying the technical potential by the penetration rate of the advanced technology. The penetration rate is a function of payback period. The relationships between payback period and market penetration for residential retrofits and new construction are presented in the Introduction to this report. The economic potential is calculated as follows:

\section{Economic Potential $=$ Market Penetration Rate $\mathrm{x}$ Technical Potential}

Table A.1 summarizes the technical and economic potentials for several residential end uses. Residential end use is disaggregated into 29 different categories and those categories are listed in column two of Table A.1. A category is defined by fuel-type and end-use function. For example, in the end-use grouping of space-heating, there are nine different end-use categories. For each end-use category, the 1990 energy use in quads is provided. Energy use is listed in column four of Table A.1. The energy-use data are based on estimates from the LBL Residential Energy Model (LBLREM) for 1990. In column five of Table A.1, the corresponding efficiency of the stock equipment is provided. The stock efficiencies are also based on estimates from LBLREM for 1990. Column six provides the current minimum efficiencies as prescribed by the National Appliance Energy Conservation Act (NAECA). It should be noted that for several of the end-use categories, notably cooking and space-heating, the stock efficiency is equivalent to the NAECA minimum efficiency. This is because performance based standards do not exist for these end-uses. The type of energy descriptor for each end-use is listed in column nine.

Of the 29 end-use categories, advanced technologies are considered for only thirteen of the categories. Advanced technologies for the remaining categories (e.g., electric room space heating, 
oil-fired water heating, electric and gas-fired ovens) were determined not to yield great enough energy savings for the Department of Energy to consider in the EPAct Section 127 analysis. The thirteen end-use categories for which advanced technologies are considered fall into six end-use groups: space-heating, water heating, refrigeration, lighting, space-cooling, and laundry. In column two of Table A.1, footnotes designate the end-use categories where advanced technologies are analyzed. For each of these end-use categories, both best available and near-term developmental advanced technologies are analyzed. The footnotes detail the specific advanced technologies which are being analyzed. With the exception of one space-conditioning end-use category (electric central air conditioning), fuel-switching was not considered in the simplified approach. For example, advanced electric heat pump technologies were not considered as alternatives to standard gas furnaces. In columns seven and eight of Table A.1, the efficiencies corresponding to the best available and near-term developmental technologies are listed. Note that for end-use categories where advanced technologies are not being analyzed, the NAECA efficiency is carried over into the "best available" and "near-term developmental" columns.

Columns ten through thirteen of Table A.1 contain the payback periods and market penetration rates for the best available and near-term (available for mass production after 1998) developmental technologies that are analyzed. As described earlier, the market penetration rate is a function of the payback period and is necessary for determining the economic potential. The payback periods are based on estimated mature market costs rather than current costs. For the advanced space-heating and space-cooling technologies analyzed, the payback periods are "regionalized". The "regionalized" payback is shorter than the national average payback as heating and/or cooling load hours, electricity and fuel prices, and equipment efficiencies are adjusted to reflect the more favorable "payback environment" which the advanced technology is assumed to operate under. Although the payback periods have been "regionalized", economic potential energy savings are still based on national average payback periods. The purpose of "regionalizing" the payback is to demonstrate the improved cost-effectiveness of the technology for areas of the country that are more likely to accept it.

Columns fourteen through 22 of Table A.1 provide the technical and economic potentials calculated with the above equations. In the case of the energy savings calculated relative to the 1990 energy use, the stock efficiency becomes the "base" efficiency. In the case of the energy savings calculated relative to NAECA efficiency standards, the NAECA minimum efficiency becomes the "base" efficiency. It should be noted that in column fourteen, the technical potential of NAECA efficiency equipment is provided. The above equation for calculating technical potential is also used to determine the technical potential due to NAECA efficiency standards. The NAECA efficiency becomes the "new" efficiency while the stock efficiency is used as the "base" efficiency.

Thermal distribution systems are not considered within Table A.1 due to the difficulties in assigning economic values to thermal distribution improvement measures. The EPAct Section 127 Report to Congress characterizes one segment of the existing ducted distribution system stock (i.e., singlefamily homes with ducts located in unconditioned spaces), showing that a 0.34 quad per year savings can be obtained if all ducts were to be insulated to an R-8 level and sealed to the extent that leakage would be reduced by $50 \%$. The body of this report (Section 5.9) discusses other duct improvement measures for various segments of the thermal distribution system population. 
Table A.1 Technical and Economic Potentials Using Simplified Approach

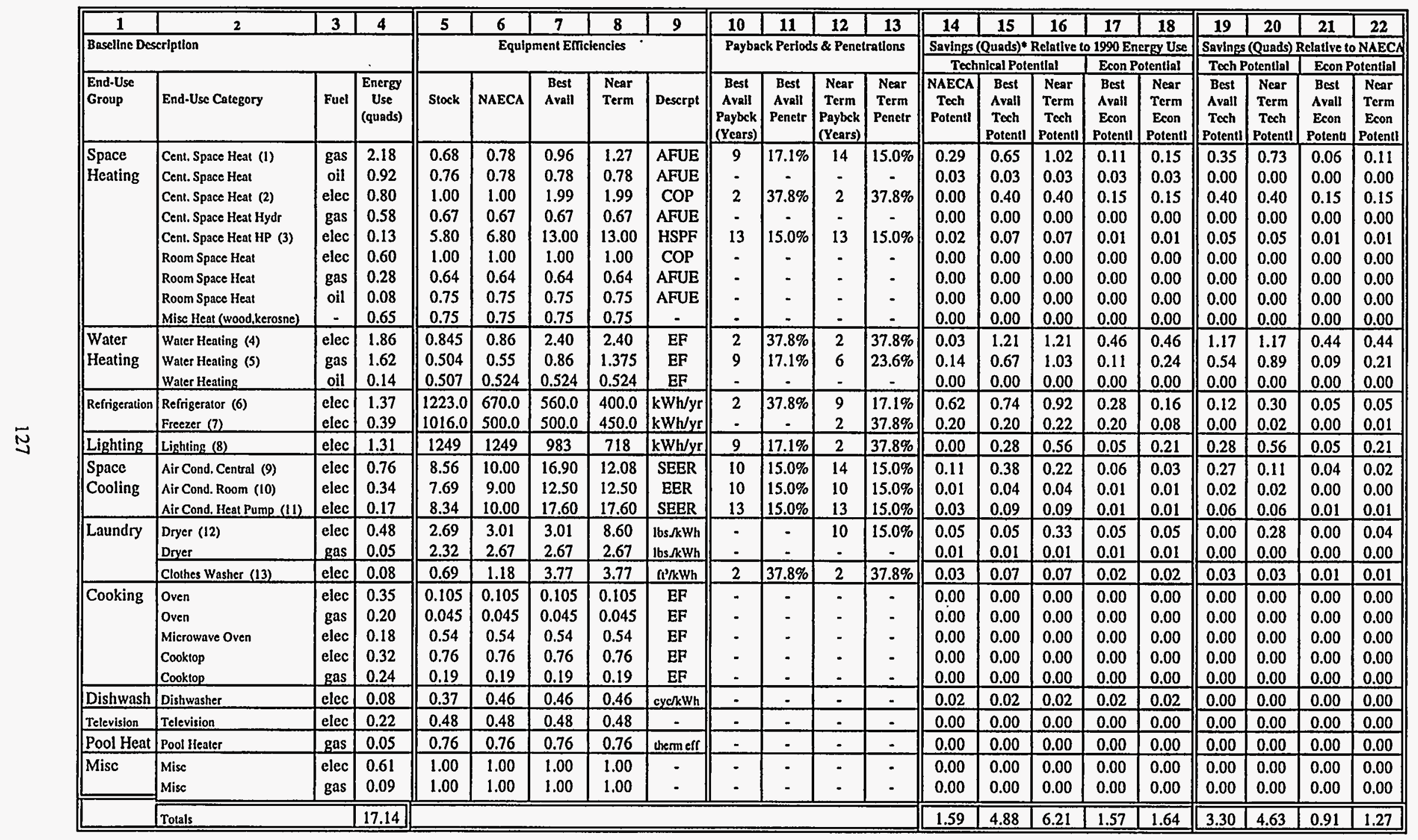




\section{Notes to Table:}

* Energy Use is primary Quads.

(1) Best Available Technology: Gas Condensing Furnace. Near-Term Developmental Technology: Gas Engine-Driven Heat Pump.

(2) Best Available Technology and Near-Term Developmental Technology: Electric Standard-Efficiency Heat Pump.

(3) Best Available Technology and Near-Term Developmental Technology: Electric Two-Speed Ground-Source Heat Pump. Heating Seasonal COP of 3.81 converted to an HSPF value by multiplying by $3.413 \mathrm{Btu} / \mathrm{kWh}$.

(4) Best Available Technology and Near-Term Developmental Technology: Electric Heat Pump Water Heater.

(5) Best Available Technology: Gas Condensing Water Heater. Near-Term Developmental Technology is Gas Absorption Heat Pump Water Heater.

(6) Best Available Technology: Refrigerator with Improved Gaskets and a 5.5 EER Compressor. Near-Term Developmental Technology: Best Available Unit with Adaptive Defrost, ECM fans, 5.8 EER Compressor, and VacuumPanel Insulation.

(7) Best Available Technology has same unit energy consumption as NAECA efficiency Freezer. Near-Term Developmental Technology is assumed to use $10 \%$ less energy than NAECA efficiency Freezer.

(8) Best Available Technology: CFL Dedicated Luminaire. Near-Term Developmental Technology: Improved Halogen IR Lamp.

(9) Best Available Technology: Electric Variable-Speed Central Air Conditioner. Near-Term Developmental Technology: Gas Engine-Driven Heat Pump.

Gas Heat Pump cooling seasonal COP of 1.05 converted to an SEER value by multiplying by a site-to-source conversion factor of $11,500 \mathrm{Btu} / \mathrm{kWh}$.

(10) Best Available Technology and Near-Term Developmental Technology: Hi-Efficiency Room Air Conditioner. Technical and Economic Potentials are based on replacing 30\% of stock. Room A/Cs with EERs of 12.5 have capacities of $\sim 10,000 \mathrm{Btu} / \mathrm{hr}$.

Room A/Cs with capacities of $\sim 10,000 \mathrm{Btu} / \mathrm{hr}$ comprise only $30 \%$ of current Room A/C shipments.

(11) Best Available Technology and Near-Term Developmental Technology: Electric Two-Speed Ground-Source Heat Pump.

(12) Best Available Technology has same efficiency as NAECA efficiency Dryer. Near-Term Developmental Technology: Heat Pump Dryer.

(13) Best Available Technology and Near-Term Developmental Technology: Horizontal-Axis Clothes Washer. 


\section{Appendix 2. Technologies Considered for Refrigerators and Freezers}

1. Increased insulation for cabinet and door

2. Improved foam insulation (e.g., microcell)

3. Vacuum insulation panels

4. Gas filled panels

5. Improved gaskets

6. Reduced heat load for through the door features

7. Reduction in energy used by anti-sweat heaters

8. Substitution of condenser hot gas for electric anti-sweat heat

9. Reduction of energy used by auto-defrost heater

10. Substitution of condenser hot gas for electric auto-defrost

11. Adaptive defrost system

12. Improved compressor efficiency

13. Two compressor system

14. Variable speed compressor

15. Improved fan motor efficiency

16. Improved fan efficiency

17. Variable speed fans

18. Two-stage two evaporator system

19. Two evaporator, single compressor system

20. Other refrigeration cycles (e.g., Lorenz, Stirling, gas-absorption, thermoacoustic)

21. Alternative refrigerants

22. Fluid control valves

23. Location of compressor, condenser and evaporator fan motor

24. Natural convection heat exchangers

25. Electrohydrodynamic enhancement of heat exchangers

26. Voltage control devices 


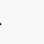

\section{.}




\section{Appendix 3. Technologies Considered for Clothes Washers, Clothes Dryers, and Dishwashers}

\section{Clothes Washers}

1. Improve Fill Control

2. Change configuration to reduce water use

3. Reduce thermal mass

4. Add Insulation

5. Increase Motor Efficiency

6. Thermostatically controlled mixing valves

7. Electrolytic dissociation of water

8. Ultrasonic vibration

9. Higher spin speed

10. Horizontal axis design

11. Bubble action

12. Microprocessor controls and fuzzy logic

13. Ozonated Laundering

\section{Clothes Dryers}

1. Automatic termination

2. Insulation

3. Recycle exhaust heat

4. Inlet air preheat

5. Inlet air preheat, condensing mode

6. Modified operating conditions

7. Heat pump

8. Microwave

\section{Dishwashers}

1. Improved food filter

2. Improved spray arm geometry

3. Improved fill control

4. Modified sump geometry

5. Reduced Inlet water temperature

6. Improved motor efficiency

7. Increased insulation

8. Flow-thru heating

9. Ultrasonic washing 
, 


\section{Appendix 4. Technologies Considered for Water Heaters}

\section{Gas Water Heaters}

1. Pilotless Instantaneous Water Heater

2. Condensing Storage Water Heater

3. Triple-Effect Absorption Heat Pump Water Heater

4. Indirect Water Heater (no central flue)

5. Instantaneous Water Heater (standing pilot)

\section{Electric Water Heaters}

1. Heat Pump Water Heaters

2. Solar

\section{Hot Water Conservation}

1. Efficient Showerheads

2. Efficient Faucet Aerators 
, 


\section{Appendix 5.1. Technologies Considered for Space- Conditioning Appliances}

\section{Gas Heating Technologies}

1. Condensing Furnace

2. Condensing Recuperating Furnace

3. Condensing Pulse Comb Furnace

4. Heat Pipe Furnace

5. Ceramic Fiber Burners

6. Condensing Boiler

\section{Gas Cooling Technologies}

1. Desiccant Evaporative Cooling

2. Desiccant Ground-Coupled Cooling

3. Gas Fired Absorption Cooling

4. Gas Fired Engine Driven Cooling

5. Heat Pipe-Assisted Air Conditioning

Gas Heating and Cooling Technologies

1. Gas Fired Absorption Heat Pump

2. Gas Fired Engine-Driven Heat Pump

3. Adsorption Heat Pump

4. Stirling Engine Driven Heat Pump

5. Direct Drive Heat Pump (Vuilleumier Cycle)

6. Thermophotovoltaic Self-Generation System

7. Gas Fired Absorption Boiler

Gas Integrated Heating, Cooling and Water Heating Technologies

1. Absorption Heat Pump

2. Engine-Driven Heat Pump

3. Condensing Water Heater / Fan Coil

4. Absorption Boiler
Electric Cooling Technologies

1. Variable-Speed Central Air Conditioner

2. Two-Speed Central Air Conditioner

3. High-Efficiency Air Room Conditioner

4. High-Efficiency Mini-Split Air Conditioner

5. Solar Photovoltaic Powered Mini-Split Air Conditioner

5. Direct Evaporative Cooling

6. Indirect/Direct Evaporative Cooling

7. Indirect Ventilative Cooling

8. High Efficiency Packaged Air Conditioner

Electric Heating and Cooling Technologies

1. Variable-Speed Air-Source Heat Pump

2. Two-Speed Air-Source Heat Pump

3. Water Source Heat Pump

4. Variable-Speed Ground Coupled Heat Pump

5. Two-Speed Ground Coupled Heat Pump

6. Single-Speed Ground Coupled Heat Pump

7. Multi-Zoned Variable-Speed Air-Source Heat Pump

8. Solar Photovoltaic Powered Variable-Speed Air-Source Heat Pump

9. Multi-Zoned Variable-Speed Ground-Source Heat Pump 
Electric Integrated Heating, Cooling and Water Heating Technologies

1. Variable-Speed Air-Source Heat Pump

2. Single-Speed Air-Source Heat Pump

3. Variable-Speed Ground Coupled Heat Pump

4. Two-Speed Ground Coupled Heat Pump

5. Single-Speed Ground Coupled Heat Pump

6. Multi-Zoned Variable-Speed Air-Source Heat Pump

7. Multi-Zoned Variable-Speed Ground-Source Heat Pump

Electric/Gas Heating and Cooling Technologies

1. Dual Fuel Heat Pump

2. Gas Hydronic Boiler / Electric Air Conditioner

\section{Oil Heating Technologies}

1. Condensing Furnace

Oil Heating and Cooling Technologies

1. Absorption Heat Pump

Oil Integrated Heating, Cooling and Water Heating Technologies

1. Absorption Heat Pump

\section{Other Technologies}

1. Improved Ducts and Fittings

2. Internal Access Duct Sealants

3. Training Programs for Servicing of HVAC Equipment

3. Active Solar Heating

4. Solar-Driven Absorption Cooling

5. Thermoelectric Cooling

6. Acoustic and Thermo-Acoustic Cooling

7. Hydraulic Refrigeration

8. Low Face Velocity / High Coolant

Velocity Coils

9. Zeotropic Refrigerants

10. Electrohydrodynamic Heat Transfer Enhancement

11. Occupancy Sensors

12. Organic Coatings on Heat Exchanger Coils 


\section{Appendix 5.2. Methodology for Characterizing and Ranking Technologies}

To establish which space-conditioning technologies were the most promising for saving energy on a national basis, a methodology was formulated to characterize and rank the technologies. The methodology consisted of (1) determining which space-conditioning systems the advanced technology could replace, (2) determining the actual percentage of new shipments, for each replaceable system, that the advanced technology would replace, (3) calculating a shipmentweighted source UEC for the advanced technology, (4) calculating a payback period for the advanced technology, and (5) ranking the advanced technology based on its capability to save energy and its cost effectiveness (payback).

\section{(1) Determining Replaceable Systems}

Technologies were categorized by fuel type (electric, gas, or oil) and function (space heating, space cooling, space heating and cooling, space heating and cooling plus water heating). For each category of technologies, the type of systems that could be replaced were chosen. For each category of advanced technology, Table 5.2.1 presents the systems that can be replaced. For example, in the case of gas heat pumps, we assume that homes needing either a new electric heat pump, new electric air conditioner, or new gas furnace can replace their equipment needs with a gas heat pump. Depending on the system being replaced, an additional piece of equipment might also need to be removed. Again using the example of gas heat pumps and examining the case where an electric air conditioner is being replaced, we assume that the air conditioner is being used with a gas furnace and, thus the existing gas furnace needs to be removed. The column titled "Stock Replacement" in Table 5.2.1 indicates whether an additional piece of equipment needs to be removed with the system that is being replaced.

\section{(2) Determining Replacement Percentage of New Shipments}

In order to establish the savings that are achievable through the use of an advanced technology, assumptions were made regarding the percentage of new shipments an advanced technology could actually replace. For each replaceable system, Table 5.2.1 summarizes the assumptions that were made in determining the percentage of new shipments that could be replaced by an advanced technology. Once defined, the percentage value was established with data from the 1990 U.S. Residential Energy Consumption Survey.

To illustrate the meaning of the percent value and how it is used to determine the percentage of shipments that can be replaced by a new technology, we examine the case of gas heat pumps. As shown in Table 5.2.1, gas heat pumps can replace new shipments of electric heat pumps, electric air conditioners, and gas furnaces. 
For replacing electric heat pumps, RECS data determined that $72 \%$ of all homes using electric heat pumps have natural gas. Thus, we assumed that only $72 \%$ of new shipments of electric heat pumps can be replaced with a gas heat pump technology.

For electric air conditioners, we determined that $80.1 \%$ of homes using electric central airconditioning units also used gas furnaces. Because the gas heat pump provides both space heating and cooling, we assumed that only $80.1 \%$ of new air conditioner shipments can be replaced with the gas heat pump technology. Since the air conditioner shipment being replaced is coupled with a gas furnace, we assumed that an equal number of gas furnaces had to be removed from the existing housing stock.

For gas furnaces, it was determined that $64.3 \%$ of homes using gas furnaces units also used electric central air conditioners. Because the gas heat pump provides both space heating and cooling, we assumed that only $64.3 \%$ of new gas furnace shipments can be replaced with the gas heat pump technology. Since the gas furnace shipment being replaced is coupled with an airconditioning unit, we assumed that an equal number of air conditioners had to be removed from the existing housing stock. 


\section{Table 5.2.1 Replaceable Systems for Space-Conditioning Technologies}

\begin{tabular}{|c|c|c|c|c|}
\hline Technology Type & Replaceable System & Stock Replacement & Assumption & Percent \\
\hline \multirow[t]{3}{*}{ Gas Heat Pumps } & Electric Central HP & - & Only Homes w/ Gas & $72.0 \%$ \\
\hline & Electric Central AC & Gas Fumaces & Only Homes w/ AC \& Furn & $80.1 \%$ \\
\hline & Gas Central Furnaces & Electric Central AC & Only Homes w/ Fum \& AC & $64.3 \%$ \\
\hline Gas Furnaces & Gas Central Furnaces & - & All Shipments & $100 \%$ \\
\hline \multirow[t]{3}{*}{ Gas Integrated HP } & Electric Central HP & Elec Water Heater & Only Homes w/ Gas \& Elec WH & $72.0 \%$ \\
\hline & Electric Central AC & $\begin{array}{l}\text { Gas Furnaces + } \\
\text { Gas Water Heaters }\end{array}$ & $\begin{array}{l}\text { Only Homes w/ AC, Furn } \\
\& \text { Gas WH }\end{array}$ & $80.1 \%$ \\
\hline & Gas Central Furnaces & $\begin{array}{l}\text { Elec Central AC + Gas } \\
\text { Water Heaters }\end{array}$ & $\begin{array}{l}\text { Only Homes w/ Furn, AC } \\
\& \text { Gas WH }\end{array}$ & $64.3 \%$ \\
\hline Gas WH / Furnace & Gas Central Furnaces & Gas Water Heaters & Only Homes w/ Gas WH & $100 \%$ \\
\hline \multirow[t]{5}{*}{ Elec Heat Pumps } & Electric Central HP & - & All Shipments & $100 \%$ \\
\hline & Electric Central AC & Electric Furnaces & Only Homes w/ AC \& Elec Fum & $13.8 \%$ \\
\hline & Electric Central AC & Gas Fumaces & Only Homes w/ AC \& Gas Fum & $60.8 \%$ \\
\hline & Electric Central AC & Oil Furnaces & Only Homes w/ AC \& Oil Fum & $6.6 \%$ \\
\hline & Elec Central Furnaces & Electric Central AC & Only Homes w/ Elec Furn \& AC & $67.6 \%$ \\
\hline \multirow[t]{5}{*}{ Elec Integrated HP } & Electric Central HP & Elec Water Heaters & Only Homes w/Elec WH & $100 \%$ \\
\hline & Electric Central AC & $\begin{array}{l}\text { Elec Furnaces + Elec } \\
\text { Water Heaters }\end{array}$ & $\begin{array}{l}\text { Only Homes w/AC, Elec Fum } \\
\text { \& Elec WH }\end{array}$ & $13.8 \%$ \\
\hline & Electric Central AC & $\begin{array}{l}\text { Gas Furnaces + } \\
\text { Gas Water Heaters }\end{array}$ & $\begin{array}{l}\text { Only Homes w/ AC, Gas Furn } \\
\& \text { Gas WH }\end{array}$ & $60.8 \%$ \\
\hline & Electric Central AC & $\begin{array}{l}\text { Oil Funnaces + } \\
\text { Oil Water Heaters }\end{array}$ & $\begin{array}{l}\text { Only Homes w/ AC, Oil Fum } \\
\& \text { Oil WH }\end{array}$ & $6.6 \%$ \\
\hline & Elec Central Furnaces & $\begin{array}{l}\text { Elec Central AC + Elec } \\
\text { Water Heaters }\end{array}$ & $\begin{array}{l}\text { Only Homes w/ Elec Fum, AC } \\
\text { \& Elec WH }\end{array}$ & $67.6 \%$ \\
\hline Elec Central AC & Electric Central AC & - & All Shipments & $100 \%$ \\
\hline Electric Room AC & Electric Room AC & - & All Shipments & $100 \%$ \\
\hline 1-Stage Evap Coolers & Electric Central AC & - & $\begin{array}{l}\text { Only Homes w/Cent } A C \& \\
\text { Wet Bulb Temp } \leq 68^{\circ} \mathrm{F}\end{array}$ & $11.6 \%$ \\
\hline 2-Stage Evap Coolers & Electric Central AC & - & $\begin{array}{l}\text { Only Homes w/Cent } A C \& \\
\text { Wet Bulb Temp } \leq 71^{\circ} \mathrm{F}\end{array}$ & $37.3 \%$ \\
\hline Room Evap Coolers & Electric Room AC & - & $\begin{array}{l}\text { Only Homes w/ Room AC \& Wet Bulb } \\
\text { Temp } \leq 70^{\circ} \mathrm{F}\end{array}$ & $8.9 \%$ \\
\hline \multirow[t]{3}{*}{ Oil Heat Pumps } & Electric Central HP & - & Only Homes w/ Oil & $11.1 \%$ \\
\hline & Electric Central AC & Oil Furnaces & Only Homes w/ AC \& Furn & $6.6 \%$ \\
\hline & Oil Central Furnaces & Electric Central AC & Only Homes w/ Furn \& AC & $58.5 \%$ \\
\hline Oil Fumaces & Oil Central Furnaces & - & All Shipments & $100 \%$ \\
\hline \multirow[t]{3}{*}{ Oil Integrated HP } & Electric Central HP & Elec Water Heaters & Only Homes w/Oil \& Elec WH & $11.1 \%$ \\
\hline & Electric Central AC & $\begin{array}{l}\text { Oil Furnaces + } \\
\text { Oil Water Heaters } \\
\end{array}$ & $\begin{array}{l}\text { Only Homes w/AC, Furn } \\
\& \text { Oil WH }\end{array}$ & $6.6 \%$ \\
\hline & Oil Central Furnaces & $\begin{array}{l}\text { Elec Central AC+ } \\
\text { Oil Water Heaters }\end{array}$ & $\begin{array}{l}\text { Only Homes w/ Furn, AC } \\
\& \text { Oil WH }\end{array}$ & $58.5 \%$ \\
\hline
\end{tabular}

\section{(3) Calculating Shipment-Weighted UECs}

The basis for establishing an advanced technology's UEC consists of calculating the ratio of the replaceable system's efficiency to the efficiency of the advanced technology and then multiplying that ratio by the UEC of the replaceable system. The following equation represents the basis for the UEC calculation:

\section{Adv Tech UEC $=($ Repl Sys Eff $\div$ Adv Tech Eff $) *$ Repl Sys UEC}


where

Adv Tech UEC $=$ Advanced Technology's UEC

Adv Tech Eff = Advanced Technology's Efficiency Rating

Repl Sys Eff = Replaceable System's Efficiency Rating

Repl Sys UEC = Replaceable System's UEC

The replaceable system's UEC and efficiency rating are based on data used in LBLREM. The stock efficiencies and UECs for the various space-conditioning equipment analyzed by LBLREM represent the efficiencies and UECs of the equipment that the advanced technology will replace. Table 5.2.2 provides the average stock efficiencies and UECs of existing space-conditioning equipment for the year 1990 (the year advanced technologies are first allowed to replace shipments of conventional space-conditioning systems).

Table 5.2.2 1990 New Appliance Characteristics from LBLREM

\begin{tabular}{|c|c|c|c|c|c|c|c|c|}
\hline \multirow[b]{2}{*}{$\begin{array}{l}\text { Technology } \\
\text { Type }\end{array}$} & \multicolumn{3}{|c|}{ Efficiency } & \multicolumn{4}{|c|}{ UEC } & \multirow[b]{2}{*}{$\begin{array}{c}\text { Gas or } \mathrm{Oi} \\
\text { Source }\end{array}$} \\
\hline & Heating & Cooling & $\begin{array}{c}\text { Water } \\
\text { Heating }\end{array}$ & $\begin{array}{l}\text { Elec } \\
\text { Site }\end{array}$ & $\begin{array}{l}\text { Elec } \\
\text { Site }\end{array}$ & $\begin{array}{c}\text { Elec } \\
\text { Source }\end{array}$ & $\begin{array}{c}\text { Elec } \\
\text { Source }\end{array}$ & \\
\hline & $\begin{array}{c}\text { AFUE or } \\
\text { HSPF }\end{array}$ & $\begin{array}{c}\text { SEER or } \\
\text { EER }\end{array}$ & $C O P$ & $\begin{array}{c}\text { Heat } \\
k W h / y r\end{array}$ & $\begin{array}{c}\text { Cool } \\
k W h / y r\end{array}$ & $\begin{array}{c}\text { Heat } \\
\text { MMBtutyr }\end{array}$ & $\begin{array}{c}\text { Cool } \\
\text { MMBtutyr }\end{array}$ & $\begin{array}{c}\text { Heat } \\
\text { MMBtulyr }\end{array}$ \\
\hline Gas Furnace & 0.733 & - & - & 458 & - & 5.27 & - & 54.2 \\
\hline Oil Furnace & 0.772 & - & - & 903 & - & 10.38 & - & 83.83 \\
\hline Electric Fumace & I & - & - & 3052 & & 35.1 & - & - \\
\hline Cent Heat Pump & 6.737 & 9.782 & - & 5964 & 2265 & 68.59 & 26.05 & - \\
\hline Central AC & - & 9.777 & - & - & 2206 & - & 25.37 & - \\
\hline Room AC & - & 8.737 & - & - & 861 & - & 9.9 & - \\
\hline $\begin{array}{l}\text { Gas Water } \\
\text { Heater }\end{array}$ & - & - & 0.533 & - & - & - & - & 28.05 \\
\hline Oil Water Heater & - & - & 0.559 & - & - & - & - & 26.52 \\
\hline $\begin{array}{l}\text { Elec Water } \\
\text { Heater }\end{array}$ & - & - & 0.878 & 4964 & - & 57.09 & - & - \\
\hline
\end{tabular}

To illustrate how a UEC is calculated for an advanced technology, we examine the case of a gas condensing furnace ( $90.5 \%$ AFUE) replacing the need for a standard efficiency furnace. The UEC of the gas condensing furnace is represented by the following calculation:

$$
\begin{aligned}
\text { Cond Furnace Gas UEC } & =(\text { Stock Furn Eff } \div \text { Cond Furn Eff }) * \text { Stock Furn UEC } \\
& =(0.733 \text { AFUE } \div 0.905 \text { AFUE }) * 54.2 \mathrm{MMBtu} / \mathrm{yr} \\
& =43.9 \mathrm{MMBtu} / \mathrm{yr}
\end{aligned}
$$

In addition to consuming fuel, the condensing furnace also uses electricity (for powering the fan motor and miscellaneous electronic devices). Thus, an electric UEC must also be calculated. The electric UEC is derived from the heating load that the stock gas furnace must meet. The stock heating load is assumed to equal the stock gas furnace's source UEC multiplied by its efficiency. The electric site UEC of the condensing gas furnace is the stock heating load divided by its electric COP 
(efficiency). The electric COP is defined as the capacity (output) of the gas furnace (in Btu/h) divided by its electrical input (in Btu/h). The electric site UEC of the gas condensing furnace is represented by the following calculation:

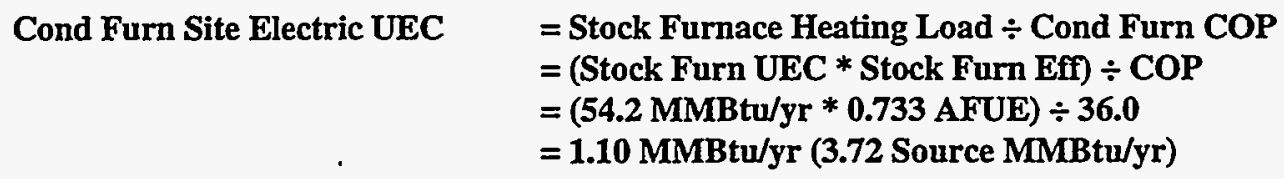

Thus, if an advanced technology is targeted to replace only one system type, the calculation of the UEC is relatively simple and straightforward. But for those advanced technologies that are targeted to replace more than one type of system, a more involved procedure is used to develop a shipmentweighted UEC.

Table 5.2.3 presents a sample calculation for determining the shipment-weighted UEC of a gas absorption heat pump. The first column of Table 5.2.3 represents the systems that gas absorption heat pumps can replace. Referring to Table 5.2.1, gas heat pumps are targeted to replace new shipments of electric heat pumps, electric air conditioners (with stock replacement of associated gas furnace), and gas furnaces (with stock replacement of associated electric air conditioner). The second column of Table 5.2.3 represents the 1998 projected shipments for each system to be replaced. Shipment data were obtained from LBLREM. The third column represents the percentage of new shipments, for each replaceable system, that can be replaced by the new technology (refer to Table 5.2.1 for percentage values). To arrive at the amount of new shipments that can be replaced by the new technology, 1998 projected shipments are multiplied by the corresponding percentage that can be replaced by the new technology. Replaceable shipments are listed in column four of Table 5.2.3. Heating and cooling UECs are formulated with respect to each replaceable system by following the previously outlined procedure. 
A shipment-weighted UEC is calculated for each UEC type (a UEC type being either source electric use for heating, source gas use for heating, source electric use for cooling, and source gas use for cooling). The shipment-weighted UECs for each UEC type are summed to yield the representative UEC for the technology. For the case of gas absorption heat pumps, the shipment weighed UEC is $72.63 \mathrm{MMBtu} /$ year.

\section{Table 5.2.3 Sample Calculation for Determining Shipment-Weighted UEC}

\begin{tabular}{|c|c|c|c|c|c|c|c|}
\hline \multirow[b]{2}{*}{$\begin{array}{l}\text { Shipments } \\
\text { Basis }\end{array}$} & \multirow[b]{2}{*}{$\begin{array}{c}1998 \\
\text { Shipmts } \\
\text { millions }\end{array}$} & \multirow[b]{2}{*}{$\begin{array}{l}\text { Replace } \\
\text { Percent }\end{array}$} & \multirow[b]{2}{*}{$\begin{array}{l}\text { Replace } \\
\text { Shipmts } \\
\text { millions }\end{array}$} & \multicolumn{2}{|c|}{ UEC Heating } & \multicolumn{2}{|c|}{ UEC Cooling } \\
\hline & & & & $\begin{array}{c}\text { Elec } \\
\text { Source } \\
\text { MMBtu }\end{array}$ & $\begin{array}{c}\text { Gas } \\
\text { Source } \\
\text { MMBtu }\end{array}$ & $\begin{array}{c}\text { Elec } \\
\text { Source } \\
\text { MMBtu }\end{array}$ & $\begin{array}{c}\text { Gas } \\
\text { Source } \\
\text { MMBtu }\end{array}$ \\
\hline Cent Heat Pump & 0.536 & 0.720 & 0.386 & 7.69 & 29.77 & 7.66 & 28.78 \\
\hline Cent $\mathrm{AC}+$ gas furn & 2.803 & 0.801 & 2.245 & 7.61 & 29.43 & 7.45 & 28.01 \\
\hline \multirow[t]{2}{*}{ Gas Furn+cent ac } & 2.211 & 0.643 & 1.422 & 7.61 & 29.43 & 7.45 & 28.01 \\
\hline & Shipmer & Weighted & otals $\Rightarrow>$ & 7.61 & 29.46 & 7.47 & 28.08 \\
\hline
\end{tabular}

\section{(4) Calculating Shipment-Weighted Payback Periods}

Payback periods for each advanced technology are determined by comparing the cost effectiveness of the advanced technology to that of systems that ONLY meet the 1992 NAECA minimum efficiency standards. The payback period for a particular advanced technology is represented by the following calculation:

\section{Payback Period $=($ AT Install Cost - Base Install Cost $) \div$ (Base Oper Cost - AT Adv Oper Cost)}

where

$\begin{array}{lll}\text { AT Install Cost } & = & \text { Advanced Technology's Total Installed Cost } \\ \text { Base Install Cost } & =\text { Base Case Technology's Total Installed Cost } \\ \text { Oper Cost } & =\quad \text { Advanced Technology's Operating Cost } \\ \text { Base Oper Cost } & =\text { Base Case Technology's Operating Cost } \\ \text { Base Case } & = & \text { Represents Technology only meeting NAECA standards }\end{array}$

The installed costs and efficiencies for the base case technologies are reported in Table 5.2.4. The installed costs were determined through discussions with HVAC distributors and contractors. Efficiencies are the current NAECA minimums. 


\section{Table 5.2.4 Base Case Installed Costs and Efficiencies}

\begin{tabular}{|c|c|c|c|c|}
\hline \multirow[b]{2}{*}{ Technology } & \multirow[b]{2}{*}{$\begin{array}{l}\text { Installed } \\
\text { Cost }\end{array}$} & \multicolumn{3}{|c|}{ Efficiency } \\
\hline & & $\begin{array}{c}\text { Heating } \\
A F U E / H S P F\end{array}$ & $\begin{array}{c}\text { Cooling } \\
\text { SEER/EER }\end{array}$ & $\begin{array}{c}\text { DHW } \\
E F\end{array}$ \\
\hline Gas Furnace & $\$ 1,560$ & 0.78 & - & - \\
\hline Oil Fumace & $\$ 3,513$ & 0.78 & - & - \\
\hline Electric Fumace & $\$ 1,000$ & 1.00 & - & - \\
\hline Central Air Cond & $\$ 2,140$ & - & 10.00 & - \\
\hline Room Air Cond & $\$ 400$ & - & 8.73 & - \\
\hline Central Heat Pump & $\$ 2,700$ & 6.80 & 10.00 & - \\
\hline Gas Water Heater & $\$ 400$ & - & - & 0.544 \\
\hline Oil Water Heater & $\$ 2,250$ & - & - & 0.520 \\
\hline Electric Water Heater & $\$ 380$ & - & - & 0.881 \\
\hline Gas Furnace / Central AC & $\$ 3,500$ & 0.78 & 10.00 & - \\
\hline Oil Furnace / Central AC & $\$ 5,453$ & 0.78 & 10.00 & - \\
\hline Elec Furnace / Central AC & $\$ 2,940$ & 1.00 & 10.00 & - \\
\hline Cent Heat Pump/ Elec WH & $\$ 3,080$ & 6.80 & 10.00 & 0.881 \\
\hline Gas Furn/ CAC/Gas WH & $\$ 3,900$ & 0.78 & 10.00 & 0.544 \\
\hline Oil Furn / CAC / Oil WH & $\$ 7,703$ & 0.78 & 10.00 & 0.520 \\
\hline Elec Furn/ CAC / ElecWH & $\$ 3,320$ & 1.00 & 10.00 & 0.881 \\
\hline Gas Furnace / Gas WH & $\$ 1,960$ & $0.764 / 0.71 \mathrm{EF}$ & - & 0.544 \\
\hline
\end{tabular}

To illustrate how a payback period is calculated for an advanced technology, we examine the case of a gas condensing furnace ( $90.5 \% \mathrm{AFUE}$ ) replacing the need for a standard efficiency furnace. Gas and electric source UECs were established for the condensing furnace in Section 3. To obtain operating cost, the source UECs are converted to site values and multiplied by the current electricity and gas rates. The UEC of the base case technology, a 78\% AFUE gas furnace, is determined using the same methodology as was used for the condensing gas furnace. The following equation represents the calculation necessary for determining the payback period of a gas condensing furnace:

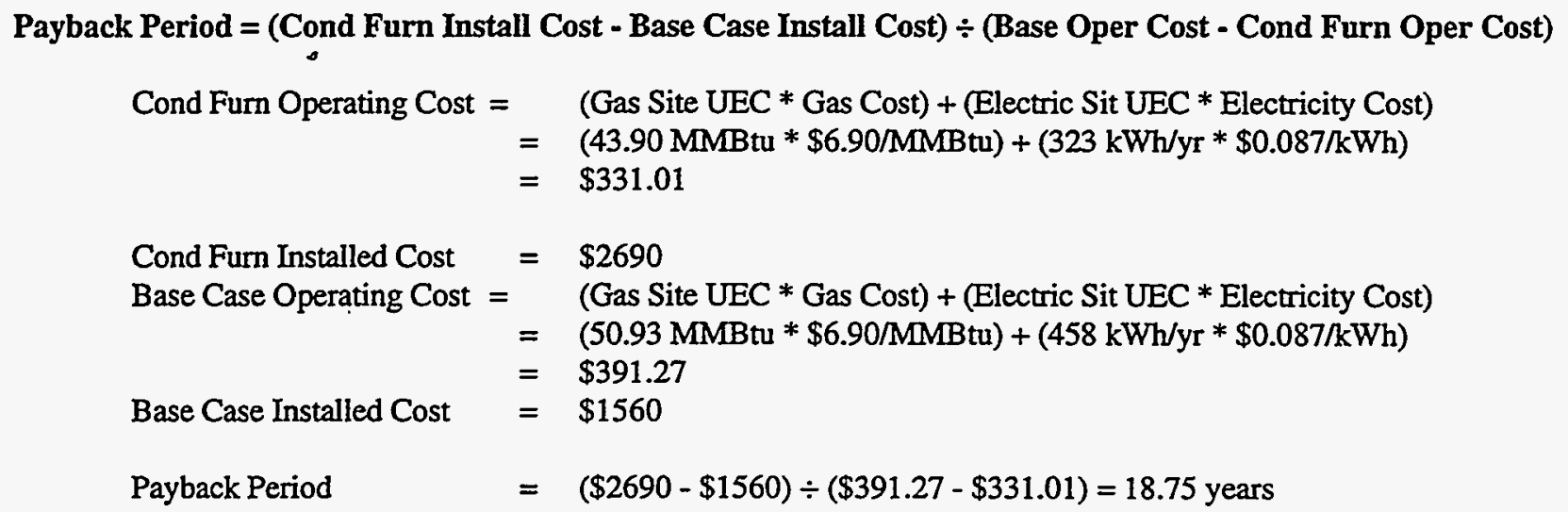

Thus, if an advanced technology is targeted to replace only one system type, the calculation of the payback is relatively simple and straightforward. But for those advanced technologies that are targeted to replace more than one type of system, a more involved procedure is used to develop a shipment-weighted payback. 
The calculation of the shipment weighted payback is similar to the process of determining the shipment-weighted UEC. A payback period is determined for each system an advanced technology is targeted to replace and a shipment-weighted calculation is performed to determine the shipmentweighted payback for the advanced technology.

Table 5.2.5 provides the installed costs, shipment-weighted payback periods, and UECs of most of the space-conditioning technologies that were considered in this analysis. For each advanced technology considered in the analysis, Table 5.2.5 also provides the projected number of shipments of the technology in the year 1998. The projected shipments corresponds to the number of standard efficiency HVAC shipments the advanced technology is targeted to replace in the year 1998. 
Table 5.2.5 UECs, Installed Costs, Payback Periods, and Shipments of Advanced Technologies

\begin{tabular}{|c|c|c|c|c|c|c|}
\hline \multirow[b]{2}{*}{ Advanced Technology } & \multirow{2}{*}{$\begin{array}{l}\text { Shipment- } \\
\text { Weighted } \\
\text { Source } \\
\text { UEC } \\
\text { MMBtufyr }\end{array}$} & \multicolumn{2}{|c|}{$\begin{array}{c}\text { Shipment- } \\
\text { Weighted } \\
\text { Site } \\
\text { UEC }\end{array}$} & \multirow[t]{2}{*}{$\begin{array}{c}\text { Installed } \\
\text { Cost }\end{array}$} & \multirow{2}{*}{$\begin{array}{c}1998 \\
\text { Shipments } \\
\text { millions } \\
\end{array}$} & \multirow[t]{2}{*}{$\begin{array}{c}\text { Shipment- } \\
\text { Weighted } \\
\text { Payback } \\
\text { years }\end{array}$} \\
\hline & & $k W h / y r$ & MMBtuکyr & & & \\
\hline Gas Absorption Heat Pump & 73.6 & 1312 & 58 & $\$ 5,150$ & 4.05 & 23.0 \\
\hline Gas Engine-Driven Heat Pump & 60.4 & 734 & 52 & $\$ 7,250$ & 4.05 & 23.1 \\
\hline Gas Adsorption Heat Pump & 60.1 & 782 & 51 & $\$ 5,450$ & 4.05 & 12.0 \\
\hline Gas Condensing Fumace & 47.6 & 323 & 44 & $\$ 2,690$ & 2.21 & 18.6 \\
\hline Gas Integrated Absorption HP & 93.6 & 1615 & 75 & $\$ 5,860$ & 4.05 & 14.0 \\
\hline Gas Integrated Engine-Driven HP & 81.7 & 953 & 71 & $\$ 8,010$ & 4.05 & 18.1 \\
\hline Gas Integrated Water Heater / Furnace & 65.5 & 469 & 60 & $\$ 3,450$ & 2.21 & 11.6 \\
\hline Elec Variable-Speed Air-Source Heat Pump & 53.8 & 4675 & - & $\$ 7,500$ & 3.19 & 25.1 \\
\hline Elec Two-Speed Air-Source Heat Pump & 60.3 & 5245 & - & $\$ 5,500$ & 3.19 & 20.5 \\
\hline Elec Var-Speed Ground-Source Heat Pump & 40.0 & 3476 & - & $\$ 10,741$ & 3.19 & 26.6 \\
\hline Elec Two-Speed Ground-Source HP & 44.4 & 3862 & - & $\$ 7,192$ & 3.19 & 15.8 \\
\hline Elec Single-Speed Ground-Source HP & 52.0 & 4518 & - & $\$ 6,552$ & 3.19 & 17.5 \\
\hline Elec PV-powered Var-Spd Air-Source HP & 43.8 & 3811 & - & $\$ 20,000$ & 3.19 & 67.5 \\
\hline Elec Integrated Var-Speed Air-Source HP & 82.2 & 7148 & $=$ & $\$ 10,500$ & 3.19 & 44.3 \\
\hline Elec Int Single-Speed Air-Source HP & 91.5 & 7955 & $=$ & $\$ 6,405$ & 3.19 & 80.8 \\
\hline Elec Integrated Var-Spd Ground-Source HP & 58.2 & 5063 & - & $\$ 11,416$ & 3.19 & 19.5 \\
\hline Elec Int Two-Speed GSHP (dedicated HX) & 64.7 & 5626 & 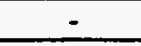 & $\$ 7,662$ & 3.19 & 11.5 \\
\hline Elec Int Two-Speed GSHP (desuperheater) & 70.6 & 6136 & - & $\$ 7,512$ & 3.19 & 13.1 \\
\hline Elec Int Single-Speed GSHP(desuperheater) & 80.1 & 6969 & $=$ & $\$ 6,872$ & 3.19 & 16.3 \\
\hline Elec Variable-Speed Air-Source Air Cond. & 66.6 & 5789 & - & $\$ 7,000$ & 2.80 & 33.3 \\
\hline Elec Two-Speed Air-Source A/C & 72.2 & 6279 & - & $\$ 5,000$ & 2.80 & 22.5 \\
\hline Elec PV-powered Var-Spd Air-Source A/C & 60.7 & 5278 & - & $\$ 19,500$ & 2.80 & 104.7 \\
\hline Elec High-Efficiency Room A/C & 7.2 & 627 & - & $\$ 849$ & 4.23 & 22.1 \\
\hline Elec High-Efficiency Mini-Split A/C & 8.0 & 696 & - & $\$ 1,660$ & 4.23 & 88.1 \\
\hline Elec PV-powered Mini-Split A/C & 4.8 & 418 & - & $\$ 17,143$ & 4.23 & 434.4 \\
\hline Single-Stage Direct Central Evap Coolers & 6.2 & 539 & - & $\$ 1,663$ & 0.33 & 0.0 \\
\hline Single-Stage Direct Room Evap Coolers & 2.5 & 216 & - & $\$ 225$ & 0.38 & 0.0 \\
\hline 2-Stage Indirect/Direct Cent Evap Coolers & 6.2 & 539 & - & $\$ 2,901$ & 1.05 & 5.4 \\
\hline Oil Absorption Heat Pump & 94.3 & 1727 & 75 & $\$ 6,050$ & 0.67 & 6.6 \\
\hline Oil Condensing Furnace & 77.4 & 612 & 70 & $\$ 4,270$ & 0.72 & 6.7 \\
\hline Oil Integrated Absorption Heat Pump & 114.4 & 1988 & 92 & $\$ 6,750$ & 0.67 & 13.3 \\
\hline Leakage-Reducing Ducts & $6.24(1)$ & - & - & $\$ 250$ & 6.84 & 6.0 \\
\hline National Service Improvement Program & $17.2(1)$ & - & - & $\$ 116$ & $0.72(2)$ & 6.1 \\
\hline
\end{tabular}

(1) UEC savings due to advanced technology.

(2) Includes existing housing stock in the year 1998 affected by advanced technolgy.

\section{(5) Ranking the Technologies}

In order to rank the importance of the advanced technologies considered for this analysis, a ranking index was created. The index is a function of the advanced technology's UEC savings (with respect 
to the shipment-weighted UEC of the systems it is targeted to replace), the number of shipments it is targeted to replace in 1998, and its payback. The index can be represented by the following equation:

$$
\text { Ranking Index }=(\text { UEC savings * } 1998 \text { Shipments }) \div \text { Payback }
$$

National energy savings for the year 1998 are roughly estimated by multiplying the UEC savings by the shipments. By dividing this quantity by the technology's payback, the index takes into account the cost-effectiveness of the technology at providing national energy savings. The larger the value of the ranking index, the more promising the advanced technology is at saving energy cost-effectively. Table 5.2.6 provides a list of the top 16 advanced technologies with their respective ranking indices. Technologies are in order of highest rank.

\section{Table 5.2.6 Ranking Indices of Most Promising Technologies}

\begin{tabular}{lc} 
Technology & $\begin{array}{c}\text { Rank } \\
\text { Index }\end{array}$ \\
\hline Single-Stage Direct Central \& Room Evaporative Coolers & $\infty$ \\
Electric Integrated Two-Speed Ground-Source Heat Pump & 15.3 \\
Gas Adsorption Heat Pump & 7.5 \\
Electric Two-Speed Ground-Source Heat Pump & 7.2 \\
Leakage-Reducing Ducts & 7.1 \\
Gas Integrated Engine-Driven Gas Heat Pump & 6.9 \\
Gas Integrated Gas-Absorption Heat Pump & 5.5 \\
Gas Engine-Drive Heat Pump & 3.8 \\
2-Stage Indirect/Direct Evaporative Coolers & 3.6 \\
Gas Integrated Water Heater / Furnace & 3.5 \\
Electric Variable-Speed Air-Source Heat Pump & 3.4 \\
Electric Integrated Variable-Speed Air-Source Heat Pump & 2.7 \\
Oil Absorption Heat Pump & 2.2 \\
National Service Improvement Program & 2.0 \\
Oil Condensing Furnace & 1.7 \\
Gas Absorption Heat Pump & 1.7 \\
\hline
\end{tabular}




\section{Appendix 6. Other Technologies Considered for Lighting}

\section{IMPROVED PHOSPHORS FOR FLUORESCENT LAMPS}

Present Status. Rare earth phosphors increase the efficacy of fluorescent lamps. Their use is becoming more widespread, but their potential for growth is still large. Energy savings can be achieved by increasing the market share of lamps with rare earth phosphors or by improving the efficacy of the lamps still further. The increase in CRI achievable with rare earth phosphors allows the use of these lamps in more color-sensitive applications. Additional improvements to CRI would increase the market potential for these lamps even further.

Rare earth phosphors are very expensive, making up a substantial fraction of the manufacturing cost of fluorescent lamps. Improved means to separate rare earths, as well as the discovery of additional ore sources, could reduce their cost, thus increasing acceptance of both full-sized and compact fluorescent technologies by end users. Sales volume also has a significant impact on the cost of lamps with rare earth phosphors, and efforts to increase their market penetration will reduce their cost.

New fluorescent lamp standards (November 1995) may shift the market in the direction of lamps using rare earth phosphors.

Energy Use and Cost. The increased efficacy of 34-W lamps with rare earth phosphors over 34-W cool white lamps is $84 \mathrm{LPW}$ to $78 \mathrm{LPW}$ (T8 lamps with rare earth phosphors have efficacy of 89 LPW). Lamps with rare earth phosphors are not yet available at the same commodity pricing as lamps with halophosphors because manufacturers are recovering the cost of retooling. Currently RE 70 lamps are about twice as expensive as cool whites, and RE 80s are almost twice as expensive as RE 70s.

\section{CFL DESIGN IMPROVEMENTS}

Present Status. Compact fluorescent lamps are gaining wider acceptance as the technology improves. New shapes and sizes that more easily fit into existing Edison sockets are becoming available, thereby increasing market penetration of CFLs.

Improved color in compact fluorescents is possible, as it is for full-sized lamps, at a price premium. The phosphors for RE $90+$ CRI lamps are even more expensive than for the RE 70 and RE 80 lamps, while the efficacy of the RE 90 s is somewhat lower. Nevertheless, improved color could result in greater market acceptance and therefore significant energy savings over incandescent technologies.

Energy Savings and Cost. Compact fluorescent lamps have a luminous efficacy of 50 to 70 LPW compared to incandescent lamps at about $15 \mathrm{LPW}$, thus potentially reducing energy use by $75 \%$. They are available from $7 \mathrm{~W}$ to $28 \mathrm{~W}$. Lamp lifetime at 10,000 hours is ten times as long as that of incandescent lamps. Prices for CFLs vary widely. 
Barriers to Implementation. There are three areas in compact fluorescent technology where significant barriers exist: the lamp, the ballast, and the luminaire. Price is the biggest barrier in all three. Luminaires and dimming ballasts have been discussed previously.

Rare earth phosphors are the major price barrier in CFL lamps. Electronic ballasts still do not have a major share of the market. Quantity affects their price in addition to the cost of the electronic circuitry and components. The life-cycle cost of electronic ballasts can be reduced by increasing their lifetime. Decreasing the ballast temperature by $10^{\circ} \mathrm{C}\left(18{ }^{\circ} \mathrm{F}\right)$ has the effect of doubling the ballast lifetime. Unfortunately, the addition of technologies to allow ballasts to operate at higher temperatures could potentially double their price.

\section{High-FrequenCy EleCTRODELESS HID LAMP}

Present Status. The GE Multilox is a specialized arc tube gas-discharge lamp that is still under development. An electromagnetic field induced by a generator and a coil within a high frequency ballast excites lamp gases. The lamp produces a white light with CRI similar to that of metal halide. Controls are required, and the expected life of the GE lamp is not known.

The GE high-pressure discharge prototype is a 400-W system with approximately 50,000 lumen output, resulting in an efficacy of $150 \mathrm{LPW}$, roughly equivalent to the efficacy of low-pressure sodium lamps (Nadel 1993). GE expects to achieve 160 to 180 lumens per watt with a CRI of 65-70 at any chromaticity (McGowan 1993).

Energy Use and Cost. Lamp costs, including controls, are currently being reviewed and are not known at this time.

Applications. The technology is primarily targeted at new construction and renovation in the industrial and outdoor sectors and therefore requires investment by fixture manufacturers for marketable luminaire and control system packages. Lack of fixtures and control products are the major barriers.

\section{High-FREQUENCY ELECTRONIC BALLASTS FOR HID LAMPS}

Present Status. High-frequency ballasts have the potential to increase market penetration of highefficacy $\mathrm{HID}$ lamps by improving their color rendition, color stability, and lifetime, and by reducing ballast weight. The efficacy of the HID lamp itself is not improved significantly by the use of a highfrequency ballast, although the ballast efficiency is increased. Thus the system efficacy is improved slightly compared with magnetically-ballasted systems.

Metal halide lamps are among the most efficient and long-lived light sources. Their application in 
display lighting and other indoor applications has been limited by color shift as the lamp ages. Use of electronic ballasts with these lamps can maintain consistent power over wide line-voltage fluctuations, thus reducing color shift. Lamp life is also extended, and maintenance and warm-up characteristics are improved.

Energy Use and Cost. Increased market share of HID lamps would represent a significant energy savings if the lamps displaced are of lower efficacy, such as large incandescents, track lighting, PAR lamps, and exterior halogen lamps. High-frequency $\mathrm{HID}$ ballasts cost more than magnetic ballasts.

Applications. Electronic ballasts allow penetration of HID lamps into markets where their poor color rendition and color stability have prohibited their use in the past. Their use may allow the source to be dimmed effectively, possibly allowing photo-electric controlled operation with available daylight.

Barriers to Implementation. Acoustic resonance is generated in the arc tubes. The frequency changes are very sensitive to lamp geometry (more so for high-pressure sodium than metal halide). Thus one manufacturer's ballasts may not be compatible with another's lamps. One alternative: the electronic low-frequency "square wave" ballast has weight advantage, though it may be large. This ballast would apply to specialty lamps.

\section{INSTANT RESTRIKE OF HID LAMPS}

Present Status. Instant restrike would increase market potential for indoor applications of HID lamps as incandescent or fluorescent substitutes. GE has such a lamp in production now. Where HIDs replace incandescents they will probably not be the only source in the space, so this feature may not be as critical in some applications.

\section{INCREASED CRI OF HID LAMPS}

Present Status. Increased CRI is important for interior applications. These lamps also have the potential to penetrate markets where lamps of low CRI have been unacceptable. For metal halide lamps, development of the metal mixture in the arc tube will increase the red portion of the spectrum.

\section{CoATED FILAMENT LAMPS}

Present Status. This technology is in the research and development stage. Lamps with a filament coated with a selective layer of transition metal oxide have low emissivity in the infrared and high emissivity in the visible portion of the electromagnetic spectrum (Atkinson 1992).

\section{Single-Crystal Hafnium Carbide Filaments}

Present Status. Incandescent lamps using a single-crystal (hafnium carbide) filament afford an opportunity to increase efficacy and life of general service incandescent lamps while maintaining their original size, weight, and color-rendering capabilities. 
EPRI is currently sponsoring a project to determine the feasibility of single-crystal hafnium carbide filaments. These filaments are whiskers of metal and ceramic with a much higher melting point $\left(400^{\circ}\right.$ or higher) than standard tungsten filaments, allowing higher lamp-operating temperatures and thus increased efficacy. The fiber strength would also result in longer lamp life.

Energy Use and Cost. Energy savings of 50\% are expected from this improvement in filament design, although theoretical work on the technology indicates savings potential close to $65 \%$. For one analysis the rough estimate of the lamp cost is $\$ 5$ (Nadel 1993).

Achievable efficacy is estimated anticipated at $50 \mathrm{LPW}$. Anticipated lamp life is estimated at 4000 hours. The lamp is expected to be feasible in $95 \%$ of incandescent applications and applicable to all market sectors (Nadel 1993).

\section{Ceria lamp}

Present Status. For almost 90 years, tungsten has been the material of choice for incandescent lamp filaments. Tungsten is mildly selective; it produces a higher ratio of visible to infrared radiation than would be produced by a black body. A number of materials such as the transition metals and rare earth oxides are considerably more selective than tungsten, but they are hard to work and their melting points are lower. New materials techniques, especially coating techniques, might make some of the more selective materials competitive.

A mixture of $\mathrm{Ce}_{2} \mathrm{O}_{3}$ and $\mathrm{ThO}_{2}$, a selective surface emitter that does not emit infrared, has been studied as a possible filament material. Data indicate that this mixture would have the same efficacy as a tungsten lamp at $1800^{\circ} \mathrm{K}$, and at $1900^{\circ} \mathrm{K}$ its efficacy would be $50 \%$ higher. However, in the past this material has only achieved about 4 LPW (22\% of the efficacy of a tungsten filament). Lamps must be large enough to minimize losses from convective currents that can cause cooling.

The efficacy of this lamp is extremely sensitive to temperature. A stronger, more workable filament can be developed by coating filaments and by examining more materials. To suppress evaporation, the filament is coiled, which reduces selectivity.

Energy Use and Cost. Six LPW at a temperature of $1600^{\circ} \mathrm{K}$ have been achieved. If $1900^{\circ} \mathrm{K}$ can be reached, a potential $30 \mathrm{LPW}$ is possible. Costs may be $\$ 5$ to 10 per lamp.

Applications. The Ceria lamp can replace any incandescents (general service or PAR) except smaller ones. Its best uses are in residential, lodging, retail, and hospital applications.

Barriers to Implementation. The lamp may have to be double-ended. The probability of success from $R \& D$ is uncertain. 


\section{LEDS}

Present Status. In the past decade substantial advancements in light-emitting diode (LED) semiconductor crystal technology have been made. These lamps have a very long life (as long as 100,000 hours) (Peralta and Ruda 1993), operate at low voltage, and have no mercury. LEDs presently give more light in the red spectrum than incandescent red light. Typically LEDs run on DC power, but a power supply can allow them to run on AC. They can be screw- or pin-based.

LED efficacy is presently good in reds and yellows, fair in greens, and poor in blues. Development of the blue LED will contribute to a white-light LED, since using red and green only gives poor CRI. LBL is presently working on blue LEDs to improve their efficacy. Current versions use material with indirect band-gap photon production, which is inherently inefficient. LBL and Hewlett Packard are working under a collaborative agreement on a promising new material using direct band-gap photon production (Rubin 1993).

Conductive plastic LEDs are being researched at the University of California at Santa Barbara (Pakbaz 1993). One present limitation to the technology is that the conducting polymers are only stable for about a year.

Energy Use and Cost. In traffic signals, LPW is now less than 1; LBL Packer 1993) estimates 7-8 LPW for traffic signals could be achieved. Peralta (Ontario Hydro) estimates commercial LEDs with efficiencies of $2-4 \%$, high-efficiency prototypes with $15 \%$, and theoretical efficiency of $30 \%$ (compared with incandescent efficiency of $10 \%$ and fluorescent efficiency, which is typically $20 \%$ and achievable $27 \%$.)

Quantity unit prices are estimated by Peralta at 3 to 5 cents ( $\$ 0.03-0.04)$, compared with 6 cents $(\$ 0.06)$ for an incandescent. LED prices are expected to fall by an order of magnitude in the next few years (Peralta and Ruda 1993).

Applications. LEDs are being considered for use in traffic signals. A present research goal is to develop a white light source that could replace incandescents with fewer than $15 \mathrm{~W}$. Substitution for higher-wattage incandescents is possible, although it is limited by the number of LEDs that must fit in a fixture to give equivalent light output. LEDs are presently used in exit signs, where they offer energy-efficiency and low maintenance.

Immediate potential applications are appliance lights, display lights (colored), automotive, and indicator lights. Since LED light output is directional (narrow angle), future applications include supplemental spotlighting and task lighting. Applications outside the scope of this report include illuminated signs, traffic control lights, and airport runway lights.

Barriers to Implementation. Materials and processing costs, which are issues being addressed, are the major barriers at present. 


\section{Polarized Lighting Panels}

Present Status. Visual performance is affected by the contrast of the objects being illuminated as well as by the total illuminance on the task. Low-contrast tasks require high illumination, and in principle high-contrast tasks can be performed with lower levels of illumination. Performance is affected by light distribution as well as by illumination. For example, specular reflections from a task surface reduce contrast. Specular reflections can be reduced by the use of polarized light. Luminaires equipped with multi-layer polarizer panels can increase the contrast of a visual task under certain viewing conditions.

Task orientation, task specularity, lighting geometry, the degree of polarization achieved, and the absolute contrast of the task affect whether polarizer panels can make a difference. For example, performance of horizontal tasks with glossy task surfaces, specular viewing angle, and very low contrast may be improved with a high degree of polarization. For other tasks, polarization may have little or no effect. At a 90-degree viewing angle, polarization may actually be a hindrance.

Energy Use and Cost. Whether multi-layer polarizer panels can be used to save energy is a matter of some controversy. Based on available research, (National Lighting Program 1993) the National Lighting Product Information Program sees little basis for the Illuminating Engineering Society to change its recommended illuminances for spaces with multi-layer polarizer panels.

\section{DC LIGHTING}

Present Status. In electronic ballasts, $\mathrm{AC}$ is rectified to $\mathrm{DC}$ and then to high-frequency $\mathrm{AC}$. Even though the rectifier makes the voltage positive, single-phase current still pulsates (varies from 0 to +) at $120 \mathrm{~Hz}$ A filter used in the ballast to smooth this pulsation causes the high harmonics experienced in electronic ballasts. In CFLs, the effect of the filter is worse; it has to be more compact so the electronic correction is less.

With three-phase $\mathrm{AC}$, at any one time one of the phases produces maximum voltage. With no filter in a ballast, some ripple would be produced, but the frequency would be $360 \mathrm{~Hz}$ and the voltage variation would be only $4 \%$ and not noticeable. However, the lighting circuit in a commercial building uses only one of the three phases. If all three phases were used for lighting, a filter would not be needed. (Magnetek has developed a three-phase lighting system, with only 23\% total harmonic distortion.)

Another approach is to use $\mathrm{DC}$ circuits. AC power is rectified to $\mathrm{DC}$ at the power main. As described previously, the ballast fluctuates at $360 \mathrm{~Hz}$. The DC power is transmitted by DC wiring through the building to individual fixture inverters that convert it back to AC.

A DC lighting system was developed at Brigham Young University. It is being produced by SENERGY Lighting Systems of Nevada and marketed by Topaz Energy Systems of Salt Lake City. 
Test installations are in place in Utah and Oregon.

Energy Use and Costs. Energy savings have been estimated at 15\% compared with T8 and electronic ballast AC systems. For a new 50,000-square foot building, the additional installation cost is estimated to be $\$ 20,000$ ( $\$ 0.40$ per square foot) (Nadel 1993). The manufacturer claims that lamp life is increased four times. Another source (Morse 1993) thinks that lamp life may not be affected, but ballast life might be increased.

Applications. The most likely application of DC lighting is in new commercial buildings with threephase power. This technology could be retrofitted in existing buildings only if the lighting circuits are separate from plug loads. It is not appropriate in residential or other applications that have only single-phase power.

Barriers to Implementation. Oregon DOE identified lack of knowledge of the system by building inspectors as a barrier.

\section{Photovoltaic-Assisted Fluorescent Lighting}

The use of photovoltaic (solar electric) panels to supply DC power to fluorescent lamps with electronic ballasts is being researched by Osram Sylvania. Since commercial lighting demand is relatively constant during daylight hours, there is a good match with the energy source. Power can be stored in batteries for nighttime use. Magnetek, Advance, Osram Sylvania, and others can supply DC electronic ballasts. Several users throughout the U.S. are experimenting with the technology (Blake 1993).

\section{Dimmable CFL Ballasts (Resmential Sector)}

Introduction of dimmable CFL ballasts into the residential sector would allow the replacement of more incandescent lamps with compact fluorescents.

The PG\&E Residential Lighting Saturation Survey (Kelsey 1992) shows that only 7\% of residential circuits are on dimmers. However, more homes may have dimmer circuits in the future, as lighting control systems become more widely used. Further research into the potential sockets for CFLs, sockets that are now not suited, is necessary to estimate potential savings from this option.

Estimated incremental cost for a dimmable CFL ballast, which would have to be hard-wired, is $\$ 15$ 20 (Hawk 1993). The fluorescent fixture itself would have no cost difference nor increased installation time over an incandescent fixture. See Section 6.13, "CFL Efficient Luminaire," on residential consumer resistance to fluorescent lighting and other barriers. 